\author{
UNIVERSIDADE DE SÃO PAULO \\ ESCOLA DE ENGENHARIA DE SÃO CARLOS \\ DEPARTAMENTO DE ESTRUTURAS
}

JESÚS ANTONIO GARCÍA SÁNCHEZ

\title{
UMA FORMULAÇÃO EM ELEMENTOS FINITOS PARA A ANÁLISE DINÂMICA E ESTÁTICA NÃO LINEAR DE RISERS INCLUINDO O CONTATO COM O LEITO DO MAR.
}

São Carlos

2013 


\author{
UNIVERSIDADE DE SÃO PAULO \\ ESCOLA DE ENGENHARIA DE SÃO CARLOS \\ DEPARTAMENTO DE ESTRUTURAS
}

JESÚS ANTONIO GARCÍA SÁNCHEZ

\title{
UMA FORMULAÇÃO EM ELEMENTOS FINITOS PARA A ANÁLISE DINÂMICA E ESTÁTICA NÃO LINEAR DE RISERS INCLUINDO O CONTATO COM O LEITO DO MAR.
}

\begin{abstract}
Tese apresentada à Escola de Engenharia de São Carlos da Universidade de São Paulo como parte dos requisitos para obtenção do Título de Doutor em Engenharia Civil (Engenharia de Estruturas).
\end{abstract}

Orientador: Prof. Humberto Breves Coda

\author{
VERSÃO CORRIGIDA \\ A versão original encontra-se na \\ Escola de Engenharia de São Carlos
}

São Carlos

2013 
AUTORIZO A REPRODUÇÃO TOTAL OU PARCIAL RESTE TRABALHO, POR QUALQUER MEIO CONVENCIONAL OU ELETRONNICO, PARA FINS DE ESTUDO E PESQUISA, DESDE QUE CITADA A FONTE.

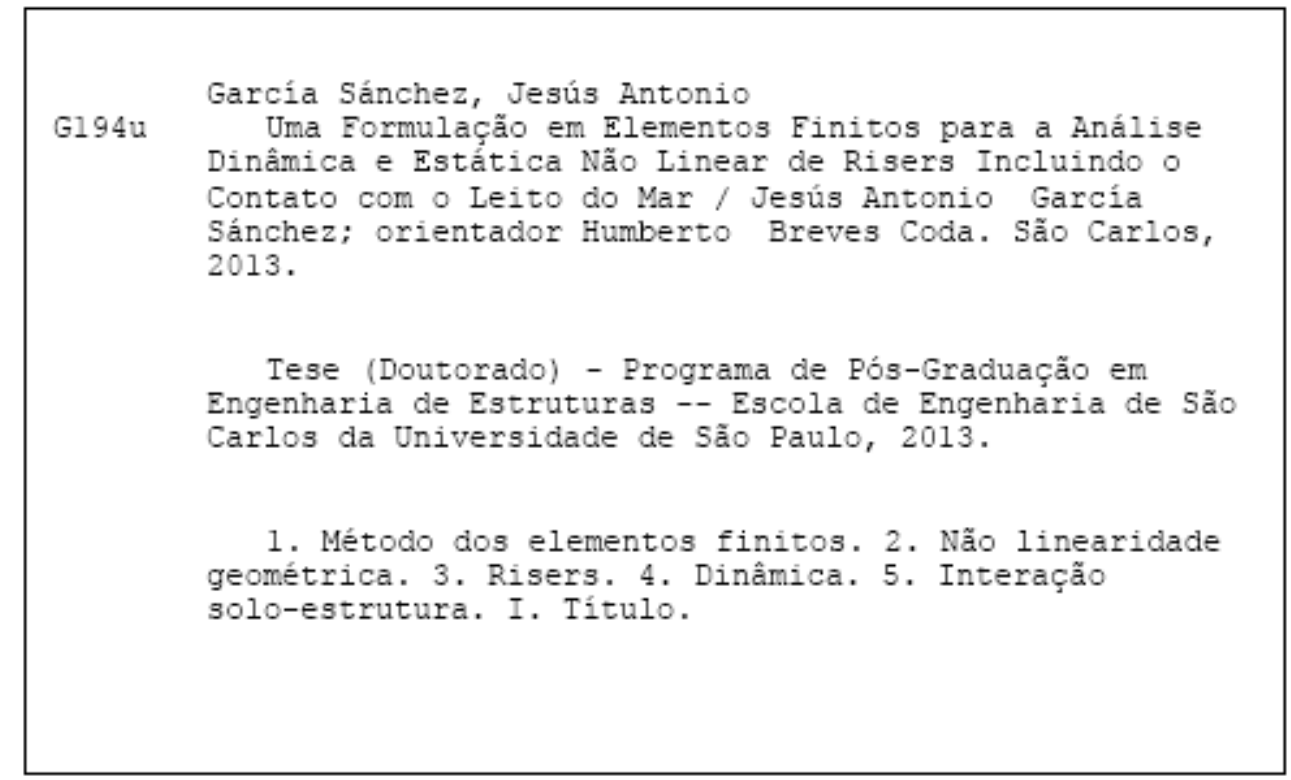


Candidato: Engenheiro JESÚS ANTONIO GARCÍA SÁNCHEZ.

Título da tese: "Uma formulação em elementos finitos para a análise dinâmica e estática não linear de risers incluindo o contato com o leito do mar".

Data da defesa: 23/08/2013

\section{Comissão Julgadora:}

\section{Resultado:}

Prof. Titular Humberto Breves Coda (Orientador)

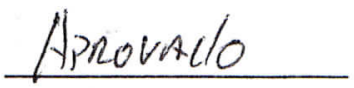

(Escola de Engenharia de São Carlos/EESC)

Prof. Titular José Elias Laier

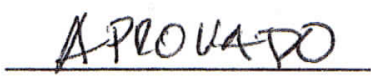

(Escola de Engenharia de São Carlos/EESC)

Prof. Dr. Rodrigo Ribeiro Paccola

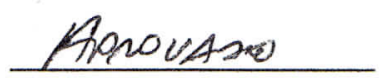

(Escola de Engenharia de São Carlos/EESC)

Prof. Dr. Renato Pavanello

APROVIDO

(Universidade Estadual de Campinas/UNICAMP)

Prof. Dr. Walter Libardi

(Universidade Federal de São Carlos/UFSCar)

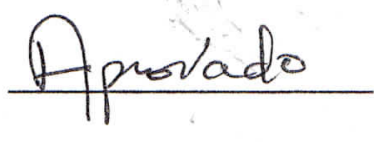

Coordenadora do Programa de Pós-Graduação em Engenharia Civil (Engenharia de Estruturas):

Profa. Associada Ana Lucia Homce de Cresce El Debs

Presidente da Comissão de Pós-Graduação:

Prof. Titular Denis Vinicius Coury

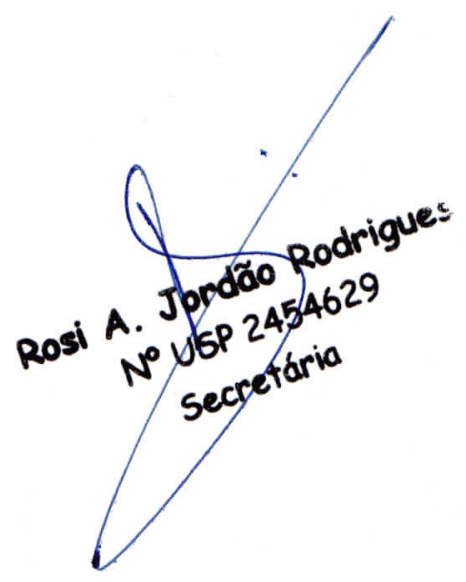



Dedicado siempre a mi Dios, a mi princesa Natália y a mi madre. 

"Caminante no hay camino, se hace camino al andar" Antonio Machado. 



\section{AGRADECIMENTOS}

A Deus por sua imensa misericórdia e sua ajuda em todos os momentos difíceis da minha vida.

A minha mãe pelo apoio e o amor. A minha filinha linda por querer-me tanto e à qual adoro.

A minha família, em especial, a Liliana, Oscar, Oscar D., Camilo, Magda, Serginho, Azdrubal, Jara e ao meu Pai.

A minha tia Socorro e a Humberto duas pessoas maravilhosas que já não estão neste mundo.

A todos e cada um dos amigos que fizeram de esta caminhada uma feliz experiência. Em especial a Carito, Pitis, Beto, Chuchin, Andrés, Marilia, Lore, Edwin, Soledad, Cesar, Rockdri, Gerson, Felipe, Luis, Ivan.

Aos amigos do SET Marcela K., Marcela F., Erika, Tati, Rafael, Aref, Bruno, Hildebrando, Rodrigo (Mario), Wanderson, Hellen, Wagner, Luis, Jefferson, Saulo, Fabio e todos aqueles com os que comparti bons momentos.

Às minhas grandes amigas Maria Lillo e Emperatriz.

A meu amigos de faculdade Sergio, Diana, Luis C, Fabian e Luis E.

A todos meus professores em especial a aqueles que durante o colégio marcaram minha vida, a Sarita, Carmensa e Florentino.

A Marta, Mario, Marcia e Neia, pelos cafezinhos e as boas conversas.

Aos meus amigos do colégio Zaira, Luz Mary, Martha, Liliana e Javier.

Aos funcionários do departamento pela ajuda. Ao pessoal da secretaria Rosi, Eli, Silvinha, Tati, em especial a Maria Nadir, pela eficiência mostrada no desempenho do seu trabalho. Ao Mario pelos papos no cafezinho.

Aos professores do departamento, sempre agradecido com eles pela imensa amabilidade e pela eficiência na execução do seu trabalho. A Laier, Adair, Paccola, Dagoberto, Proença e Venturini.

Ao professor Coda pela excelente orientação, na qual sempre mostrou muita paciência e sabedoria. Obrigado por ajudar de forma desinteressada os seus orientados.

À CNPq pela bolsa de estudos e os recursos disponibilizados. 


\section{RESUMO}

\section{SÁNCHEZ J.A.G. Uma Formulação em Elementos Finitos Para a Análise}

Dinâmica e Estática Não linear de Risers Incluindo o Contato com o Leito do mar. 2013. Tese (Doutorado) - Escola de Engenharia de São Carlos, Universidade de São Paulo, São Carlos, 2013.

Aplica-se uma formulação Lagrangeana total do Método dos elementos Finitos (MEF) baseada em posições para obter a resposta dinâmica não linear de risers bidimensionais em contato com o leito do mar. Os elementos finitos adaptados e aplicados nas soluções são de barras curvas de pórtico com cinemática de Reissner. Os risers são estruturas cilíndricas e esbeltas utilizadas na indústria offshore para transportar desde o fundo do mar até a plataforma gases, óleos, minerais ou lodo, entre outros produtos. $\mathrm{Na}$ modelagem dessas estruturas, destacam-se três problemas de imediato, são eles: a determinação da catenária inicial da tubulação, o comportamento estrutural após a aplicação de deslocamentos severos no topo do riser quando ancorado à plataforma ou embarcação flutuante e o contato do riser com o leito do mar. Estes problemas resultam ou são agravados pela forte instabilidade presente nessas estruturas em razão da grande relação entre a extensão dos dutos e sua rigidez transversal. Para obter a configuração inicial, três técnicas de penalização foram desenvolvidas e comparadas. A primeira utiliza a redução progressiva da rigidez da seção transversal do riser, a segunda aplica a penalização direta nos deslocamentos nodais do riser e a terceira emprega uma solução dinâmica amortecida com redução progressiva da massa e do amortecimento. As técnicas são comparadas entre si e com resultados das bibliografias. A metodologia desenvolvida para a aplicação de deslocamentos severos no topo do riser é fundamentada na suavização da posição tentativa, através de fórmula empírica baseada na remodelagem de malhas da mecânica dos fluidos. Discretiza-se o solo com molas distribuídas, de comportamento linear e não linear físico, cuja influência nodal é desenvolvida consistentemente. De forma geral a introdução dessas molas é feita através da técnica da penalização da energia potencial total. Descreve-se o comportamento não linear, comumente utilizado para solos coesivos argilosos, com um modelo P-y que considera a penetração inicial, a elevação, assim como a repenetração e alguns ciclos de carregamento e descarregamento delimitados pelas curvas das cargas extremas. Uma técnica de moderação das penalidades é utilizada para auxiliar no problema de contato entre o solo e o riser. Além desses aspectos específicos do trabalho, implementaram-se na formulação do MEF as ações decorrentes de carregamentos de flutuação, peso próprio, forças das correntes do mar e condições de contorno (forças e deslocamentos) devidas às ondas do mar. Realiza-se a integração temporal pelo método clássico de Newmark. A formulação desenvolvida junto com as estratégias implementadas mostram-se adequadas e precisas para o tratamento de risers.

Palavras-chave: método dos elementos finitos, não linearidade geométrica, risers, dinâmica, interação solo-estrutura. 



\section{ABSTRACT \\ SÁNCHEZ J.A.G. A Finite Element Formulation for the Non-linear Static and Dynamics Analysis of Risers Including Seabed interaction. 2013}

A total Lagrangian Finite Element Method (FEM) formulation based on positions is applied to achieve the static and dynamic responses of two dimensional risers that touch the seabed. The adapted finite elements to model risers are curved frame elements based on the Reissner kinematics. Risers are cylindrical slender structures used in the offshore industry to transport from the underground mineral resources (gas, petroleum, mud etc) to the platforms or vessels. In the analysis of this kind of structure three problems immediately arise, that are: the determination of the initial static position (catenary) of the riser, its dynamic behavior when subjected to severe loads or displacements at the top (floating platforms or vessels) and the interaction among the riser and the seabed. These problems come from or are worsened by the strong instability resulting from the large rate between the extension and the transverse dimension of the riser. In order to solve the initial position three techniques are developed and compared. The first uses a progressive reduction of the transverse stiffness of the riser, the second applies a direct penalization on the nodal displacements of the riser and the third employs a dynamic solution with mass and damping reduction. The achieved results are compared with the ones available in literature. The developed methodology to apply severe displacements at the top of risers is a smoothing procedure of the first trial position, based on a strategy of remeshing used in fluid-structure interaction analysis. The soil (seabed), with linear or non-linear behavior is represented by distributed springs and their nodal influence is consistently developed. In a general way the introduction of these springs is done penalizing the total potential energy function. The non-linear behavior, commonly used for cohesive and clayey soil, is done by a P-y model that takes into account the initial penetration, the elevation, as well as some cyclical loads established by extreme curves. A moderation technique of penalty is used to improve the convergence of the soil-structure interaction process. In addition to these specific aspects of the thesis, there are implemented actions resulting from floating, selfweight, sea streams, and waive forces. The time integration is performed by the Newmark method. Examples reveal that the developed formulation and the proposed strategies are adequate to model submersed risers in contact with the seabed.

Key words: Finite Element Method, Geometrical Non-linearity, risers, dynamic and Soil-structure interaction. 


\section{Conteúdo}

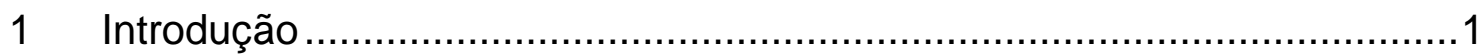

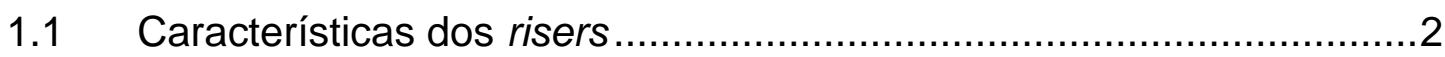

1.2 Desafios numéricos na modelagem de risers...................................

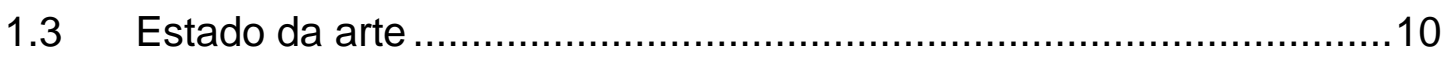

1.3.1 Sobre o método de análise utilizado ............................................10

1.3.2 Formulação do MEF a ser empregada........................................18

1.3.3 Integrador temporal............................................................

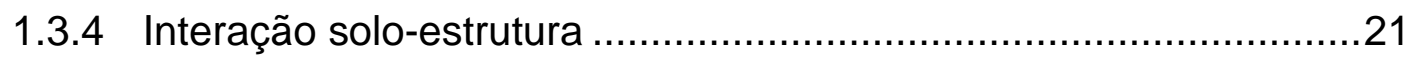

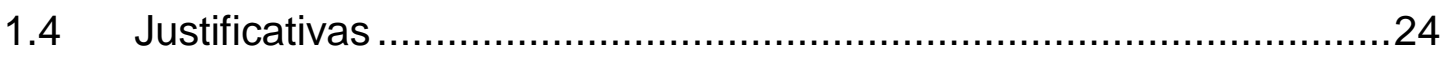

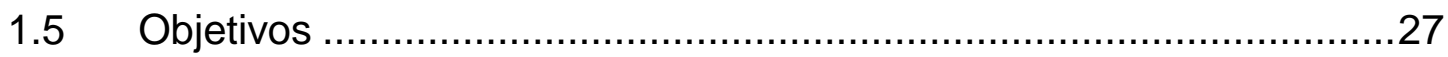

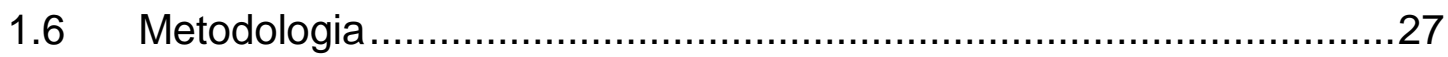

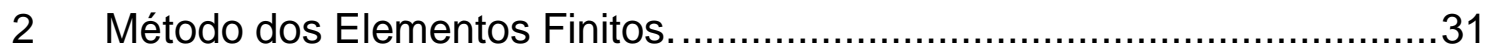

2.1 Formulação dinâmica do método dos elementos finitos.....................31

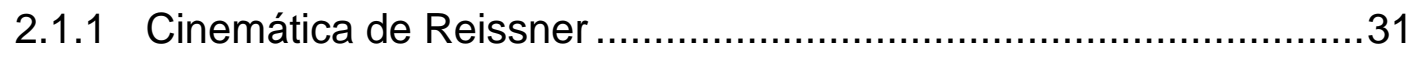

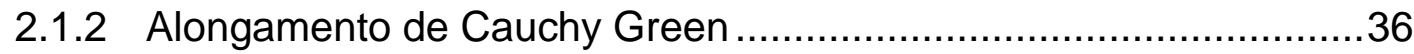

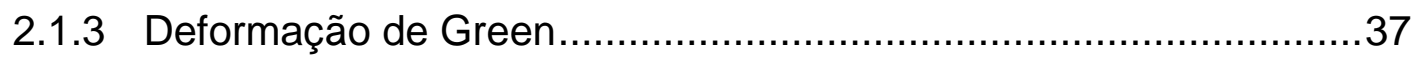

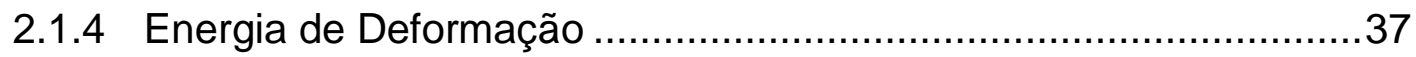

2.1.5 Segundo Tensor de Tensões de Piola-Kirchhoff ...........................38 


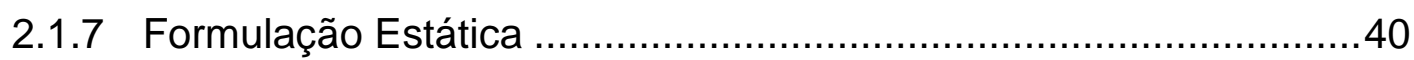

2.1.8 Método de Newton Raphson.................................................... 41

2.1.9 Formulação Dinâmica ............................................................... 42

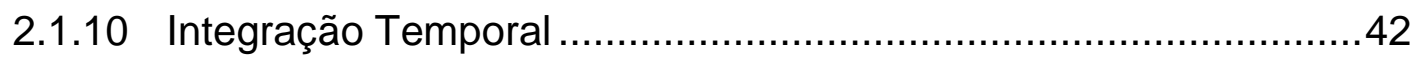

2.1.11 Implementação do algoritmo de Newmark- $\boldsymbol{\beta}$..............................44

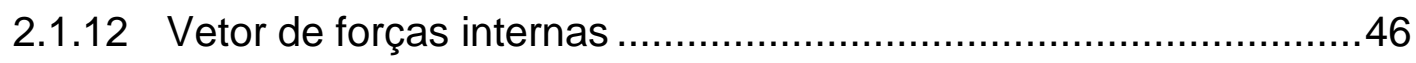

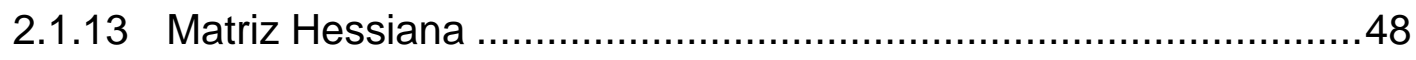

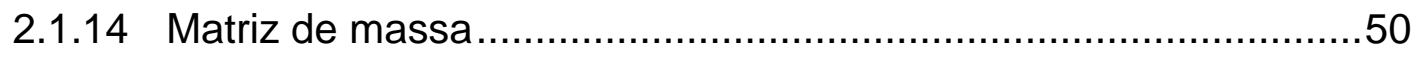

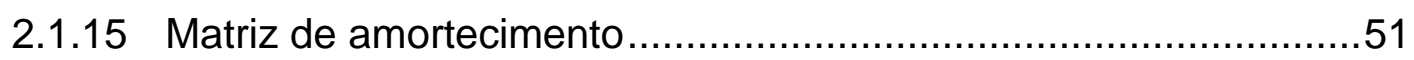

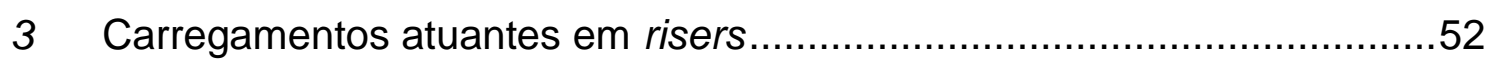

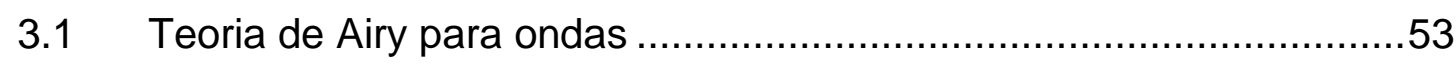

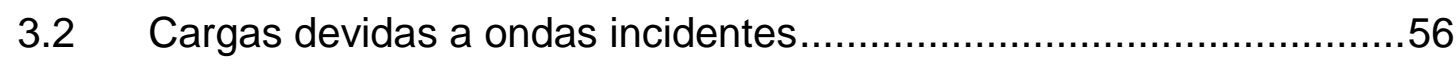

3.3 Cargas devidas às correntes e cargas de pressão ………………....56

3.4 Massa adicional e forças de amortecimento ...................................57

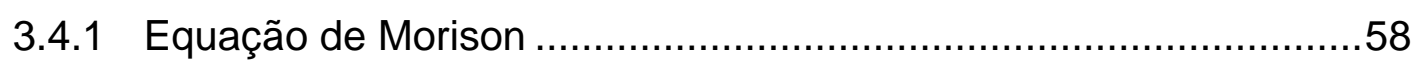

3.5 Força de Flutuação (Empuxo) ..................................................59

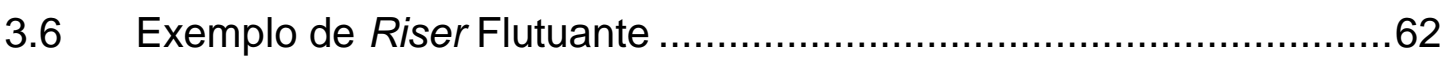

3.7 Tubo em balanço - Análise estática...............................................64

4 Obtenção da configuração estática inicial e deslocamentos impostos. ....68 
4.1 Estratégia para aplicação das condições de contorno em deslocamentos .69

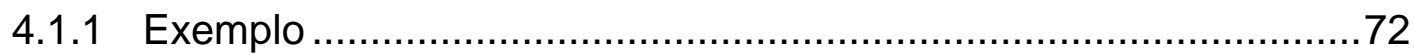

4.2 Problemas com matrizes Hessianas mal condicionadas...................73

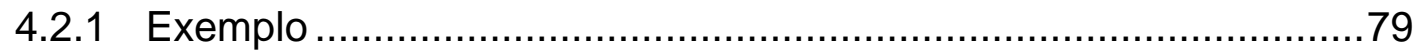

4.2.2 Exemplo de validação ........................................................... 83

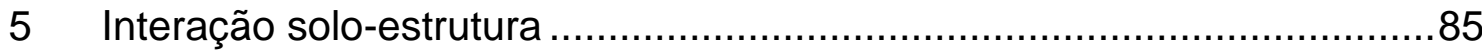

5.1 Método das Penalidades ........................................................86

5.2 Solo Elástico Linear - Método de Winkler.......................................87

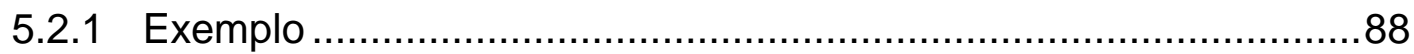

5.3 Solo Elástico Não Linear ........................................................92

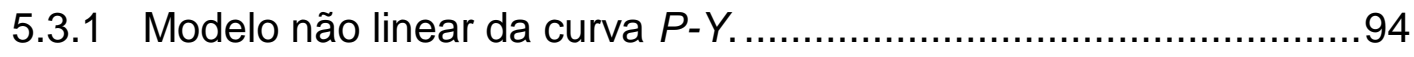

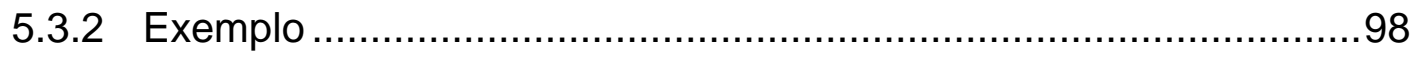

6 Exemplos Numéricos e Aplicações .............................................. 107

6.1 Riser Vertical - Análise estática ...........................................107

6.2 Riser Inclinado - Análise estática..........................................109

6.3 Exemplo API - Análises estática e dinâmica.............................110

6.4 Instalação de um riser, grandes deslocamentos impostos..............118

6.5 Instalação de um riser em contato com o solo. ...........................120

6.6 Riser com configuração Lazy-Wave..................................... 121

6.7 Riser rígido de perfuração desconectado................................130 
6.8 Mangote flexível entre duas plataformas...................................135

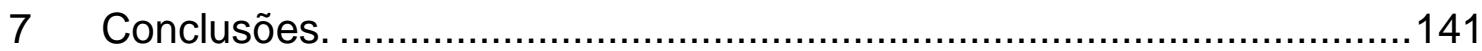

8 Referências bibliográficas ........................................................... 143

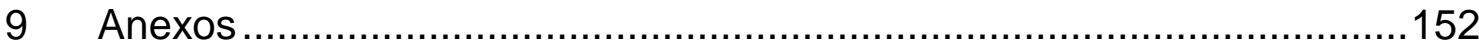

9.1 Anexo 1: Termos adicionais na matriz Hessiana devidos ao solo não linear. $\quad 152$ 


\section{Introdução}

A busca por novos recursos energéticos tem obrigado à indústria a realizar explorações em águas cada vez mais profundas e sob condições mais severas. Por exemplo, no Brasil, na Bacia de Santos - no campo de Tupi, encontram-se explorações de até $6 \mathrm{~km}$ de profundidade com relação à superfície do mar, sendo $2 \mathrm{~km}$ de lâmina de água.

As explorações em águas mais profundas, como também, o aumento nas exigências de segurança nas estruturas offshore, têm impulsionado a utilização de estruturas mais complexas e, também, de ferramentas computacionais que sejam capazes de realizar análises em condições críticas e utilizando modelos mais refinados. Em outras palavras, os softwares atuais procuram modelar risers com grandes comprimentos, com novos materiais, com solicitações extremas devidas às correntes oceânicas - com altos valores de velocidades e intensidades de onda -, com condições de apoio diversas - interação com o leito marinho e com a plataforma flutuante etc. Segundo Sanches (2009) as grandes profundidades e as condições de contorno dos sistemas estruturais que envolvem os riser criam a necessidade de realizar análises dinâmicas não lineares.

Apresentam-se, neste capitulo, a conceituação de risers, as dificuldades de sua solução mecânica, um estado da arte sobre o assunto e os principais objetivos da tese. 


\subsection{Características dos risers}

Os risers são estruturas esbeltas, amplamente utilizadas na indústria off-shore para extrair ou transportar produtos como gás natural, gases químicos, despejos químicos, óleos, lodo, minerais triturados, etc. Em geral, o riser pode ser definido como uma estrutura de ligação entre a plataforma ou embarcação e o poço no fundo do mar.

Os risers podem ser classificados segundo o material como sendo flexíveis ou rígidos. Os risers rígidos, geralmente, são construídos de aço enquanto os flexíveis são compostos de camadas de vários materiais. As aplicações abordadas neste trabalho mostram que a formulação desenvolvida serve para analisar globalmente tanto risers flexíveis como risers rígidos.

Os risers rígidos são formados por tubos de aço de aproximadamente $12 \mathrm{~m}$ acoplados com juntas. Estas estruturas são utilizadas em atividades de perfuração, completação e produção (MOURELLE, 1993). A depender do tipo de plataforma, por exemplo, em plataformas TLPs (Tension Leg Plataforms), a utilização de risers rígidos resulta uma alternativa mais econômica (PESCE et al., 1995).

As seções transversais de risers flexíveis são compostas de varias camadas. As principais, iniciando da mais interna para a mais externa, são: uma carcaça, um revestimento feito de algum material polimérico com a função de resistir à pressão interna, uma camada de armadura intertravada para aguentar a pressão, uma camada para prevenir o desgaste, duas camadas de armaduras para resistir à tração e finalmente o revestimento plástico externo. O revestimento externo tem a 
função de impermeabilizar, assim como também, proteger da corrosão e dos danos ocasionados durante o funcionamento.

Os risers flexíveis são classificados como risers não ligados, sem agentes adesivos entre as camadas, e risers ligados, com reforço ligado a uma matriz elastomérica. Os primeiros possuem a particularidade de conseguir resistir, em situações extremas, a esforços de flexão significativos, como também a grandes pressões mantendo a força axial controlada. Esta característica os torna estruturas eficientes para águas ultraprofundas (KRAINCANIC; KEBADZE, 2001).

Estas estruturas são classificadas, também, como: risers de produção e risers de extração ou injeção. Os risers de produção, em geral, consistem em um conjunto de linhas de transmissão de óleo ou gás entre o fundo do oceano e a superfície. Geralmente, os risers de produção são linhas verticais rígidas feitas de aço, com uma carga de tração na parte superior para evitar o colapso por flambagem.

Limita-se o uso de risers rígidos, geralmente, a águas pouco profundas. Isto se deve aos excessivos deslocamentos e aos problemas de flambagem. Porém, estas estruturas possuem melhor comportamento quando existem grandes pressões hidrostáticas. Os risers de extração são utilizados para a extração exploratória, muitas vezes são feitos de aço e são bastante utilizados em águas profundas ou ultraprofundas.

Consideram-se os risers flexíveis como sendo os novos risers de produção, já que resistem melhor a movimentos da plataforma ou da embarcação que os sustenta. Outra vantagem dos risers flexíveis é que não necessitam da força de tração na sua extremidade superior. 
Para grandes profundidades utilizam-se risers mistos. Estas estruturas são compostas, por risers rígidos e por risers flexíveis. As peças rígidas são utilizadas nos trechos mais profundos, já que elas possuem melhor resistência à pressão. Os risers flexíveis, por terem melhor desempenho perante grandes deslocamentos, utilizam-se no intervalo superior, o qual se encontra conectado com a plataforma flutuante ou a embarcação.

\subsection{Desafios numéricos na modelagem de risers}

Os risers, em geral, possuem uma série de problemas bastante conhecidos na modelagem numérica. Entre os mais importantes encontram-se:

\section{Grandes giros e deslocamentos:}

Os giros e os deslocamentos são ocasionados, principalmente, à baixa rigidez à flexão, quando comparada com a rigidez à torção e à rigidez axial.

\section{Interação fluido-estrutura:}

Os risers encontram-se submersos total ou parcialmente na água. Isto faz que a estrutura esteja submetida a carregamentos hidrodinâmicos. Entre os principais carregamentos encontram-se: a força de arrasto (drag), a força inercial, a força de empuxo e os deslocamentos impostos devidos aos movimentos oscilantes que as ondas do mar provocam na plataforma ou na embarcação que sustenta o riser. 
Realizam-se, muitas vezes, as análises hidrostáticas ou hidrodinâmicas baseadas na hipótese que a estrutura é completamente rígida, assim, estas análises são calculadas completamente desacopladas da análise estrutural. Bergan e Mathisen (1986) indicam que para estruturas altamente flexíveis deve existir uma interação entre os cálculos estruturais e a análise hidrodinâmica, já que algumas forças, como a pressão, dependem da posição da estrutura.

As forças de arrasto e de inércia por depender da velocidade e da aceleração da estrutura, também requerem uma interação constante com a análise estrutural. A força de arrasto pode ser considerada como uma variação no amortecimento da estrutura. A força de inércia geralmente é modelada como massa adicional e representa a parcela da água que se movimenta junto com o tubo. É importante mencionar que as forças hidrodinâmicas dependem de forma não linear da posição da estrutura.

\section{Vibrações induzidas por vórtices (VIV):}

As VIV, geralmente, são movimentos induzidos em corpos devido à interação com fluidos externos.

As oscilações produzidas pelo corpo, no caso o tubo, criam movimentos periódicos e irregulares no fluido ao seu redor. Quando existe movimento relativo entre o riser submerso e o fluido que o contém formam-se as denominadas linhas de corrente. Em alguns pontos as linhas de corrente podem-se separar do corpo devido à curvatura excessiva das mesmas, então se formam os denominados vórtices. Quando os vórtices não conservam a simetria com relação ao eixo do cilindro, criam- 
se forças de flutuação sobre o corpo as quais criam movimentos na direção transversal do tubo denominados vibrações induzidas por vórtices.

As VIV podem ocasionar um dano por fadiga, importante de ser detectado para ser analisado. Além disso, forças oscilatórias dos vórtices podem causar ressonância na estrutura.

\section{Iteração solo-estrutura:}

Consiste em representar a resistência do fundo do mar ao movimento do riser. Geralmente, os modelos de interação solo-estrutura tentam determinar com precisão a pressão entre o solo e a estrutura, a rigidez do solo e o atrito equivalente.

O atrito equivalente comumente encontra-se baseado na lei de Coulomb para areias, no conceito da coesão para argilas ou numa combinação de ambos no caso de solos mistos.

O solo, em geral, é modelado através da técnica das penalizações (molas nodais ou continuas) ou pelos multiplicadores de Lagrange. Entre as teorias de discretização mais utilizadas encontra-se o método de Winkler, no qual o solo é representado por molas lineares. Outros modelos consideram diversos efeitos como as características plásticas do solo, a formação de trincheiras, a sucção, ... etc.

A consideração da interação entre o solo e a estrutura influência, fortemente, na determinação da vida útil do riser. 


\section{Condições de contorno severas:}

É comum que os risers estejam sustentados por embarcações, ou plataformas temporárias. Com isto, os risers encontram-se submetidos às oscilações que as ondas do mar provocam sobre as embarcações. Mecanicamente estas oscilações são modeladas como deslocamentos impostos.

Quando se tenta modelar, por exemplo, condições de tormenta, onde as amplitudes e as frequências de oscilação são altas (amplitudes de até $30 \mathrm{~m}$, períodos de 15 a 20 segundos ou em raros casos períodos de até 4 segundos (FALTINSEN, 1990)), aumenta-se a incidência de instabilidades numéricas nos modelos disponíveis na estrutura. Estas instabilidades devem-se ao comportamento súbito das condições de contorno em posições (ou deslocamentos), se este valor é alto a mudança energética de uma solução tentativa no ponto pode ser tão elevada que o modelo numérico não consegue encontrar a configuração de mínima energia fisicamente compatível com a alteração imposta.

Algumas tecnologias permitem a atenuação dos movimentos da embarcação, diminuindo as tensões geradas sobre os risers. Exemplos destas tecnologias são "sistemas de compensação heave" e os sistemas de posicionamento dinâmico. Os primeiros, praticamente, eliminam os deslocamentos verticais que a embarcação transfere ao riser, enquanto que os segundos limitam os movimentos horizontais da embarcação a pequenas regiões.

A utilização destes recursos não é sempre viável. Santos Mello (2004) coloca que a utilização destes equipamentos deve ser compatível com as características do projeto, tais como orçamento ou operacionalidade do sistema, já que muitas vezes utilizam-se estes equipamentos de forma desnecessária ou antieconômica. 


\section{Instabilidades globais e locais:}

Quando os risers encontram-se submetidos a carregamentos de compressão pode-se apresentar neles o fenômeno de instabilidade. Quando isto acontece, um pequeno incremento na intensidade da força provoca um movimento excessivo na estrutura, ou seja, a configuração de equilíbrio no instante de tempo t pode-se encontrar longe da configuração do passo $t-\Delta t$, levando à perda de estabilidade global.

Os risers consistem em tubos de parede delgada cujas seções quando comprimidas e submetidas a ações combinadas, como por exemplo as VIV, podem sofrer perda de estabilidade local, onde a deformada da seção transversal toma formas muito diferentes da forma original.

\section{Problemas com temperatura e atrito:}

O projeto estrutural dos risers deve considerar que os produtos transportados podem ocasionar nos risers cargas de temperatura e de atrito. A não consideração destas cargas pode levar a previsões pouco precisas nos estados de tensão do material.

\section{Seções transversais de vários materiais:}

As seções transversais dos risers flexíveis, geralmente, são compostas por camadas de materiais diferentes. Isto faz com que a modelagem numérica do riser, muitas vezes, inclua algum método de homogeneização da seção transversal. 
Alguns outros modelos consideram a possibilidade de deslocamento rotacional relativo entre camadas devido à torção.

\section{Etapas críticas com solicitações e estados de esforços diferentes:}

Os risers, basicamente, devem ser analisados em três etapas: instalação, operação e manutenção. Em cada uma destas etapas a estrutura é solicitada de forma diferente, por exemplo, na etapa de instalação, geralmente, o riser encontrase sem produto no seu interior e as ondas que movimentam a plataforma não apresentam um comportamento extremo, enquanto que na operação o produto no interior solicita a estrutura e as ondas podem apresentar condições criticas. Estas diferenças, se desconsideradas, podem levar à má avaliação dos estados de tensão no riser e uma previsão irreal das possibilidades de ruína.

\section{Configurações diversas:}

Na Figura 1 são mostradas algumas das possíveis configurações nas que, geralmente, encontra-se um riser. Cada uma destas formas apresenta estados de esforços diferentes. A variedade nas configurações dificulta que as soluções analíticas sejam aplicadas de forma geral.

Existem muitos outros problemas relacionados à engenharia dos risers, mas não são citados devido à pouca relação que eles possuem com este trabalho, para maiores informações ver Kyriakides e Corona (2007). Com isto, conclui-se que os risers são um verdadeiro desafio para qualquer metodologia numérica, já que muitos 
desses problemas ainda não se encontram totalmente resolvidos na mecânica computacional.

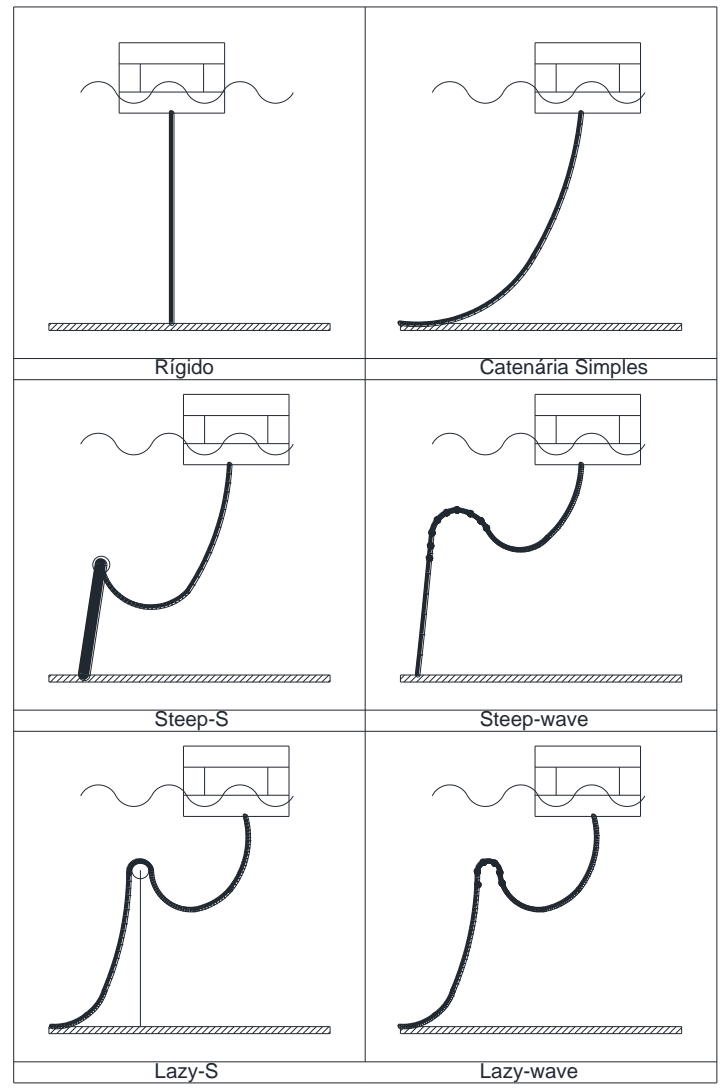

Figura 1, Diferentes configurações de risers (Patel e Seyed, 1995).

\subsection{Estado da arte}

\subsubsection{Sobre o método de análise utilizado}

As análises de estruturas tipo risers posem ser realizadas, principalmente, de três formas: utilizando formulações analíticas, por meio do método das diferenças finitas ou pelo método dos elementos finitos. 
As formulações analíticas são limitadas a poucas configurações da estrutura, por exemplo, estruturas em catenária. Nos parágrafos seguintes são descritos alguns trabalhos que utilizam procedimentos matematicamente analíticos.

Tikhonov e Fisher (1986) resolvem o problema de valor de contorno de estruturas tipo risers realizando uma expansão assintótica. Eles analisam o comportamento bidimensional de risers utilizados para a extração de minerais. Incluem-se as forças hidrostáticas que aparecem durante o transporte dos minerais. Não se consideram as cargas hidrodinâmicas devidas às ondas ou aos movimentos da embarcação.

Seyed e Patel (1992) apresentam métodos analíticos para a análise de risers em duas dimensões. Os autores incluem nas expressões matemáticas apresentadas os efeitos de pressão interna e externa e o peso próprio. As equações governantes são derivadas para algumas configurações especificas como a catenária simples, steep-S, lazy-S, steep-wave e lazy-wave, ver Figura 1. Os autores mostram expressões matemáticas para a força de flutuação de elementos curvos e retos. Yazdchi e Crisfield (2002a) observam que a adaptação das equações apresentadas por Seyed e Patel (1992) para o cálculo da força de flutuação e das pressões internas no método dos elementos finitos não é simples.

Atadan et al. (1997) estudam de forma analítica e numérica a resposta dinâmica tridimensional de risers sustentados por plataformas flutuantes considerando o fluido interno, as correntes e as ondas do mar. Nesse trabalho, o continuo é discretizado utilizando funções e coordenadas modais. Eles realizam uma análise dinâmica não linear com uma cinemática que considera os efeitos de cisalhamento. Avaliam-se os efeitos dos parâmetros hidrodinâmicos na amplitude do 
movimento. Entre os casos considerados, o parâmetro que mais afeta a deflexão do riser é o comprimento do mesmo. Eles mostram que para risers longos a amplitude do deslocamento torna-se muito grande. Concluem, também, que o aumento da rigidez reduz notoriamente a deflexão do sistema riser-plataforma, ou seja, à medida que a rigidez à flexão aumenta o deslocamento da plataforma diminui significativamente. Observa-se que a influencia da massa da plataforma afeta a amplitude no primeiro modo de vibração. Nos outros modos a influência é insignificante. Embora a massa da plataforma afete a primeira ressonância do sistema, o efeito que causa é relativamente pequeno se comparado ao efeito do comprimento e da rigidez à flexão. Quanto ao efeito causado pelas correntes, é observado por Atadan et al. que, quando a amplitude da corrente é muito maior que a amplitude das ondas do mar e seus sentidos são opostos, a estrutura exibe pequenas oscilações ao redor de uma posição de equilíbrio. Finalmente os autores apresentam os efeitos das ondas do mar, as quais se descrevem como sendo a principal força de excitação dos sistemas com risers, sendo que a altura da onda representa a magnitude do carregamento.

O método das diferenças finitas tem sido amplamente utilizado na literatura, porém apresenta algumas desvantagens já conhecidas, por exemplo, quando se utilizam métodos implícitos são necessários passos de tempo muito pequenos para que o problema seja convergente. Quando se utiliza algum método explícito, a solução apresenta um comportamento oscilante na vizinhança de descontinuidades (QUARTERONI; SACCO; SALERI, 2000). Na sequência do texto são apresentados alguns trabalhos que utilizam esta metodologia. 
Langer (1985) utiliza o método das diferenças finitas para analisar risers do tipo catenária simples. O autor mostra resultados precisos na distribuição do momento fletor ao longo do riser, porém nas extremidades são bastante distantes da solução esperada.

Chatjigeorgiou (2008) utiliza um método de diferenças finitas baseado na aproximação de caixa (Box approximation) para resolver o problema não linear de equilíbrio dinâmico de risers bidimensionais. $\mathrm{O}$ autor descreve o método como condicionalmente estável e rápido. Nesse artigo, observa-se que os termos não lineares aumentam sua contribuição quando a estrutura é exitada com movimento oscilatório na direção vertical na extremidade ligada à plataforma. Sob estas condições, Chatjigeorgiou mostra que a estrutura pode-se encontrar, em alguns instantes, sob compressão. Consequentemente, esta ação reflete-se no momento de flexão total, o qual exibe uma forte variação ao longo da metade superior da estrutura e um incremento excessivo do momento de flexão estático na vizinhança do ponto de contato com o solo (TDP).

Na literatura encontram-se diversos trabalhos onde a aplicação do método dos elementos finitos em estruturas tipo risers é bem sucedida.

Bernitsas et al. (1985) resolvem numericamente o problema não linear estático de risers, considerando grandes deformações e pequenos deslocamentos. O modelo analisado considera os efeitos de pressão interna e externa assim como condições de contorno não lineares. A condição de extensibilidade ou inextensibilidade utilizase como a relação constitutiva na direção tangencial. Os efeitos de torção e flexão 
são acoplados ${ }^{1}$. Os autores utilizam um algoritmo de elementos finitos incremental, o qual envolve um sistema preditor-corretor. Eles mostram a importância de considerar os efeitos de flexão, assim como também os efeitos não lineares dos carregamentos.

McNamara et al. (1986) realizam análises estática e dinâmica em duas dimensões para risers flexíveis sujeitos a cargas devidas às ondas e aos movimentos impostos pela embarcação. Eles desenvolvem a formulação de um elemento finito híbrido onde a força axial combina-se com o correspondente deslocamento via restrição Lagrangeana. O autor nota dificuldades quando se tenta considerar o atrito entre as camadas do riser.

Hoffman et al. (1991) realizam uma revisão das metodologias de projeto e das ferramentas de analises utilizadas para sistemas de risers. Os autores focalizam o trabalho em dois casos: risers em águas rasas e risers em águas profundas. Hoffman et al. apresentam de forma simples e resumida as características dos sistemas de risers flexíveis, os critérios, parâmetros e procedimentos de projeto, a forma de selecionar uma configuração adequada, assim como, algumas ferramentas de análises e validação. Eles concluem que o projeto de risers em águas rasas é mais complicado, pois o riser encontra-se submetido a cargas ambientais mais severas.

Howell (1992) utiliza o método das diferenças finitas para estudar cabos com tração baixa ou zero. Ele mostra que, quando a tração se aproxima de zero, é importante considerar os efeitos não lineares geométricos na rigidez à flexão. Estes

${ }^{1}$ Nordgren (1974) observou em um trabalho anterior ao de Bernitsas et al. que ao serem ignorados os efeitos de inextensibilidade junto com os acoplamentos em torção surgem dificuldades para acoplar as equações diferenciais para deslocamentos e tempo. 
efeitos combinados com alguns outros, como mudanças bruscas na direção tangencial do elemento, são importantes para explicar os efeitos de ovalização (Yazdchi \& Crisfield, 2002a).

Yazdchi e Crisfield (2002a) efetuam uma análise bidimensional dinâmica e não linear de risers. Os autores utilizam o método dos elementos finitos formulado de forma co-rotacional, no qual a configuração de referência encontra-se em movimento continuo. Eles adotam a cinemática de Reissner-Simo, a qual inclui deformação de cisalhamento. Nesse trabalho, eles adaptam tais formulações para incluir as forças hidrodinâmicas e hidrostáticas. Destacam a importância de incluir as cargas de pressão devidas aos efeitos de curvatura, especialmente quando se trabalha com estruturas altamente flexíveis. As cargas de pressão devidas à curvatura dos elementos são escritas em função dos graus de liberdade da estrutura. Yazdchi e Crisfield limitam-se a mostrar seus resultados para elementos finitos lineares, o que deixa em aberto a implementação de elementos de maior ordem.

No trabalho de Yazdchi e Crisfield (2002b) realiza-se uma pesquisa semelhante, à descrito anteriormente, porém em três dimensões.

Seyed e Patel (1992) também observaram a importância de incluir os efeitos das curvaturas nas estruturas altamente flexíveis. O equacionamento para estruturas curvas, encontrado no trabalho de Seyed e Patel, possui a dificuldade de ser analítico e de difícil adaptação para procedimentos em elementos finitos. Além das cargas de curvatura, os autores, incluem na sua análise os efeitos devidos ao fluido interno, notando que sua ausência nas análises produz erros consideráveis apenas no comportamento local da estrutura. 
Bergan e Mathisen (1986) utilizam o método dos elementos finitos para a modelagem não linear de estruturas offshore. Os autores propõem um método para a determinação da estabilidade hidrostática destas estruturas. No trabalho descrevem as forças hidrostáticas em elementos finitos retos e parcialmente submersos.

Low e Langley (2006) desenvolvem e validam duas formulações uma no domínio do tempo e a outra linearizada no domínio das frequências. Eles realizam as análises em sistemas flutuantes de produção posicionados em águas profundas. Em ambas acoplam os efeitos da plataforma flutuante, dos risers e do sistema de ancoragem. Eles mostram que a resposta no domínio das frequências oferece uma boa aproximação quando comparada com a análise no domínio do tempo. Os autores atribuem a similaridade entre as duas formulações à linearização da força de arrasto e à pouca presença de não linearidades geométricas nos exemplos analisados. Em geral, não recomendam que a aproximação no domínio das frequências seja utilizada quando as não linearidades geométricas são predominantes. Nota-se que nos exemplos numéricos desse trabalho impõem-se deslocamentos verticais devidos às ondas do mar, porém estes não produzem compressão no riser, já que eles são todos positivos.

García-Palacios et al. (2009) realizam uma análise dinâmica não linear do processo de instalação de risers e linhas de ancoragem flutuantes. Os autores modelam as estruturas com elementos de pórtico bidimensionais de NavierBernoulli. A estrutura é simulada desde uma situação de flutuação inicial até uma posição final no fundo do mar. Nesse trabalho consideram-se os carregamentos 
devidos ao peso próprio, às correntes e às ondas. Uma descrição detalhada de cada uma das ações consideradas é mostrada no artigo.

Hosseini et al. (2011) utilizam o método dos elementos finitos com uma formulação Lagrangeana tridimensional com adaptação incremental para realizar análises dinâmica de risers. O método apresentado comporta grandes deslocamentos e rotações. Consideram-se os efeitos de flutuação e os carregamentos devidos às correntes. Os resultados mostrados são comparados com exemplos existentes na literatura. Pequenas diferenças aparecem no campo de deslocamentos de alguns exemplos. Segundo os autores, estas variações devem-se ao fato da formulação utilizada apresentar maior precisão que as formulações da literatura, sob o regime de grandes deslocamentos e deformações. Observa-se que nos exemplos numéricos mostrados por Hosseini et al. impõem-se deslocamentos no topo do riser, unicamente, na direção horizontal.

As informações apresentadas permitem notar que o MEF é uma ferramenta moderna a qual permite acoplar de forma eficiente varias análises e efeitos.

No Brasil, têm-se realizado trabalhos importantes sobre análise estrutural de risers. Destacam-se o trabalho de Mourelle (1993) e Sousa (2005). Mourelle desenvolveu um algoritmo numérico com elementos co-rotacionais de pórtico espacial, o código desenvolvido serviu depois como base para o programa ANFLEX (1993). Sousa concentra-se na análise local, especificamente, no comportamento das camadas que conformam o riser. 


\subsubsection{Formulação do MEF a ser empregada}

Neste Trabalho adota-se a formulação do MEF desenvolvida no departamento de Engenharia de Estruturas (SET) da Escola de Engenharia de São Carlos (EESC) da Universidade de São Paulo (USP).

Coda e Greco (2004) propõem um método de elementos finitos (MEF) descrito em função das posições, o qual se encontra baseado no teorema de mínima energia potencial escrito em função das posições nodais. Ou seja, a velocidade, a aceleração e as deformações são extraídas diretamente da posição da estrutura, não dos deslocamentos (CODA, 2009). Este método tem apresentado resultados satisfatórios quando aplicado em estruturas com grandes deslocamentos e rotações. Coda e Greco utilizam o MEF para analisar estaticamente pórticos bidimensionais com cinemática de Euler-Bernoulli.

Coda e Greco (2006) apresentam uma formulação do MEF para análise dinâmica não linear de estruturas de pórticos bidimensionais. Para resolver as integrais numéricas os autores utilizam o algoritmo Newmark- $\beta$.

Coda e Paccola (2011) utilizam o MEF junto com uma descrição cinemática exata baseada em vetores irrestritos para obter a resposta dinâmica não linear de pórticos tridimensionais.

\subsubsection{Integrador temporal}

Os risers são estruturas cuja resposta dinâmica é importante, e em muitos casos pode variar muito da resposta estática. A análise dinâmica envolve integrais 
temporais. Existem vários métodos na literatura para resolver estas integrais. Sendo o algoritmo de Newmark o mais utilizado, devido à facilidade na implementação e à estabilidade incondicional quando aplicado a problemas de dinâmica linear.

O método de Newmark aplicado em análises não lineares, nem sempre mostra um comportamento tão robusto. Alguns autores (como descrito abaixo) não recomendam a utilização do método de Newmark em problemas estruturais semelhantes aos encontrados em risers. Porém, ao longo do trabalho mostram-se as vantagens de este método quando combinado com o MEF posicional, ver Coda e Paccola (2011) e Coda e Greco (2006).

Nos seguintes parágrafos são mostrados alguns trabalhos importantes de algoritmos de integração temporal, diferentes do método de Newmark, e as relações destes com risers.

Crisfield et al. (1997) testaram três métodos de integração temporal, o de Newmark, o método do ponto médio (HILBERT; HUGHES; TAYLOR, 1977) e o método da conservação de energia-momento (SIMO; TARNOW; WONG, 1992). Entre os algoritmos testados o de Newmark apresenta um comportamento menos robusto, porém os outros dois métodos exigem um gasto computacional maior, devido à falta de simetria das suas matrizes Hessianas.

A formulação co-rotacional - (YAZDCHI; CRISFIELD, 2002a) e (YAZDCHI; CRISFIELD, 2002b) - proporciona resultados independentes do tamanho do passo de tempo, das rotações e das translações, porém apresenta instabilidades quando se utiliza o algoritmo integrador de Newmark (NEWMARK, 1959), motivo pelo qual se faz necessário o uso de outros métodos de integração temporal. 
McNamara et al. (1986) recomendam o uso do método implícito de HughesTaylor por ser um método de passo controlável. Os autores consideram essencial a utilização de um método de passo controlável quando se abordam problemas que se iniciam com oscilações transientes.

Crisfield et al. (1997) aplicam três algoritmos de integração temporal para resolver algumas vigas co-rotacionais. Os autores comparam o método $\alpha$, o método do ponto médio e o método de Newmark, concluindo que este último apresenta o comportamento menos robusto. Os autores concluem que as dificuldades apresentadas pelo método de Newmark, na formulação co-rotacional, devem-se principalmente à necessidade de se ter uma matriz de massa global, a qual se obtém pela interpolação, com funções de forma, dos deslocamentos translacionais e rotacionais.

Coda e Paccola (2009) mostram que o algoritmo de Newmark, aplicado a uma formulação Lagrangeana total, conserva tanto a quantidade de movimento linear como a angular. A prova realizada pelos autores não se estende às formulações corotacionais. Os autores, também, mostram que na formulação de elementos finitos proposta, a qual possui uma formulação Lagrangeana total, o método de Newmark comporta-se de forma robusta. Isto se deve, principalmente, ao fato da matriz de massa da formulação ser constante. Como na técnica a ser utilizada apenas a matriz Hessiana, varia então o comportamento do integrador temporal é semelhante ao comportamento obtido em problemas geometricamente lineares com não linearidade física. 
Assim, as conclusões dos autores citados e que usaram a formulação corotacional, não se aplicam ao nosso trabalho e o integrador temporal a ser adotado é o de Newmark- $\beta$, tal como sugerem Coda e Paccola (2009).

Algumas leituras complementares e interessantes para 0 estudo de integradores temporais são: Briseghella et al. (1999), Kuhl e Crisfield (1999), Bui (2004), Armero e Romero (2001a) e (2001b), Laier (1998) e Pimenta et al. (2008).

\subsubsection{Interação solo-estrutura}

Em muitos casos os risers encontram-se apoiados, total ou parcialmente, no fundo do mar. A modelagem desta interação, como a maioria de problemas de contato, envolve certo grau de dificuldade, mais ainda quando combinado com os outros problemas mecânicos encontrados nos risers, ver seção 1.2.

O tipo de cenário de contato que se aplica depende da superfície do fundo do mar, o qual pode variar desde um impacto perfeitamente plástico (velocidade de retorno igual a zero) até um perfeitamente elástico (velocidade de retorno com a mesma magnitude e direção, mas em sentido contrario à velocidade de impacto) (CHAI; VARYANI; BARLTROP, 2002).

Nos últimos anos a interação solo-estrutura tem ganhado importância nas análises de risers devido à influencia que ela exerce na vida útil da estrutura.

Chai et al. (2002) propõem uma formulação tridimensional, com matriz de massa concentrada, para risers em catenária. Nesse trabalho os autores consideram a interação entre a estrutura e um fundo do mar irregular. A formulação proposta por Chai et al. inclui a rigidez à torção e à flexão. $\mathrm{O}$ modelo adotado para simular a 
interação solo estrutura substitui a superfície do fundo do mar por um colchão elástico com molas elásticas independentes e com uma espessura arbitraria. $\mathrm{Na}$ análise é possível adicionar parametricamente o efeito de amortecimento no colchão elástico, porém não se considera nenhum efeito de atrito.

Martínez e Goncalves (2003) utilizam uma formulação co-rotacional com elementos de pórtico de Bernoulli para realizar uma análise não linear de risers. Eles utilizam o método das penalidades com elementos de contato tipo mola para representar de forma precisa as condições de contorno com o stinger e com o solo.

Hosseini et al. (2008) realizam uma análise não linear de risers flexíveis utilizando na interação solo-estrutura o modelo proposto por Laver et al. (2004). Os autores discretizam a estrutura com elementos finitos tipo cotovelo (elbow) de 4 nós e 24 graus de liberdade para aumentar a precisão nesse tipo de modelos, obtendo resultados coerentes com os existentes na literatura.

Nakhaee e Zhang (2010) simulam a interação entre risers de aço em catenária com o fundo do mar. Os autores consideram o efeito da força de suporte que o solo realiza sobre a estrutura, a penetração da estrutura no solo e o efeito da trincheira ocasionada pelo impacto do riser no fundo do mar. Nakhaee e Zhang analisam como o fato de considerar a trincheira influencia os momentos de flexão ao longo do riser. Concluem que o desenvolvimento da trincheira ocasiona uma diminuição na variação do momento máximo perto da região onde o riser começa a se apoiar no solo (touch-down zone).

Hu et al. (2011) avaliam as respostas de penetração e extração do solo sob alguns carregamentos verticais repetitivos exercidos pelo riser através de um modelo de centrifuga, o qual simula o movimento vertical repetitivo de um trecho do riser em 
um solo argiloso. Devido às diversas formas do carregamento experimentadas pelo riser e às diversas condições do solo, foram realizados diversos testes para investigar o efeito da resistência do solo, a taxa de deslocamento e o modo de carregamento da interação solo-estrutura sob o movimento vertical do riser.

Morini (2009) utiliza a formulação de elementos finitos, descrita em função das posições, para simular o problema de interação solo-estrutura de estruturas tipo risers. Ele modela o solo como um conjunto de molas fixas. O autor considera duas simulações, a primeira com as molas sempre ativas e a segunda com as molas que se ativam quando ultrapassam a cota que define o solo. $O$ autor mostra resultados que indicam que o segundo modelo é mais realista.

Aubeny et al. (2005) mostram a importância de considerar o efeito de trincheira (trench) no problema de contato entre o riser e os solos coesivos. No trabalho, o contato é modelado utilizando a teoria clássica da plasticidade.

Aubeny e Biscontin (2009) modelam o contato entre o riser e o fundo do mar. Com ênfase no dano causado pela fadiga, proveniente da interação cíclica entre a estrutura e o solo. Os autores desenvolvem um modelo dado por uma curva P-y (carga-penetração) que considera o efeito de trincheira (trench), rigidez não linear do solo, sucção do solo e a separação do riser do solo. O modelo permite considerar várias formas para os ciclos de carregamento e descarregamento.

Nakhaee e Zhang (2010) propõem um modelo que considera a deformação plástica do solo devida aos ciclos de cargas. Eles realizam comparações com o modelo proposto por Aubeny e Biscontin (2009). Os autores descrevem, como resultado das simulações com o novo modelo, o desenvolvimento da trincheira e a variação dos momentos fletores ao longo do tempo. 
Colajanni et al. (2009) encontram uma solução analítica simplificada para a equação diferencial que governa o comportamento de uma viga sobre uma fundação elástica modelada pelo método de Winkler. A solução descrita considera os casos mais gerais de carregamento e vinculações.

Antonio (2011) estuda vários modelos utilizados para discretizar e descrever o comportamento do solo. Entre as metodologias estudadas pelo autor se encontram os métodos de Winkler, Filonenko-Borodich e Pasternak. Nesse trabalho realizam-se análises dinâmicas e estáticas de forma não linear.

Neste trabalho para simular o solo, utilizam-se dois modelos, o modelo linear de Winkler e molas não lineares que seguem o modelo $P$-y proposto por Aubeny e Biscontin (2009).

\subsection{Justificativas}

O Brasil encontra-se entre os países em desenvolvimento. Parte da sua fortaleza econômica suporta-se na indústria offshore. Desde a descoberta de reservas de petróleo na camada pré-sal, a Petrobras tem aumentado significativamente os investimentos nesta área. Em 2010 foram gastos 75 bilhões de reais, principalmente em exploração e produção de óleo e gás. Em 2011 o orçamento foi de 93 bilhões, utilizado em parte, para a expansão da companhia. Segundo José Sergio Gabrielli, presidente da Petrobras, a companhia produz dois milhões de barris de petróleo por dia e pretende triplicar essa produção até 2020.

Patel e Seyed (1995) colocam que "os desenvolvimentos tecnológicos na construção das estruturas offshore têm sido acompanhados, em paralelo, de 
avanços na análise do seu comportamento mecânico e hidrodinâmico", objetivo deste trabalho.

Nos últimos anos a procura de novas fontes de energia tem feito que as pesquisas para o uso eficiente e seguro de risers em diversos ambientes avancem de forma significativa.

Dificuldades básicas têm sido encontradas pelo autor sobre as análises de risers: A determinação da catenária inicial, a aplicação de deslocamentos severos no topo do riser quando ancorado à plataforma flutuante (tanto na direção vertical como na horizontal) e o problema de contato com o solo. Estas dificuldades resultam da forte instabilidade presente neste tipo de estruturas devido à grande extensão dos dutos quando comparada à sua rigidez transversal.

Considerando o descrito nos parágrafos anteriores e na seção 1.3, observa-se que ainda existe a necessidade de formulações e métodos que consigam obter respostas realistas para problemas dinâmicos não lineares aplicados a estruturas de risers e que consigam considerar carregamentos complexos, como as cargas hidrodinâmicas e os deslocamentos impostos.

Encontra-se, na literatura, que as técnicas de elementos finitos aplicadas a risers possuem boa aceitação, por exemplo, segundo Hosseini (2009) uma técnica não linear de elementos finitos é necessária para aumentar a precisão da solução durante o estudo do comportamento dos risers sob cargas ocasionadas por fluidos.

Nos últimos anos as formulações co-rotacionais têm sido aplicadas a diversos problemas de engenharia entre os quais, também, encontram-se os risers. Yazdchi e Crisfield (2002a) descrevem as formulações co-rotacionais com elementos finitos, 
como formulações modernas de análises. Embora as formulações co-rotacionais sejam eficientes, seu entendimento e sua implementação não são simples. Como visto na seção 1.3 as formulações co-rotacionais requerem algoritmos de integração temporal específicos e diferentes do algoritmo de Newmark. Estas outras estratégias de integração temporal, geralmente, trabalham com matrizes Hessianas não simétricas, as quais consequentemente produzem altos custos computacionais.

A metodologia de elementos finitos apresentada por Coda e Greco (2004) e Maciel (2008) tem apresentado bom comportamento quando aplicada a problemas dinâmicos com grandes deformações e rotações. O MEF descreve-se em função das posições, sendo de fácil entendimento e permitindo a aplicação de carregamentos complexos de uma forma simples. O método, quando aplicado a problemas dinâmicos não lineares e sendo combinado com algoritmo de Newmark, apresenta bons resultados e mostra boa estabilidade e convergência.

Na seção 1.3.4 nota-se que a interação entre o fundo do mar e os risers influência fortemente na resposta da estrutura e no colapso por fadiga.

Com isto, ao utilizar a formulação de elementos finitos Lagrangeana apresentada por Coda e Greco (2004) para o cálculo estático e dinâmico não linear de risers, sendo que estas estruturas estejam submetidas a grandes deslocamentos, cargas hidrodinâmicas e contato com o solo (modelado de forma linear e não linear), aborda-se um problema atual com características de alto interesse acadêmico e econômico. 


\subsection{Objetivos}

- Utilizar o MEF proposto por Coda e Greco (2004) e Maciel (2008) para obter a resposta dinâmica não linear de estruturas de risers utilizando, inicialmente, elementos de barra bidimensionais com cinemática de Reissner e depois, elementos de barra tridimensionais com cinemática exata.

- Solucionar o problema na determinação da configuração estática inicial de risers com baixa rigidez à flexão.

- Considerar nas análises diversos carregamentos de peso próprio, forças devidas às correntes, movimentos devidos às ondas e forças resultantes da pressão da água.

- Aplicar de forma eficiente e estável condições de contorno em deslocamentos.

- Simular o problema de contato entre o solo e a estrutura. Sendo que o solo siga modelos constitutivos lineares e não lineares.

- Considerar várias etapas e configurações do risers como, por exemplo, as etapas de instalação e operação ou as configurações em catenária simples ou em LazyWave.

\subsection{Metodologia}

Realizam-se análises estáticas e dinâmicas de estruturas de extração de petróleo denominadas risers em contato com o leito marinho. As soluções destas estruturas procuram-se mediante a minimização do potencial de energia descrito em função das posições. A modelagem é realizada com elementos de barra bidimensionais e com cinemática de Reissner, segundo o descrito na seção 2.1. 
Nos problemas dinâmicos a integração temporal é resolvida utilizando o algoritmo Newmark- $\beta$.

Na modelagem o peso próprio da estrutura é aplicado como uma carga vertical na direção negativa e distribuída no comprimento dos elementos.

Considera-se o carregamento de empuxo ou de flutuação nos elementos como sendo a integral da área na superfície de revolução que se encontra em contato com a água, diferente do principio de Arquimedes que geralmente é utilizado, a formulação para o cálculo desta última força mostra-se no item 3.5. Os resultados são comparados com o empuxo clássico de Arquimedes.

As cargas hidrodinâmicas, comumente denominadas cargas de arrasto e massa adicional, são simuladas com a equação de Morison modificada, estas forças são descritas nas seções 3.4 e 3.4.1.

As instabilidades numéricas encontradas nas modelagens de risers são melhoradas aplicando algumas estratégias originais.

A técnica desenvolvida para a aplicação de deslocamentos severos no topo do riser baseia-se na suavização da posição tentativa, através da fórmula empírica utilizada na remodelagem de malhas da mecânica dos fluidos. Um exemplo geral da análise estática de risers com movimentação do topo é utilizado para a validação desta proposta, isto se explica em detalhes na seção 4.1 .

Para resolver o problema da configuração estática inicial, três técnicas de penalização foram desenvolvidas e comparadas. A primeira utiliza a redução progressiva da rigidez da seção transversal do riser, a segunda aplica penalização direta nos deslocamentos nodais do riser e a terceira aplica solução dinâmica 
amortecida (proporcional à massa) do problema com redução progressiva da massa. As técnicas são comparadas entre si e com resultados da bibliografia.

Para simular o contato do riser com o leito marinho. Discretiza-se o solo com molas nodais, lineares e não lineares. O método de Winkler é utilizado para simular as molas lineares. As não lineares, comumente utilizadas para solos coesivos argilosos, são descritas com um modelo $P-y$ que considera a penetração inicial, a elevação, assim como a repenetração e alguns ciclos de carregamento e descarregamento delimitados pelas curvas das cargas extremas. O método das penalidades é utilizado para auxiliar no problema de contato entre o solo e o riser. 



\section{Método dos Elementos Finitos.}

Neste trabalho utilizou-se a metodologia de elementos finitos proposta por Coda e Greco (2004), a qual é adaptada por Maciel (2008) para considerar a cinemática de Reissner. Utiliza-se também o algoritmo de Newmark- $\beta$ para realizar a discretização temporal.

\subsection{Formulação dinâmica do método dos elementos finitos}

A formulação de elementos finitos proposta por Coda e Greco (2004) encontrase baseada no teorema de mínima energia potencial, escrito em função das posições nodais. Ou seja, a velocidade, a aceleração e as deformações são extraídas diretamente da posição da estrutura (MEFP), não dos deslocamentos (CODA, 2009).

\subsubsection{Cinemática de Reissner}

Sendo $B_{0}$ e $B_{1}$ as configurações indeformada e deformada de um corpo no espaço cartesiano, definido pelos eixos $\mathrm{X}_{1}$ e $\mathrm{X}_{2}$. Define-se f como a função mudança de configuração, a qual mapeia $\mathrm{B}_{0} \rightarrow \mathrm{B}_{1}$. O MEFP auxilia-se de um espaço adimensional que mapeia as configurações $B_{0}$ e $B_{1}$, o qual se define pelos eixos $\xi$ e $\eta$. Como pode ser visto na Figura 2, a configuração $B_{0}$ mapeia-se do espaço adimensional através da função $f_{0}$. De forma semelhante, a função $f_{1}$ mapeia à configuração $\mathrm{B}_{1}$. Assim, a configuração deformada do corpo pode ser descrita de forma lagrangeana como função dos mapeamentos $\mathrm{f}_{0}$ e $\mathrm{f}_{1}$ 


$$
f=f_{1}^{\circ}\left(f_{0}\right)^{-1}
$$

A utilização do espaço adimensional facilita a integração numérica das derivadas da energia.

O trabalho realizado possibilita utilizar elementos finitos com funções de forma de aproximação polinomial qualquer. Ou seja, as funções que discretizam os elementos de barra da estrutura podem ser lineares, quadráticas, cúbicas etc. Isto permite realizar discretizações gerais e analisar a convergência dos resultados (PASCON, 2012).

Neste trabalho, modelam-se as estruturas com elementos de barra bidimensionais. A cinemática utilizada para descrever a posição deformada do corpo é a de Reissner. Para explicar esta cinemática utiliza-se um procedimento semelhante ao proposto por Coda (2009), que mostra primeiro o mapeamento da linha media para depois introduzir os vetores que geram as posições fora desta linha. Esta sequência facilita o entendimento da formulação.

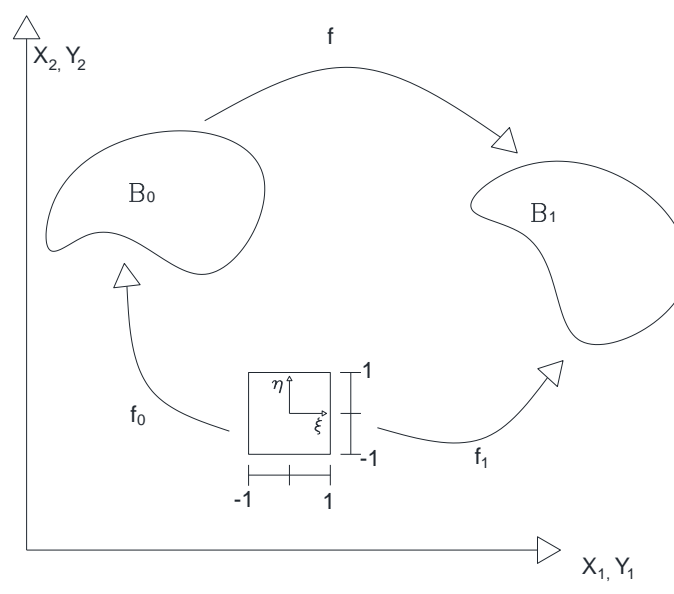

Figura 2. Mapeamento configuração de referência-espaço adimensional e espaço adimensionalconfiguração deformada

Definindo $x$ como sendo a posição de um ponto na configuração de referência $\mathrm{B}_{0}$ e y como a posição de um ponto na posição deformada $\mathrm{B}_{1}$, é possível definir o 
mapeamento da linha media do corpo, $f^{m}$, como a função que realiza a operação $x_{m} \rightarrow y_{m}$. Também se definem os mapeamentos $f_{0}^{m}$ e $f_{1}^{m}$ como as funções que realizam as operações $\xi \rightarrow x_{m}$ e $\xi \rightarrow y_{m}$, respectivamente. $O$ anterior encontra-se ilustrado na Figura 3. Assim, as funções de mapeamento da linha média são escritas como:

$$
\begin{aligned}
& f_{0 i}^{m}=x_{i}^{m}\left(\xi, X_{l i}\right)=\phi_{l}(\xi) X_{l i} \\
& f_{1 i}^{m}=y_{i}^{m}\left(\xi, Y_{l i}\right)=\phi_{l}(\xi) Y_{l i},
\end{aligned}
$$

onde $X_{l i}$ é a coordenada nodal na posição de referência do nó $l$ na direção $i, Y_{l i}$ é a coordenada nodal na posição deformada do nó $l$ na direção $i$ e $\phi_{l}(\xi)$ representa as funções de forma, as quais dependem da coordenada adimensional $\xi$. Assim, $x_{i}^{m}$, $y_{i}^{m}$ e $\phi_{l}$ definem-se no domínio do respectivo elemento finito. As funções de forma adotadas são os polinômios de Lagrange, que apresentam a seguinte propriedade:

$$
\phi_{l}\left(\xi_{k}\right)=\delta_{l k}
$$

onde $\xi_{k}$ representa as coordenadas adimensionais do nó $k$; e $\delta_{l k}$ é o delta de Kronecker.

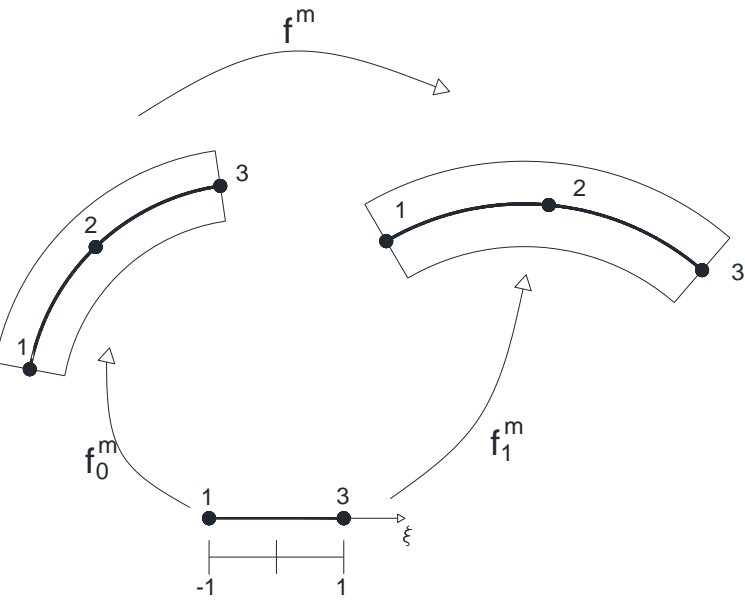

Figura 3. Mapeamento da linha media de um elemento quadrático. 
A cinemática de Reissner enuncia que, a seção transversal do elemento não permanece perpendicular à linha media do mesmo após a mudança de configuração. A posição de um ponto fora da linha media do corpo encontra-se ilustrada na Figura 4. As funções que descrevem as posições destes pontos, na posição de referência e deformada, são escritas como:

$$
\begin{aligned}
& x_{i}(\xi, \eta)=x_{i}^{m}(\xi)+g_{i}^{0}(\xi, \eta), \\
& y_{i}(\xi, \eta)=y_{i}^{m}(\xi)+g_{i}^{1}(\xi, \eta),
\end{aligned}
$$

onde os vetores $g_{i}^{0}(\xi, \eta)$ e $g_{i}^{1}(\xi, \eta)$ encontram-se descritos na Figura 4. Com isto, o mapeamento posicional da configuração inicial determina-se pelas seguintes equações:

$$
\begin{aligned}
& x_{1}(\xi, \eta)=\phi_{a}(\xi) X_{1 a}^{m}+\frac{h_{0}}{2} \eta \operatorname{Cos}\left(\phi_{a}(\xi) \Theta_{a}^{0}\right), \\
& x_{2}(\xi, \eta)=\phi_{a}(\xi) X_{2 a}^{m}+\frac{h_{0}}{2} \eta \operatorname{Sin}\left(\phi_{a}(\xi) \Theta_{a}^{0}\right),
\end{aligned}
$$

onde $\boldsymbol{\phi}_{\boldsymbol{a}}$ representa as funções de forma, $\boldsymbol{X}_{i \boldsymbol{a}}^{\boldsymbol{m}}$ as posições nodais e $\boldsymbol{\Theta}_{\mathbf{a}}^{\mathbf{0}} \circ$ ângulo inicial da seção transversal do nó "a" em relação ao eixo coordenado horizontal. As equações (5) e (6) resumem a cinemática de Reissner. O mapeamento da configuração atual faz-se substituindo $X$ por $Y$ e $\Theta^{0}$ por $\Theta$.

Para completar a definição do mapeamento de uma estrutura, é necessário descrever o gradiente dos mapeamentos $x_{i}(\xi, \eta)$ e $y_{i}(\xi, \eta)$. A definição do gradiente das funções de mapeamento é importante, já que proporciona o valor da energia de deformação por unidade de volume associada à mudança de configuração. Assim, $A_{0}$ é definido como o gradiente da função $f_{0}\left(x_{i}(\xi, \eta)\right)$. $A_{f}$ é definido como o gradiente da função $f_{1}\left(y_{i}(\xi, \eta)\right)$. Os gradientes são escritos como: 


$$
\begin{gathered}
A_{i j}^{0}=\left[\begin{array}{ll}
\frac{\partial x_{1}}{\partial \xi} & \frac{\partial x_{1}}{\partial \eta} \\
\frac{\partial x_{2}}{\partial \xi} & \frac{\partial x_{2}}{\partial \eta}
\end{array}\right], \\
A_{i j}^{f}=\left[\begin{array}{ll}
\frac{\partial y_{1}}{\partial \xi} & \frac{\partial y_{1}}{\partial \eta} \\
\frac{\partial y_{2}}{\partial \xi} & \frac{\partial y_{2}}{\partial \eta}
\end{array}\right],
\end{gathered}
$$

onde

$$
\begin{gathered}
\frac{\partial x_{1}}{\partial \xi}=\phi_{a, \xi} X_{1 a}^{m}-\frac{h_{0}}{2} \eta \phi_{k, \xi} \Theta_{\mathrm{k}}^{0} \operatorname{Sin}\left(\phi_{a} \Theta_{a}^{0}\right) \\
\frac{\partial x_{1}}{\partial \eta}=\frac{h_{0}}{2} \operatorname{Cos}\left(\phi_{a}(\xi) \Theta_{a}^{0}\right) \\
\frac{\partial x_{2}}{\partial \xi}=\phi_{a, \xi} X_{2 a}^{m}+\frac{h_{0}}{2} \eta \phi_{k, \xi} \Theta_{k}^{0} \operatorname{Cos}\left(\phi_{a} \Theta_{a}^{0}\right) \\
\frac{\partial x_{2}}{\partial \eta}=\frac{h_{0}}{2} \operatorname{Sin}\left(\phi_{a}(\xi) \Theta_{a}^{0}\right)
\end{gathered}
$$

Definem-se também:

$$
\begin{gathered}
\frac{\partial y_{1}}{\partial \xi}=\phi_{a, \xi} Y_{1 a}^{m}-\frac{h_{0}}{2} \eta \phi_{k, \xi} \Theta_{\mathrm{k}} \operatorname{Sin}\left(\phi_{a} \Theta_{a}\right), \\
\frac{\partial y_{1}}{\partial \eta}=\frac{h_{0}}{2} \operatorname{Cos}\left(\phi_{a}(\xi) \Theta_{a}\right), \\
\frac{\partial y}{\partial \xi}=\phi_{a, \xi} Y_{2 a}^{m}+\frac{h_{0}}{2} \eta \phi_{k, \xi} \Theta_{k} \operatorname{Cos}\left(\phi_{a} \Theta_{a}\right), \\
\frac{\partial y_{2}}{\partial \eta}=\frac{h_{0}}{2} \operatorname{Sin}\left(\phi_{a}(\xi) \Theta_{a}\right)
\end{gathered}
$$




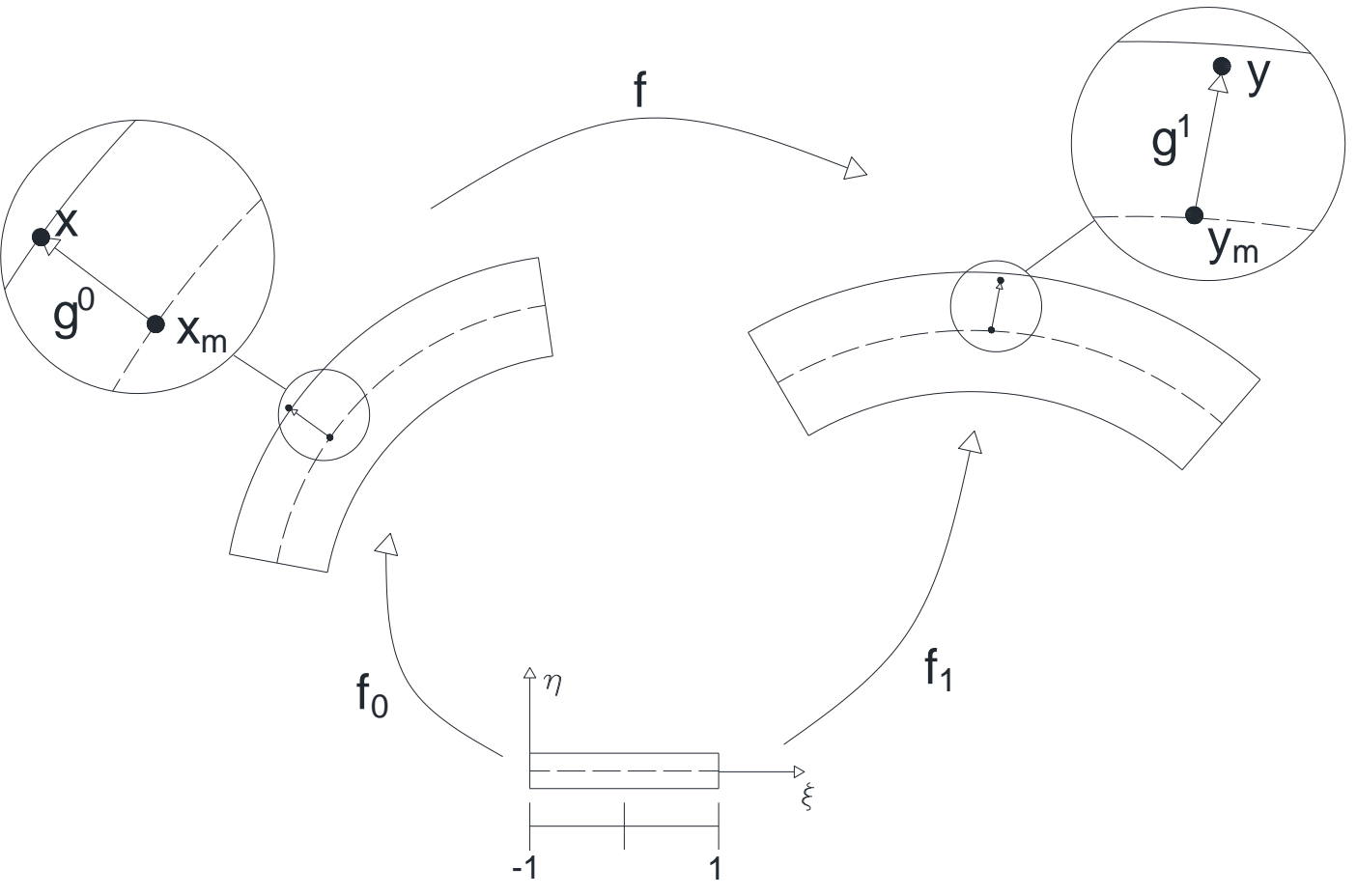

Figura 4. Mapeamento de pontos fora da linha media.

\subsubsection{Alongamento de Cauchy Green}

O tensor de Cauchy $\mathbb{C}$ define-se em função da função mudança de configuração, ver equações (7) - (9), como:

Definindo

$$
\mathbb{C}=A_{0}^{-T} A_{f}^{T} A_{f} A_{0}^{-1} .
$$

$$
\begin{aligned}
\boldsymbol{A} & =\boldsymbol{A}_{\boldsymbol{f}} \boldsymbol{A}_{0}^{-1}, \\
\boldsymbol{A}^{T} & =\boldsymbol{A}_{0}^{-T} \boldsymbol{A}_{f}^{T},
\end{aligned}
$$

Rescreve-se a equação (11) da seguinte forma:

$$
\mathbb{C}=\boldsymbol{A}^{T} \boldsymbol{A}
$$




\subsubsection{Deformação de Green}

O tensor de deformação de Green, $\mathbb{E}$, define-se em função do alongamento de Cauchy-Green como:

$$
\mathbb{E}=\frac{1}{2}(\mathbb{C}-I)
$$

substituindo a equação (14) na equação (15) obtém-se o tensor de deformação de Green em função das funções mudança de configuração,

$$
\mathbb{E}=\frac{1}{2}\left(\boldsymbol{A}^{T} \boldsymbol{A}-\boldsymbol{I}\right)
$$

onde $\boldsymbol{A}^{T}$ e $\boldsymbol{A}$ são definidas nas equações (12) e (13).

\subsubsection{Energia de Deformação}

Define-se o funcional quadrático da energia de deformação por unidade de volume como:

$$
u_{e}=\frac{1}{2}(\mathbb{E} \mathbb{C} \mathbb{E})
$$

o termo $u_{e}$ denomina-se como a energia especifica, a qual é dada por

$$
u_{e}=\frac{G}{(1-v)}\left[\left(E_{11}^{2}+2 v E_{11} E_{22}+E_{22}^{2}\right)+(1-v)\left(E_{12}^{2}+E_{21}^{2}\right)\right]
$$

onde $\boldsymbol{G}=\boldsymbol{E} /(\mathbf{2}(\mathbf{1}+\boldsymbol{v})), \boldsymbol{E}_{\boldsymbol{i j}}$ representa a componente $\boldsymbol{i j}$ do tensor de deformações de Green, $\boldsymbol{E}$ é o módulo de elasticidade e $\boldsymbol{v}$ é o coeficiente de Poisson. Para estado plano de tensões a equação (18) simplifica-se para: 


$$
u_{e}=\frac{G}{(1-v)}\left[E_{11}{ }^{2}+E_{22}{ }^{2}+2 v\left(E_{11} E_{22}\right)+(1-v)\left(E_{12}{ }^{2}+E_{21}{ }^{2}\right)\right] .
$$

Esta energia especifica de deformação define a lei constitutiva de SaintVenant-Kirchhoff, conforme item seguinte. Finalmente escreve-se a energia de deformação total como sendo a integral no volume do corpo da energia especifica de deformação

$$
U_{e}=\int_{V_{0}} u_{e} d V_{0}
$$

\subsubsection{Segundo Tensor de Tensões de Piola-Kirchhoff}

Para completar a definição da lei elástica de Saint-Venant-Kirchhoff mostra-se o tensor de tensões conjugado da deformação de Green, denominado de segundo tensor de tensões de Piola-Kirchhoff, o qual é dado pela derivada da energia de deformação, dada pela equação (17), com relação à deformação de Green, assim,

$$
S=\frac{\partial u_{e}}{\partial \mathbb{E}}=\mathbb{C} \mathbb{E},
$$

aplicando a equação (21) sobre a equação (19) obtém-se cada uma das componentes do segundo tensor de tensões de Piola-kirchhoff

$$
\begin{gathered}
\frac{\partial u_{e}}{\partial E_{11}}=S_{11}=\frac{2 G}{(1-v)}\left[E_{11}+v E_{22}\right] \\
\frac{\partial u_{e}}{\partial E_{22}}=S_{22}=\frac{2 G}{(1-v)}\left[v E_{11}+E_{22}\right] \\
\frac{\partial u_{e}}{\partial E_{12}}=S_{12}=2 G E_{12} \\
\frac{\partial u_{e}}{\partial E_{21}}=S_{21}=2 G E_{21}
\end{gathered}
$$




\subsubsection{Principio da mínima energia potencial}

Como mencionado anteriormente, o método dos elementos finitos proposto por Coda e Greco (2004) está baseado no teorema da mínima energia potencial, escrito em função das posições nodais. O principio da mínima energia é aplicável, unicamente, se o sistema respeita a lei da conservação da energia. Isto só é possível se as entradas e as saídas de energia se encontram em balanço. Assim, define-se a energia potencial total do sistema como:

$$
\Pi=\Pi_{0}-Q,
$$

onde $\Pi_{0}$ é a energia idealizada do sistema (LANCZOS, 1970), a qual é sempre constante e $Q$ representa a parcela da energia que é subtraída de $\Pi_{0}$ por causa do amortecimento ou outras dissipações. Com isto, a equação (26) pode ser escrita como:

$$
\Pi_{0}=\Pi+Q .
$$

Na equação (27) observa-se que П é a energia mecânica restante do sistema (CODA; PACCOLA, 2009). Com isto, escreve-se a energia potencial ideal como:

$$
\Pi_{0}=U_{e}+K+Q-P,
$$

onde $\boldsymbol{U}_{\boldsymbol{e}}$ representa a energia de deformação, $\boldsymbol{K}$ é a energia cinética, e $\boldsymbol{P}$ é a energia potencial das forças externas. A energia de deformação é escrita como a integral da energia especifica de deformação $\boldsymbol{u}_{\boldsymbol{e}}$ no volume do corpo $\boldsymbol{V}_{\mathbf{0}}$, definida em (17), ou seja,

$$
U_{e}=\int_{V_{0}} u_{e} d V_{0}
$$

A energia potencial das forças externas conservativas é dada por 


$$
P=F_{i} Y_{i}+\int_{S_{0}} p_{i} y_{i} d S_{0}
$$

onde $F_{i}$ descreve a força aplicada na direção $i$ e $Y_{i}$ corresponde à posição nodal, na configuração deformada, na direção $i$ na qual a força $F_{i}$ é aplicada, $p_{i}$ é a força na direção $i$ distribuída no comprimento $S_{0}$ do elemento. A energia cinética é escrita como:

$$
K=\frac{1}{2} \int_{V_{0}} \rho_{0} \dot{y}_{l} \dot{y}_{l} d V_{0}
$$

onde $\dot{y}_{l}$ representa a velocidade do corpo na posição atual e $\rho_{0}$ é a densidade de massa com relação ao volume inicial $V_{0}$. A parcela que representa a dissipação de energia é escrita de forma diferencial como:

$$
\frac{\partial Q}{\partial Y_{i}}=\int_{V_{0}} \frac{\partial q(x, t)}{\partial Y_{i}} d V_{0}=\int_{V_{0}} \lambda_{m} \dot{y}_{l} d V_{0}
$$

onde $q$ é o funcional especifico de dissipação e $\lambda_{m}$ é a constante de proporcionalidade do amortecimento. Substituindo (29)-(32) na equação (28) obtémse

$$
\Pi_{0}=\int_{V_{0}} u_{e} d V_{0}-F_{i} Y_{i}-\int_{S_{0}} p_{i} y_{i} d S_{0}+\frac{1}{2} \int_{V_{0}} \rho_{0} \dot{y}_{l} \dot{y}_{l} d V_{0}+Q
$$

\subsubsection{Formulação Estática}

Nesta seção, as forças inerciais e de amortecimento são negligenciadas. Com isto e aplicando o principio da mínima energia potencial sobre a equação (33) recaise na seguinte equação: 


$$
\frac{\partial \Pi}{\partial \boldsymbol{Y}}=g(\boldsymbol{Y})=\frac{\partial U_{e}}{\partial \boldsymbol{Y}}-\boldsymbol{F}=0,
$$

onde $Y$ é o vetor de posições nodais na configuração atual. A equação (34) escrita em forma vetorial fica:

$$
g(\boldsymbol{Y}, \boldsymbol{F})=\frac{\partial U_{e}}{\partial \boldsymbol{Y}}-\boldsymbol{F}=0
$$

\subsubsection{Método de Newton Raphson}

A quantidade $g(\boldsymbol{Y}, \boldsymbol{F})$ na equação (35) é não linear em relação aos parâmetros $\boldsymbol{Y}$ e $\boldsymbol{F}$. Para resolver esta equação utiliza-se o método iterativo de Newton Raphson.

Inicialmente realiza-se uma linearização em serie de Taylor ao redor do ponto $\boldsymbol{Y}_{\mathbf{0}}$ da equação (35), assim, tem-se:

$$
g(\boldsymbol{Y})=0 \cong g\left(\boldsymbol{Y}_{\mathbf{0}}\right)+\nabla g\left(\boldsymbol{Y}_{\mathbf{0}}\right) \Delta \boldsymbol{Y}
$$

ou seja,

$$
\Delta \boldsymbol{Y}=-\left[\nabla g\left(\boldsymbol{Y}_{\mathbf{0}}\right)\right]^{-1} g\left(\boldsymbol{Y}_{\mathbf{0}}\right) .
$$

onde $\boldsymbol{Y}$ é o vetor posição incógnito, $\boldsymbol{Y}_{\mathbf{0}}$ é a posição tentativa e $\Delta \boldsymbol{Y}$ é o vetor que contém as correções sobre a posição tentativa. Também, define-se $\nabla g(\boldsymbol{Y})$ como sendo a matriz Hessiana, a qual se determina derivando a equação (37) com relação à posição nodal,

$$
\nabla g(\boldsymbol{Y})=\frac{\partial g(\boldsymbol{Y})}{\partial \boldsymbol{Y}}=\frac{\partial^{2} \Pi}{\partial \boldsymbol{Y}^{2}}=\frac{\partial^{2} U_{e}}{\partial \boldsymbol{Y}^{2}}-\frac{\partial \boldsymbol{F}}{\partial \boldsymbol{Y}}=0
$$

Para forças conservativas $\frac{\partial \boldsymbol{F}}{\partial \boldsymbol{Y}}=0$. Os passos a seguir para resolver a equação (34) segundo o método de Newton Raphson são:

1) Escolhe-se a posição teste $\boldsymbol{Y}_{\mathbf{0}}$ (inicialmente a configuração indeformada) 
2) Com a solução tentativa é calculado o vetor desbalanceado $g\left(\boldsymbol{Y}_{\mathbf{0}}\right)$, segundo a equação (36).

3) Calcula-se a matriz Hessiana com a equação (38).

4) Com a equação (37) é calculada a variação do vetor posição $\Delta \boldsymbol{Y}$ e correge-se com ele a posição $\boldsymbol{Y}_{\mathbf{0}}$. A correção realiza-se segundo $\boldsymbol{Y}=\boldsymbol{Y}_{\mathbf{0}}+\Delta \boldsymbol{Y}$.

5) Calcula-se a norma mediante norma $=|\Delta \boldsymbol{Y}| /\left|\boldsymbol{Y}_{\mathbf{0}}\right|$ e verifica-se a convergência do algoritmo mediante norma $\leq$ tol.

6) Verifica-se se a norma é menor que a tolerância dada (tol), caso seja o método converge. Senão repete-se desde o passo 2 .

\subsubsection{Formulação Dinâmica}

Aplicando o principio de mínima energia potencial sobre $\Pi_{0}$ dado pela equação (33), tem-se que, derivando $\Pi_{0}$ com relação às posições nodais $Y_{i}$

$$
\frac{\partial \Pi}{\partial Y}=g(Y)=\frac{\partial U_{e}}{\partial Y}-\boldsymbol{F}+\boldsymbol{M} \ddot{Y}+\boldsymbol{C} \dot{Y}=0,
$$

\subsubsection{Integração Temporal}

A equação (39) denomina-se comumente como equação do movimento, nela $Y$ representa a posição $\dot{Y}$ a velocidade e $\ddot{Y}$ a aceleração. O problema de valor inicial procura encontrar a posição $Y=Y(t)$ que satisfaça a equação (39) e as seguintes condições iniciais

$$
\begin{aligned}
& Y=Y_{0}(t), \\
& \dot{Y}=\dot{Y}_{0}(t) .
\end{aligned}
$$


Para resolver o problema (39) sujeito às condições (40) utilizam-se algoritmos de integração temporal. Entre os mais usados encontra-se o algoritmo de Newmark$\beta$, o método $\alpha$, o método do ponto médio entre outros. O algoritmo de Newmark- $\beta$ é o mais utilizado na resolução de integrais temporais em problemas de engenharia de estruturas. O grande uso do método de Newmark deve-se a que, com a adequada escolha dos seus parâmetros, o algoritmo apresenta uma estabilidade incondicional na aplicação de problemas dinâmicos lineares (Hughes, 1987). Em análises dinâmicas não lineares o método de Newmark perde sua propriedade de estabilidade incondicional (Hughes, 1975). Quando se utilizam formulações corotacionais o método de Newmark torna-se dissipativo, entretanto para formulações Lagrangeanas totais sua aplicação resulta energeticamente coerente (CODA; PACCOLA, 2009).

Especificamente para risers, alguns carregamentos dependem da aceleração e velocidade do riser. Na dinâmica não linear este tipo de carregamento conhece-se como não ideal e pode causar instabilidades no algoritmo de integração temporal. Entretanto, se estes carregamentos aplicam-se de forma explicita, ou seja, calculados apenas no inicio de cada passo de tempo, sua influência na estabilidade do Método de Newton-Raphson acoplado ao método de integração temporal diminui, permitindo a análise em passos de tempo aceitáveis. Outra limitação observada é a aplicação de condições de contorno em posições, relacionada ao movimento da embarcação conectada ao topo do riser. Sua aplicação, considerando a estratégia usual de previsão conduz a resultados instáveis, pois esta concentra toda a variação inicial da energia de deformação no nó movimentado. Para sanar esta deficiência, uma estratégia baseada na adaptação de malhas para a análise de mecânicas dos fluidos, (Sanches, 2011), será aplicada e detalhada em item pertinente. 
Assim, adota-se o método proposto por Newmark (1959) para resolver o problema (39) sujeito às condições (40). O algoritmo de Newmark resume-se no seguinte conjunto de equações:

$$
\begin{gathered}
\left.\frac{\partial U_{e}}{\partial X}\right|_{S+1}-\boldsymbol{F}_{S+1}+\boldsymbol{M} \ddot{Y}_{S+1}+\boldsymbol{C} \dot{Y}_{S+1}=0, \\
Y_{S+1}=Y_{S}+\Delta t \dot{Y}_{S}+\Delta t^{2}\left[\left(\frac{1}{2}-\beta\right) \ddot{Y}_{S}+\beta \ddot{Y}_{S+1}\right], \\
\dot{Y}_{S+1}=\dot{Y}_{S}+\Delta t\left[(1-\gamma) \ddot{Y}_{S}+\gamma \ddot{Y}_{S+1}\right],
\end{gathered}
$$

onde $S$ indica o passo de tempo, $Y_{S}, \dot{Y}_{S}$ e $\ddot{Y}_{S}$ representam as aproximações de $Y\left(t_{S}\right)$, $\dot{Y}\left(t_{S}\right)$ e $\ddot{Y}\left(t_{S}\right)$, respectivamente. Os parâmetros $\beta$ e $\gamma$ determinam a estabilidade do algoritmo em consideração. A segunda e terceira equações (41) são formulas de diferenças finitas utilizadas para descrever a evolução da solução aproximada. Nos exemplos numéricos implementados neste trabalho utilizaram-se os valores de $\gamma=1.5$ e $\beta=1.0$.

\subsubsection{Implementação do algoritmo de Newmark- $\beta$}

Hughes (1987) mostra diversas formas de implementação do método de Newmark. Neste trabalho, o método desenvolve-se utilizando o algoritmo preditormulticorretor. Primeiro, definem-se como "preditores" os valores conhecidos de velocidade e aceleração nas equações (41), ou seja, os valores do passo $S$, assim:

$$
\begin{gathered}
\ddot{Y}_{p}=\frac{Y_{S}}{\beta \Delta t^{2}}+\frac{\dot{Y}_{S}}{\beta \Delta t}+\left[\left(\frac{1}{2 \beta}-1\right) \ddot{Y}_{S}\right], \\
\dot{Y}_{p}=\dot{Y}_{S}+\Delta t\left[(1-\gamma) \ddot{Y}_{S}\right] .
\end{gathered}
$$


Substituindo as equações (42) nas equações (41), reescrevem-se a aceleração e a velocidade como:

$$
\begin{gathered}
\ddot{Y}_{S+1}=\frac{Y_{S+1}}{\beta \Delta t^{2}}-\ddot{Y}_{p}, \\
\dot{Y}_{S+1}=\gamma \frac{Y_{S+1}}{\beta \Delta t}+\dot{Y}_{p}-\Delta t \gamma \ddot{Y}_{p} .
\end{gathered}
$$

Assim, com as equações (41)-(43), escreve-se a equação de equilíbrio como a seguinte equação algébrica:

$$
\begin{aligned}
g\left(Y_{S+1}\right)=\left.\frac{\partial \Pi}{\partial Y}\right|_{S+1} & \\
& =\left.\frac{\partial U_{e}}{\partial Y}\right|_{S+1}-\boldsymbol{F}_{S+1}+\frac{\boldsymbol{M}}{\beta \Delta t^{2}} Y_{S+1}-\boldsymbol{M} \ddot{Y}_{p}+\boldsymbol{C} \dot{Y}_{p}+\frac{\gamma \boldsymbol{C}}{\beta \Delta t} Y_{S+1} \\
& -\gamma \boldsymbol{C} \Delta t \ddot{Y}_{p}=0 .
\end{aligned}
$$

A equação (44) pode ser rescrita como:

$$
g\left(Y_{S+1}\right)=\left.\frac{\partial \Pi}{\partial Y}\right|_{S+1}=\left.\frac{\partial U_{e}}{\partial Y}\right|_{S+1}-\boldsymbol{F}_{S+1}+\boldsymbol{F}_{\text {iner }}+\boldsymbol{F}_{\text {amort }}=0,
$$

onde,

$$
\begin{gathered}
\boldsymbol{F}_{\text {iner }}=\boldsymbol{M}\left(\frac{Y_{S+1}}{\beta \Delta t^{2}}-\ddot{Y}_{p}\right) \\
\boldsymbol{F}_{\text {amort }}=\boldsymbol{C}\left(\dot{Y}_{p}+\frac{\gamma}{\beta \Delta t} Y_{S+1}-\gamma \Delta t \ddot{Y}_{p}\right) .
\end{gathered}
$$

A equação (44) apresenta, claramente, um comportamento não linear com relação a $Y_{S+1}$. Para resolver esta equação realiza-se uma linearização da mesma. Realiza-se a linearização mediante uma expansão de primeira ordem em serie de Taylor ao redor do ponto $Y^{0}$ da equação (44),

$$
g(Y) \cong g\left(Y^{0}\right)+\nabla g\left(Y^{0}\right) \Delta Y
$$

onde,

$$
\nabla g\left(Y_{S+1}\right)=\frac{\partial g\left(Y_{S+1}\right)}{\partial Y}=\left.\frac{\partial^{2} \Pi}{\partial Y^{2}}\right|_{S+1}=\left.\frac{\partial^{2} U_{e}}{\partial Y^{2}}\right|_{S+1}-\frac{\partial \boldsymbol{F}_{S+1}}{\partial Y}+\frac{\boldsymbol{M}}{\beta \Delta t^{2}}+\frac{\gamma \boldsymbol{C}}{\beta \Delta t}=0
$$


Deriva-se da equação (47) o procedimento de Newton-Raphson para resolver a equação (44), o qual é

$$
\nabla g\left(Y^{0}\right) \Delta Y=-g\left(Y^{0}\right),
$$

nesta equação $Y^{0}$ é uma posição "tentativa", comumente a posição do passo anterior, $Y_{S}$. O procedimento de Newton-Raphson resolve iterativamente a equação (49) até encontrar um valor $\Delta Y$ menor que uma tolerância dada, sendo que,

$$
Y_{S+1}=Y_{S}+\Delta Y \text {, }
$$

a cada nova iteração o valor $Y_{S+1}$ passa a ser a nova posição tentativa. $O$ valor final devolvido pelo procedimento de Newton-Raphson proporciona a posição no passo de tempo $S+1$. Uma vez conhecido o valor $Y_{S+1}$, utiliza-se junto das equações (43) para corrigir os valores de velocidade e aceleração. Esta última etapa é denominada etapa corretora do algoritmo de Newmark.

\subsubsection{Vetor de forças internas}

A primeira parcela da equação (33) é denominada energia de deformação e é definida como:

$$
U_{e}=\int_{V_{0}} u_{e} d V_{0}
$$

Denomina-se como vetor de forças internas a primeira derivada da energia de deformação, a qual se obtém derivando a expressão (19) com relação aos parâmetros nodais

$$
\frac{\partial u_{e}}{\partial Y_{k \beta}}=\frac{\partial u_{e}}{\partial E_{i j}} \frac{\partial E_{i j}}{\partial Y_{k \beta}},
$$


onde $\frac{\partial u_{e}}{\partial \mathbb{E}}$ é o segundo tensor de Piola-Kirchhoff dado pelas equações (22)-(25), $k$ é a direção da posição e $\beta$ o nó em questão. A derivada da deformação de Green com relação aos pontos nodais $\frac{\partial E_{i j}}{\partial Y_{k \beta}}$, segundo a equação (15), é dada por

$$
\frac{\partial \mathbb{E}}{\partial Y_{k \beta}}=\frac{\partial \mathbb{E}}{\partial \mathbb{C}} \frac{\partial \mathbb{C}}{\partial Y_{k \beta}}
$$

onde,

$$
\frac{\partial \mathbb{E}}{\partial \mathbb{C}}=\frac{1}{2}
$$

Lembra-se que $\mathbb{C}$, tensor de Cauchy-green, o qual segundo a equação (11) é dado por,

$$
\mathbb{C}=\boldsymbol{A}^{T} \boldsymbol{A}=\boldsymbol{A}_{0}^{-T} \boldsymbol{A}_{f}^{T} \boldsymbol{A}_{f} \boldsymbol{A}_{0}^{-1} .
$$

Definindo $\boldsymbol{B}_{0}=\boldsymbol{A}_{0}^{-1}$ e lembrando que as posições iniciais não variam, pode-se concluir que a variação com relação às posições nodais de $\mathbb{C}$ fica dada por:

$$
\frac{\partial \mathbb{C}}{\partial Y_{k \beta}}=\boldsymbol{B}_{0}^{T}\left(\left(\frac{\partial \boldsymbol{A}_{f}}{\partial Y_{k \beta}}\right)^{T} \boldsymbol{A}_{f}+\boldsymbol{A}_{f}^{T} \frac{\partial \boldsymbol{A}_{f}}{\partial Y_{k \beta}}\right) \boldsymbol{B}_{0},
$$

onde $k$ é a direção e $\beta$ o nó. Na equação (56) $\frac{\partial A_{f}}{\partial Y_{k \beta}}$ é dada como,

$$
\frac{\partial \boldsymbol{A}_{f}}{\partial Y_{1 \beta}}=\left[\begin{array}{cc}
\phi_{\beta, \xi} & 0 \\
0 & 0
\end{array}\right]
$$

onde $\phi_{\beta, \xi}$ é a derivada da função de forma no ponto $\beta$ com relação à coordenada adimensional $\xi$,

$$
\begin{gathered}
\frac{\partial \boldsymbol{A}_{f}}{\partial Y_{2 \beta}}=\left[\begin{array}{cc}
0 & 0 \\
\phi_{\beta, \xi} & 0
\end{array}\right], \\
\frac{\partial \boldsymbol{A}_{f}}{\partial Y_{3 \beta}}=\left[\begin{array}{cc}
-\frac{h}{2} \eta\left[\phi_{\beta}\left(\phi_{l, \xi} \theta_{l}\right) \operatorname{Cos}\left(\phi_{m} \theta_{m}\right)+\phi_{\beta, \xi} \operatorname{Sin}\left(\phi_{m} \theta_{m}\right)\right] & -\frac{h}{2} \phi_{\beta} \operatorname{Sin}\left(\phi_{m} \theta_{m}\right) \\
\frac{h}{2} \eta\left[\phi_{\beta, \xi} \operatorname{Cos}\left(\phi_{m} \theta_{m}\right)-\phi_{\beta}\left(\phi_{l, \xi} \theta_{l}\right) \operatorname{Sin}\left(\phi_{m} \theta_{m}\right)\right] & \frac{h}{2} \phi_{\beta} \operatorname{Cos}\left(\phi_{m} \theta_{m}\right)
\end{array}\right] .
\end{gathered}
$$


Expandindo a equação (52) nas suas componentes, tem-se:

$$
\frac{\partial u_{e}}{\partial Y_{k \beta}}=\frac{\partial u_{e}}{\partial E_{11}} \frac{\partial E_{11}}{\partial Y_{k \beta}}+\frac{\partial u_{e}}{\partial E_{22}} \frac{\partial E_{22}}{\partial Y_{k \beta}}+\frac{\partial u_{e}}{\partial E_{12}} \frac{\partial E_{12}}{\partial Y_{k \beta}}+\frac{\partial u_{e}}{\partial E_{21}} \frac{\partial E_{21}}{\partial Y_{k \beta}},
$$

com as equações (53) e (54), a equação (60) fica:

$$
\frac{\partial u_{e}}{\partial Y_{k \beta}}=\frac{1}{2}\left[\frac{\partial u_{e}}{\partial E_{11}} \frac{\partial C_{11}}{\partial Y_{k \beta}}+\frac{\partial u_{e}}{\partial E_{22}} \frac{\partial C_{22}}{\partial Y_{k \beta}}+\frac{\partial u_{e}}{\partial E_{12}} \frac{\partial C_{12}}{\partial Y_{k \beta}}+\frac{\partial u_{e}}{\partial E_{21}} \frac{\partial C_{21}}{\partial Y_{k \beta}}\right] .
$$

Segundo a equação (22) e a expressão (61) o vetor de forças internas resulta,

$$
\frac{\partial u_{e}}{\partial Y_{k \beta}}=\frac{1}{2}\left[S_{11} \frac{\partial C_{11}}{\partial Y_{k \beta}}+S_{22} \frac{\partial C_{22}}{\partial Y_{k \beta}}+S_{12} \frac{\partial C_{12}}{\partial Y_{k \beta}}+S_{21} \frac{\partial C_{21}}{\partial Y_{k \beta}}\right] .
$$

\subsubsection{Matriz Hessiana}

A derivada da equação (62) é a segunda derivada da energia especifica com relação aos parâmetros nodais, a qual se denomina matriz Hessiana,

$$
\frac{\partial^{2} u_{e}}{\partial Y_{l \gamma} \partial Y_{k \beta}}=\frac{1}{2} \frac{\partial}{\partial Y_{l \gamma}}\left[S_{11} \frac{\partial C_{11}}{\partial Y_{k \beta}}+S_{22} \frac{\partial C_{22}}{\partial Y_{k \beta}}+S_{12} \frac{\partial C_{12}}{\partial Y_{k \beta}}+S_{21} \frac{\partial C_{21}}{\partial Y_{k \beta}}\right] .
$$

Distribuindo a derivada obtém-se,

$$
\begin{gathered}
\frac{\partial^{2} u_{e}}{\partial Y_{l \gamma} \partial Y_{k \beta}=\frac{1}{2}[} \frac{\partial S_{11}}{\partial Y_{l \gamma}} \frac{\partial C_{11}}{\partial Y_{k \beta}}+\frac{\partial S_{22}}{\partial Y_{l \gamma}} \frac{\partial C_{22}}{\partial Y_{k \beta}}+\frac{\partial S_{12}}{\partial Y_{l \gamma}} \frac{\partial C_{12}}{\partial Y_{k \beta}}+\frac{\partial S_{21}}{\partial Y_{l \gamma}} \frac{\partial C_{21}}{\partial Y_{k \beta}}+S_{11} \frac{\partial^{2} C_{11}}{\partial Y_{l \gamma} \partial Y_{k \beta}} \\
\left.+S_{22} \frac{\partial^{2} C_{22}}{\partial Y_{l \gamma} \partial Y_{k \beta}}+S_{12} \frac{\partial^{2} C_{12}}{\partial Y_{l \gamma} \partial Y_{k \beta}}+S_{21} \frac{\partial^{2} C_{21}}{\partial Y_{l \gamma} \partial Y_{k \beta}}\right],
\end{gathered}
$$

a qual é dada em notação indicial como

$$
\frac{\partial^{2} u_{e}}{\partial Y_{l \gamma} \partial Y_{k \beta}}=\frac{1}{2}\left[\frac{\partial S_{i j}}{\partial Y_{l \gamma}} \frac{\partial C_{i j}}{\partial Y_{k \beta}}+S_{i j} \frac{\partial^{2} C_{i j}}{\partial Y_{l \gamma} \partial Y_{k \beta}}\right],
$$

onde as derivadas do segundo tensor de Piola-kirchhoff são dadas como,

$$
\frac{\partial S_{k m}}{\partial Y_{l \gamma}}=\frac{\partial S_{k m}}{\partial E_{i j}} \frac{\partial E_{i j}}{\partial Y_{l \gamma}}=\frac{\partial S_{k m}}{\partial E_{i j}} \frac{\partial E_{i j}}{\partial Y_{l \gamma}},
$$




$$
\begin{gathered}
\frac{\partial S_{k m}}{\partial Y_{l \gamma}}=\frac{\partial S_{k m}}{\partial E_{i j}} \frac{\partial E_{i j}}{\partial Y_{l \gamma}}, \\
\frac{\partial S_{k m}}{\partial Y_{l \gamma}}=\frac{\partial S_{k m}}{\partial E_{i j}} \frac{\partial E_{i j}}{\partial C_{i j}} \frac{\partial C_{i j}}{\partial Y_{l \gamma}}, \\
\frac{\partial S_{k m}}{\partial Y_{l \gamma}}=\frac{1}{2} \frac{\partial S_{k m}}{\partial E_{i j}} \frac{\partial C_{i j}}{\partial Y_{l \gamma}} .
\end{gathered}
$$

A segunda derivada do alongamento de Cauchy-Green é escrita como:

$$
\frac{\partial^{2} \mathbb{C}}{\partial Y_{l \gamma} \partial Y_{k \beta}}=\frac{\partial}{\partial Y_{l \gamma}}\left(\frac{\partial \mathbb{C}}{\partial Y_{k \beta}}\right)
$$

Derivando a equação (56) com relação a $Y_{k \beta}$

$$
\begin{gathered}
\frac{\partial^{2} \mathbb{C}}{\partial Y_{l \gamma} \partial Y_{k \beta}}=\frac{\partial}{\partial Y_{l \gamma}}\left(\boldsymbol{B}_{0}^{T}\left(\left(\frac{\partial \boldsymbol{A}_{f}}{\partial Y_{k \beta}}\right)^{T} \boldsymbol{A}_{f}+\boldsymbol{A}_{f}^{T} \frac{\partial \boldsymbol{A}_{f}}{\partial Y_{k \beta}}\right) \boldsymbol{B}_{0}\right), \\
\frac{\partial^{2} \mathbb{C}}{\partial Y_{l \gamma} \partial Y_{k \beta}}=\boldsymbol{B}_{0}^{T}\left(\left(\frac{\partial^{2} \boldsymbol{A}_{f}}{\partial Y_{l \gamma} \partial Y_{k \beta}}\right)^{T} \boldsymbol{A}_{f}+\left(\frac{\partial \boldsymbol{A}_{f}}{\partial Y_{k \beta}}\right)^{T} \frac{\partial \boldsymbol{A}_{f}}{\partial Y_{l \gamma}}+\left(\frac{\partial \boldsymbol{A}_{f}}{\partial Y_{l \gamma}}\right)^{T} \frac{\partial \boldsymbol{A}_{f}}{\partial Y_{k \beta}}\right. \\
\left.+\boldsymbol{A}_{f}^{T} \frac{\partial^{2} \boldsymbol{A}_{f}}{\partial Y_{l \gamma} \partial Y_{k \beta}}\right) \boldsymbol{B}_{0},
\end{gathered}
$$

No programa as segundas derivadas de $\boldsymbol{A}_{f}$ não foram consideradas, devido ao aumento no custo computacional e pouco ganho na precisão. Entretanto, escreve-se:

$$
\begin{gathered}
\frac{\partial^{2} \boldsymbol{A}_{f}}{\partial Y_{l \gamma} \partial Y_{1 \beta}}=\frac{\partial^{2} \boldsymbol{A}_{f}}{\partial Y_{l \gamma} \partial Y_{2 \beta}}=0 \\
\frac{\partial^{2} \boldsymbol{A}_{f}}{\partial Y_{l \gamma} \partial Y_{3 \beta}}=0, \text { para } l=1,2 \\
\frac{\partial^{2} \boldsymbol{A}_{f}}{\partial Y_{3 \gamma} \partial Y_{3 \beta}}=\frac{\partial}{\partial Y_{3 \gamma}}\left[\begin{array}{cc}
-\frac{h}{2} \eta\left[\phi_{\beta}\left(\phi_{l, \xi} \theta_{l}\right) \operatorname{Cos}\left(\phi_{m} \theta_{m}\right)+\phi_{\beta, \xi} \operatorname{Sin}\left(\phi_{m} \theta_{m}\right)\right] & \left.-\frac{h}{2} \phi_{\beta} \operatorname{Sin}\left(\phi_{m} \theta_{m}\right)\right] \\
\frac{h}{2} \eta\left[\phi_{\beta, \xi} \operatorname{Cos}\left(\phi_{m} \theta_{m}\right)-\phi_{\beta}\left(\phi_{l, \xi} \theta_{l}\right) \operatorname{Sin}\left(\phi_{m} \theta_{m}\right)\right] & \frac{h}{2} \phi_{\beta} \operatorname{Cos}\left(\phi_{m} \theta_{m}\right)
\end{array}\right]
\end{gathered}
$$




$$
\begin{aligned}
& \frac{\partial^{2} \boldsymbol{A}_{f}}{\partial Y_{3 \gamma} \partial Y_{3 \beta}} \\
& =\left[\begin{array}{ll}
-\frac{h}{2} \eta\left[\phi_{\gamma, \xi} \phi_{\beta} \operatorname{Cos}\left(\phi_{m} \theta_{m}\right)-\phi_{\gamma} \phi_{\beta}\left(\phi_{l, \xi} \theta_{l}\right) \operatorname{Sin}\left(\phi_{m} \theta_{m}\right)+\phi_{\gamma} \phi_{\beta, \xi} \operatorname{Cos}\left(\phi_{m} \theta_{m}\right)\right] & -\frac{h}{2} \phi_{\gamma} \phi_{\beta} \operatorname{Cos}\left(\phi_{m} \theta_{m}\right) \\
-\frac{h}{2} \eta\left[\phi_{\gamma} \phi_{\beta, \xi} \operatorname{Sin}\left(\phi_{m} \theta_{m}\right)+\phi_{\gamma, \xi} \phi_{\beta} \operatorname{Sin}\left(\phi_{m} \theta_{m}\right)+\phi_{\gamma} \phi_{\beta}\left(\phi_{l, \xi} \theta_{l}\right) \operatorname{Cos}\left(\phi_{m} \theta_{m}\right)\right] & -\frac{h}{2} \phi_{\gamma} \phi_{\beta} \operatorname{Sin}\left(\phi_{m} \theta_{m}\right)
\end{array}\right]
\end{aligned}
$$

$$
\begin{aligned}
\frac{\partial^{2} u_{e}}{\partial Y_{l \gamma} \partial Y_{k \beta}}=\frac{1}{2}[ & \frac{\partial S_{11}}{\partial Y_{l \gamma}} \frac{\partial C_{11}}{\partial Y_{k \beta}}+\frac{\partial S_{22}}{\partial Y_{l \gamma}} \frac{\partial C_{22}}{\partial Y_{k \beta}}+\frac{\partial S_{12}}{\partial Y_{l \gamma}} \frac{\partial C_{12}}{\partial Y_{k \beta}}+\frac{\partial S_{21}}{\partial Y_{l \gamma}} \frac{\partial C_{21}}{\partial Y_{k \beta}}+S_{11} \frac{\partial^{2} C_{11}}{\partial Y_{l \gamma} \partial Y_{k \beta}} \\
& \left.+S_{22} \frac{\partial^{2} C_{22}}{\partial Y_{l \gamma} \partial Y_{k \beta}}+S_{12} \frac{\partial^{2} C_{12}}{\partial Y_{l \gamma} \partial Y_{k \beta}}+S_{21} \frac{\partial^{2} C_{21}}{\partial Y_{l \gamma} \partial Y_{k \beta}}\right],
\end{aligned}
$$

\subsubsection{Matriz de massa}

A matriz de massa por elemento "e" é dada como:

$$
\boldsymbol{m}^{e}=\left[m_{k i l j}^{e}\right]
$$

onde $k$ e $l$ são nós e $i$ e $j$ as direções.

$$
\begin{gathered}
m_{k i l j}^{e}=\delta_{i j} \int_{\Omega^{\mathrm{e}}} \varphi_{k} \rho \varphi_{l} d \Omega, \\
m_{k i l j}^{e}=\delta_{i j} \iint \varphi_{k} \rho \varphi_{l} J d \xi d \eta,
\end{gathered}
$$

onde $J$ é o jacobiano, $\delta_{i j}$ o delta de kronecker, $\varphi_{i}$ as funções de forma no ponto $i, \rho$ a densidade do material e $\Omega^{\mathrm{e}}$ o volume inicial do elemento finito. para o espaço adimensional auxiliar. Integrando numericamente por meio da quadratura de Gauss, reescreve-se a equação (80) como,

$$
m_{k i l j}^{e} \cong \delta_{i j} \sum_{d=1}^{N p g 1} \sum_{c=1}^{N p g 2} \varphi_{k}\left(\xi_{c}\right) \rho \varphi_{l}\left(\xi_{d}\right) J W_{c} W_{d}
$$


sendo Npg1 o número de pontos de Gauss usados como aproximação na seção transversal, Npg1 o número de pontos de Gauss usados como aproximação no comprimento, $W_{c}$ e $W_{d}$ os pesos de cada um dos pontos de Gauss no comprimento e na seção transversal e $\xi_{c}$ as coordenadas dos pontos de Gauss.

É interessante notar que tanto a matriz Hessiana quanto a matriz de massa são organizadas para serem escritas com apenas dois índices relativos aos graus de liberdade, combinando-se os nós e as direções.

\subsubsection{Matriz de amortecimento}

Adota-se, neste trabalho, o amortecimento segundo o modelo de Rayleigh, no qual a matriz de amortecimento resulta de uma combinação linear da matriz de massa e da matriz de rigidez. Considera-se que o amortecimento é, unicamente, proporcional à massa, ou seja,

$$
\boldsymbol{C}=\lambda_{m} \boldsymbol{M}
$$

onde $\lambda_{m}$ é uma constante de proporcionalidade. 


\section{Carregamentos atuantes em risers}

Os carregamentos encontrados em risers são atípicos se comparados com as estruturas usuais. Entre as diversas cargas são modeladas neste trabalho as seguintes: cargas hidrodinâmicas (arrasto e massa adicional), atrito devido à passagem do produto transportado, peso próprio, empuxo, pré-tensão no topo e deslocamentos impostos.

Um conjunto de trabalhos foram consultados para descrever as cargas consideradas neste trabalho, são eles: Faltinsen (1990), Morison et al. (1950), Patel e Seyed (1995), Seyed e Patel (1992), Yazdchi e Crisfield (2002a), Yazdchi e Crisfield (2002b), Bergan e Mathisen (1986), Hosseini e Bahai (2008), (CHATJIGEORGIOU, 2008), entre outros.

Os carregamentos hidrodinâmicos podem ser classificados em dois grandes grupos:

- Carregamentos devidos à incidência de ondas.

- Carregamentos devidos à corrente do mar. Estas cargas são classificadas em termos de massa adicional, forças de amortecimento e forças de restituição (restoring). O movimento oscilatório da estrutura produz ondas de saída.

Os carregamentos hidrodinâmicos dependem da velocidade e da aceleração relativa entre a estrutura e as linhas de corrente do mar. As propriedades das linhas de corrente, no trabalho, são determinadas de duas formas. A primeira com a utilização de perfis dados de corrente e aceleração. Esses perfis são obtidos com dados experimentais do local onde será utilizado o riser. Outra forma é utilizar a teoria linear de Airy para ondas. No código computacional resultante deste trabalho 
é possível escolher a forma de calcular estas propriedades da corrente. A teoria de Airy é descrita na seção seguinte.

\subsection{Teoria de Airy para ondas}

Para descrever os carregamentos que o mar exerce sobre os risers necessitase conhecer a forma de propagação das ondas do mar. Em outras palavras, precisam-se conhecer os perfis, as velocidades e as acelerações no mar devidas às ondas.

A propagação das ondas em um fluido é um processo não linear. Para simplificar a análise utiliza-se a teoria linear de Airy. Assim, assume-se que as ondas incidentes são regulares e periódicas, que a água é um fluido não viscoso e incompressível, que o efeito de Coriolis e as perdas de energia são desprezíveis e que a única força exterior que atua sobre o fluido é a gravidade.

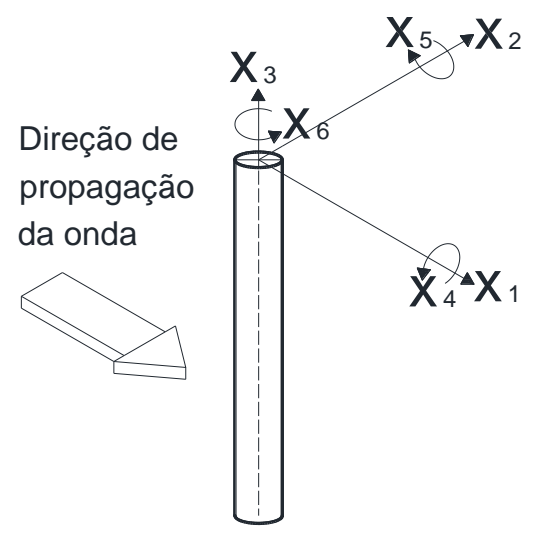

Figura 5. Sistema local de referência.

Considerando as simplificações anteriores, usa-se o potencial de velocidade, $\emptyset$, para descrever o comportamento da velocidade do fluido $\boldsymbol{V}$, no tempo $t$, assim o vetor de velocidade é dado por: 


$$
\boldsymbol{V}\left(x_{1}, x_{2}, x_{3}, t\right)=\frac{\partial \emptyset}{\partial x_{1}} \boldsymbol{i}+\frac{\partial \emptyset}{\partial x_{2}} \boldsymbol{j}+\frac{\partial \emptyset}{\partial x_{3}} \boldsymbol{k}=\nabla \emptyset
$$

onde $\boldsymbol{i}, \boldsymbol{j}$ e $\boldsymbol{k}$ são os versores nas direções $x_{1}, x_{2}$ e $x_{3}$. Considera-se o fluido como sendo irrotacional, ou seja, a voriticidade, $\boldsymbol{\omega}$, é zero

$$
\boldsymbol{\omega}=\nabla \times \boldsymbol{V}=0 .
$$

Sendo o fluido incompressível, tem-se que

$$
\nabla \cdot \boldsymbol{V}=0
$$

Com as hipóteses definidas em (84) e (85) o potencial satisfaz a equação de Laplace

$$
\frac{\partial^{2} \emptyset}{\partial x_{1}^{2}} \boldsymbol{i}+\frac{\partial^{2} \emptyset}{\partial x_{2}^{2}} \boldsymbol{j}+\frac{\partial^{2} \emptyset}{\partial x_{3}^{2}} \boldsymbol{k}=0
$$

Substituindo (83) e as hipóteses (84) e (85) na equação de Bernoulli resulta

$$
p+\rho g x_{3}+\rho \frac{\partial \emptyset}{\partial t}+\frac{\rho}{2} \boldsymbol{V} \cdot \boldsymbol{V}=\mathrm{C}
$$

onde $p$ é a pressão e $C$ é uma função arbitraria do tempo. A equação (87) representa o principio de conservação de energia em uma linha de corrente de um fluido incompressível, sem atrito e sujeito a forças volumétricas de origem gravitacional.

Reescrevendo a equação de Bernoulli como:

$$
\frac{p}{\rho}+g x_{3}+\frac{\partial \emptyset}{\partial t}+\frac{1}{2} \boldsymbol{V} \cdot \boldsymbol{V}=\mathrm{C}
$$

nota-se que cada um dos termos pode ser interpretado como uma parcela de energia. O primeiro termo $p / \rho$ é o fluxo de trabalho ou energia de fluxo por unidade de massa. A expressão $g x_{3}$ é a energia potencial por unidade de massa. Finalmente o termo $\frac{1}{2} \boldsymbol{V} \cdot \boldsymbol{V}$ representa a energia cinética por unidade de massa. 
Define-se a condição de contorno na superfície do mar como:

$$
\frac{\partial \emptyset}{\partial x_{3}}=0
$$

Utilizando a equação de Laplace, dada em (86), junto da condição de contorno de superfície livre, ver (89), e considerando que a superfície de mar é horizontalmente infinita, encontra-se a solução da teoria linear de propagação de ondas de Airy. Os resultados para profundidades finitas são encontrados na Tabela 1.

Tabela 1. Solução da propagação de ondas (Faltinsen, 1990).

\begin{tabular}{|l|c|}
\hline Potencial de velocidade & $\emptyset=\frac{g \zeta_{a}}{\omega} \frac{\operatorname{Cosh} \kappa\left(h+x_{3}\right)}{\operatorname{Cosh} \kappa h} \operatorname{Cos}\left(\omega t-\kappa x_{1}\right)$ \\
\hline Perfil da onda & $\zeta=\zeta_{a} \operatorname{Sin}\left(\omega t-\kappa x_{1}\right)$ \\
\hline Pressão dinâmica & $p_{d}=\rho g \zeta_{a} \frac{\operatorname{Cosh} \kappa\left(h+x_{3}\right)}{\operatorname{Cosh} \kappa h} \operatorname{Sin}\left(\omega t-\kappa x_{1}\right)$ \\
\hline $\begin{array}{l}\text { Componente } x_{1} \text { da } \\
\text { velocidade }\end{array}$ & $u_{x 1}=\omega \zeta_{a} \frac{\operatorname{Cosh} \kappa\left(h+x_{3}\right)}{\operatorname{Sinh} \kappa h} \operatorname{Sin}\left(\omega t-\kappa x_{1}\right)$ \\
\hline $\begin{array}{l}\text { Componente } x_{2} \text { da } \\
\text { velocidade }\end{array}$ & $u_{x 2}=\omega \zeta_{a} \frac{\operatorname{Sinh} \kappa\left(h+x_{3}\right)}{\operatorname{Sinh} \kappa h} \operatorname{Cos}\left(\omega t-\kappa x_{1}\right)$ \\
\hline $\begin{array}{l}\text { Componente } x_{1} \text { da } \\
\text { aceleração }\end{array}$ & $a_{x 1}=\omega^{2} \zeta_{a} \frac{\operatorname{Cosh} \kappa\left(h+x_{3}\right)}{\operatorname{Sinh} \kappa h} \operatorname{Cos}\left(\omega t-\kappa x_{1}\right)$ \\
\hline $\begin{array}{l}\text { Componente } x_{2} \text { da } \\
\text { aceleração }\end{array}$ & $a_{x 2}=\omega^{2} \zeta_{a} \frac{\operatorname{Sinh} \kappa\left(h+x_{3}\right)}{\operatorname{Sinh} \kappa h} \operatorname{Sin}\left(\omega t-\kappa x_{1}\right)$ \\
\hline
\end{tabular}

Na Tabela $1 \rho$ é a densidade do fluido, $g$ é a aceleração da gravidade, $\zeta_{a}$ é a amplitude da onda incidente, $h$ é a altura média da onda, a frequência é dada por 
$\omega=2 \pi / T, \kappa=2 \pi / \lambda, \lambda$ é o comprimento de onda, T é o período da onda e $x_{1}$ é a direção de propagação de onda.

Neste trabalho foram considerados e implementados os perfis de velocidade e aceleração segundo a teoria de ondas de Airy, mas também implementou-se a possibilidade de definir perfis por intervalos ao longo da profundidade, pois na maioria dos exemplos, dos trabalhos encontrados na literatura, estes perfis são dados desta forma.

\subsection{Cargas devidas a ondas incidentes}

Os risers flexíveis geralmente sustentam-se por plataformas flutuantes ou por embarcações. As ondas do mar provocam nas embarcações movimentos oscilantes tanto na direção horizontal como na vertical. Os movimentos que a embarcação aplica sobre os risers dependem da resposta que a embarcação tem ante as ondas incidentes, esta resposta é descrita por uma função que depende, entre outras coisas, da geometria. Devido à dificuldade de obter uma função resposta geral, neste trabalho os movimentos da embarcação são descritos pela teoria de Airy para ondas, assumindo que a resposta da embarcação é idêntica às ondas incidentes, ou por simples funções sinusoidais.

\subsection{Cargas devidas às correntes e cargas de pressão}

Quando um corpo é submerso em um fluido e existem velocidades e acelerações relativas entre as partículas do fluido e as do corpo, surgem forças e 
momentos sobre o corpo entre as que se destacam a força de flutuação, a massa adicional e as forças de amortecimento.

\subsection{Massa adicional e forças de amortecimento}

Os conceitos de massa adicional e forças de amortecimento podem ser entendidos como forças e momentos hidrodinâmicos ocasionados pela imposição de movimentos harmônicos de corpo rígido, sem a incidência de ondas. Sendo que estes movimentos impostos resultam em pressões oscilantes na superfície do corpo. A integração dessas pressões na área superficial do corpo proporciona forças e momentos no corpo.

Segundo o sistema coordenado mostrado na Figura 5 e sendo $F_{i}$ as forças no eixo $i, u_{i}$ o deslocamento na direção $i$, então, definem-se a massa adicional e as forças de amortecimento devidas ao movimento harmônico $u_{j}$ como:

$$
F_{k}=-A_{k j} \frac{d^{2} u_{j}}{d t^{2}}-B_{k j} \frac{d u_{j}}{d t}
$$

onde $A_{k j}$ e $B_{k j}$ são definidos como coeficientes de massa adicional e de amortecimento. Em detalhe, $A_{k j}$ e $B_{k j}$ são funções da forma do corpo, da frequência de oscilação e da velocidade de avanço (Faltinsen, 1990). Existem outros fatores que também influenciam na determinação destes coeficientes, como, por exemplo, a altura da superfície da água.

O conceito de massa adicional, geralmente, entende-se como se uma quantidade de água fosse conectada ao corpo e oscilasse rigidamente com ele, mas isto não é totalmente certo, pois as partículas do fluido podem oscilar com diferentes amplitudes ao longo do fluido. 


\subsubsection{Equação de Morison}

A equação de Morison (Morison, O'brien et al., 1950) frequentemente é utilizada para calcular as cargas devidas às correntes sobre cilindros verticais submersos ou sobre plataformas offshore fixas. Esta define o infinitésimo de força horizontal atuando em um $d x_{3}$ de um cilindro vertical rígido. Escreve-se a força como:

$$
d \boldsymbol{F}=\rho \pi \frac{D^{2}}{4} d x_{3} C_{m} a_{f}+\rho C_{d} \frac{D}{2} d x_{3}\left|u_{f}\right| u_{f},
$$

onde $\rho$ é a densidade do fluido, $D$ é o diâmetro do cilindro, $a_{f}$ e $u_{f}$ são a aceleração e a velocidade horizontais do fluido, considerados sem a presença da estrutura. $a_{f} \mathrm{e}$ $u_{f}$ são valores médios na altura $x_{3}$ do fluido. $C_{m}$ e $C_{d}$ são os parâmetros de inércia e de amortecimento, estes valores são empíricos e dependem de vários fatores como o número de Reynolds, o número de Keulegan-Carpenter, entre outros.

Modifica-se a equação de Morison para incluir nela as forças hidrodinâmicas do corpo, assim

$$
d \boldsymbol{F}=\rho \pi \frac{D^{2}}{4} d z\left[C_{m} a_{f}-\left(C_{m}-1\right) a_{c}\right]+\rho C_{d} \frac{D}{2} d z\left|u_{f}-u_{c}\right|\left(u_{f}-u_{c}\right),
$$

onde $u_{c}$ e $a_{c}$ são a velocidade e a aceleração horizontal do corpo, respectivamente.

Quando o cilindro se encontra inclinado aparece uma força vertical que também pode ser representada pela equação de Morison. Faltinsen (1990) propõe utilizar a força no cilindro inclinado como sendo a mesma força do cilindro vertical. 
Quando a estrutura encontra-se submetida à ação de correntes e ondas é possível superpor os efeitos somando vetorialmente a velocidade da corrente e a velocidade induzida pela onda.

\subsection{Força de Flutuação (Empuxo).}

Define-se flutuação ou empuxo como a força que exerce um fluido sobre um corpo submerso. Está força é a resultante das pressões hidrostáticas do fluido atuando na superfície (Seyed e Patel, 1992). Ou seja, é a integral de superfície de um corpo totalmente submerso. Geralmente, em elementos finitos estas forças são aplicadas segundo o principio de Arquimedes, porém a continuidade entre elementos faz com que a força resultante da integração das pressões na superfície seja diferente do peso do fluido deslocado ${ }^{2}$.

Seyed e Patel (1992) derivam matematicamente as expressões para as forças de flutuação, eles consideram, além da pressão, os efeitos de curvatura, as forças nas extremidades e as forças devidas ao fluido interno. Os autores mostram que devido à consideração destes efeitos o comportamento mecânico do riser torna-se mais próximo do real. A dificuldade da formulação proposta por estes autores encontra-se na incorporação dela no contexto dos elementos finitos (Yazdchi, M e Crisfield, M. A., 2002a).

Yazdchi e Crisfield (2002a) apresentam as forças de flutuação e a forma em que estas se incluem no método dos elementos finitos. Os autores utilizam um

${ }^{2}$ Observado por vários autores (Seyed e Patel, 1992), (Yazdchi, M e Crisfield, M. A., 2002), (Bergan e Mathisen, 1986) entre outros. 
elemento de aproximação linear para discretizar os risers. Eles distribuem a pressão ao longo do comprimento de arco da linha central do elemento, e as cargas devidas às curvaturas concentram-se nos nós das extremidades.

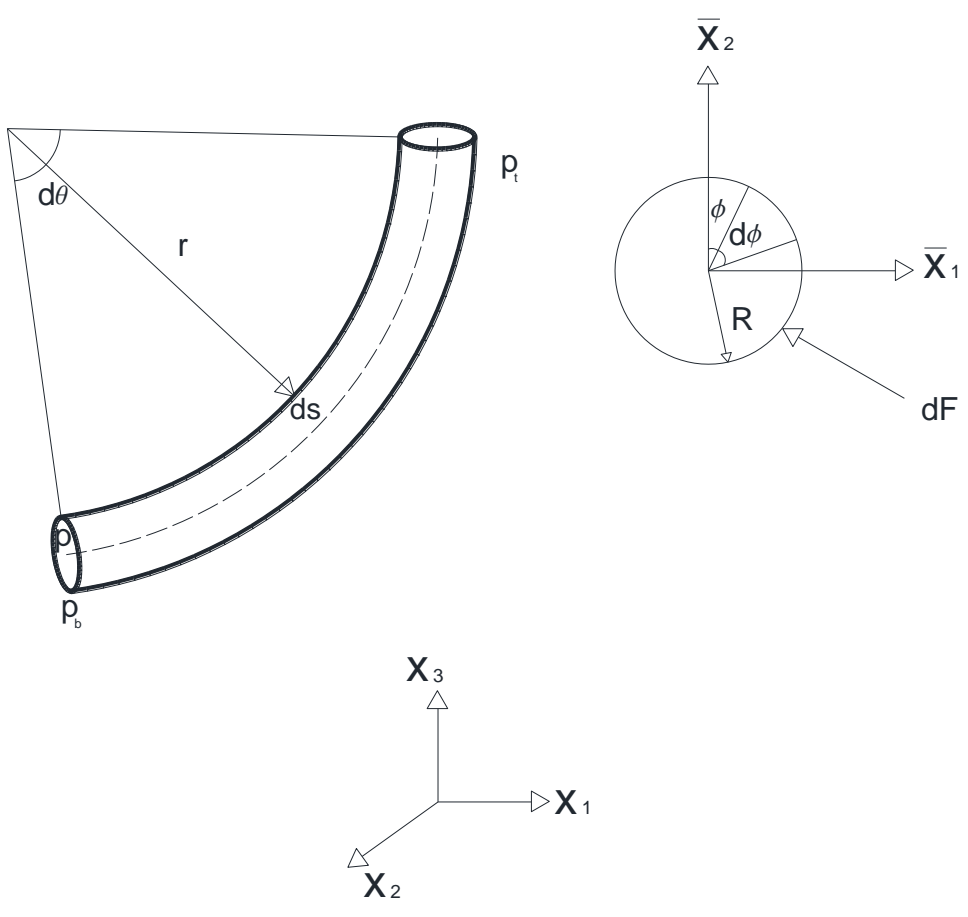

Figura 6. Pressões em um elemento finito curvo (Seyed e Patel, 1992).

Yazdchi e Crisfield (2002a) dividem os carregamentos de flutuação em três tipos: 1) a pressão distribuída no elemento, 2) as forças devidas à curvatura do elemento e 3) as forças nas extremidades do riser.

As forças de flutuação consideradas neste trabalho foram tomadas de Seyed e Patel (1992), com a diferença que adaptadas para elementos finitos com grau de aproximação qualquer. Neste trabalho, também se implementou a força de empuxo segundo o principio de Arquimedes, isto com o objetivo de realizar comparações entre as duas formas de calcular a flutuação. 
Com isto, a força de flutuação proposta por Seyed e Patel (1992) segue as formulações expostas nos seguintes parágrafos.

Define-se $P$ como a pressão no centro da base do elemento finito, ver Figura 6 , então, a pressão ao longo da circunferência da base escreve-se como:

$$
P_{b}=P-R \gamma_{w} \operatorname{Cos}(\theta) \operatorname{Sin}(\phi),
$$

onde $\gamma_{w}$ é a densidade do fluido externo ao tubo, $\theta$ é o ângulo da normal ao centro do elemento com relação ao eixo $X_{1}$ e $\phi$ é o ângulo ao redor da circunferência do tubo, ver Figura 6.

A pressão em qualquer ponto ao longo da circunferência do lado superior do elemento é dada como

$$
P_{t}=P_{b}-\gamma_{w} \operatorname{Sin}(\theta) d s,
$$

Sendo $d s$ o comprimento de arco. A força atuando em um diferencial de área $d A$ é

$$
d \boldsymbol{F}=\frac{1}{2}\left(P_{b}-P_{t}\right) d A
$$

Substituindo as equações (93) e (94), são reescritas as componentes da força dada na equação (95) como:

$$
\begin{gathered}
d \boldsymbol{F}_{x 1}=d \boldsymbol{F} \operatorname{Cos}(\theta) \operatorname{Sin}(\phi)=\pi R^{2} \gamma_{w} \operatorname{Cos}(\theta) \operatorname{Sin}(\theta) d s, \\
d \boldsymbol{F}_{x 3}=d \boldsymbol{F} \operatorname{Sin}(\theta) \operatorname{Sin}(\phi)=-\pi R^{2} \gamma_{w} \operatorname{Sin}(\theta)^{2} d s .
\end{gathered}
$$

As forças mostradas nas equações (96) distribuem-se nas direções globais $x_{1}$ e $x_{3}$, respectivamente. 
As forças nas extremidades são perpendiculares às superfícies que fecham o tubo e são aplicadas como forças concentradas, as quais são produto da integração da pressão na área da tampa, assim,

$$
\boldsymbol{F}_{e}=\pi R^{2} \gamma_{w} P_{e} d s
$$

onde $P_{e}$ é a pressão no centro da tampa.

Os exemplos seguintes permitem ver a diferença da aplicação da força de empuxo segundo o principio de Arquimedes ou segundo a forma descrita na seção 3.5.

\subsection{Exemplo de Riser Flutuante}

O exemplo descrito foi modelado por Yazdchi e Crisfield (2002a) e por Bergan e Mathisen (1986). No exemplo, modela-se um riser que está flutuando na superfície do mar. A Figura 7 mostra a configuração indeformada da estrutura. $\mathrm{Na}$ Tabela 2 mostram-se as propriedades geométricas e do material deste exemplo. A estrutura é modelada com três elementos finitos cúbicos.

A estrutura é guiada aplicando um deslocamento vertical para baixo de $18 \mathrm{~m}$ na extremidade esquerda. O carregamento devido ao empuxo é aplicado de duas formas diferentes. A primeira segue a formulação exposta na seção 3.5., para facilitar a notação, denomina-se a esta força "empuxo do MEF". A segunda calculase de forma clássica com o principio de Arquimedes. 

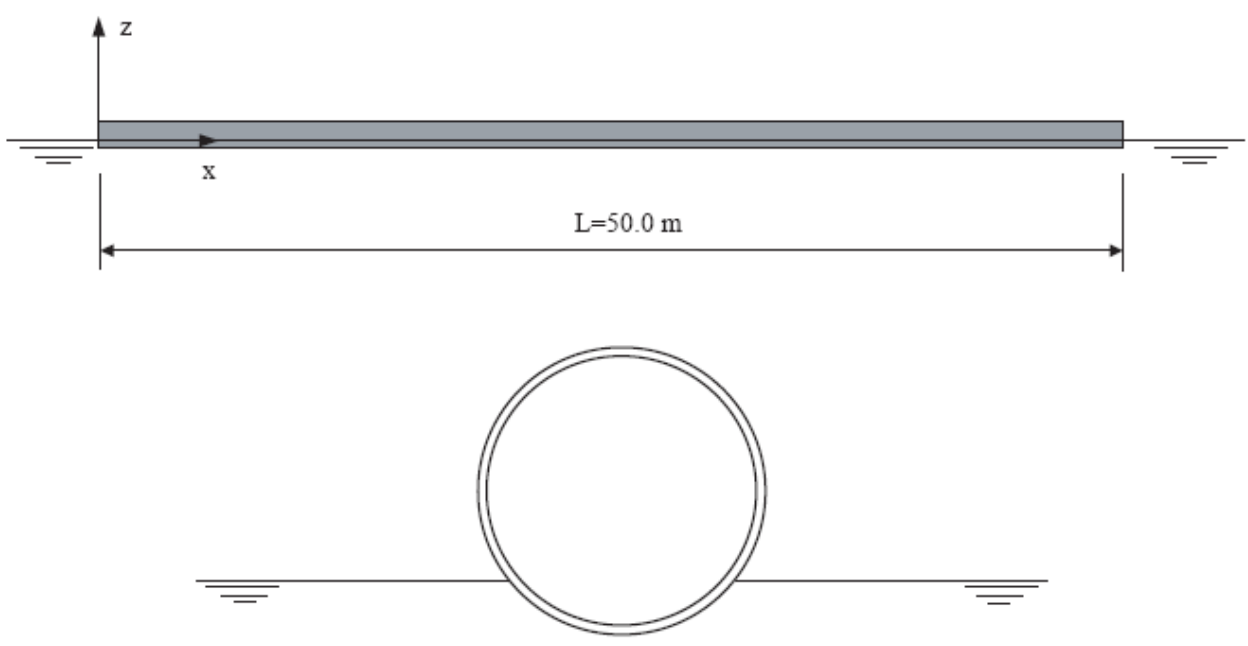

Figura 7. Riser flutuando na superfície do mar (YAZDCHI; CRISFIELD, 2002).

A Figura 8 compara os resultados obtidos neste trabalho com os resultados de Yazdchi e Crisfield (2002a) e de Bergan e Mathisen (1986). Nota-se, também, na figura, a diferença que existe entre as soluções ao se aplicar a força de empuxo do MEF ou utilizando-se o principio de Arquimedes.

Tabela 2. Dados do riser flutuante.

\begin{tabular}{|l|c|}
\hline Módulo de elasticidade $E$ & $2.0 e 9 \mathrm{~N} / \mathrm{m}^{2}$ \\
\hline Módulo de Poisson $v$ & 0.0 \\
\hline Peso do riser por unidade de volume $\gamma_{r}$ & $1.177 e 4 \mathrm{~N} / \mathrm{m}^{3}$ \\
\hline Peso da água por unidade de volume $\gamma_{w}$ & $1.005 e 4 \mathrm{~N} / \mathrm{m}^{3}$ \\
\hline Diâmetro interno do riser $D_{i}$ & $0.775 \mathrm{~m}$ \\
\hline Diâmetro externo do riser $D_{e}$ & $0.825 \mathrm{~m}$ \\
\hline
\end{tabular}

Com os resultados mostrados é possível afirmar que as estruturas flutuantes que se encontram em equilíbrio hidrostático (estruturas hipostáticas equilibradas pelas forças de empuxo) apresentam respostas diferentes quando a força de empuxo calcula-se com o principio de Arquimedes ou com a força de empuxo do MEF. 


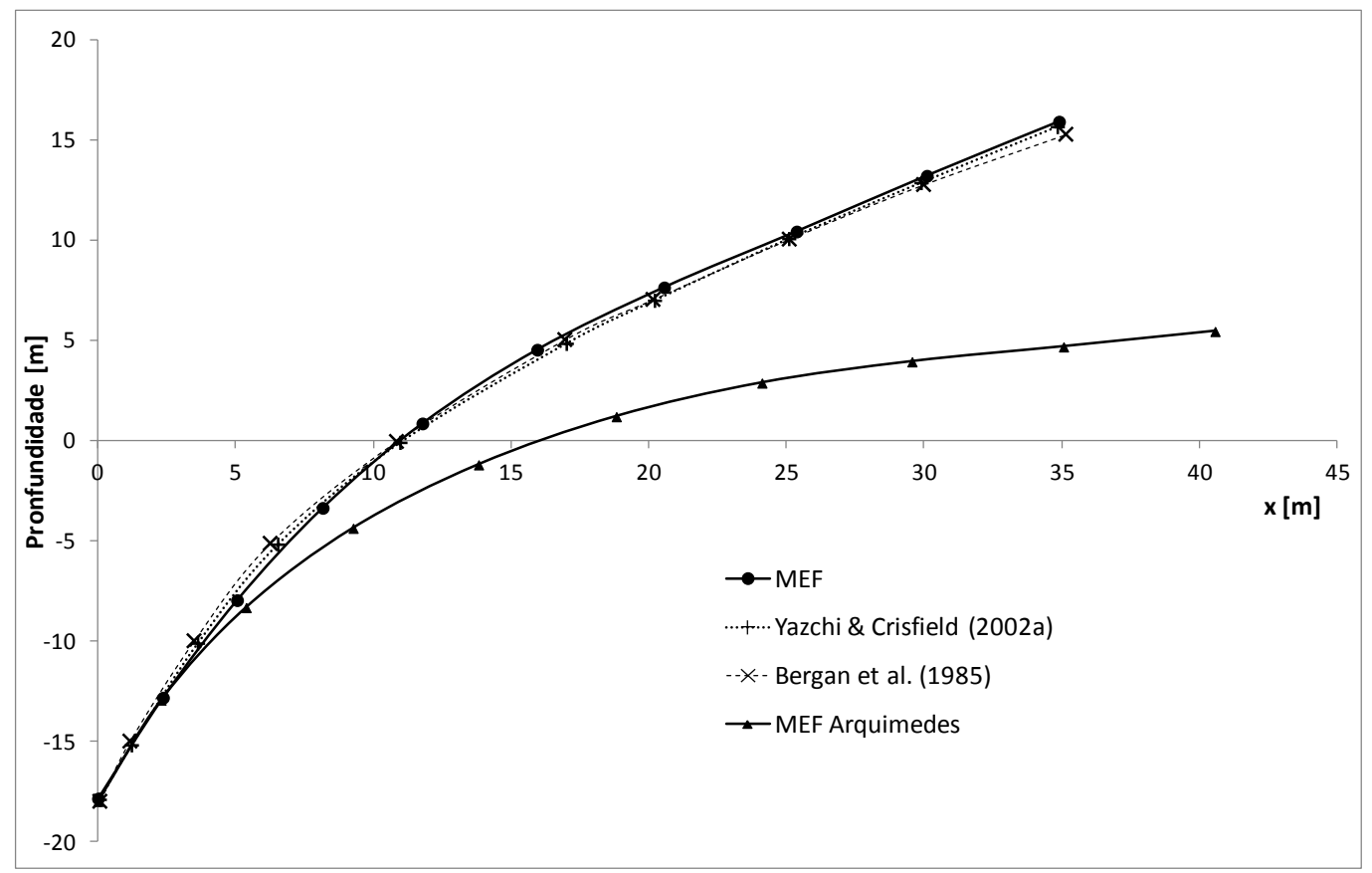

Figura 8. Configurações deformadas do riser flutuante.

\subsection{Tubo em balanço - Análise estática}

Em este exemplo realiza-se uma análise estática de uma viga em balanço de seção tubular sujeita a carregamentos hidrostáticos e peso próprio. O objetivo deste exemplo é verificar a formulação, comparando os resultados do método proposto com os resultados mostrados por Yazdchi e Crisfield (2002a) e, também, validar as forças de flutuação utilizadas.

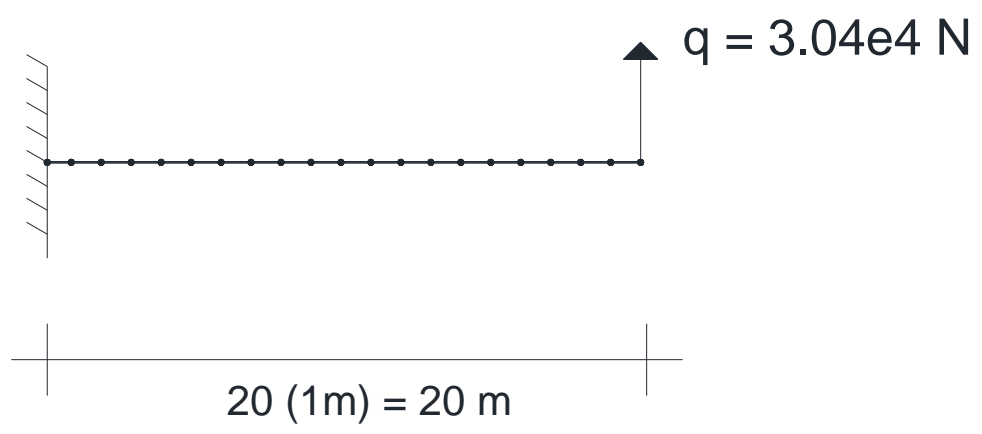

Figura 9. Tubo em balanço com as extremidades fechadas e carregamento vertical para cima. 
A Figura 9 mostra um tubo de polietileno em balanço, com $20 \mathrm{~m}$ de comprimento, com as extremidades fechadas e submerso a uma profundidade de $100 \mathrm{~m}$. O tubo carrega-se na extremidade livre com uma carga $q$. As características geométricas e do material mostram-se na Tabela 3.

Tabela 3. Tubo em balanço

\begin{tabular}{|l|c|}
\hline Módulo de elasticidade $E$ & $2.0 e 9 \mathrm{~N} / \mathrm{m}^{2}$ \\
\hline Módulo de Poisson $v$ & 0.25 \\
\hline Peso do riser por unidade de volume $\gamma_{r}$ & $1.2 e 4 \mathrm{~N} / \mathrm{m}^{3}$ \\
\hline Peso da água por unidade de volume $\gamma_{w}$ & $1.025 e 4 \mathrm{~N} / \mathrm{m}^{3}$ \\
\hline Diâmetro interno do riser $D_{i}$ & $0.80 \mathrm{~m}$ \\
\hline Diâmetro externo do riser $D_{e}$ & $0.85 \mathrm{~m}$ \\
\hline
\end{tabular}

A Figura 10 mostra as posições finais de equilíbrio estático para o tubo em balanço da Figura 9. As duas posições de equilíbrio mostradas na figura correspondem a dois casos de carga diferentes $q$ e $-q$. O exemplo é discretizado com 10 elementos finitos quadráticos. Na figura, os resultados obtidos com a carga de empuxo calculada segundo a seção 3.5 são indicados como MEF. Mostram-se, na mesma figura, as curvas com a força de empuxo segundo o principio de Arquimedes, estas curvas denominam-se como MEF Arquimedes. Também, mostram-se os resultados obtidos por Yazdchi e Crisfield (2002a), os quais são próximos das curvas MEF.

A Figura 11 e a Figura 12 mostram a configuração deformada do problema anterior, porém com condições de contorno diferentes. A estrutura da Figura 11 tem uma articulação do lado esquerdo e um apoio simples do lado direito. Na Figura 12 do lado esquerdo tem-se um engaste e do lado direito um apoio simples. O objetivo destes resultados é comparar o comportamento obtido com a força de empuxo segundo o definido na seção 3.5 com aquele obtido com a força de empuxo clássica, calculada com o principio de Arquimedes. 


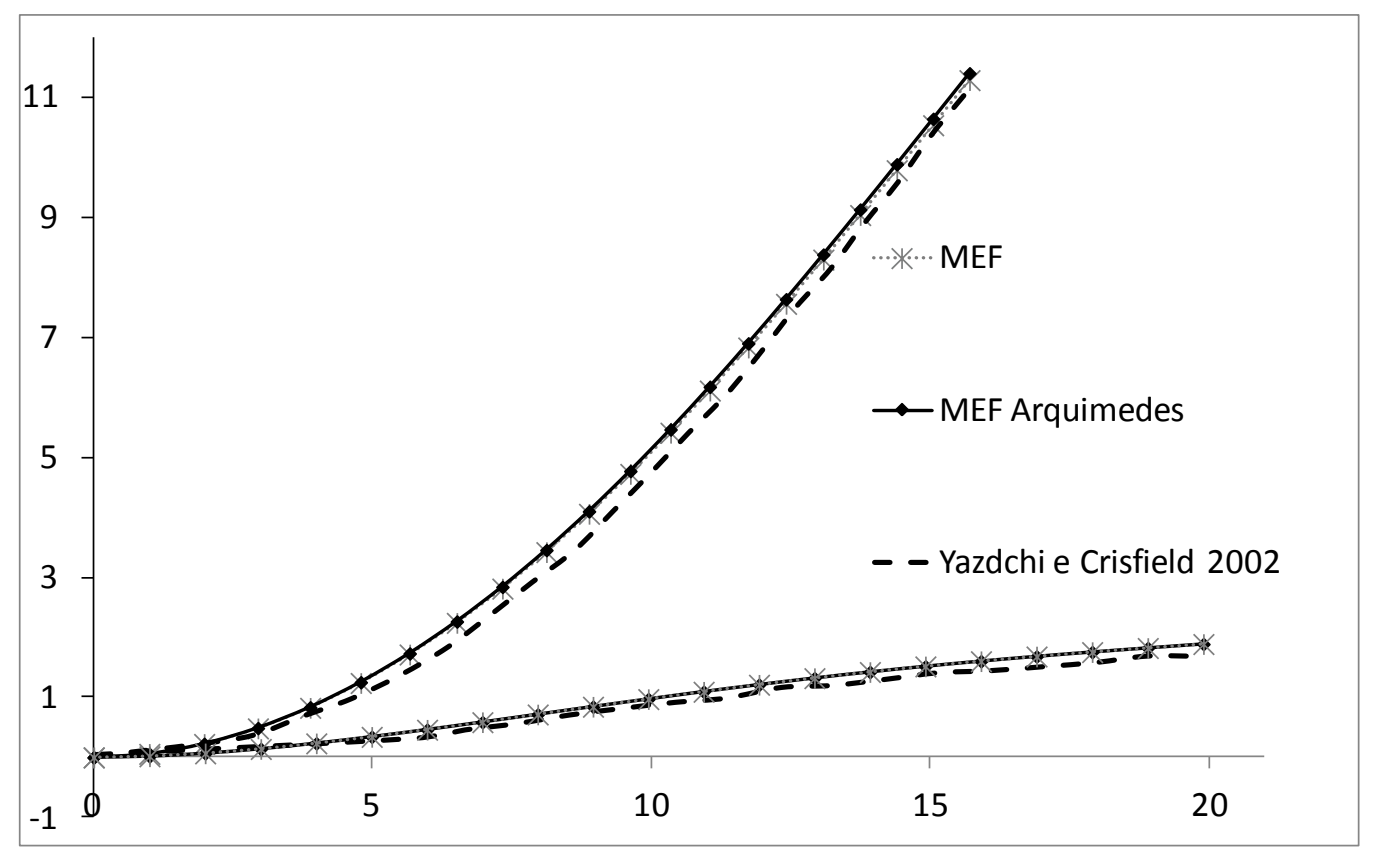

Figura 10. Configuração deformada de um tubo em balanço com diferentes condições de carregamento (Yazdchi, M e Crisfield, M. A., 2002a). Os valores são indicados em metros.

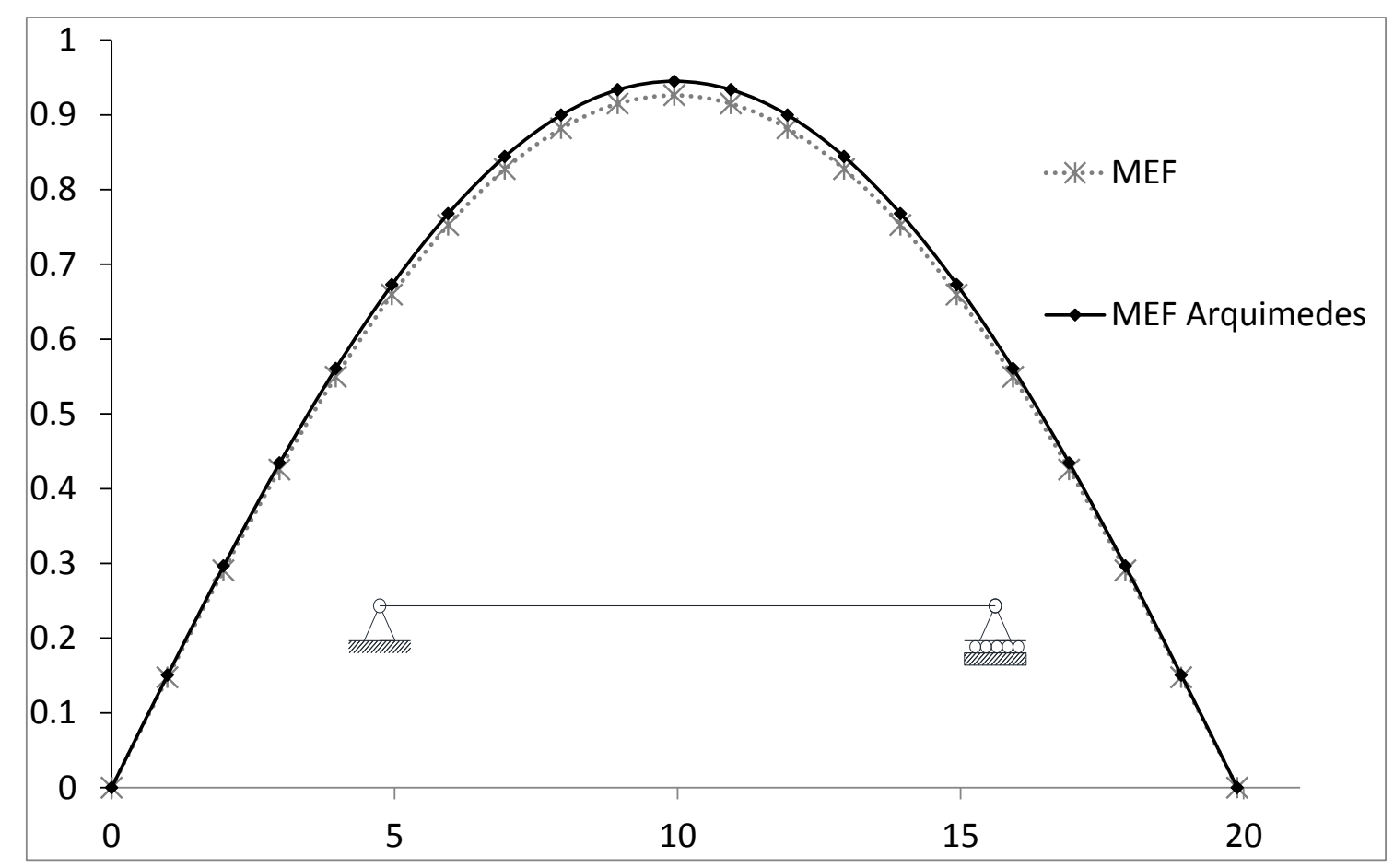

Figura 11. Configuração deformada do tubo com as extremidades fechadas, simplesmente apoiado. Os valores são indicados em metros.

A proximidade dos resultados MEF e "MEF Arquimedes" indicam que, quando a estrutura não é hipostática (equilibrada com as cargas hidrodinâmicas ou 
hidrostáticas) a diferença das respostas da estrutura com relação à forma de calcular as cargas de empuxo é insignificante.

Para implementar a força de empuxo do MEF, segundo a seção 3.5, existe mais dificuldade e custo computacional que com a força de empuxo segundo o principio de Arquimedes. O anterior indica que em alguns casos, com estruturas hiperestáticas ou isostáticas, o principio de Arquimedes proporciona resultados suficientemente precisos.

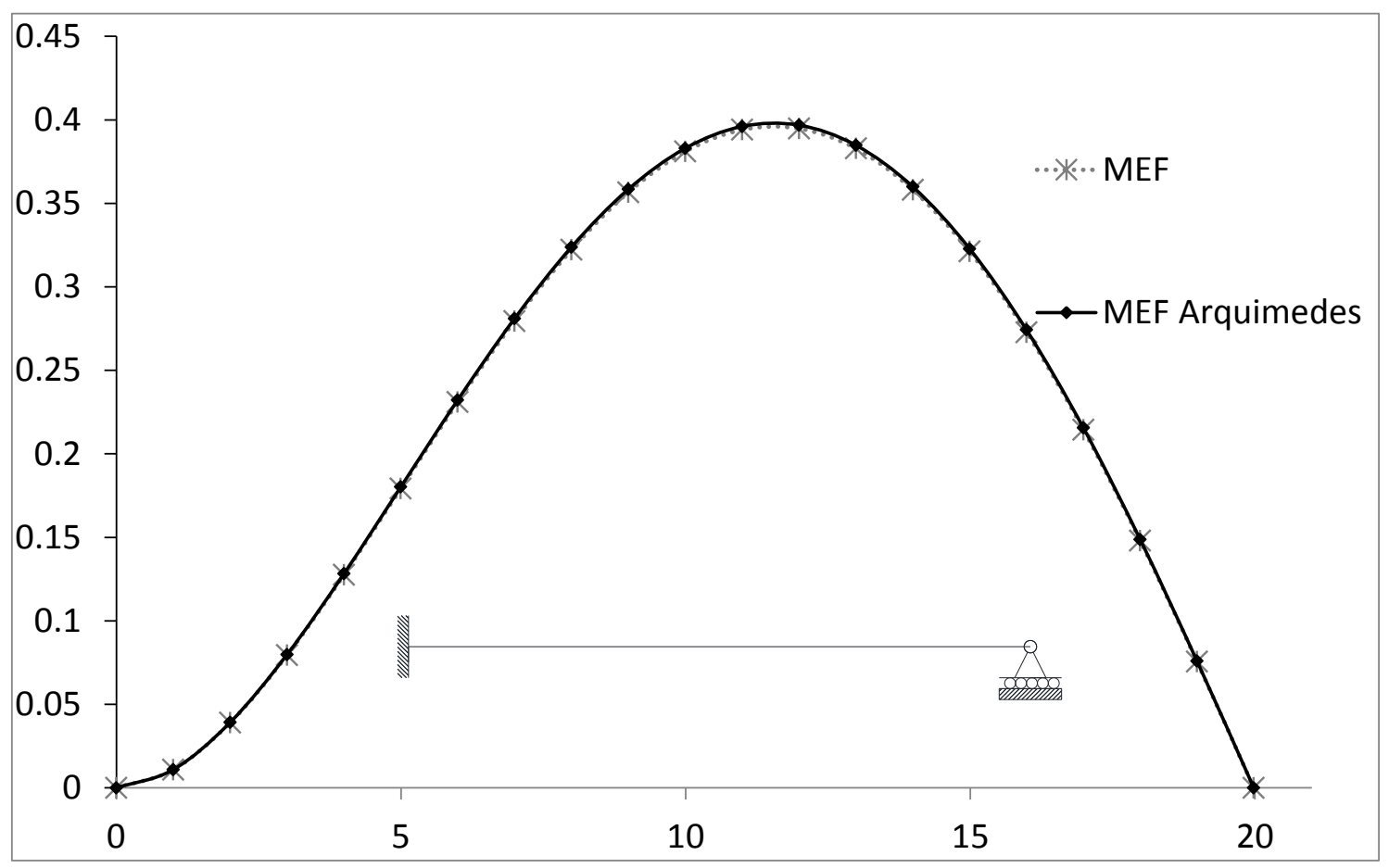

Figura 12. Configuração final do tubo com as extremidades fechadas, engastado e simplesmente apoiado. Os valores são indicados em metros. 


\section{Obtenção da configuração estática inicial e deslocamentos impostos.}

Os risers, como descrito anteriormente, são estruturas que envolvem diversos problemas estruturais, pelo qual resultam em instabilidades numéricas. Neste trabalho, foca-se principalmente nas seguintes dificuldades:

- A aplicação deslocamentos no topo do riser

- A obtenção da configuração estática inicial

Resolver estes problemas é essencial para obter a resposta da estrutura. Por exemplo, segundo Yazdchi e Crisfield (2002a) é indispensável determinar corretamente a configuração estática de equilíbrio, já que ela é a base para uma análise dinâmica consistente. Porém, a análise estática apresenta problemas, principalmente, em estruturas com uma grande relação entre a extensão e a rigidez transversal. Estas características recaem em matrizes Hessianas mal condicionadas.

O outro problema analisado apresenta-se em risers fixados a estruturas flutuantes, os quais, em geral ${ }^{3}$, estão submetidos a deslocamentos no topo. As instabilidades numéricas ocasionadas por este tipo de condição aparecem, especialmente, se os deslocamentos aplicam-se na direção vertical para abaixo ou se o deslocamento tem dimensão similar ao tamanho dos elementos finitos, nos quais se discretiza a estrutura.

Para resolver estes problemas e conseguir um comportamento adequado da estrutura, propõem-se, neste trabalho, alguns recursos ou estratégias numéricas.

${ }^{3}$ Algumas vezes as plataformas possuem compensadores de movimento que evitam a transferência de deslocamentos ao risers.

68 
Assim, o problema de condições de contorno transientes em posições foi abordado com uma estratégia oriunda da modelagem numérica de fluidos (Sanches, 2011). Esta se emprega para a adaptação de malhas de fluido quando seu contorno é móvel, a técnica é mostrada na seção 4.1 .

Para encontrar a solução estática de estruturas altamente flexíveis são empregadas as estratégias descritas na seção 4.2. Estas são, praticamente, adaptações do método das penalidades. Sendo que a estrutura é resolvida desde um problema inicial, com propriedades fictícias que garantem a estabilidade, o qual gradativamente vai mudando para um problema com os valores reais da estrutura.

\subsection{Estratégia para aplicação das condições de contorno em deslocamentos}

Os risers são estruturas que se encontram vinculadas no seu topo a plataformas flutuantes ou a embarcações. As embarcações e as plataformas encontram-se submetidas a movimentos harmônicos devidos à incidência de ondas, estes movimentos são impostos aos risers como condições de contorno em deslocamento (no caso do código resultante, em posições).

Os deslocamentos aplicados podem ser de grande magnitude. Por exemplo, no projeto estrutural de risers consideram-se as situações extremas, geralmente situações de tormenta, onde a amplitude das ondas pode alcançar até 30 metros (FALTINSEN, 1990).

Alguns deslocamentos impostos podem provocar problemas de instabilidade numérica. Problemas deste tipo encontram-se quando se tentam resolver, com o 
método dos elementos finitos, risers com condições de deslocamentos verticais negativos no topo.

Ao se impor um deslocamento em um ponto é induzida uma perturbação muito grande no estado de energia do elemento finito que o contem, deixando o funcional da energia distante da posição de mínima energia procurada.

O problema de convergência encontrado é resolvido utilizando uma estratégia de adaptação de malhas, a qual se utiliza comumente na modelagem numérica de fluidos. Com sua aplicação, a variação da energia devida à imposição de deslocamentos é suavizada ao longo do comprimento do riser.

Utiliza-se, neste trabalho, o método proposto por Teixeira (2001), o qual também se utiliza por Sanches (2011) no contexto da mecânica dos fluidos. Neste trabalho, propõe-se que um deslocamento aplicado suavize-se na totalidade da estrutura, distribuindo a perturbação da energia produto da imposição da condição de contorno, através da formula:

$$
\boldsymbol{u}^{i}=\frac{\sum_{k=1}^{n c} a_{i k} \boldsymbol{u}^{k}}{\sum_{k=1}^{n c} a_{i k}}
$$

onde $n c$ é o número de nós com deslocamento prescrito, $\boldsymbol{u}^{k}$ é o deslocamento imposto no nó $k, a_{i k}$ é o coeficiente de influência do nó $k$ do contorno no nó $i$ da estrutura, o qual é dado pela equação

$$
a_{i j}=\frac{1}{d_{i j}^{g e}}
$$

onde ge é um expoente que indica a influência entre o nó $i$ e o nó $j$ e $d_{i j}$ é a distância entre o nó $i$ e o nó $j$. Cada uma de estas variáveis é mostrada na Figura 13. 


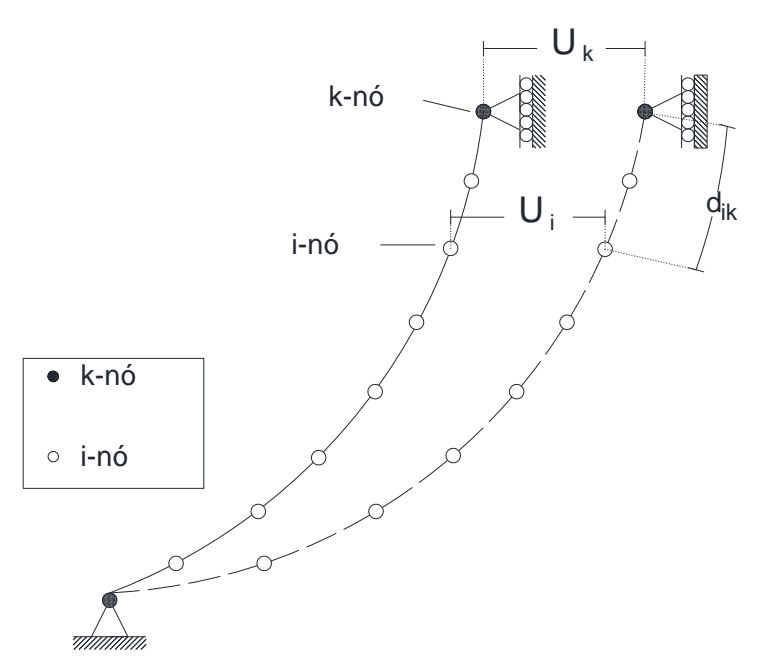

Figura 13. Distribuição proporcional dos deslocamentos.

A Figura 14a mostra a configuração atual, obtida com a aplicação normal das condições de contorno, onde aparece uma variação brusca no elemento onde se aplica o deslocamento. Enquanto, como visto na Figura 14b, o deslocamento aplicado com a técnica de suavização proporciona uma configuração tentativa suave.

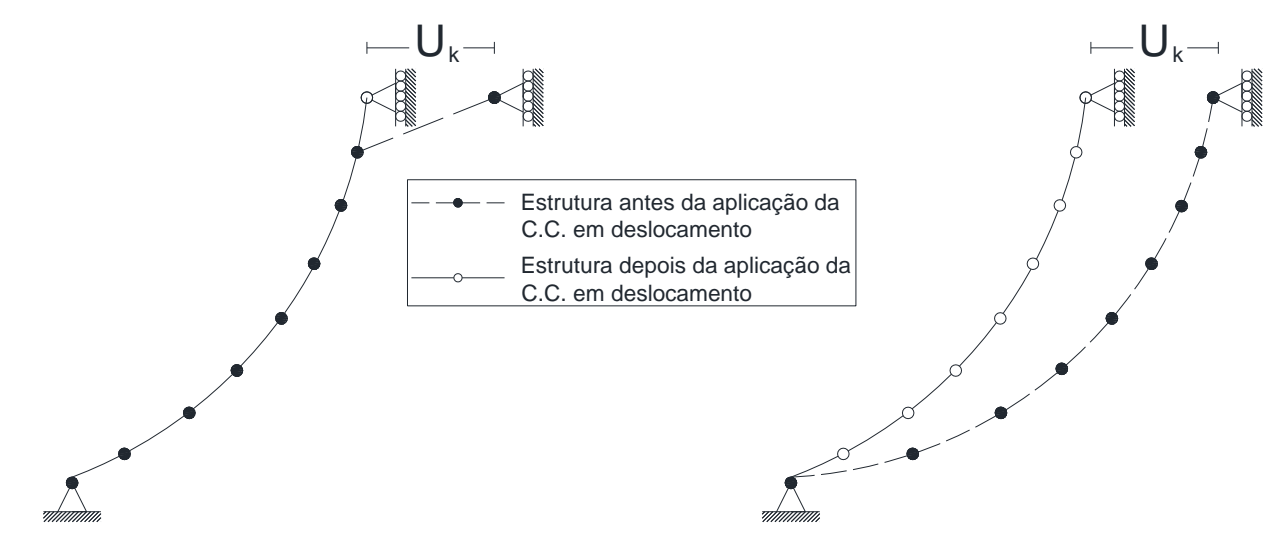

Figura 14. a) Aplicação de forma normal da C. C. em deslocamento. b) Aplicação da C.C. em deslocamento com a técnica de suavização.

McNamara et al. (1986) consideram que métodos de integração temporal como Newmark apresentam dificuldades quando se abordam problemas que iniciam com 
oscilações transientes. Como descrito na seção 1.3.3, muitos autores buscam solucionar este problema utilizando outros métodos de integração, que além de serem mais difíceis de implementar, requerem maior custo computacional. Neste trabalho, sendo utilizada uma formulação Lagrangeana total, abordou-se o problema de forma distinta, utilizando o integrador de Newmark e a técnica de suavização dos deslocamentos impostos descrita.

No seguinte exemplo mostram-se algumas vantagens no uso da técnica de distribuição proporcional do deslocamento imposto.

\subsubsection{Exemplo}

Utiliza-se a técnica de suavização, descrita anteriormente, para aplicar um deslocamento horizontal no topo de um riser. A estrutura é simplesmente apoiada nas suas extremidades. A configuração inicial é indicada na Figura 15 pela linha continua sem marcadores.

Tabela 4. Dados do exemplo 4.1.1

\begin{tabular}{|l|l|}
\hline L (Comprimento) & $142.5 \mathrm{~m}$. \\
\hline A (Área da seção transversal) & $8.0 \times 10-3 \mathrm{~m} 2$. \\
\hline I (Momento de inercia) & $5.1 \times 10-6 \mathrm{~m} 4$. \\
\hline E (Módulo de elasticidade) & $100 \mathrm{GPa}$. \\
\hline q (Força distribuida na direção vertical) & $-177.0 \mathrm{~N}$. \\
\hline
\end{tabular}

Este exemplo é proposto por Lacarbonara e Pacitti (2008), sendo modelado também por Hosseini (2009). Nos trabalhos destes autores, para realizar a modelagem, requerem-se 1024 passos de deslocamento. Utilizando a técnica de suavização, neste trabalho, necessitam-se 250 passos de carga. Isto indica uma melhoria na convergência do algoritmo. 


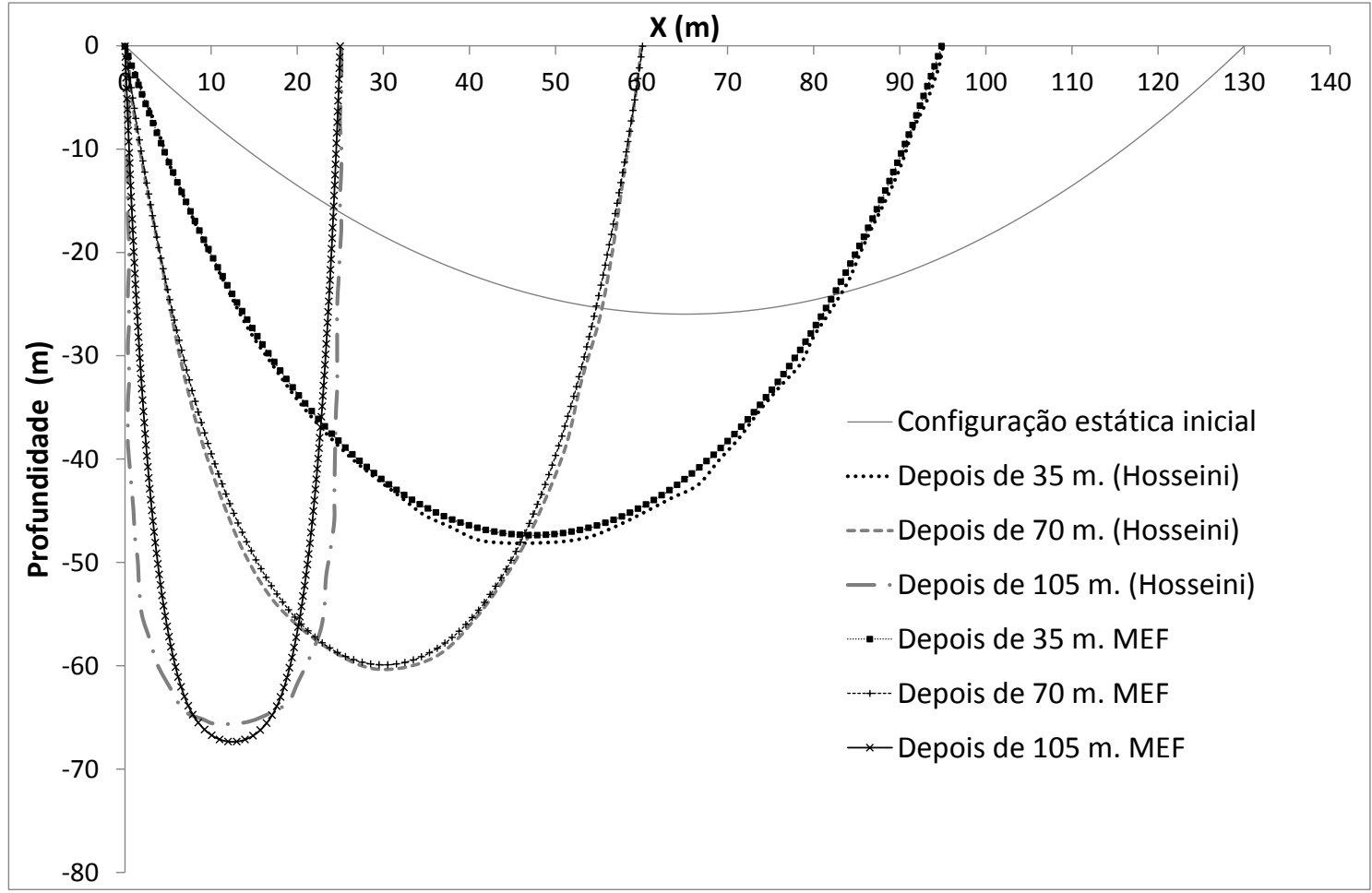

Figura 15. Equilíbrio estático do riser com deslocamento imposto na extremidade direita.

A Figura 15 mostra a configuração deformada depois da aplicação de 35,70 m e $105,00 \mathrm{~m}$ de deslocamento horizontal. Na figura são mostradas as respostas utilizando o MEF, sendo que os deslocamentos são aplicados com a técnica de suavização. Também se mostram os resultados obtidos por Hosseini (2009), com deslocamentos aplicados de forma comum. Como visto na figura, os resultados são semelhantes, o que indica que os comportamentos obtidos são precisos.

\subsection{Problemas com matrizes Hessianas mal condicionadas.}

A busca da configuração inicial do riser resulta em problemas estáticos não lineares de estruturas altamente flexíveis, onde a matriz Hessiana é mal condicionada. Este problema ocasiona instabilidades numéricas no algoritmo de busca da solução. Para abordar este comportamento indesejado, neste trabalho, 
utilizaram-se três estratégias para melhorar o condicionamento da matriz. Estas se baseiam no método de otimização com restrições denominado método das penalidades.

A primeira metodologia resolve o problema estrutural com uma rigidez à flexão penalizada, $\mathrm{E}_{\mathrm{p}}=\mathrm{E} \cdot$ Penalty. Sendo que $\mathrm{E}$ representa $\mathrm{o}$ valor da rigidez original do problema e Penalty representa o fator penalidade que variaria de um valor inicial (suficientemente grande para melhorar o condicionamento da matriz Hessiana) até 1. A matriz Hessiana obtida com a rigidez $\mathrm{E}_{\mathrm{p}}$ denomina-se $\mathrm{H}_{\mathrm{p}}$. A solução final obtém-se como resultado de uma sequencia de problemas, cada um com um valor diferente do fator penalidade, o qual se reduz gradativamente até tomar um valor igual a 1 . A metodologia mostra-se de forma algorítmica na Figura 16.

O segundo método utiliza molas auxiliares nos nós do riser. Estas adicionam um valor $\mathrm{H}_{\mathrm{s}}=\mathrm{K}_{\mathrm{s}}$. Penalty na diagonal da matriz Hessiana. Sendo que $\mathrm{K}_{\mathrm{s}}$ é a rigidez da mola e Penalty seria o fator penalidade, o qual adota um valor inicial grande até um valor aproximadamente igual a zero. Com isto, melhora-se o condicionamento da matriz. A força das molas, a qual se adiciona ao vetor de forças internas, é calculada como uma função do deslocamento (e não da posição) da estrutura. 


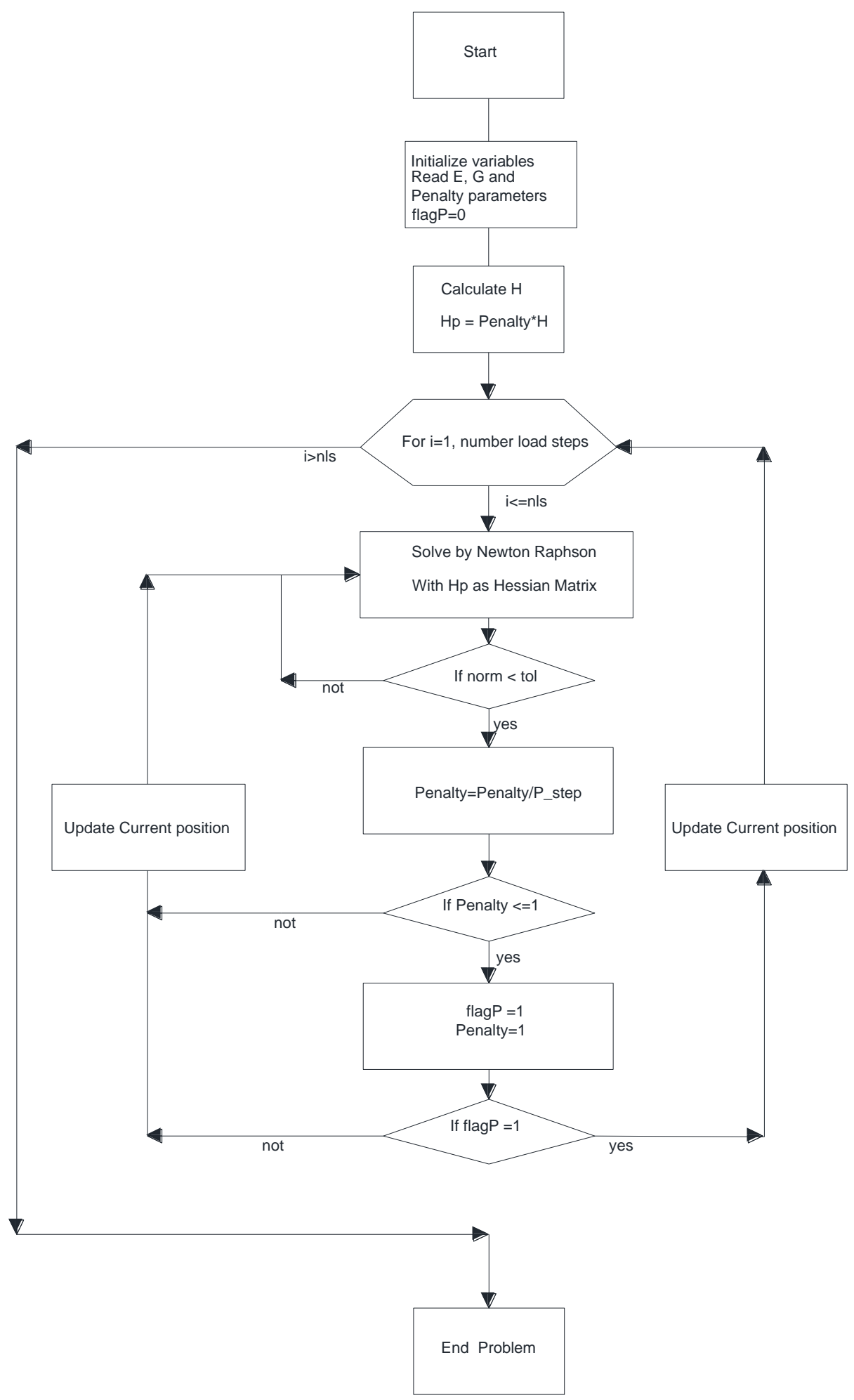

Figura 16. Fluxograma E-decrescente. 


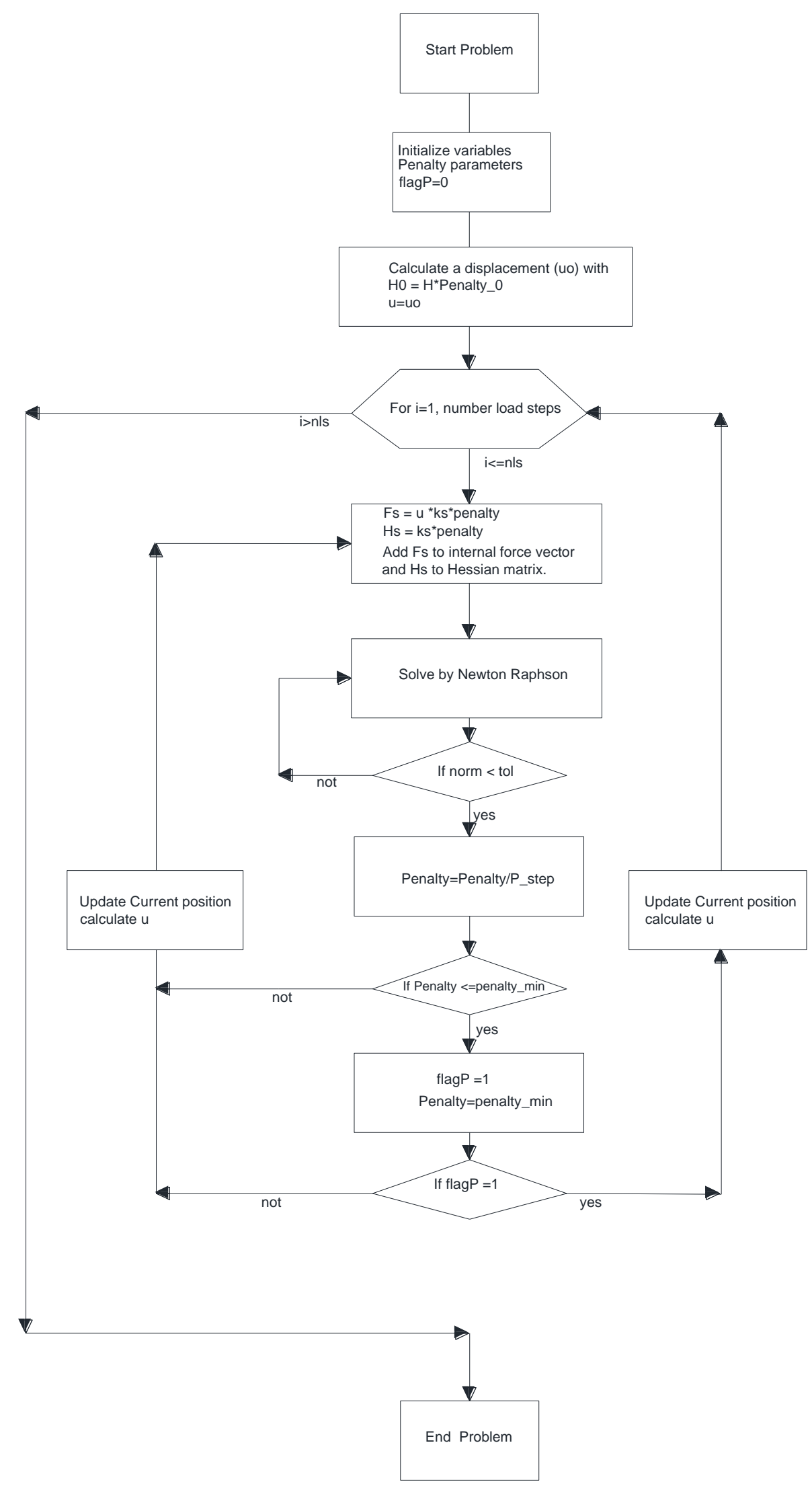

Figura 17. Fluxograma das molas artificiais. 


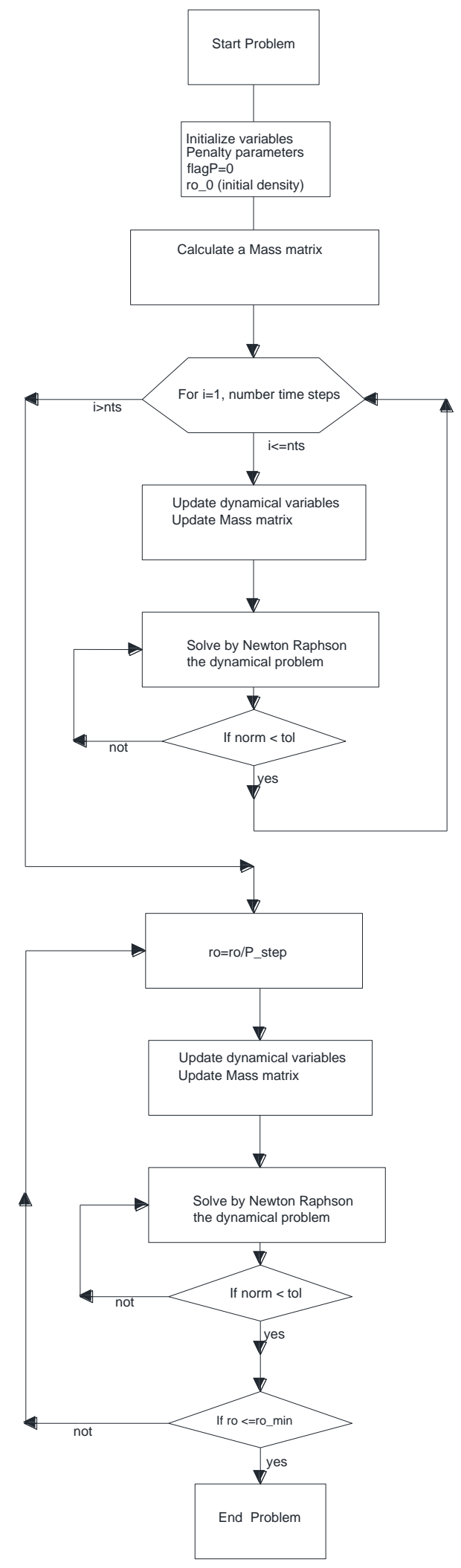

Figura 18. Fluxograma de massa decrescente. 
Nesta metodologia, para se calcular o deslocamento inicial é necessario utilizar um problema estável. Para isto, utiliza-se uma matriz Hessiana bem condicionada, que se obtém com uma rigidez $\mathrm{E}_{0}=\mathrm{E} \cdot$ Penalty_0, onde Penalty_0 representa um valor suficientemente grande para se garantir a estabilidade do problema inicial e E é o módulo de elasticidade original. Esta modificação à rigidez utiliza-se unicamente no passo inicial. A metodologia, também, obtém a solução final como uma sequência de problemas de minimização, como mostrado na Figura 17, sendo que cada problema tem um valor diferente do fator penalidade. A procura do valor inicial do parâmetro Penalty, neste método, resultou ser um trabalho difícil. Mostrando assim, que sua aplicação não é simples nem generalizável, já que pode proporcionar dificuldades de convergência para alguns problemas.

Tabela 5. Dados do riser do exemplo 4.2.1.

\begin{tabular}{|l|l|}
\hline L (Comprimento) & $5 \mathrm{~m}$. \\
\hline EI (Rigidez à flexão) & $1.7 \mathrm{~N} \cdot \mathrm{m}^{2}$. \\
\hline EA (Rigidez axial) & $2.0 \times 103 \mathrm{~N}$. \\
\hline q (Força vertical distribuída no elemento) & $100 \mathrm{~N} / \mathrm{m}$. \\
\hline
\end{tabular}

Finalmente, a última metodologia proposta alcança a configuração estática a partir de uma sequência de análises dinâmicas. Tal que, a matriz de massa da estrutura é sequencialmente reduzida até um valor de zero. O fluxograma desta metodologia mostra-se na Figura 18.

Tabela 6. Dados dos parâmetros utilizados na metodologia E decrescente no exemplo 4.2.1.

\begin{tabular}{|l|l|}
\hline Penalidade inicial & 1000 \\
\hline Passo de redução da penalidade & 0.5 \\
\hline Tolerância no método de Newton-Raphson & $1.0 \times 10-8$ \\
\hline
\end{tabular}

As três metodologias são comparadas no seguinte exemplo. 


\subsubsection{Exemplo}

O objetivo deste exemplo é comparar e descrever as três metodologias descritas na seção 4.2 para a determinação da configuração inicial de um riser. A estrutura analisada consiste em um riser horizontal com $5 \mathrm{~m}$ de comprimento. Os dados do riser são mostrados na Tabela 5. Nesta metodologia, para se calcular o deslocamento inicial necessita-se utilizar um problema estável. Para isto, utiliza-se uma matriz Hessiana bem condicionada, que se obtém com uma rigidez E_0 = E . Penalty_0, onde Penalty_0 representa um valor o suficientemente grande para garantir a estabilidade do problema inicial e E é o módulo de elasticidade original. Esta modificação à rigidez é utilizada unicamente no passo inicial. A metodologia, também, obtém a solução final como uma sequência de problemas de minimização, como mostrado na Figura 17, sendo que cada problema tem um valor diferente do fator penalidade. A procura do valor inicial do parâmetro Penalty, neste método, resultou ser um trabalho difícil. Mostrando assim, que sua aplicação não é simples nem generalizável, já que pode proporcionar dificuldades de convergência para alguns problemas.

A Figura 19 mostra as configurações deformadas do riser obtidas com o método da rigidez decrescente (E-decrescente), na medida em que o parâmetro penalidade diminui. Os valores utilizados no método das penalidades encontram-se na Tabela 6. Este método comporta-se de forma estável, considerando que a determinação dos parâmetros iniciais é simples e rápida. 
Tabela 7. Dados dos parâmetros utilizados na metodologia das molas auxiliares no exemplo 4.2.1.

\begin{tabular}{|l|l|}
\hline Penalidade inicial & 100 \\
\hline Passo de redução da penalidade & 0.3 \\
\hline Tolerância no método de Newton-Raphson & $1.0 \times 10-8$ \\
\hline Módulo de elasticidade inicial (para o deslocamento inicial) & $10000 \mathrm{E}$ \\
\hline Penalidade mínima (tolerância do método) & 0.01 \\
\hline
\end{tabular}

A Figura 20 contém as configurações deformadas do riser estimadas com o método das molas auxiliares, na medida em que o fator penalidade decresce. Os valores iniciais utilizados no método mostram-se na Tabela 7. Observou-se, em particular, a dificuldade em obter condições iniciais que garantissem a convergência da metodologia.

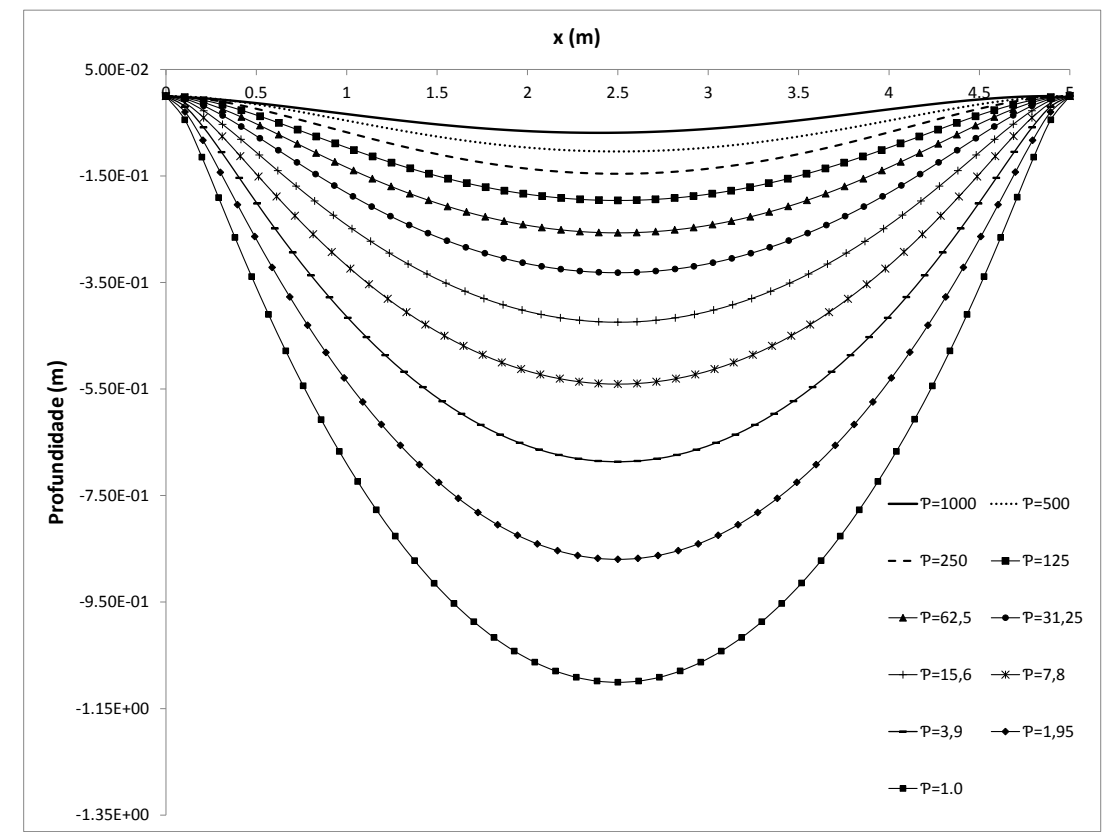

Figura 19. Configurações deformadas obtidas com o método E-decrescente, na medida em que a penalidade varia-se.

Na Figura 21 mostra-se a sequência de posições de equilíbrio dinâmico, a qual converge para o equilíbrio estático na medida em que a massa do sistema diminuí. Sendo que a massa é dada por uma densidade inicial, qualquer, vezes a penalidade. A Tabela 8 mostra os parâmetros utilizados pelo método. 
Tabela 8. Dados dos parâmetros utilizados na metodologia da M decrescente no exemplo 4.2.1.

\begin{tabular}{|l|l|}
\hline Penalidade inicial & 1000 \\
\hline Passo de redução da penalidade & 0.5 \\
\hline Tolerância no método de Newton-Raphson & $1.0 \times 10-8$ \\
\hline
\end{tabular}

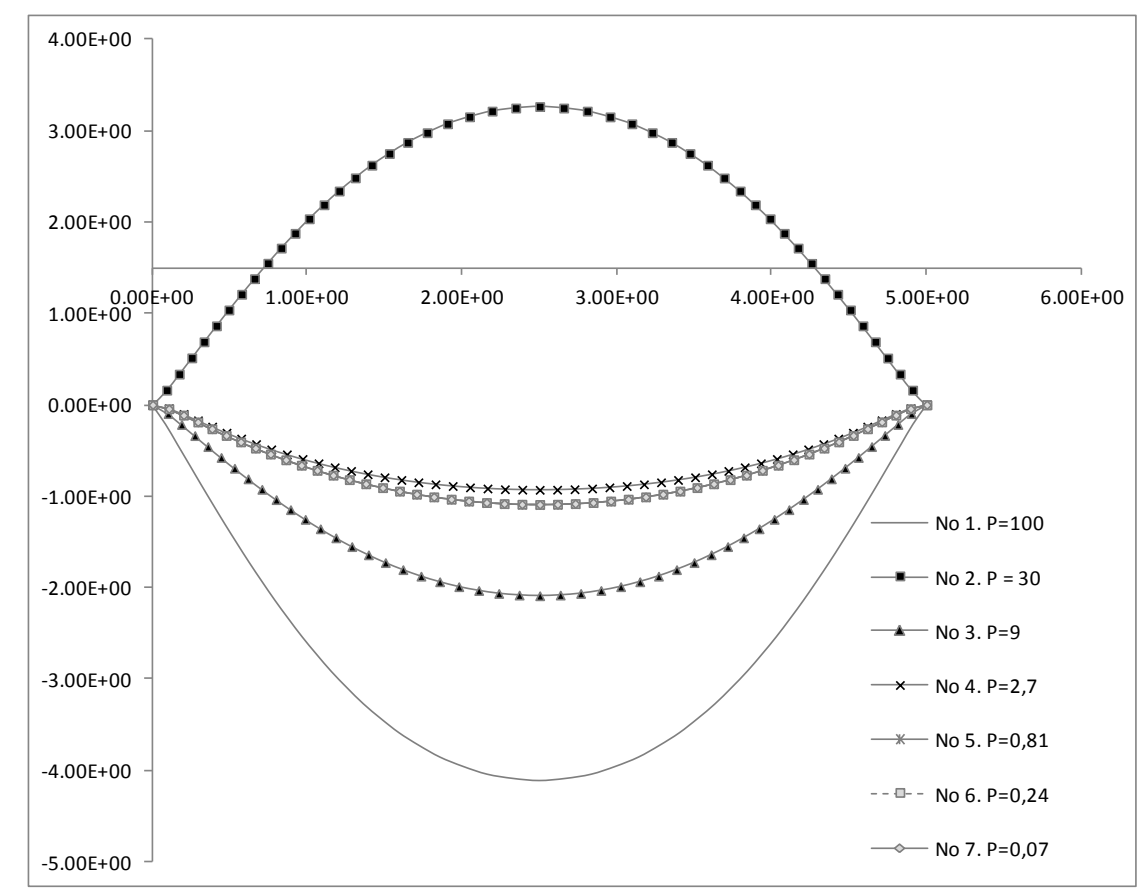

Figura 20. Configurações deformadas obtidas com o método das molas artificiais, na medida em que a penalidade varia-se. Os valores são indicados em metros.

Como forma de comparação das metodologias, utiliza-se o número de vezes que o método de Newton-Raphson é ativado. Observa-se na Tabela 9 que a metodologia da rigidez decrescente (E-decrescente) utiliza um menor número de iterações, enquanto o método das molas auxiliares tem uma convergência mais lenta.

A Figura 22 contem as configurações de equilíbrio finais, após a convergência do método das penalidades, obtidas mediante as três metodologias da seção 4.2 . Nota-se que o comportamento das soluções é similar. 


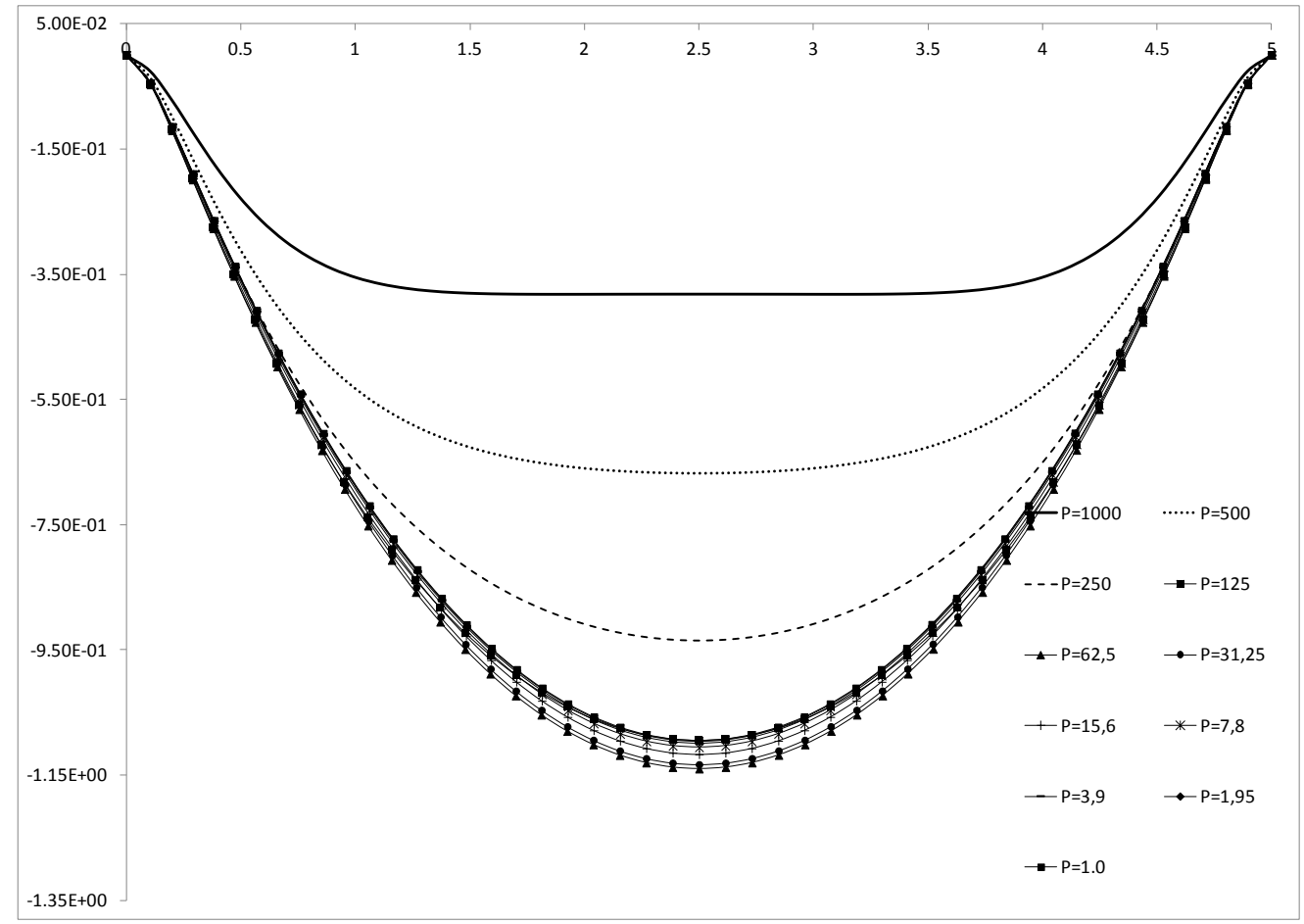

Figura 21. Configurações deformadas obtidas com o método M-decrescente, na medida em que a penalidade varia-se. Os valores são indicados em metros.

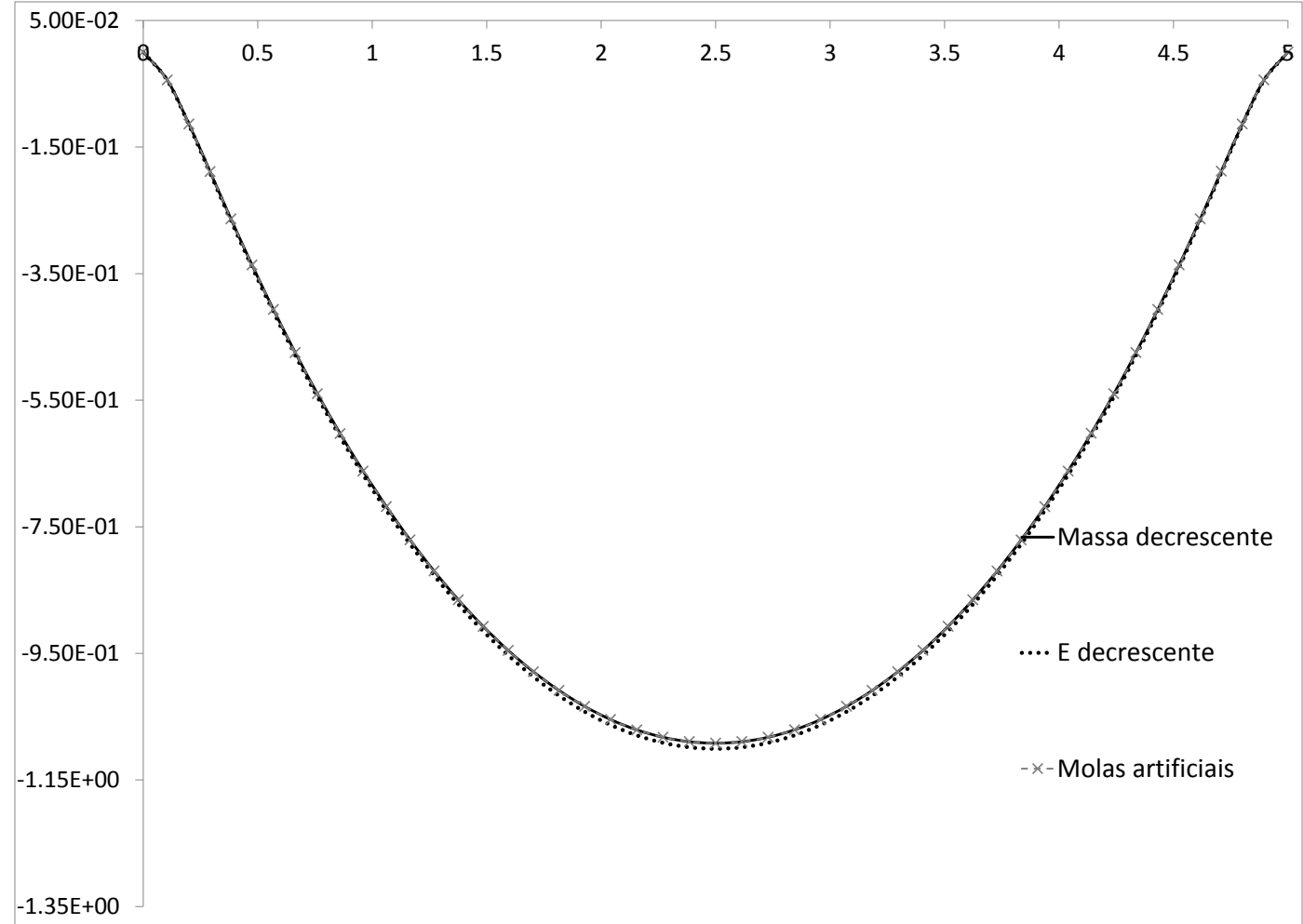

Figura 22. Comparação das soluções finais com as metodologias da seção 4.2. Os valores são indicados em metros 
Tabela 9. Número de iterações de Newton-Raphson segundo a metodologia utilizada.

\begin{tabular}{|l|l|}
\hline E-Decrescente & 67 \\
\hline Molas auxiliares & 113 \\
\hline M-decrescente & 97 \\
\hline
\end{tabular}

\subsubsection{Exemplo de validação}

Com este exemplo pretende-se mostrar que as configurações de equilíbrio estático, obtidas com estas metodologias, são coerentes com os resultados encontrados na literatura.

Tabela 10. Dados do exemplo 4.2.2

\begin{tabular}{|l|c|}
\hline Módulo de elasticidade $\mathrm{E}$ & $2.0 \mathrm{e} 11 \mathrm{~N} / \mathrm{m}^{2}$ \\
\hline Coeficiente de Poisson $v$ & 0.25 \\
\hline Peso próprio do riserpor unidade de volume $\gamma_{\mathrm{r}}$ & $1.2 \mathrm{e} 4 \mathrm{~N} / \mathrm{m}^{3}$ \\
\hline Peso próprio da água por unidade de volume $\gamma_{\mathrm{w}}$ & $1.025 \mathrm{e} 4 \mathrm{~N} / \mathrm{m}^{3}$ \\
\hline Diâmetro interno do riser $\mathrm{D}_{\mathrm{i}}$ & $0.25 \mathrm{~m}$. \\
\hline Diâmetro externo do riser $\mathrm{D}_{\mathrm{e}}$ & $0.21 \mathrm{~m}$. \\
\hline Tração no topo & $510 \mathrm{KN}$. \\
\hline Comprimento & $1500 \mathrm{~m}$. \\
\hline
\end{tabular}

$\mathrm{Na}$ Figura 23 mostra-se a deformada da estrutura obtida por Chathigeorgiou (2008) e as configurações estáticas finais obtidas com as metodologias da seção

4.2. Os resultados deste trabalho apresentam coerencia com a literatura. 


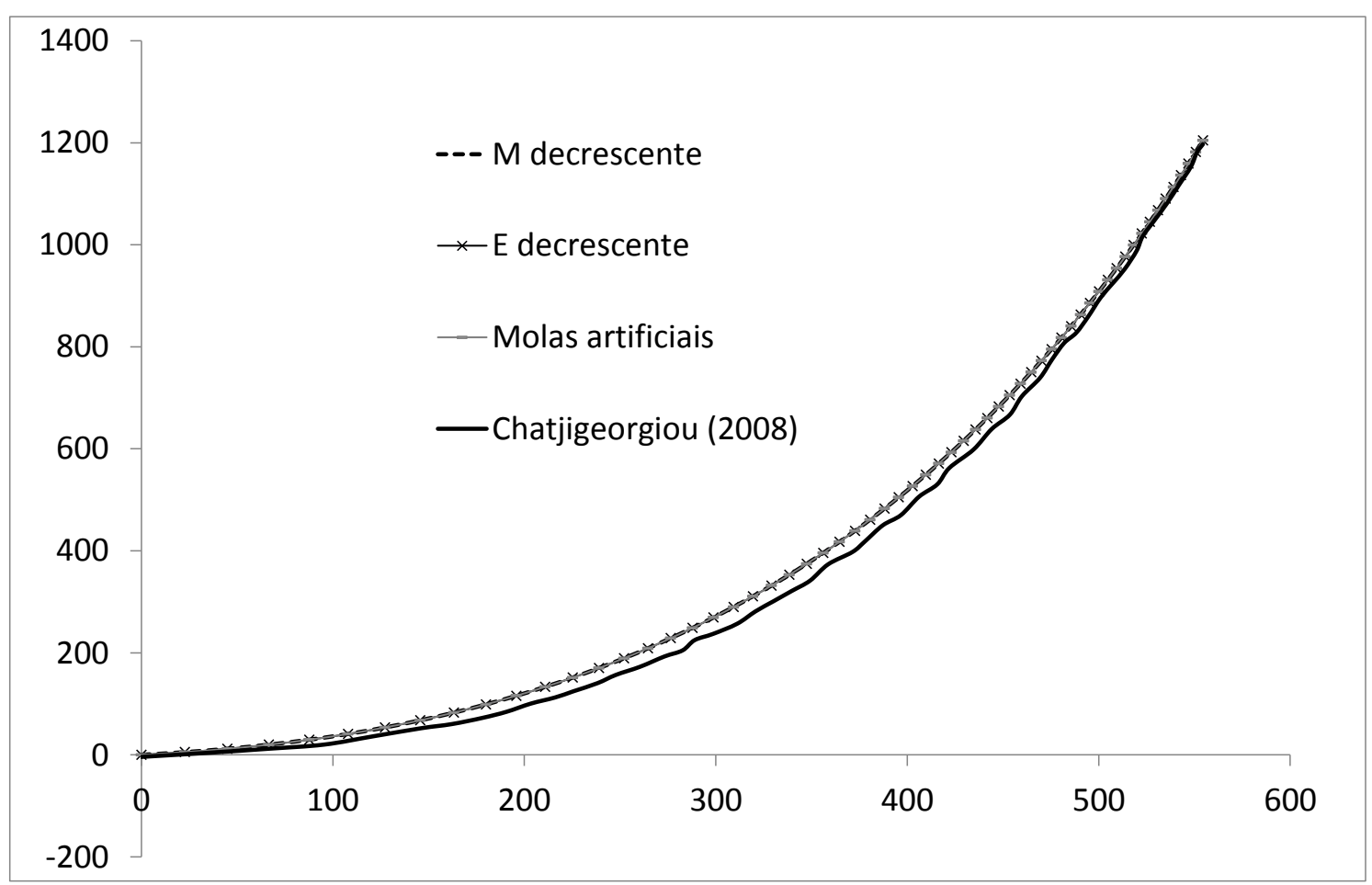

Figura 23.Configurações deformadas do riser do exemplo 4.2.2. Soluções estáticas obtidas por Chathigeorgiou e por medio das metodologias da seção 4.2. . Os valores são indicados em metros.

Outra forma de melhorar a convergência é aplicar na primeira fase de carga um carregamento vertical para cima no topo do riser, resultando em uma pré-tensão que favorece o comportamento da metodologia numérica e algumas vezes não permite a aparição de cargas de compressão no riser. Depois disso, aplicam-se nas seguintes fases de carga todos os carregamentos próprios da estrutura, como peso próprio ou cargas hidrostáticas. 


\section{Interação solo-estrutura}

A vida útil dos risers encontra-se altamente influenciada pela interação com o fundo do oceano. Este contato ocasiona fadiga perto da TDZ (touch-down zone). Considerando isto, a iteração solo-estrutura apresenta-se como uma variável importante na modelagem de risers. Artigos recentes como Hosseini E Bahai (2008), Hu et al. (2011), Pesce et al. (2006), Nakhaee e Zhang (2010), etc mostram a importância deste assunto. Na seção 1.3.4. mencionam-se, também, alguns trabalhos que relatam a importância da interação solo-estrutura.

A interação solo-estrutura pode ser simulada de diversas formas. Por exemplo, alguns modelos consideram o solo como um simples anteparo rígido, outros consideram modelos de molas ou alguns mais completos simulam a penetração do riser no solo incluindo o atrito.

Neste trabalho, o método das penalidades é utilizado para auxiliar no problema de contato entre o solo e o riser. O solo é discretizado com molas distribuídas e suas contribuições nodais, lineares e não lineares. O método de Winkler é utilizado para simular as molas lineares. As molas não lineares, comumente utilizadas para solos coesivos argilosos, são descritas com um modelo $P-y$ que considera a penetração inicial, a elevação, assim como a repenetração e alguns ciclos de carregamento e descarregamento delimitados pelas curvas das cargas extremas. 


\subsection{Método das Penalidades}

No modelo o solo é adicionado ao problema de mínima energia como uma restrição mediante o método das penalidades. Assim, quando o riser ultrapassa a cota do solo (existe penetração) a energia penaliza-se $\Pi_{\mathcal{P}}$ da seguinte forma:

$$
\Pi_{\mathcal{P}}(\mathcal{P}, \mathbf{Y})=\Pi(\mathbf{Y})+\frac{1}{\mathcal{P}} F_{\mathcal{P}}(\mathbf{Y})
$$

onde $\mathcal{P}$ é um fator moderador da função penalidade $F_{\mathcal{P}}$ que se denomina passo da penalidade $\left(\frac{1}{\mathcal{P}}<1\right) . \quad F_{\mathcal{P}}$ são as forças que o solo exerce sobre o riser, as quais penalizam o sistema ${ }^{4}$. Aplicar esta metodologia permite obter a posição final de equilíbrio de forma suave à medida que $\mathcal{P}$ diminui até que $\frac{1}{\mathcal{P}}=1$.

O algoritmo básico do método das penalidades é o seguinte:

i. Define-se um valor inicial para Y. Adota-se um valor inicial moderado para $\mathcal{P}$.

ii. Encontra-se um valor $\mathbf{Y}^{*}$ que minimiza à função (100).

iii. Analisa-se se o valor $\frac{1}{\mathcal{P}}$ é maior que 1 .

iv. Se o resultado do passo iii é verdadeiro, finaliza-se; senão, escolhe-se um $\mathcal{P}^{\prime}<\mathcal{P}$ e, iniciando do ponto $\mathbf{Y}^{*}$ calculado anteriormente, retorna-se ao passo ii, minimizando $\Pi_{\mathcal{P}}\left(\mathcal{P}^{\prime}, \mathbf{Y}\right)$.

${ }^{4} \mathrm{O}$ solo simula-se como molas contínuas. As forças $F_{\mathcal{P}}$ calculam-se como forças equivalentes nos nós. Estas seguem modelos lineares e não lineares segundo os modelos descritos nas seções 5.2 e 5.3 . 


\subsection{Solo Elástico Linear - Método de Winkler}

Nesta seção utiliza-se o modelo de molas lineares de Winkler para simular o solo. Segundo Pesce et al. (2006) a aproximação com fundações elásticas lineares pode ser uma alternativa válida, pelo menos, para solos relativamente rígidos.

Neste modelo, adota-se o solo como tendo um comportamento elástico linear. Sendo $K_{\text {soil }}$ a rigidez por unidade de comprimento do solo.

As molas, deste modelo, ativam-se ao ultrapassar a cota que indica o fundo do oceano e desativam-se em seu retorno. As restrições dadas pelas molas são aplicadas mediante o método das penalidades, descrito na seção 5.1 .

Modelos semelhantes são muito utilizados na literatura. Por exemplo, Morini (2009) aplica esta representação do solo para a análise estática de risers. Pesce et al. (1998) avaliam o efeito da rigidez do solo sobre a configuração estática de um riser. Pesce et al. (2006) consideram um solo linear para a análise dinâmica da estrutura.

Sendo a cota do leito do mar definida pela variável $y_{\text {sea }}$ e a posição do ponto nodal dada pela variável $y$, então se define a penetração da estrutura no solo como $u_{\text {sea }}=y_{\text {sea }}-y$. Com isto, as forças de reação de um solo contínuo são dadas como:

$$
F_{\text {soil }}=-K_{\text {soil }} u_{\text {sea }}
$$

Como as forças das molas são distribuídas, faz-se necessária a transferência destas aos nós. Isto se realiza mediante:

$$
F_{k i l j}^{e}=\delta_{i j} \int_{\mathrm{L}^{\mathrm{e}}} \varphi_{k} F_{\text {soil }}^{e} \varphi_{l} d \mathrm{~L}
$$




$$
F_{k i l j}^{e}=\delta_{i j} \int_{\xi} \varphi_{k} F_{\text {soil }}^{e} \varphi_{l} J d \xi
$$

onde $J$ é o jacobiano que relaciona um infinitésimo de comprimento a um infinitésimo de coordenada adimensional, $\delta_{i j}$ o delta de kronecker, $\varphi_{i}$ as funções de forma no ponto $i$, e $\mathrm{L}^{\mathrm{e}}$ o comprimento inicial do elemento finito.

Na passagem da equação (102) para a (103) realiza-se uma mudança no sistema de coordenadas, tal que $\xi$ representa o comprimento no novo espaço, que no caso é o espaço adimensional auxiliar. Integrando numericamente por meio da quadratura de Gauss, reescreve-se que a equação como:

$$
F_{k i l j}^{e} \cong \delta_{i j} \sum_{d=1}^{N p g 1} \varphi_{k}\left(\xi_{d}\right) F_{\text {soil }}^{e} \varphi_{l}\left(\xi_{d}\right) J W_{d}
$$

sendo Npg1 o número de pontos de Gauss usados como aproximação no comprimento, $W_{c}$ os pesos de cada um dos pontos de Gauss no comprimento e $\xi_{d}$ as coordenadas dos pontos de Gauss.

Também, adiciona-se na matriz Hessiana, utilizada para resolver o algoritmo de Newton Raphson, a derivada da equação (101) com relação aos parâmetros nodais, que seria:

$$
F_{\text {soil }}=-K_{\text {soil }} .
$$

\subsubsection{Exemplo}

O objetivo deste exemplo é validar a metodologia aplicada quando considerado o problema de interação solo-estrutura. Assim, os resultados são comparados com a 
solução analítica mostrada por Colajanni et al. (2009) e com os resultados numéricos obtidos por Antonio (2011).

A solução analítica é dada pela seguinte equação:

$$
y(x)=e^{\bar{k} x}\left(C_{1} \operatorname{Cos}(\bar{k} x)+C_{2} \operatorname{Sin}(\bar{k} x)\right)+e^{-\bar{k} x}\left(C_{3} \operatorname{Cos}(\bar{k} x)+C_{4} \operatorname{Sin}(\bar{k} x)\right)+\frac{q}{k^{\prime}}
$$

onde $C_{i}$ são constantes de integração, as quais são determinadas mediante a aplicação das condições de contorno da estrutura, e $\bar{k}$ é dado pela seguinte expressão

$$
\bar{k}=\sqrt[4]{\frac{k}{4 E I}} .
$$

A estrutura modelada é uma viga bi-engastada, a qual se apoia integralmente sobre uma fundação elástica e sujeita a uma força uniformemente distribuída. Os dados do problema são mostrados na Tabela 11.

Tabela 11. Dados da viga do exemplo 5.2.1.

\begin{tabular}{|l|c|}
\hline Comprimento $L$ & $5 \mathrm{~m}$. \\
\hline Rigidez à flexão $E I$ & $1.75 \times 10^{6} \mathrm{Nm}^{2}$ \\
\hline Rigidez do solo $k$ & $2.00 \times 10^{7} \mathrm{~N} / \mathrm{m} / \mathrm{m}$ \\
\hline Carregamento distribuído $q$ & $100.00 \mathrm{~N} / \mathrm{m}$ \\
\hline
\end{tabular}

Na Figura 24 é mostrada a deformada da estrutura em contato com o solo. A linha tracejada com marcador " $x$ " representa a deformada obtida com a formulação proposta. O comportamento representado por linha continua com marcador "|" mostra a solução analítica. A linha tracejada com marcador triangular descreve os resultados de Antonio (2011). Comparando os resultados obtidos com o MEF com aqueles dados pela solução analítica, nota-se que a solução numérica apresenta um comportamento bem aproximado, isto se evidencia com o erro dado na Figura 25. 0 
erro é a diferença entre a solução numérica (obtida neste trabalho) e a solução analítica sobre a solução sobre o máximo valor da solução numérica, tudo vezes 100. Na Figura 26 mostra-se o momento fletor ao longo do comprimento da viga e compara-se com o valor analítico. Na Figura 27 é mostrado o erro em porcentagem ao longo do comprimento.

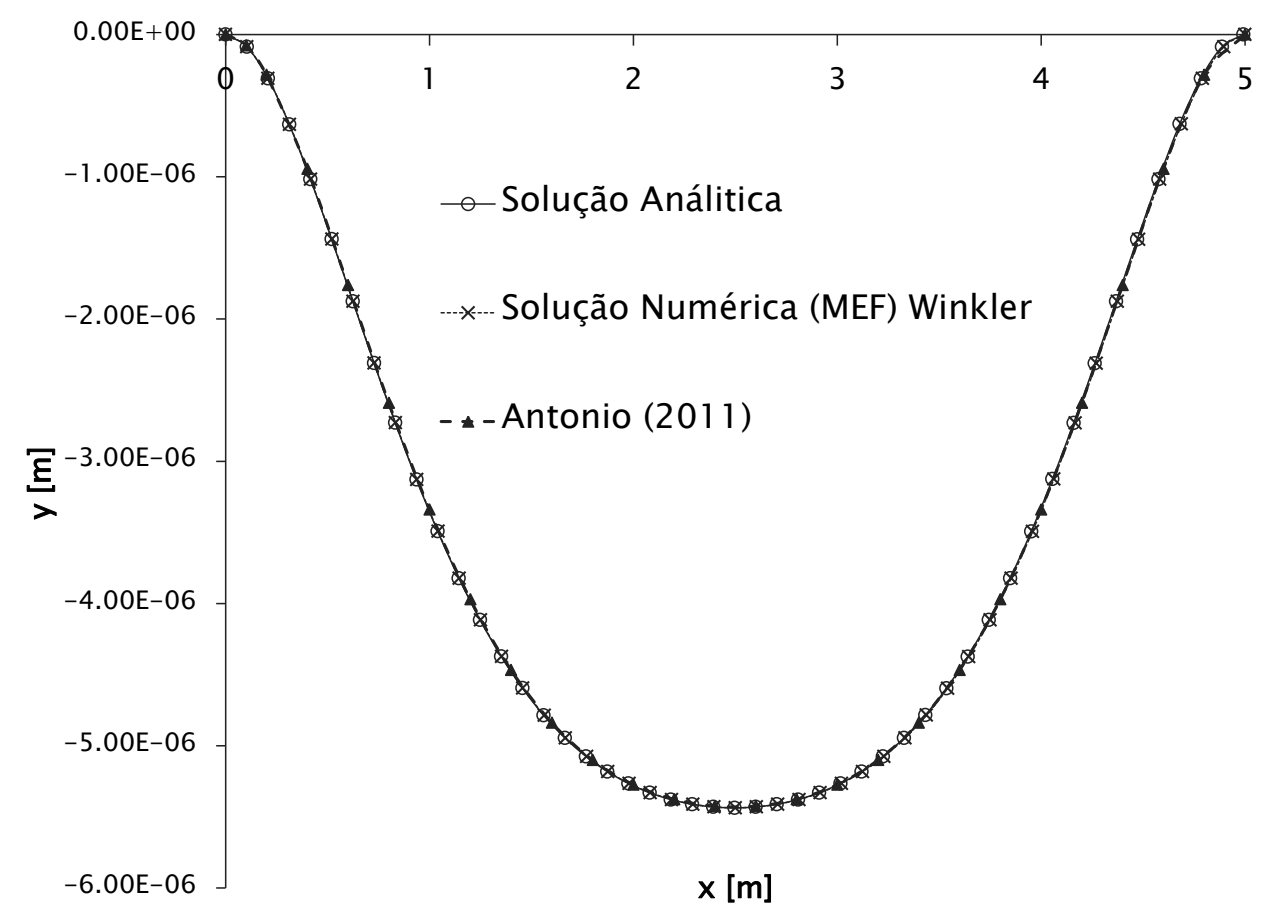

Figura 24. Deformada da viga do exemplo 5.2.1 sobre molas elásticas lineares. Comparação com resultados analíticos e da literatura. 


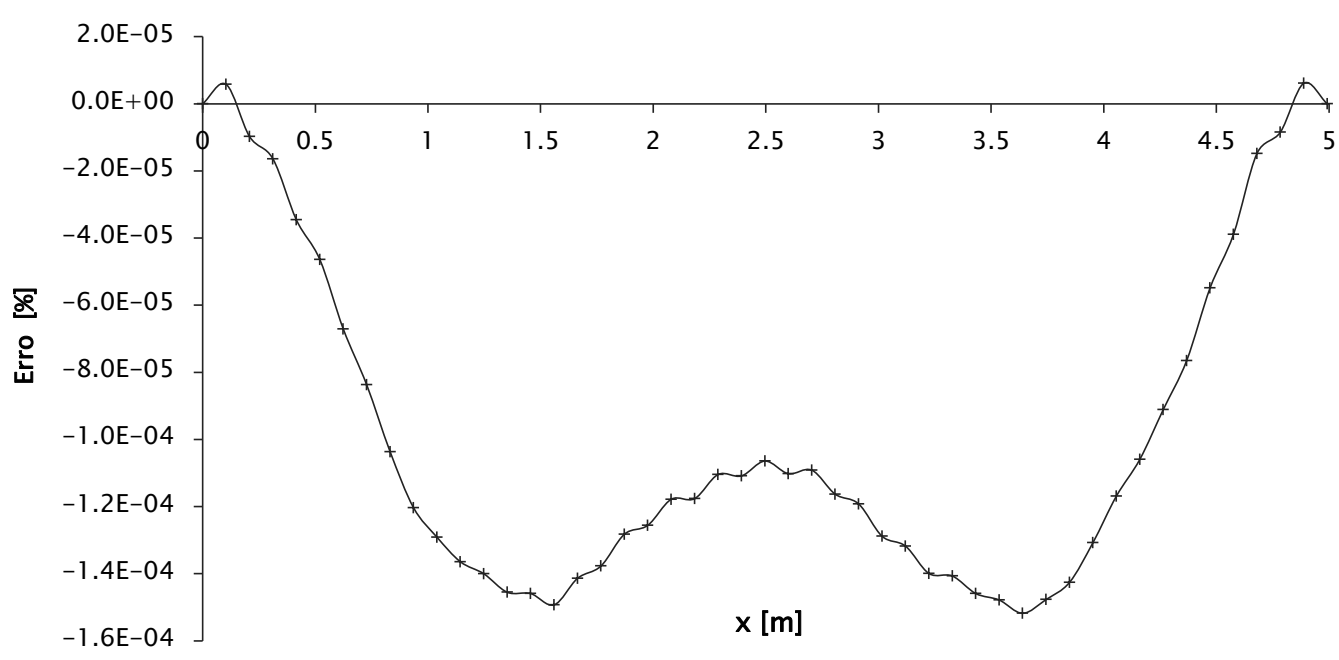

Figura 25. Erro $=\left(Y[\right.$ SolMEF]-Y[SolAna] $) / M a ́ x(Y[S o l M E F])^{\star} 100$ do exemplo 5.2.1.

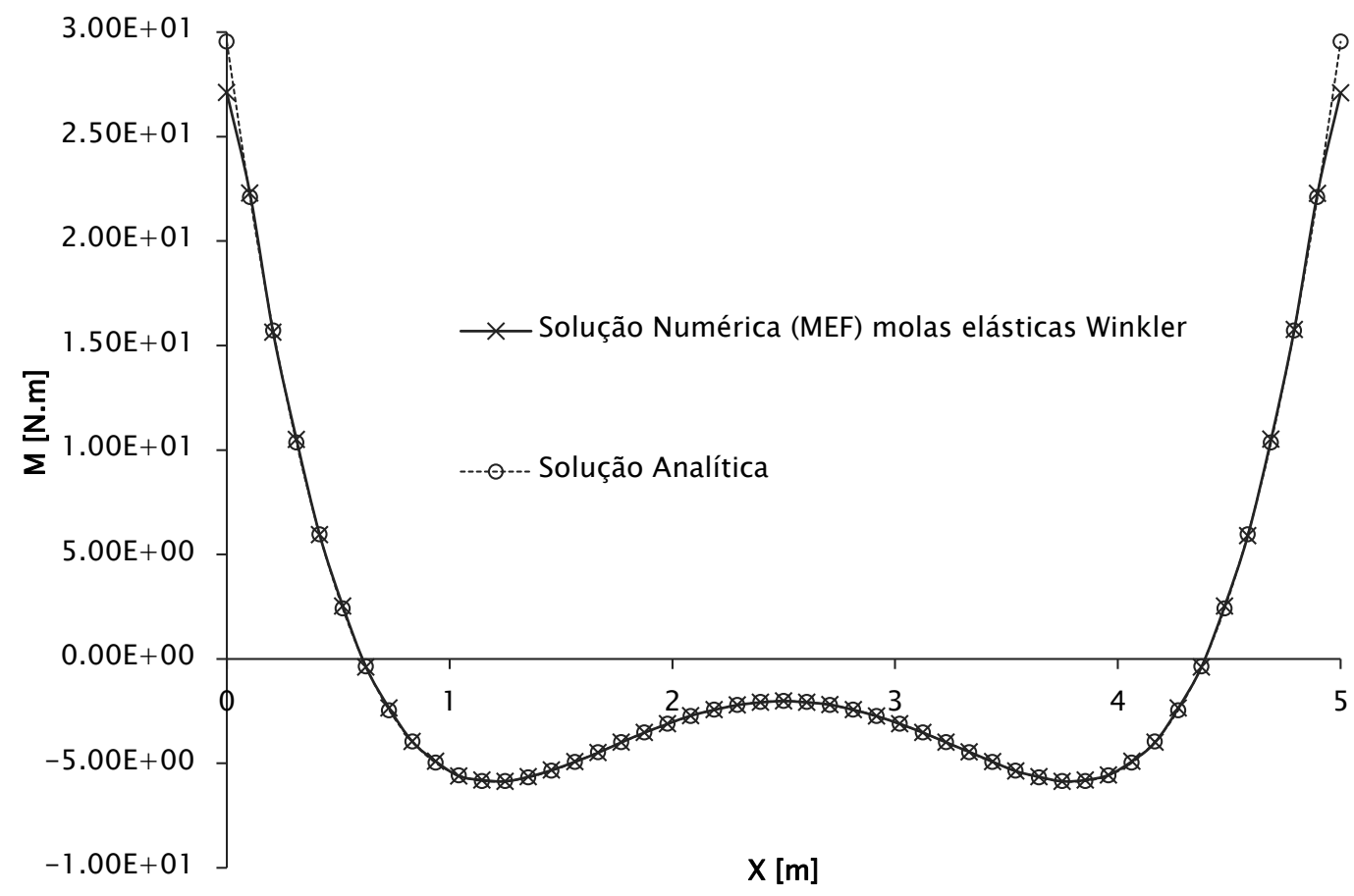

Figura 26. Momento fletor da viga do exemplo 5.2.1 sobre molas elásticas lineares. Comparação com resultados analíticos e da literatura. 


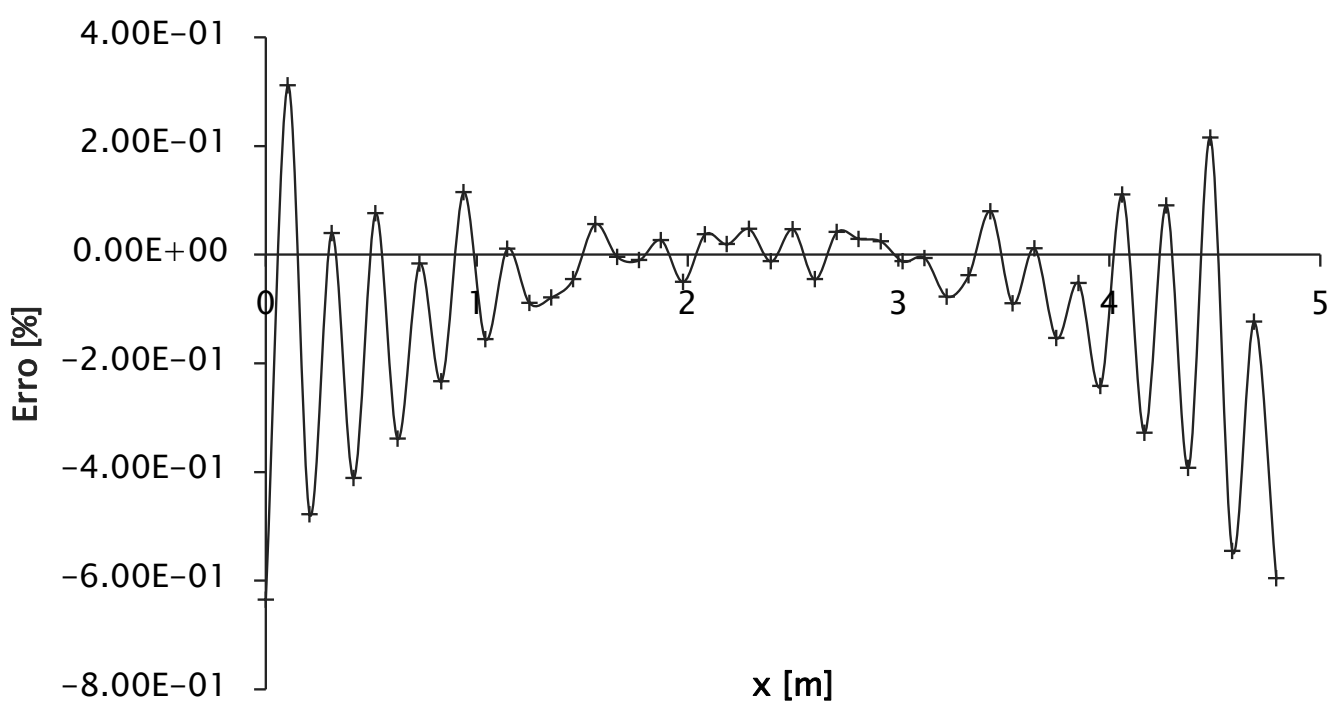

Figura 27. Erro = $(M[$ SolMEF]-M[SolAna])/Máx(M[SolMEF])*100 do exemplo 5.2.1.

\subsection{Solo Elástico Não Linear}

Recentemente, a maioria das pesquisas têm sido realizadas em solos com modelos não lineares. Particularmente com ênfases nos efeitos altamente não lineares, combinando métodos experimentais e numéricos (PESCE; MARTINS; SILVEIRA, 2006).

Considerar um modelo não linear é importante para determinar o comportamento critico de um riser em contato com o leito marinho. A posição crítica, devida ao dano por fadiga, encontra-se na região de contato com o solo TDP (touch down zone), onde a interação cíclica acontece. Muitos trabalhos da literatura mostram a importância de considerar alguns efeitos na interação dos risers com o fundo do mar. Entre eles, a formação de trincheiras (trench), rigidez não linear do solo, efeito de sucção, entre outras (AUBENY; BISCONTIN, 2009). 
Com isto, na segunda parte deste capitulo, modela-se o solo de forma não linear segundo o método proposto Aubeny e Biscontin (2009). Isto permite considerar os seguintes efeitos: penetração inicial, movimentos verticais ascendentes (uplift), repenetração e pequenos movimentos dentro das curvas extremas do modelo. A Figura 28 (extraída de Aubeny e Biscontin (2009)) mostra o comportamento mecânico do modelo, tendo no eixo vertical o valor da força exercida pelo solo em função da penetração do riser, a qual se mostra no eixo horizontal. Aprecia-se que o modelo $P-Y$ do solo é composto por vários trechos, os quais consideram os efeitos descritos anteriormente.

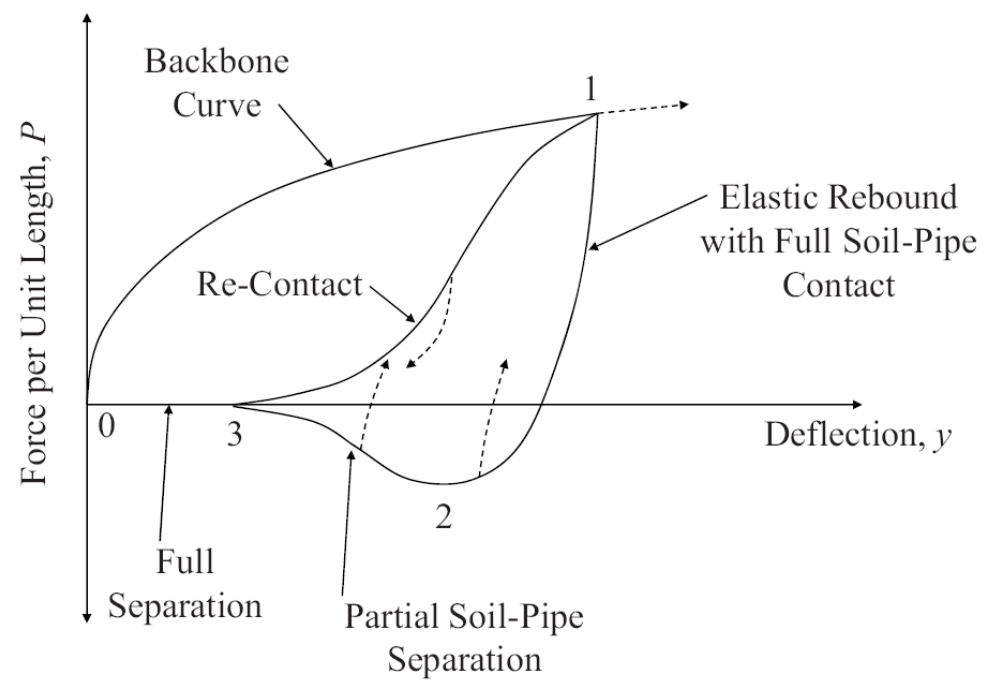

Figura 28. Comportamento P-y do solo. Figura extraída de Aubeny e Biscontin (2009).

O comportamento do modelo mostrado por Aubeny e Biscontin (2009) é o típico de um solo com pouca rigidez, formado por sedimentos. As curvas enquadram-se no comportamento experimental encontrado por Dunlap et al. (1990). No que segue, mostra-se detalhadamente o modelo não linear utilizado. A descrição do modelo da seção seguinte baseia-se no artigo de Aubeny e Biscontin (2009). 


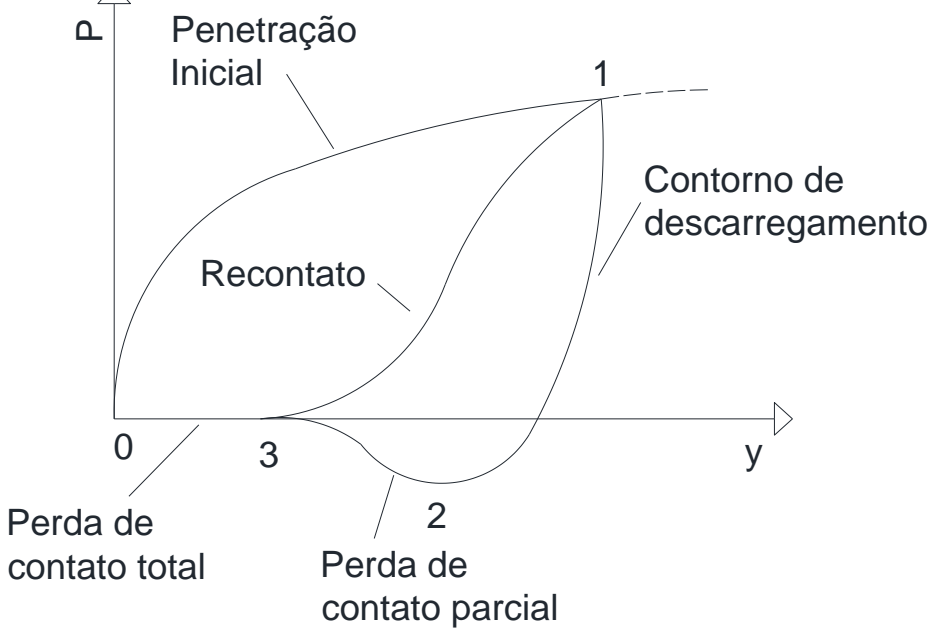

Figura 29. Modelo P-y não linear.

\subsubsection{Modelo não linear da curva $P$ - $Y$.}

O modelo completo está composto por quatro etapas, que são:

1. Curva de Carregamento Inicial (Backbone curve): descreve o comportamento $P$-y do solo quando acontece a penetração inicial. Na Figura 29, esta curva encontra-se definida entre os pontos "0" e "1". O ponto "0" indica a penetração inicial, geralmente zero. O ponto "1" indica o começo do descarregamento.

2. Curvas de Contorno de carregamento e descarregamento (Bounding loop): Estas se dividem em três fases, o descarregamento com contato total risersolo (curva 1-2), o desprendimento parcial (curva 2-3) e recarregamento (curva 3-1).

3. Movimentos reversos desde qualquer ponto arbitrário pertencente às curvas de contorno (Bounding loop).

4. Cargas cíclicas entre curvas de contorno.

\section{Curva de carregamento inicial (Backbone)}


A curva de carregamento inicial é definida entre os pontos "0" $\left(P_{0}, y_{0}\right)$ e "1" $\left(P_{1}, y_{1}\right)$, ver Figura 29. O ponto "0" indica o primeiro contato entre o solo e a estrutura. O Ponto "1" marca o inicio do descarregamento. Matematicamente, a curva é dada pela equação:

$$
P=N_{p} c D,
$$

onde $N_{p}$ é um fator que considera o efeito da trincheira, a geometria do riser e a profundidade de penetração $y$. Assim,

$$
N_{p}=a(y / D)^{b} .
$$

Diferentes valores para os coeficientes $a$ e $b$ são mostrados no trabalho de Aubeny e Biscontin (2009). Estes fatores dependem fortemente das dimensões da trincheira e do atrito produzido pelo solo. A forma do perfil da tensão de cisalhamento não drenada, $c$, é dada pela equação:

$$
c=c_{0}+\rho y,
$$

onde $c_{0}$ é a resistência ao cisalhamento na superfície do leito do mar, $\rho$ é o gradiente da tensão de cisalhamento com relação à penetração $y$.

\section{Curvas de contorno de descarregamento e recarregamento}

Estas curvas definem o comportamento da carga, $P$, exercida pelo solo quando existe uma perda total ou parcial do contato, ou, quando existe um recontato entre o solo e o riser. 


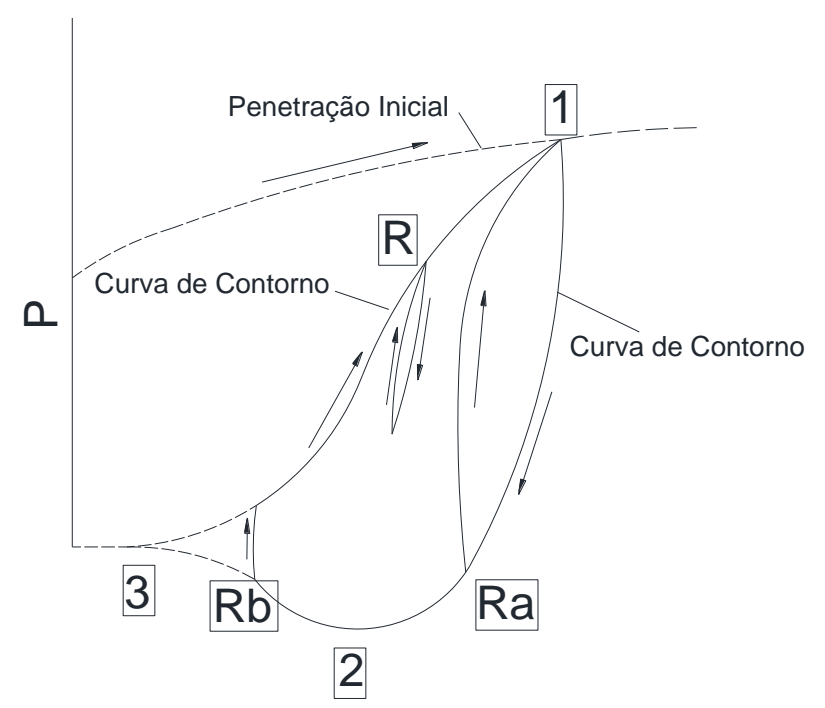

Figura 30. Curvas de contorno e loops internos.

Para definir matematicamente as curvas do contorno são utilizados os pontos mostrados na Figura 30. O ponto "1" já foi descrito anteriormente. O ponto "2" $\left(P_{2}, y_{1}\right)$ indica a máxima sucção possível. $O$ ponto "3" $\left(P_{3}, y_{3}\right)$ é o ponto no qual existe a separação total entre o riser e o solo.

Assim, o ponto "2" calcula-se como:

$$
P_{2}=\phi P_{1},
$$

onde $\phi$ é um parâmetro do modelo. O ponto " 3 " é definido segundo a seguinte relação

$$
\left(y_{2}-y_{3}\right)=\psi\left(y_{1}-y_{2}\right),
$$

onde $\psi$ é outro parâmetro do modelo.

Com isso, define-se a curva 1-2 como:

$$
P=P_{1}+\frac{\left(y-y_{1}\right)}{\frac{1}{k_{0}}+\chi \frac{\left(y-y_{1}\right)}{(1+\omega) P_{1}}},
$$


onde $k_{0}$ define a inclinação inicial da hipérbole e $\omega$ está relacionada com a curvatura. $\chi$ é um parâmetro, positivo ou negativo, que controla se a etapa é de carregamento ou descarregamento.

O ponto "2" é totalmente definido pela relação:

$$
y_{2}=y_{1}+\frac{(1+\omega) P_{1}(1+\phi)}{k_{0}(\omega-\phi)}
$$

Entre os pontos "2" e "3" a curva P-y é dada por

$$
P=\frac{P_{2}}{2}+\frac{P_{2}}{4}\left[3\left(\frac{y-y_{0}}{y_{m}}\right)-\left(\frac{y-y_{0}}{y_{m}}\right)^{3}\right]
$$

onde,

$$
\begin{aligned}
& y_{0}=\left(\frac{y_{2}+y_{3}}{2}\right), \\
& y_{m}=\left(\frac{y_{2}-y_{3}}{2}\right),
\end{aligned}
$$

A curva de contorno 3-1 segue uma relação semelhante à curva 2-3

$$
P=\frac{P_{1}}{2}+\frac{P_{1}}{4}\left[3\left(\frac{y-y_{0}}{y_{m}}\right)-\left(\frac{y-y_{0}}{y_{m}}\right)^{3}\right]
$$

onde,

$$
\begin{aligned}
& y_{0}=\left(\frac{y_{1}+y_{3}}{2}\right), \\
& y_{m}=\left(\frac{y_{1}-y_{3}}{2}\right),
\end{aligned}
$$

\section{Movimentos reversos}

Na Figura 30 são mostrados os ciclos de carregamento e descarregamento entre as curvas de contorno. Assim, a curva de um ciclo reverso, o qual pode se 
encontrar sobre a curva 1-2 ou 3-1, é dada em função do ponto de revés ${ }^{5},\left(P_{R a}, y_{R a}\right)$ ou $\left(P_{R}, y_{R}\right)$,

$$
P=P_{R}+\frac{\left(y-y_{R}\right)}{\frac{1}{k_{0}}+\chi \frac{\left(y-y_{R}\right)}{(1+\omega) P_{1}}} .
$$

O ciclo reverso sobre a curva 2-3, ou seja, partindo do ponto de revés $R b$ $\left(P_{R b}, y_{R b}\right)$, é dado por:

$$
P=\frac{P_{R b}+P_{1}}{2}+\frac{P_{1}-P_{R b}}{4}\left[3\left(\frac{y-y_{0}}{y_{m}}\right)-\left(\frac{y-y_{0}}{y_{m}}\right)^{3}\right]
$$

onde,

$$
\begin{aligned}
& y_{0}=\left(\frac{y_{1}+y_{R b}}{2}\right), \\
& y_{m}=\left(\frac{y_{1}-y_{R b}}{2}\right),
\end{aligned}
$$

Também, adiciona-se na matriz Hessiana, utilizada para resolver o algoritmo de Newton Raphson, a derivada das equações (108), (113), (115), (117), (119) e (120) com relação à posição nodal. Estas derivadas encontram-se indicadas no Anexo 1, seção 9.1.

\subsubsection{Exemplo}

Modela-se neste exemplo um riser em contato com o solo. $\mathrm{O}$ solo segue 0 modelo constitutivo não linear descrito na seção 5.3.1. Os dados da estrutura são mostrados na Tabela 13. O riser consiste em um tubo de aço biarticulado, tal que, na configuração inicial, encontra-se apoiado no solo nos primeiros $50 \mathrm{~m}$ de comprimento e o trecho restante segue uma função catenária, dada pela equação:

${ }^{5}$ Os pontos de revés mostram-se na Figura 30. Tal que "R" encontra-se sobre a curva 3-1, "Ra" sobre a 1-2 e "Rb" sobre a 2-3. 


$$
P_{y}=a \operatorname{Cosh}\left(\frac{x}{a}\right)-a+P_{y 0}
$$

onde $P_{y}$ é a coordenada vertical do riser, $a$ é uma constante, $x$ é a variação na direção $\times\left(P_{x}-P_{x 0}\right)$ desde o ponto de inicio da catenária e $P_{y_{0}}$ é a coordenada vertical no inicio da catenária. Os dados utilizados se encontram na Tabela 12.

Tabela 12. Dados do riser do exemplo 5.3.2.

\begin{tabular}{|c|c|}
\hline$a$ & 955.5 \\
\hline$P_{y 0}$ & -0.08 \\
\hline$P_{x 0}$ & 50.979 \\
\hline
\end{tabular}

O exemplo é adaptado das modelagens numéricas e experimentais encontradas em alguns trabalhos relevantes (AUBENY; BISCONTIN, 2006), (AUBENY; BISCONTIN, 2009), (WILLIS; WEST, 2001), entre outros.

Tabela 13. Dados do riser do exemplo 5.3.2.

\begin{tabular}{|l|c|}
\hline Comprimento projetado no eixo horizontal $L_{x}$ & $180 \mathrm{~m}$. \\
\hline Comprimento projetado no eixo vertical $L_{y}$ & $9.6 \mathrm{~m}$. \\
\hline Módulo de elasticidade $E$ & $2.11 \times 10^{11} \mathrm{~N} / \mathrm{m}^{2}$ \\
\hline Rigidez linear do solo $k$ & $8.00 \times 10^{3} \mathrm{~N} / \mathrm{m} / \mathrm{m}$ \\
\hline Carregamento distribuído $q$ & $-915.00 \mathrm{~N} / \mathrm{m}$ \\
\hline Profundidade da água & $3.85 \mathrm{~m}$. \\
\hline Diâmetro externo & $0.1683 \mathrm{~m}$. \\
\hline Diâmetro interno & $0.0993 \mathrm{~m}$. \\
\hline Coeficiente de arrasto $C_{d}$ & 0.7 \\
\hline Coeficiente de arrasto $C_{m}$ & 1.5 \\
\hline Passo de tempo $\Delta t$ & 0.01 \\
\hline Número de passos de tempo & 4000 \\
\hline Período $T$ & $25 \mathrm{seg}$. \\
\hline Amplitude $A$ & $0.4 \mathrm{~m}$ \\
\hline
\end{tabular}

Com intuito de comparação, modela-se também o riser sobre um solo elástico linear. Neste caso, o solo segue o modelo de Winkler descrito na seção 5.2. 


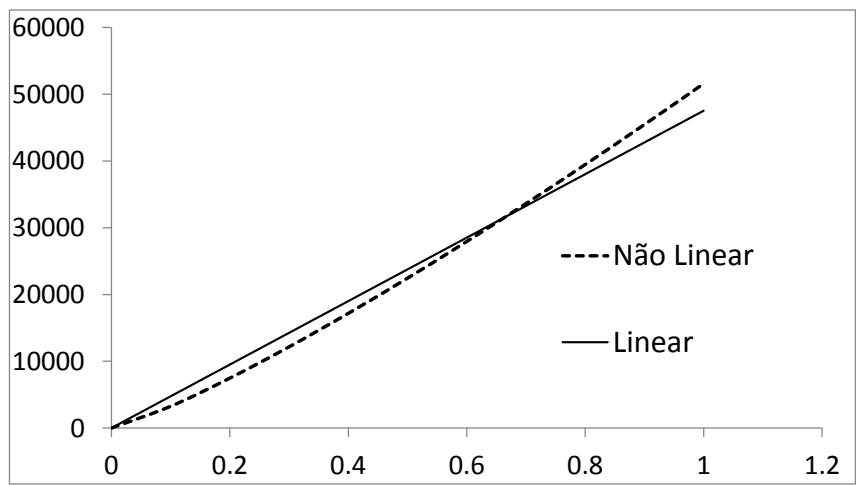

Figura 31. Ajuste do solo linear com relação ao solo não linear. O eixo vertical encontra-se em Newtons e o horizontal em metros.

Na Tabela 13 mostram-se os dados do solo não linear. A rigidez do solo linear é dada como o ajuste linear da curva de penetração inicial, ver Figura 31.

A malha utilizada tem 56 elementos com funções de grau 4. O número de nós utilizado é de 169. Adota-se inicialmente a catenária fornecida por Aubeny e Biscontin (2006) como posição inicial. Depois, aplica-se um deslocamento vertical no topo do riser, utilizando a técnica proposta na seção 4.1, segundo a equação:

$$
\boldsymbol{u}^{k}=A \operatorname{Cos}(w \Delta t p t)
$$

onde $A$ é a amplitude, $w$ é a frequência, $\Delta t$ é o tamanho do passo de tempo e $p t$ é o número do passo de tempo.

Tabela 14. Solo não linear do exemplo 5.3.2.

\begin{tabular}{|c|c|}
\hline Resistência ao cisalhamento na superfície $c_{0}$ & 0 \\
\hline Gradiente da tensão de cisalhamento $\rho$ & $6.0 \mathrm{KPa} / \mathrm{m}$ \\
\hline Rigidez do solo linear $k$ & $8.0 \mathrm{KN} / \mathrm{m} / \mathrm{m}$ \\
\hline Coeficiente $a$ & 6.02 \\
\hline Coeficiente $b$ & 0.2 \\
\hline Rigidez inicial do descarregamento $K_{0} P_{1}$ & 160 \\
\hline Fator de descarregamento $\omega$ & 0.433 \\
\hline Força limite de descarregamento $\phi$ & 0.203 \\
\hline Fator de separação solo-riser $\psi$ & 0.661 \\
\hline Cota da superfície do solo & $-0.085 \mathrm{~m}$. \\
\hline
\end{tabular}


Os parâmetros do método das penalidades utilizados para auxiliar na aplicação da restrição do solo mostram-se na Tabela 15.

Tabela 15. Dados dos parâmetros utilizados penalidade do exemplo 5.3.2.

\begin{tabular}{|l|l|}
\hline Penalidade inicial & 30 \\
\hline Passo de redução da penalidade & 0.5 \\
\hline Tolerância no método de Newton-Raphson & $1.0 \times 10-6$ \\
\hline Penalidade mínima (tolerância do método) & 0.01 \\
\hline
\end{tabular}

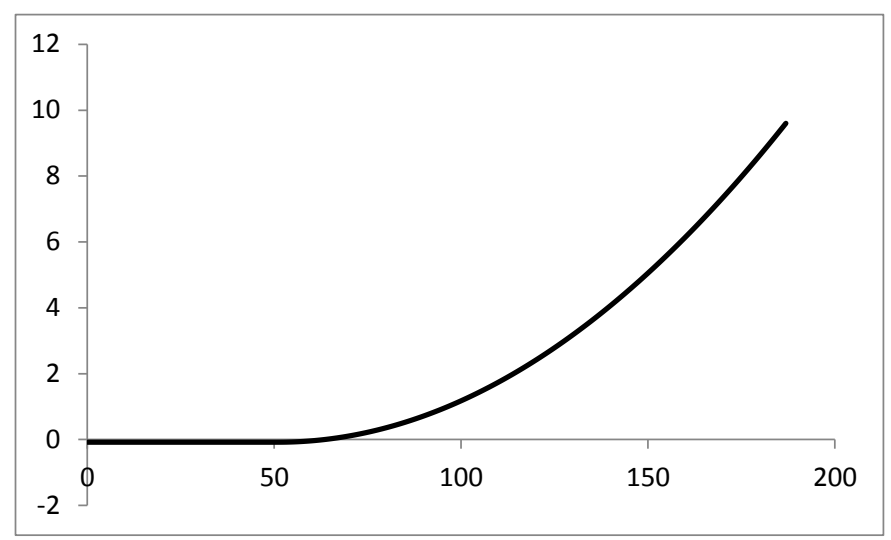

Figura 32. Indeformada do riser modelado no exemplo 5.3.2. Os valores são indicados em metros.

A Figura 33 e a Figura 36 mostram as configurações deformadas das análises dinâmicas à medida que o tempo avança, sendo a primeira em contato com o solo não linear e a outra com o solo linear. Entre estas figuras aprecia-se um comportamento semelhante. Na Figura 34 e na Figura 37 realiza-se um zoom ao redor da região do TDZ e observa-se que o solo não linear é um pouco menos rígido que o linear.

A deformação máxima mostrada na Figura 34 é coerente com os resultados reportados por Aubeny e Biscontin (2006). Nesse trabalho os autores descrevem que a máxima penetração no solo, com os testes realizados, é de $0.38 \mathrm{~m}$. A penetração máxima obtida com o solo não linear, neste trabalho, é de $0.3 \mathrm{~m}$ (na 
Figura 34 se observa um valor de $0.39 \mathrm{~m}$, porém a cota do solo é de $-0.085 \mathrm{~m})$. O valor da penetração aumenta à medida que o ciclo de carregamento repete-se, segundo a seção 5.3.1. O fato de termos realizado poucos ciclos justifica que a penetração obtida tenha sido menos que a encontrada por Aubeny e Biscontin (2006).

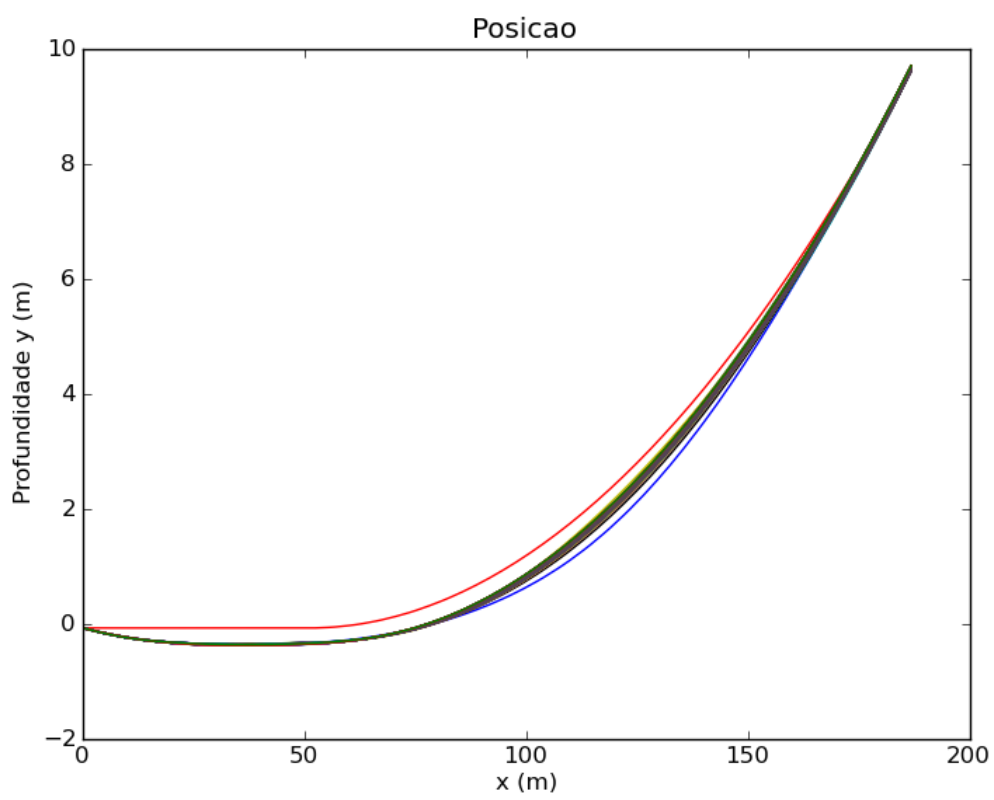

Figura 33. Deformada do riser em contato com o solo não linear por diversos instantes.

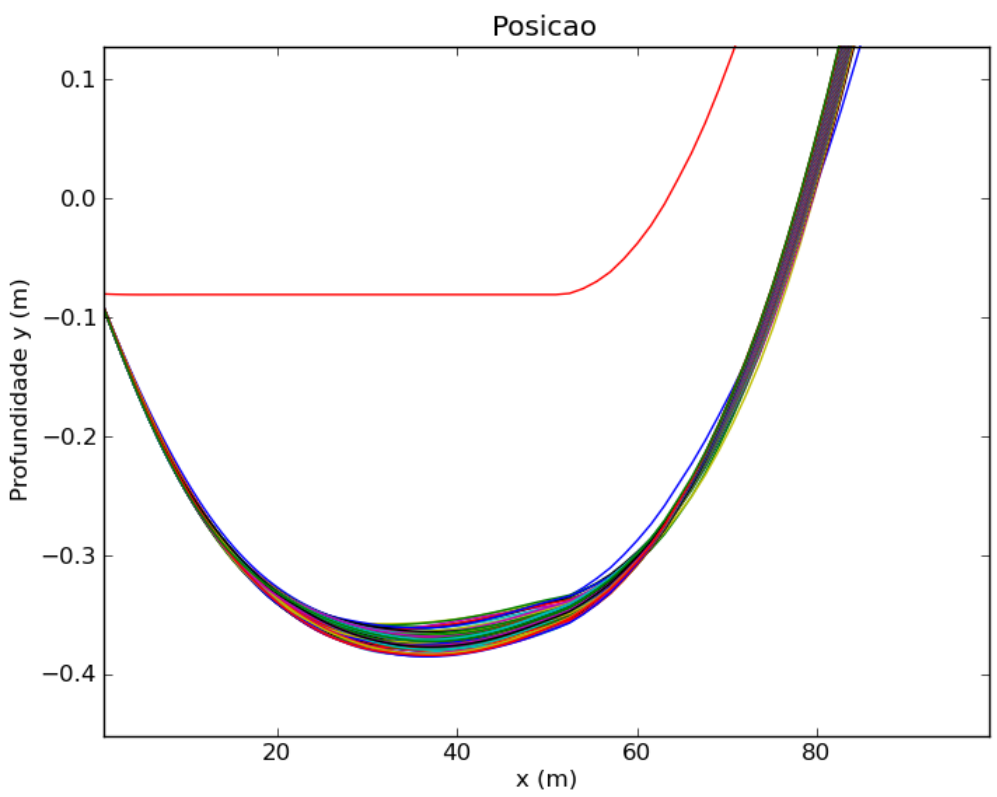

Figura 34. Zoom em TDZ da deformada do riser em contato com o solo não linear. 
Na Figura 35 e na Figura 38 mostram-se o momento fletor e o esforço normal ao longo do riser à medida que o tempo avança, tanto para o contato com o solo não linear como para o linear, respectivamente. Nota-se que os momentos fletores máximos encontram-se na região em contato com o solo. O riser apresenta esforços maiores quando está em contato com o solo não linear.
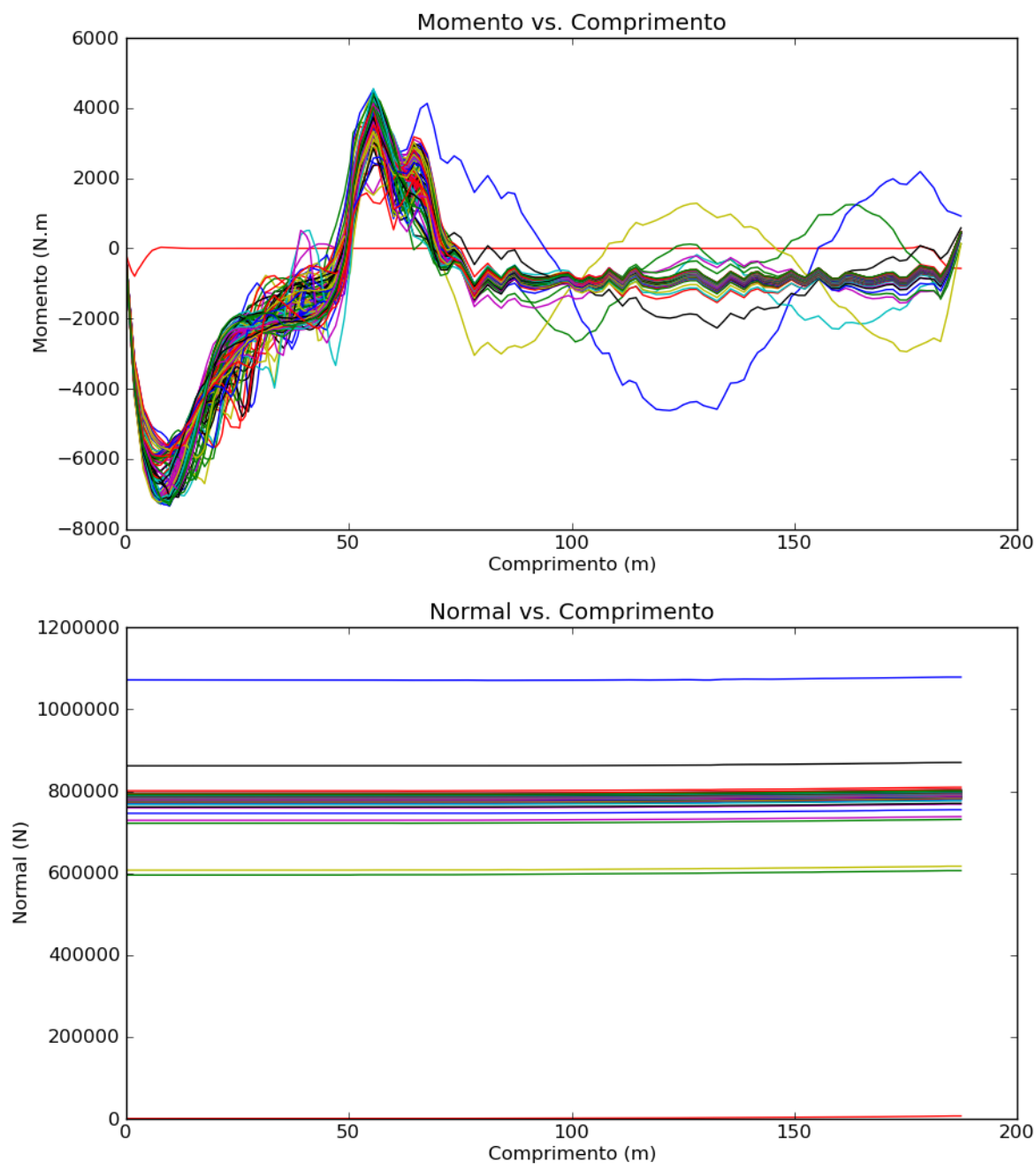

Figura 35. Esforços ao longo do riser em contato com o solo não linear. 


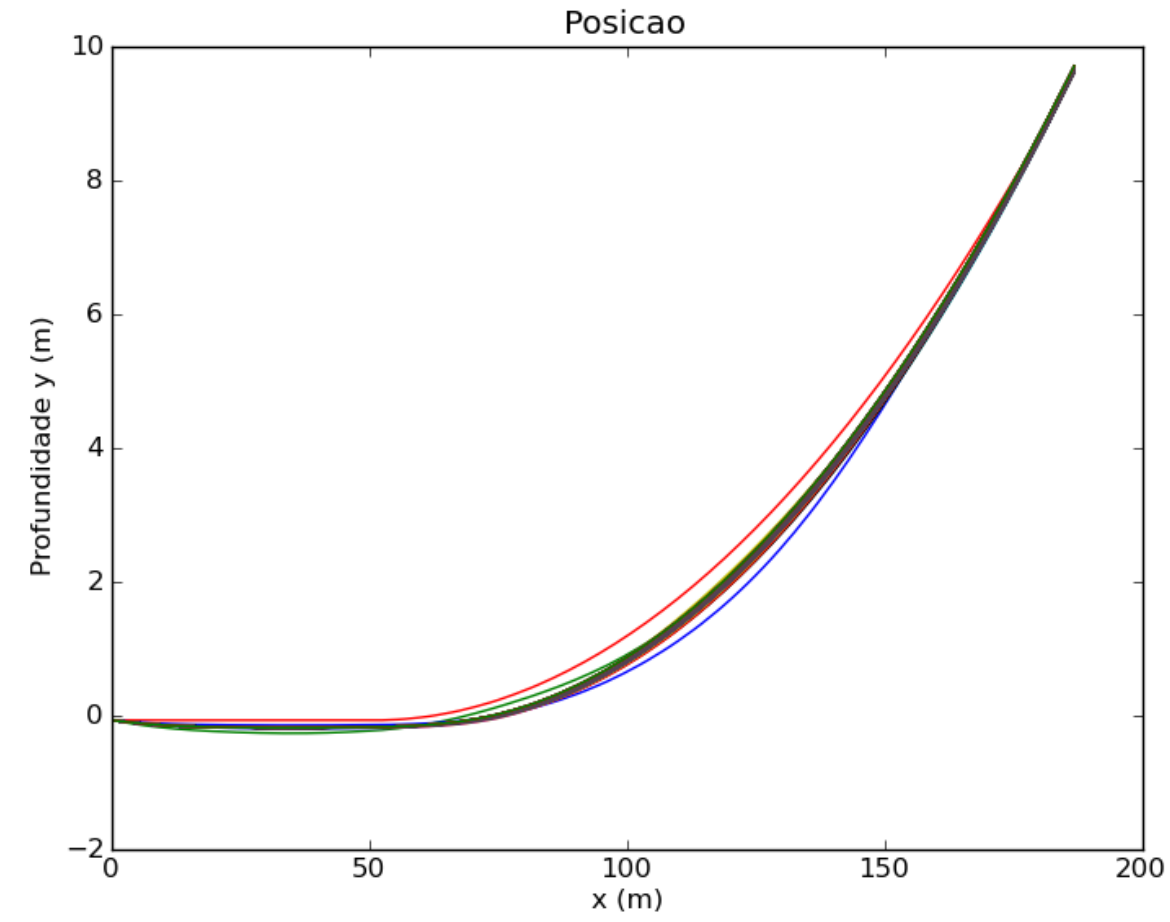

Figura 36. Deformada do riser em contato com o solo linear por diversos instantes.

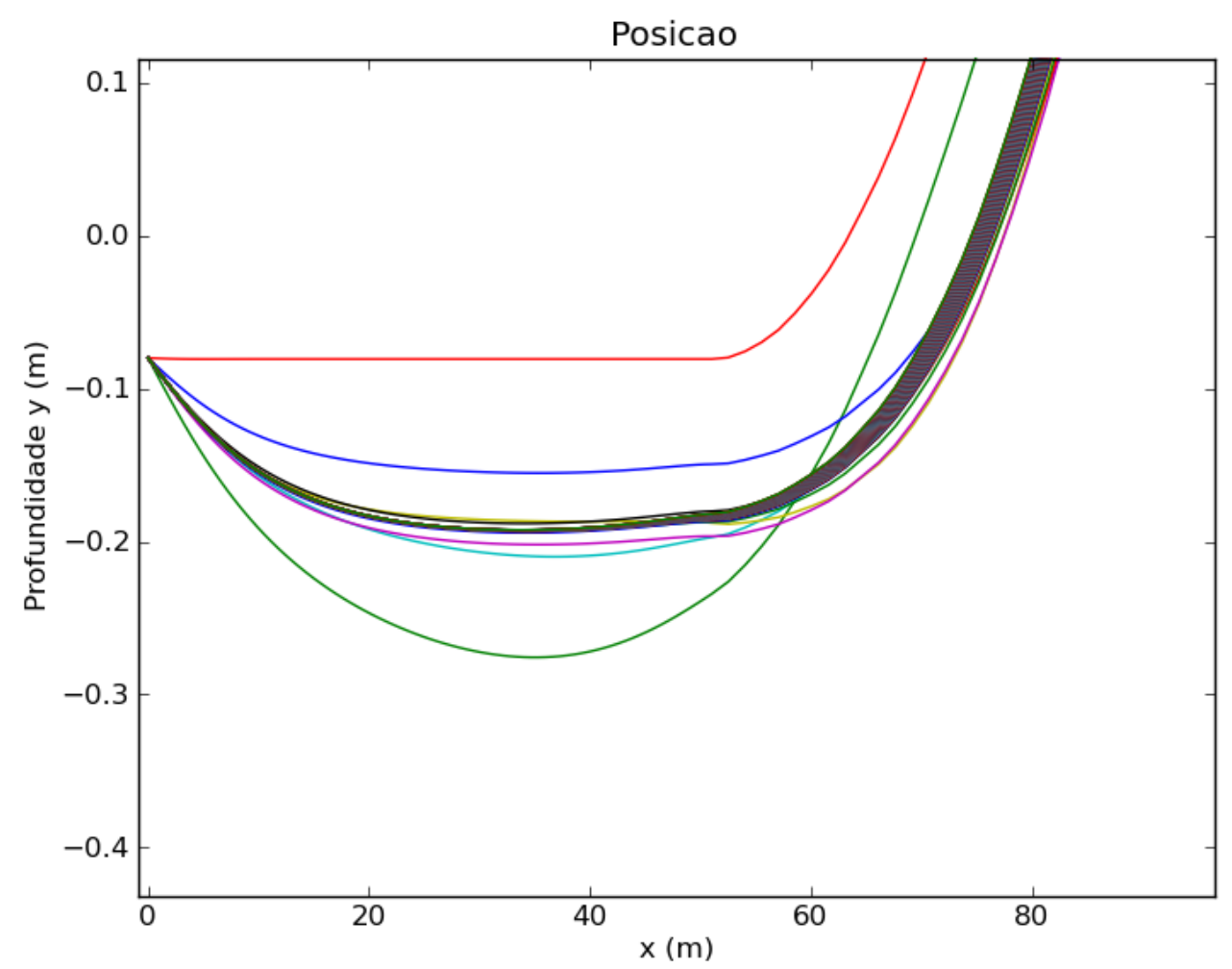

Figura 37. Zoom em TDZ da deformada do riser em contato com o solo linear. 
Segundo os resultados mostrados neste exemplo, conclui-se que o modelo não linear foi implementado com sucesso. Além disso, dentro das possíveis comparações com a literatura os resultados são coerentes, indicando, entretanto, que a forte não linearidade geométrica limita as possibilidades de comparação entre métodos numéricos. A presença de resultados experimentais que corroborem para "benchmarks" confiáveis torna-se imprescindível para desenvolvimentos futuros.
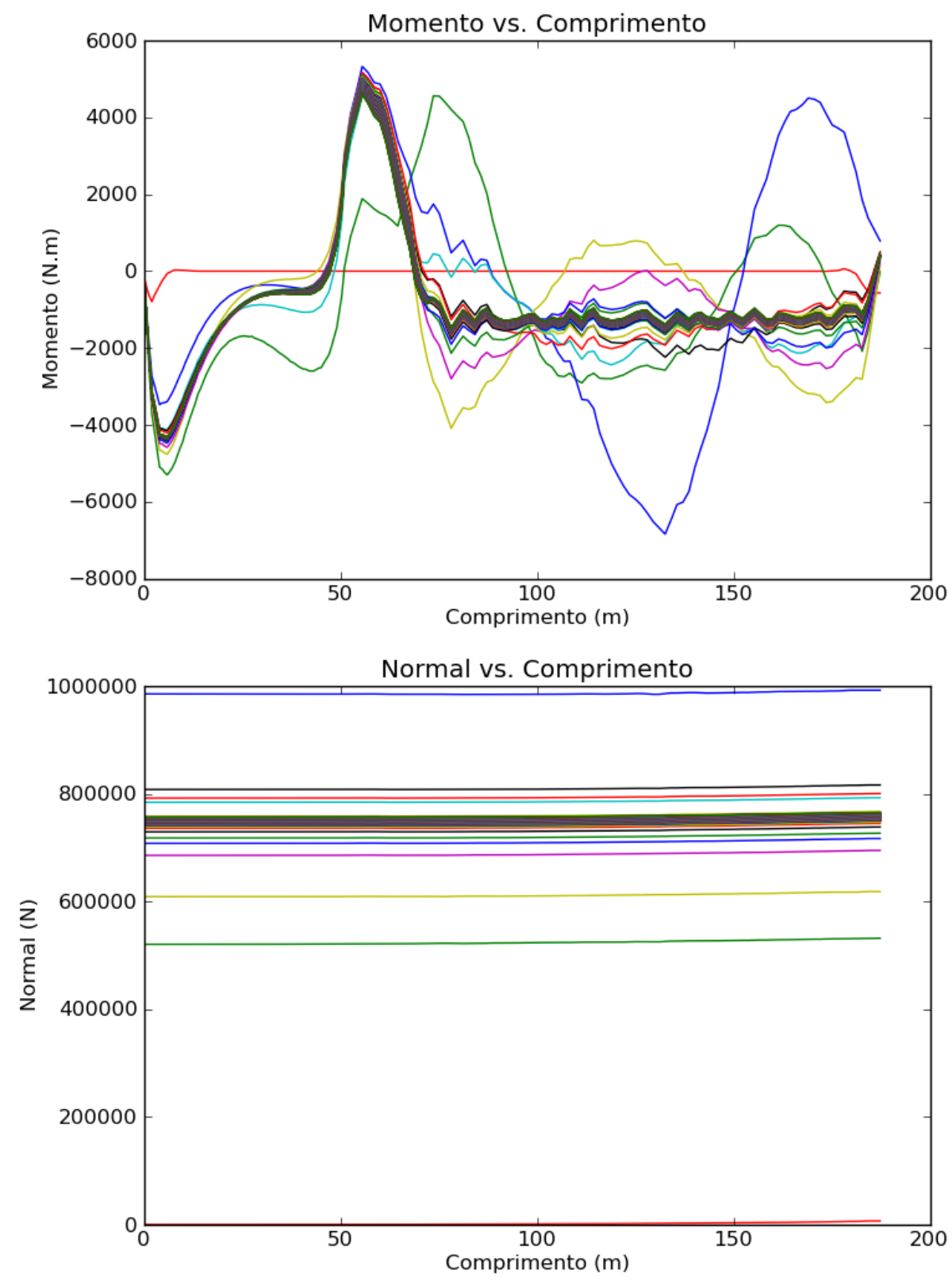

Figura 38. Esforços ao longo do riser em contato com o solo linear. 


\section{Exemplos Numéricos e Aplicações}

Neste capitulo, simulam-se alguns problemas relevantes da literatura, assim como também são realizadas algumas aplicações que buscam apresentar os risers em situações diversas como, por exemplo, fases de instalação. Os exemplos iniciais procuram, também, comparar os resultados, com aqueles encontrados na literatura.

\subsection{Riser Vertical - Análise estática}

Neste exemplo, analisa-se o riser vertical descrito na Figura 39 submetido às forças de flutuação, ao peso próprio e aos carregamentos estáticos da corrente. Os carregamentos hidrostáticos seguem a equação (91). Os dados do exemplo encontram-se na Tabela 16. Aplicam-se forças de corrente com velocidades de $1 \mathrm{~m} / \mathrm{s}$ e $2 \mathrm{~m} / \mathrm{s}$. Procura-se com este exemplo validar as cargas hidrostáticas devidas à corrente.

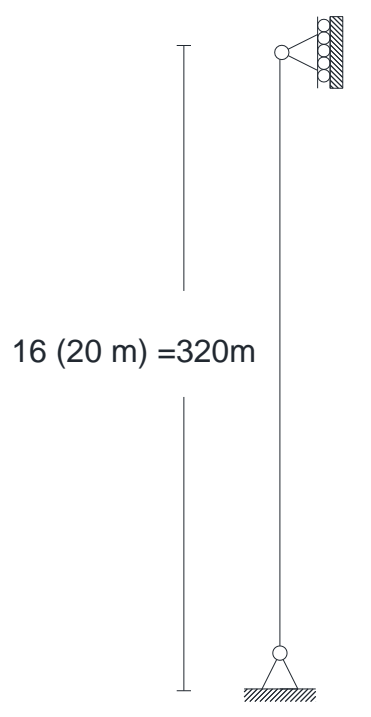

Figura 39. Riser vertical submetido a carregamentos hidrostáticos. 
A Figura 40 descreve as posições de equilíbrio estático para as duas velocidades da corrente descritas no parágrafo anterior. O exemplo discretiza-se com 8 elementos finitos quadráticos. Os resultados encontrados neste trabalho são similares aos disponibilizados por Yazdchi e Crisfield (2002a).

Tabela 16. Dados do Riser vertical.

\begin{tabular}{|l|c|}
\hline Módulo de elasticidade $E$ & $2.0 e 11 \mathrm{~N} / \mathrm{m}^{2}$ \\
\hline Coeficiente de Poisson $v$ & 0.25 \\
\hline Peso do riser por unidade de volume $\gamma_{r}$ & $1.2 e 4 \mathrm{~N} / \mathrm{m}^{3}$ \\
\hline Peso da água por unidade de volume $\gamma_{w}$ & $1.025 e 4 \mathrm{~N} / \mathrm{m}^{3}$ \\
\hline Diâmetro interno do riser $D_{i}$ & $0.25 \mathrm{~m}$ \\
\hline Diâmetro externo do riser $D_{e}$ & $0.21 \mathrm{~m}$ \\
\hline Tração no topo & $510 \mathrm{KN}$ \\
\hline Cd transversal & 1.0 \\
\hline Cd tangencial & 0.01 \\
\hline
\end{tabular}

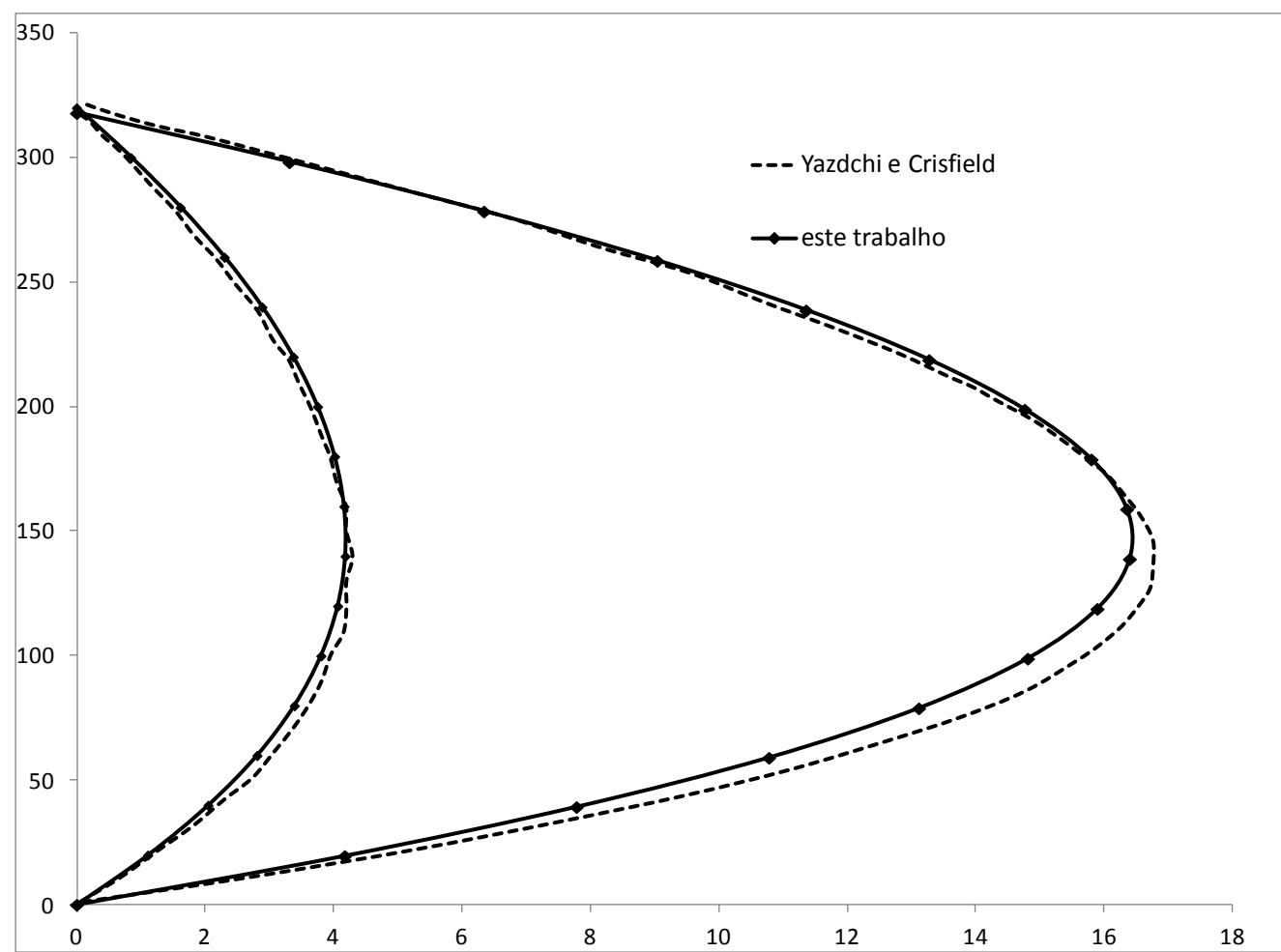

Figura 40. Riser vertical com velocidades de corrente de $1 \mathrm{~m} / \mathrm{s}$ e $2 \mathrm{~m} / \mathrm{s}$ (Yazdchi, M e Crisfield, M. A., 2002a)

Para obter a resposta estática mostrada na Figura 40 utilizou-se a metodologia da rigidez decrescente. Os dados utilizados para a aplicação deste procedimento são mostrados na Tabela 17. 
Tabela 17. Dados dos parâmetros utilizados penalidade do riser vertical

\begin{tabular}{|l|l|}
\hline Penalidade E inicial & 1000 \\
\hline Passo de redução da penalidade & 0.5 \\
\hline Tolerância no método de Newton-Raphson & $1.0 \times 10-6$ \\
\hline Penalidade mínima (tolerância do método) & 0.01 \\
\hline
\end{tabular}

\subsection{Riser Inclinado - Análise estática}

Mostra-se na Figura 41 a configuração inicial de um riser inclinado, o exemplo foi extraído do artigo de Chatjigeoirgiou (2008). O riser possui um carregamento vertical no topo, tem uma articulação na base e encontra-se restrito na direção horizontal no topo. O exemplo é importante devido à baixa rigidez à flexão do riser, resultado do seu grande comprimento.

Tabela 18. Dados do riser inclinado

\begin{tabular}{|l|c|}
\hline Módulo de elasticidade $E$ & $2.0 e 11 \mathrm{~N} / \mathrm{m}^{2}$ \\
\hline Módulo de Poisson $v$ & 0.25 \\
\hline Peso do riser por unidade de volume $\gamma_{r}$ & $1.2 e 4 \mathrm{~N} / \mathrm{m}^{3}$ \\
\hline Peso da água por unidade de volume $\gamma_{w}$ & $1.025 e 4 \mathrm{~N} / \mathrm{m}^{3}$ \\
\hline Diâmetro interno do riser $D_{i}$ & $0.25 \mathrm{~m}$ \\
\hline Diâmetro externo do riser $D_{e}$ & $0.21 \mathrm{~m}$ \\
\hline Tração no topo & $510 \mathrm{KN}$ \\
\hline Cd transversal & 1.0 \\
\hline Cd tangencial & 0.01 \\
\hline
\end{tabular}

Para encontrar esta resposta utilizou-se a estratégia da rigidez decrescente, uma vez que esta se mostrou a mais eficiente, conforme descrito no capitulo 4. Os parâmetros utilizados mostram-se na Tabela 19.

Tabela 19. Dados dos parâmetros utilizados penalidade do riser inclinado

\begin{tabular}{|l|l|}
\hline Penalidade E inicial & 1000 \\
\hline Passo de redução da penalidade & 0.5 \\
\hline Tolerância no método de Newton-Raphson & $1.0 \times 10-6$ \\
\hline Penalidade mínima (tolerância do método) & 0.01 \\
\hline
\end{tabular}


Na Figura 42 mostra-se a posição de equilíbrio do riser inclinado, os resultados mostram-se muito próximos aos encontrados por Chatjigeorgiou (2008).

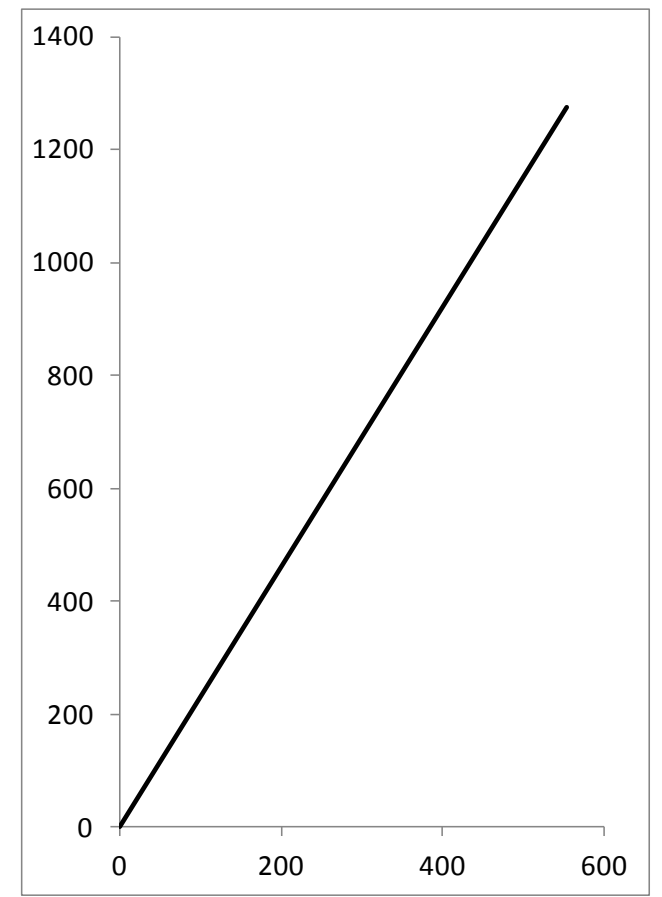

Figura 41. Configuração inicial do riser inclinado.

\subsection{Exemplo API - Análises estática e dinâmica}

O instituto americano do petróleo (API) na procura de padronizar as análises das estruturas offshore definiu um conjunto de risers, sobre os quais, buscou-se obter um comportamento que pudesse servir como base de comparação de análises com carregamentos dinâmicos e estáticos. Os resultados foram publicados no boletim da API (1977). Dentre os exemplos dessa publicação, encontra-se o caso 500-20-1D, o qual também é modelado por Patel e Sarohia (1984). Os principais dados desta estrutura são mostrados na Tabela 20. 


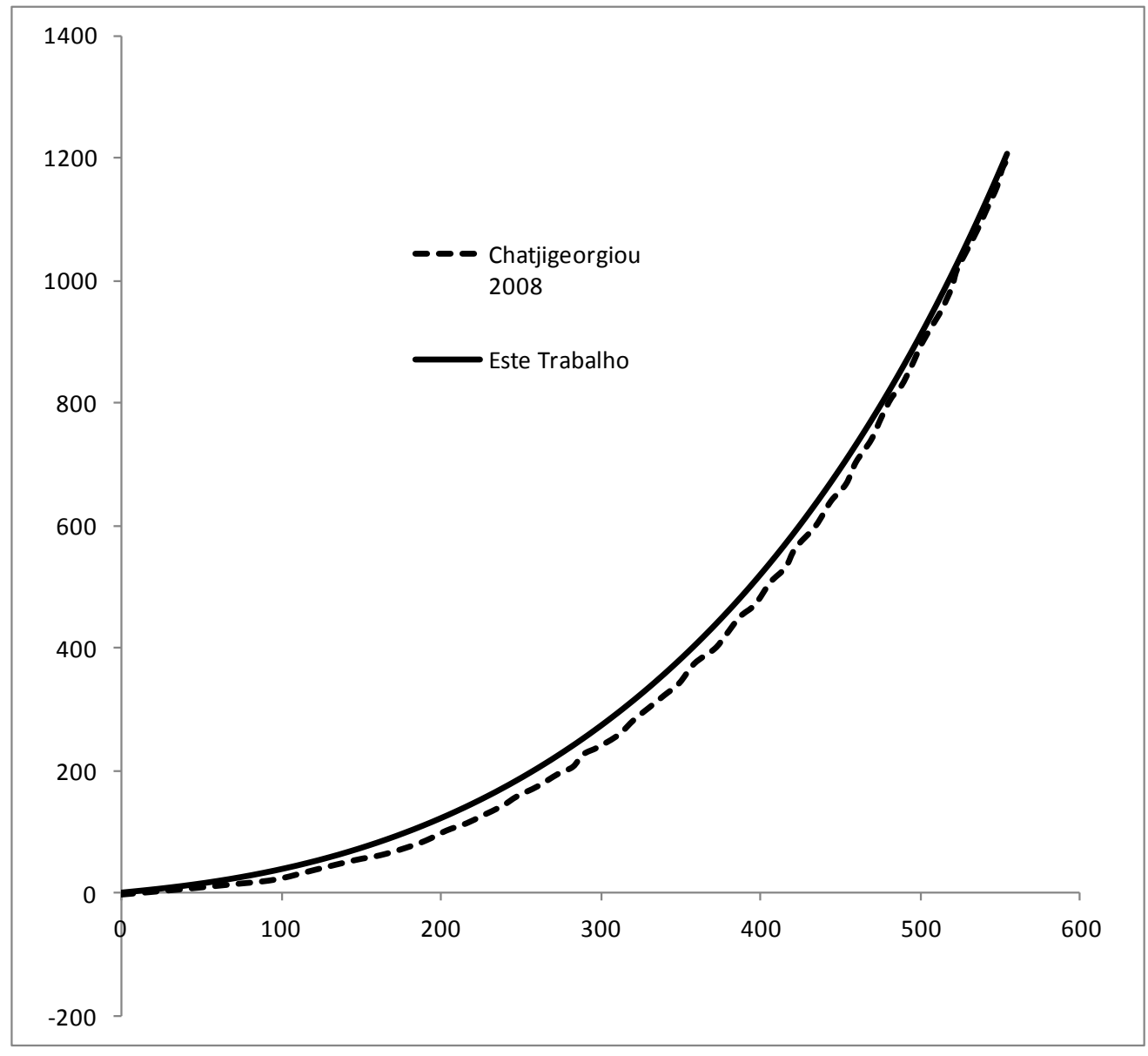

Figura 42. Equilíbrio estático de um riser inclinado

Tomou-se como posição indeformada o riser mostrado na Figura 43, ou seja, a configuração inicial é a estrutura reta. A modelagem dividiu-se em duas fases. $\mathrm{Na}$ primeira, deixou-se estabilizar a estrutura na sua posição de equilíbrio aplicando sobre ela, unicamente, cargas estáticas. Depois disso, aplicaram-se os carregamentos dinâmicos. As cargas hidrodinâmicas foram calculadas segundo a equação de Morison descrita na seção 3.4.1. A velocidade da corrente, presente na equação de Morison, foi calculada segundo a teoria linear de Airy para ondas, mostrada na seção 3.1. As análises mostradas neste exemplo executaram-se durante o tempo de um período do riser. 


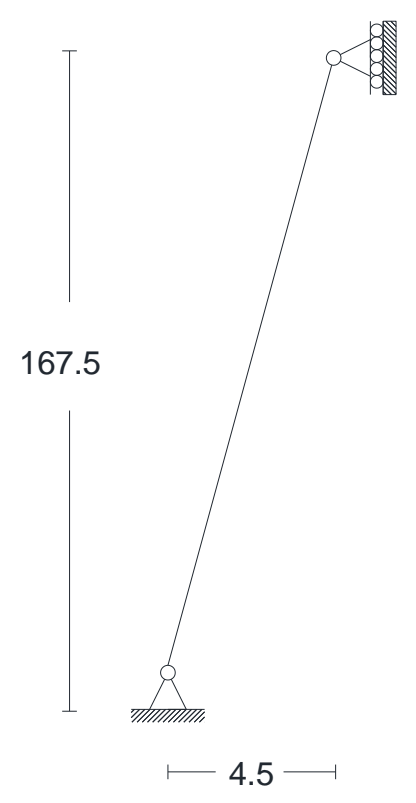

Figura 43. Configuração indeformada do exemplo API 500-20-1D.

Na Figura 44 são mostradas as configurações deformadas de três trabalhos diferentes. As linhas tracejadas contem os resultados divulgados no Boletim da $\mathrm{API}^{6}$. As linhas pontilhadas descrevem os resultados encontrados por Patel e Sarohia (1984). Finalmente, mostram-se os resultados encontrados neste trabalho, os quais são descritos com linhas continuas. Neste gráfico mostram-se três tipos de análises: a solução estática, a envoltória mínima das soluções dinâmicas e a envoltória máxima das soluções dinâmicas. As envoltórias mínimas das soluções dinâmicas são identificadas com um marcador triangular, as envoltórias máximas com um marcador circular e as soluções estáticas não possuem marcador. 


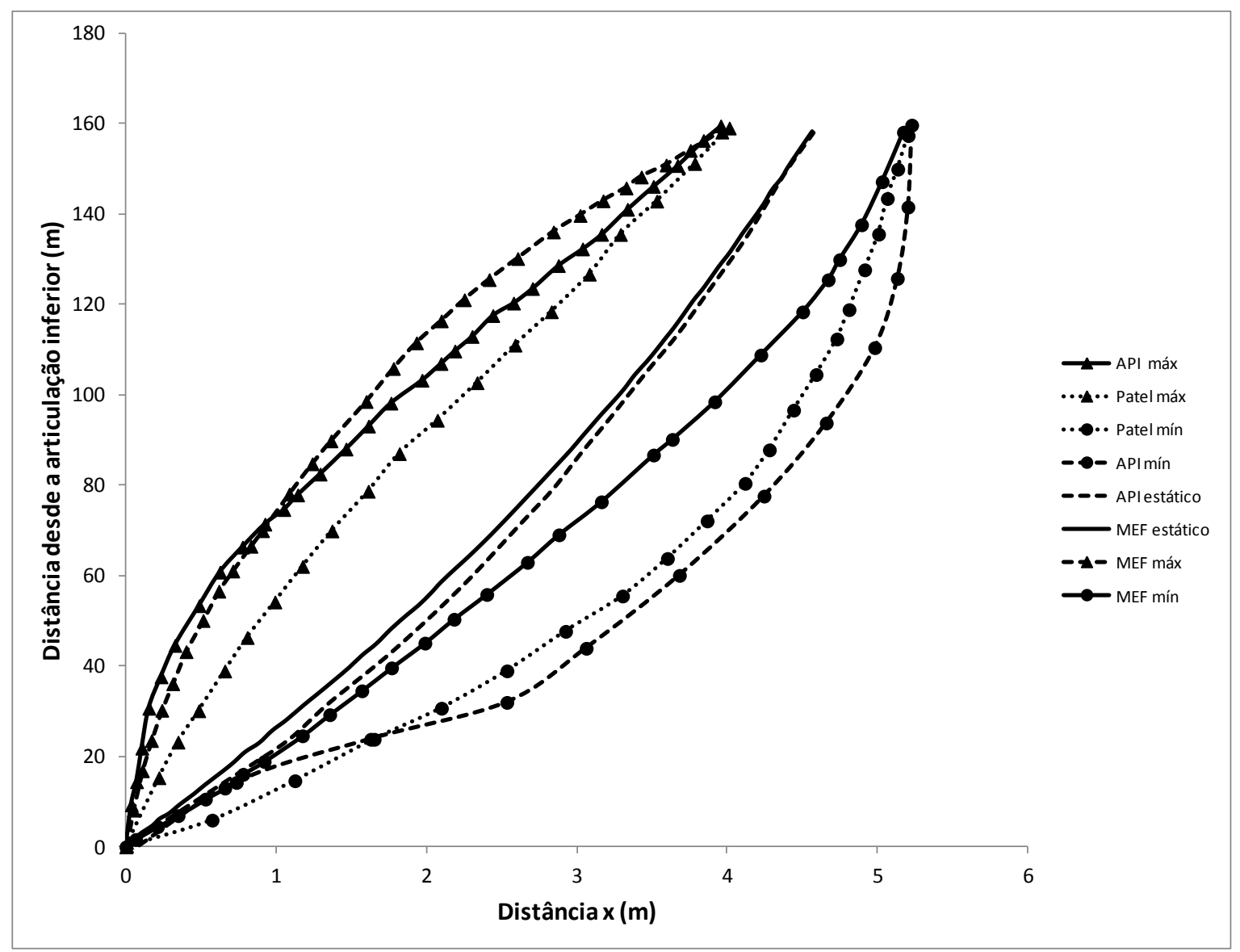

Figura 44. Deformada do exemplo 500-20-1D da API.

Observa-se, na Figura 44, bastante proximidade da solução estática encontrada neste trabalho (MEF em função das posições) com a solução mostrada no API. A envoltória máxima mantém-se próxima às soluções mostradas pelo API. Porém a envoltória mínima fica distante das duas soluções mostradas pelos outros autores. Justifica-se esta última diferença à utilização de formulações diferentes e à liberdade na escolha de alguns parâmetros não exatamente definidos nas referências que, devido à grande não linearidade do problema, muda totalmente os resultados. Alguns parâmetros não especificados são o sentido do movimento da embarcação (direita ou esquerda), o sentido da velocidade da corrente na superfície, entre outros. 
Tabela 20. Dados do exemplo do API 500-20-1D.

\begin{tabular}{|l|c|}
\hline $\begin{array}{l}\text { Distância desde o nível médio da superfície do mar até a } \\
\text { articulação superior do riser }\end{array}$ & $15.24 \mathrm{~m}$. \\
\hline $\begin{array}{l}\text { Distância desde o nível do fundo do oceano até a } \\
\text { articulação inferior do riser }\end{array}$ & $9.144 \mathrm{~m}$. \\
\hline Profundidade da água & $152.4 \mathrm{~m}$. \\
\hline Diâmetro externo do riser & $0.4064 \mathrm{~m}$. \\
\hline Espessura da parede do riser & $0.01587 \mathrm{~m}$. \\
\hline Diâmetro da linha redutora de pressão & $0.1016 \mathrm{~m}$. \\
\hline Espessura da parede da linha redutora de pressão & $0.01651 \mathrm{~m}$. \\
\hline Diâmetro do material de flutuação & $0.6096 \mathrm{~m}$. \\
\hline Módulo de elasticidade do riser & $2.1 * 10^{11} \mathrm{~N} / \mathrm{m}^{2}$ \\
\hline Densidade da água do oceano & $1025 \mathrm{Kg} / \mathrm{m}^{3}$ \\
\hline Densidade do lodo transportado & $1438 \mathrm{Kg} / \mathrm{m}^{3}$ \\
\hline Coeficiente de arrasto & 0.7 \\
\hline Coeficiente de massa adicional & 1.5 \\
\hline Diâmetro efetivo para o cálculo das cargas hidrodinâmicas & $0.6604 \mathrm{~m}$. \\
\hline Densidade do material de flutuação & $160.2 \mathrm{Kg} / \mathrm{m}^{3}$ \\
\hline Velocidade da corrente na superfície & $0.2574 \mathrm{~m} / \mathrm{s}$ \\
\hline Offset estático na superfície & $4.572 \mathrm{~m}$. \\
\hline Peso do riser por unidade de comprimento no ar & $2282 \mathrm{~N} / \mathrm{m}$ \\
\hline Altura da onda & $6.096 \mathrm{~m}$. \\
\hline Período da onda & $9 \mathrm{~s}$. \\
\hline Amplitude do movimento da embarcação & $0.6096 \mathrm{~m}$. \\
\hline Ângulo de fase do movimento da embarcação & $15^{\circ}$ \\
\hline
\end{tabular}

Na Figura 45 mostram-se as tensões de flexão da solução, calculadas no lado convexo do tubo, do exemplo do 500-20-1D do API. A notação utilizada nesta figura é equivalente à utilizada na figura anterior, onde se encontram as deformadas, tanto para as linhas como para os marcadores. As envoltórias das tensões de flexão das análises dinâmicas (máximas e mínimas) mostradas na figura, são a soma das envoltórias encontradas nas análises dinâmicas mais o valor das tensões de flexão da análise estática. Os resultados são mostrados desta forma (envoltórias estática mais a dinâmica) para facilitar a comparação com as figuras do artigo de Patel e Sarohia (1984). 


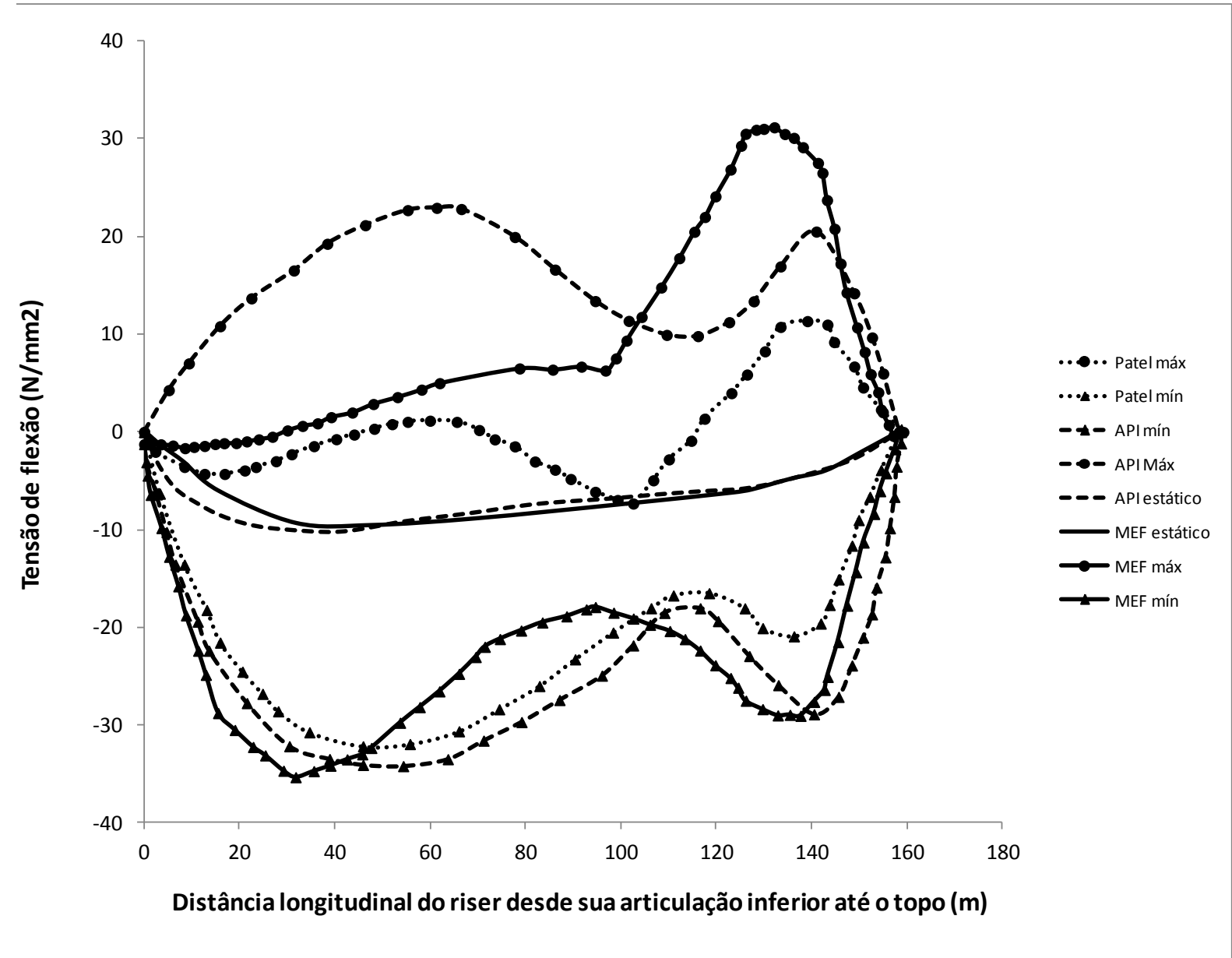

Figura 45. Tensão de flexão ao longo do comprimento do riser.

Observa-se que as envoltórias máximas das tensões de flexão das três análises são bastante distantes, ver Figura 45, o qual também se justifica pela diferença entre as formulações utilizadas e a flexibilidade na escolha de alguns parâmetros. Porém os resultados estáticos são semelhantes, o mesmo ocorre com as envoltórias mínimas. Nos resultados obtidos o movimento da embarcação sempre segue o sentido esquerda direita e o perfil de velocidades inicial é mostrado na Figura 46. 


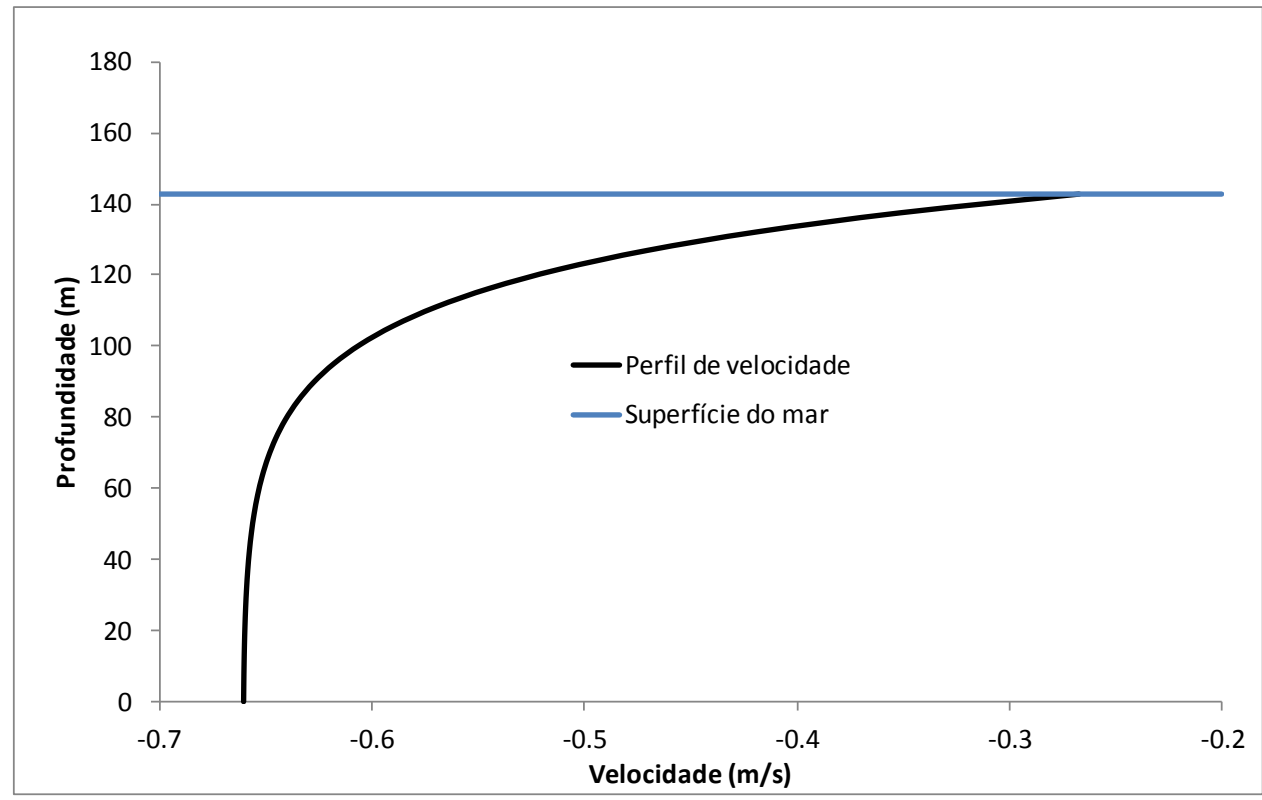

Figura 46. Perfil de velocidade inicial utilizado para o exemplo 500-20-1D do API.

Como aporte para este trabalho, aplica-se no exemplo 500-20-1D do API um movimento vertical no topo. O movimento começa no sentido norte-sul, o perfil de velocidades utilizado é mostrado na Figura 46. A deformada, aplicando este tipo de deslocamentos, é mostrada na Figura 47. A tensão de flexão encontra-se na Figura 48. Os resultados mostram que para esta configuração de risers a aplicação de deslocamentos verticais produz um incremento significativo na tensão de flexão, se comparado com a obtida aplicando deslocamentos na direção horizontal. 


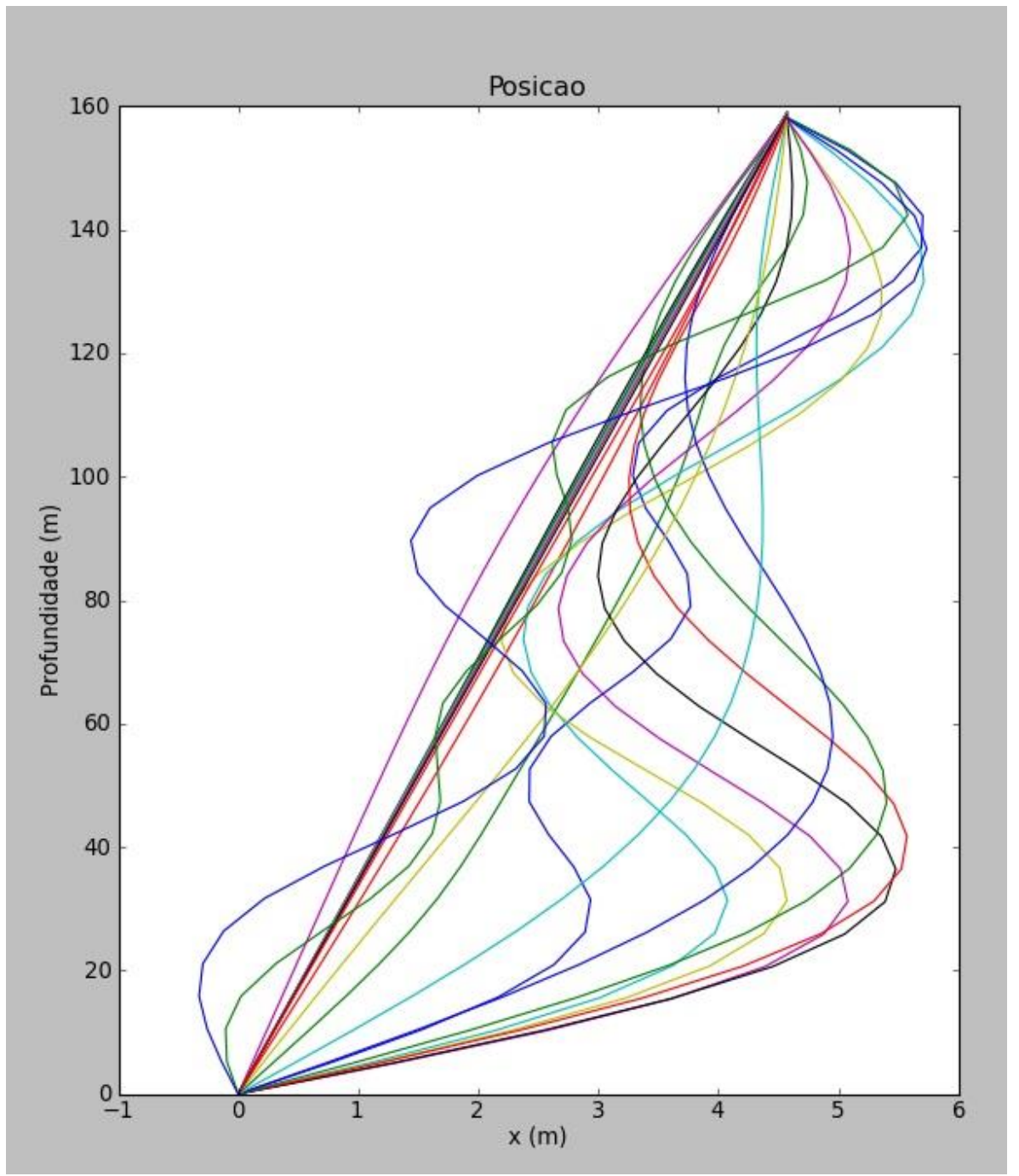

Figura 47. Deformada do exemplo 500-20-1D do API, aplicando deslocamentos verticais no seu topo.

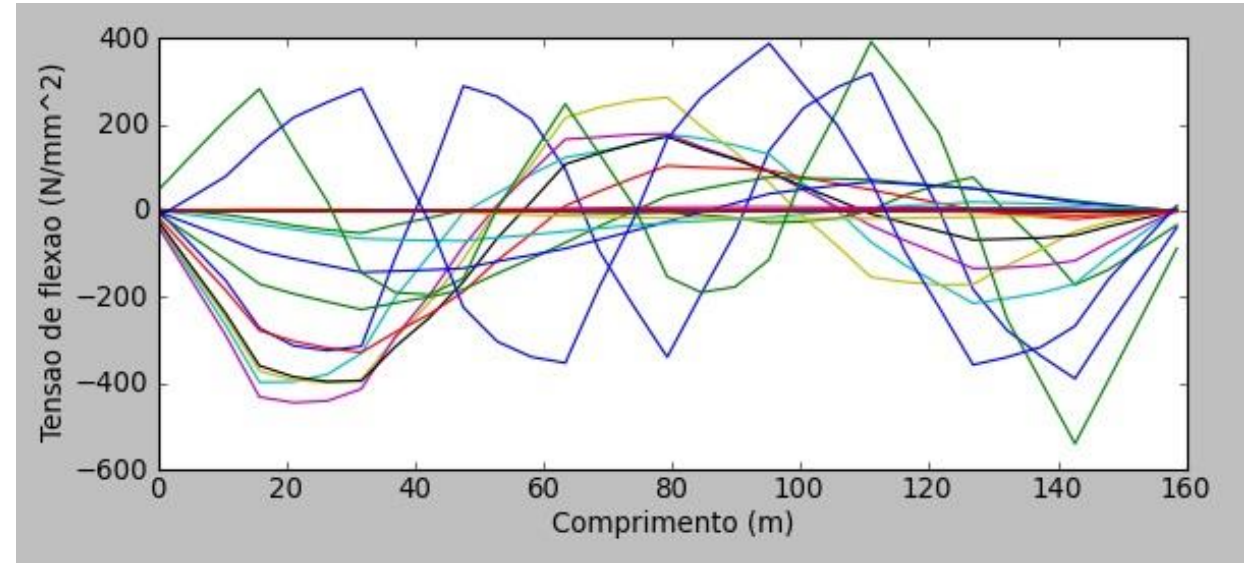

Figura 48. Tensão de flexão do exemplo 500-20-1D do API, aplicando deslocamentos verticais no seu topo. 


\subsection{Instalação de um riser, grandes deslocamentos impostos.}

Neste exemplo, busca-se simular a etapa simplificada de instalação de um riser. A estrutura inicialmente encontra-se na posição horizontal sobre a superfície do mar. Ela possui uma extremidade articulada e outra com um apoio móvel. A extremidade articulada simula a vinculação com a embarcação ou com a plataforma. A extremidade do apoio móvel simula uma bóia, a qual guia o riser para o fundo do mar por meio de deslocamentos controlados. O comprimento do riser é de $168 \mathrm{~m}$ e encontra-se posicionado de forma horizontal na cota $152.4 \mathrm{~m}$. O intervalo de tempo é de 0.01 segundos com 15400 passos de tempo. Em cada passo de tempo é imposto na estrutura um deslocamento de $-1 \mathrm{~cm}$. O fundo do mar encontra-se na cota zero. E a rigidez do solo é de $1 * 10^{4} \mathrm{~N} / \mathrm{m}^{2}$ e a cota do mesmo é $-0.01 \mathrm{~m}$.

Tabela 21. Dados riser.

\begin{tabular}{|l|c|}
\hline Profundidade da água & $152.4 \mathrm{~m}$. \\
\hline Diâmetro externo do riser & $0.4064 \mathrm{~m}$. \\
\hline Espessura da parede do riser & $0.01587 \mathrm{~m}$. \\
\hline Módulo de elasticidade do riser & $2.1 * 10^{11} \mathrm{~N} / \mathrm{m}^{2}$ \\
\hline Densidade da água do oceano & $1025 \mathrm{Kg} / \mathrm{m}^{3}$ \\
\hline Cota do solo & $-0.01 \mathrm{~m}$. \\
\hline Rigidez do solo & $1000.0 \mathrm{~N} / \mathrm{m} / \mathrm{m}$ \\
\hline Coeficiente de arrasto & 0.7 \\
\hline Coeficiente de massa adicional & 1.5 \\
\hline Peso do riser por unidade de comprimento no ar & $-1440.0 \mathrm{~N} / \mathrm{m}$ \\
\hline Força horizontal na extremidade esquerda & $-150.0 \mathrm{KN}$ \\
\hline
\end{tabular}

A Figura 49 mostra a estabilidade do algoritmo implementado ao conseguir deslocar a estrutura $153 \mathrm{~m}$ na vertical. Na Figura 50 são encontrados os esforços desenvolvidos no riser durante a instalação. Na Figura 49 nota-se uma linha, em cor preto e posicionada à direita, que vária de forma mais acelerada, se comparada com as outras configurações mostradas, isto se deve ao inicio do contato com o solo. $\mathrm{Na}$ 
Figura 50, sobre o diagrama de momento fletor também se nota esta variação, a linha preta indica o maior valor de momento fletor (em módulo).

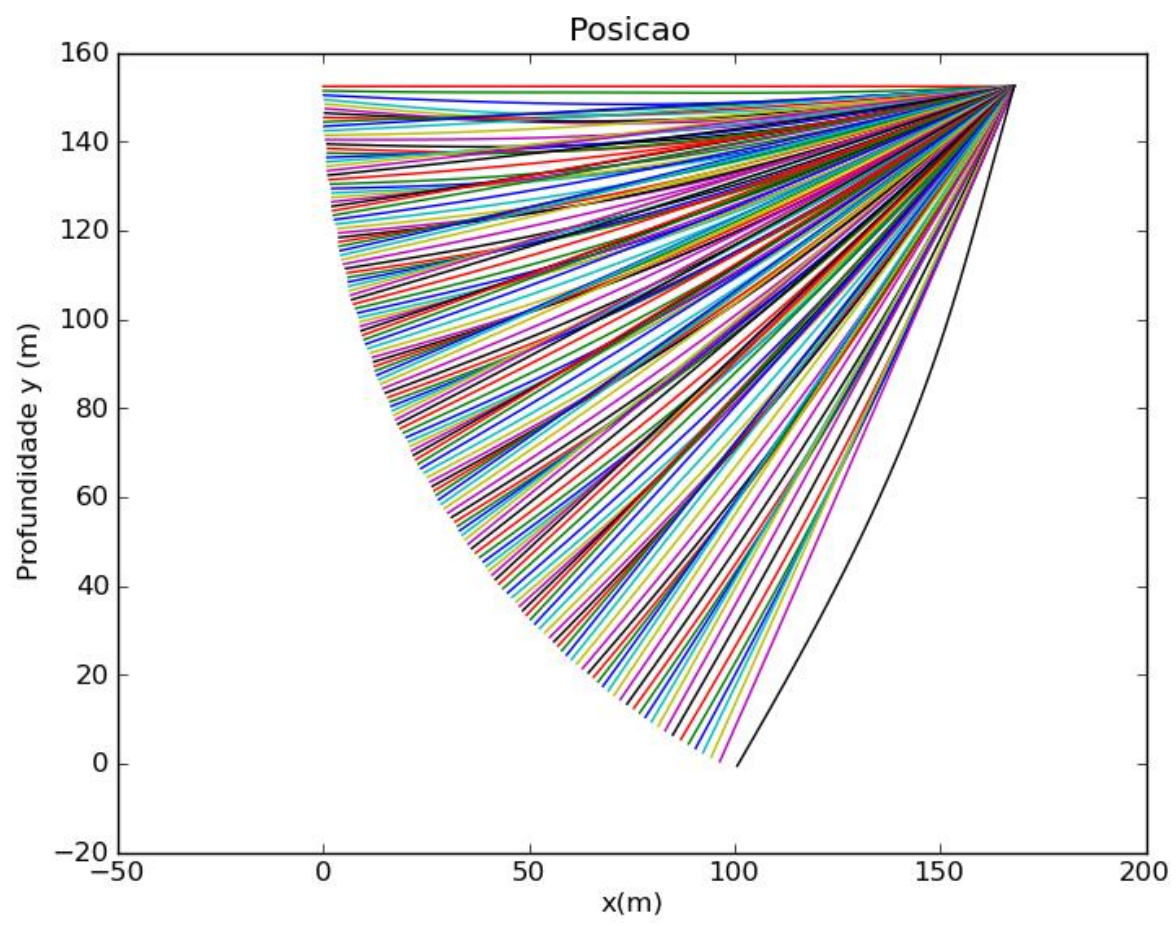

Figura 49. Exemplo de instalação de um riser tendo contato com o solo
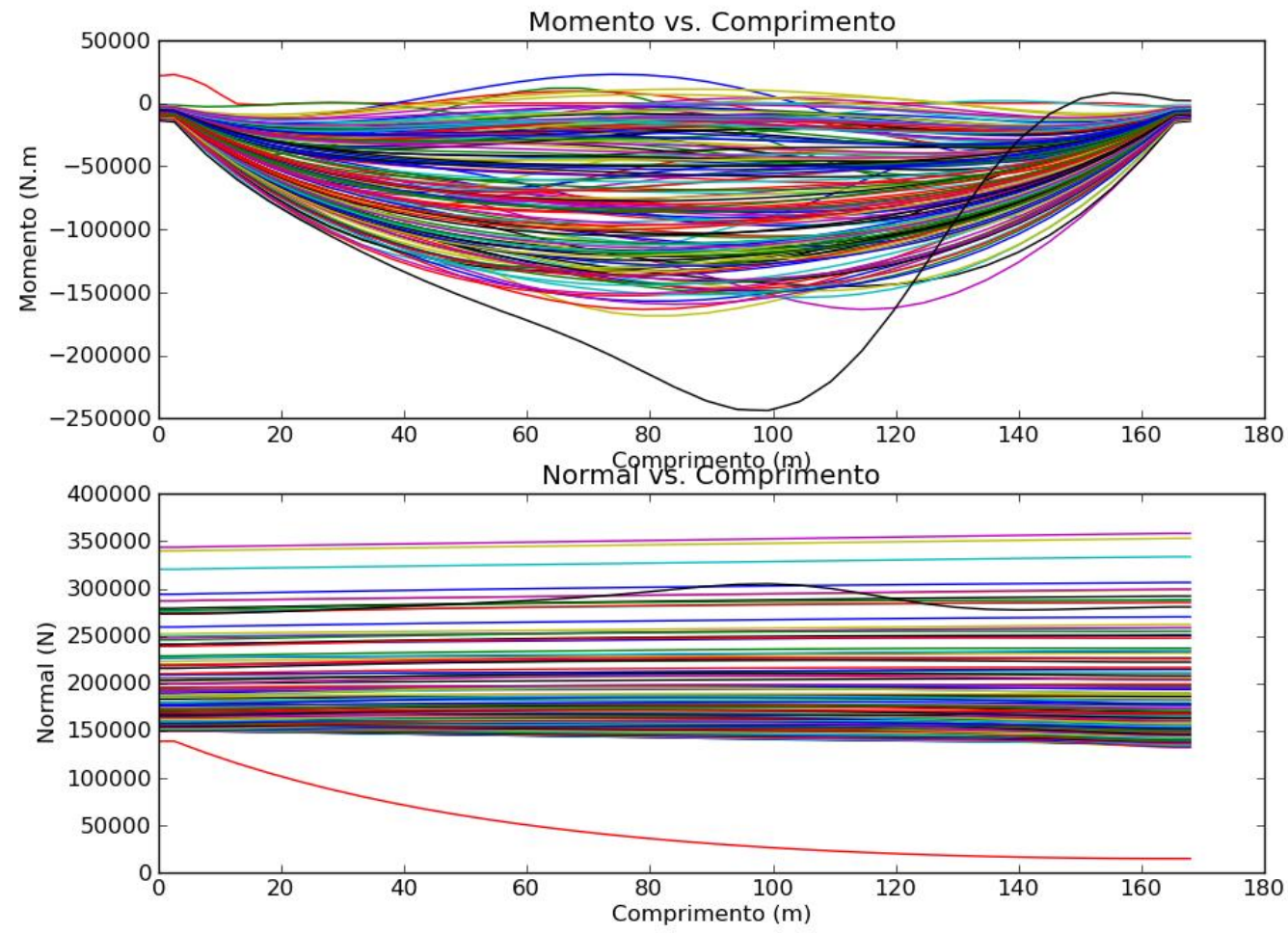

Figura 50. Esforços durante a instalação do riser. 
Os resultados mostrados anteriormente, permitem concluir que o código computacional implementado é robusto e estável para a aplicação de grandes deslocamentos, como os presentes durante a instalação dos risers. Assim como também se nota a variação que existe, tanto em deslocamentos como em esforços, quando considerado o contato com o solo.

\subsection{Instalação de um riser em contato com o solo.}

Modela-se o mesmo exemplo anterior, porém a cota do solo é modificada para o valor de $146.4 \mathrm{~m}$. Isto permite verificar a estabilidade do código, resultado desta pesquisa, para modelar problemas de impacto de risers, como também risers em águas rasas.

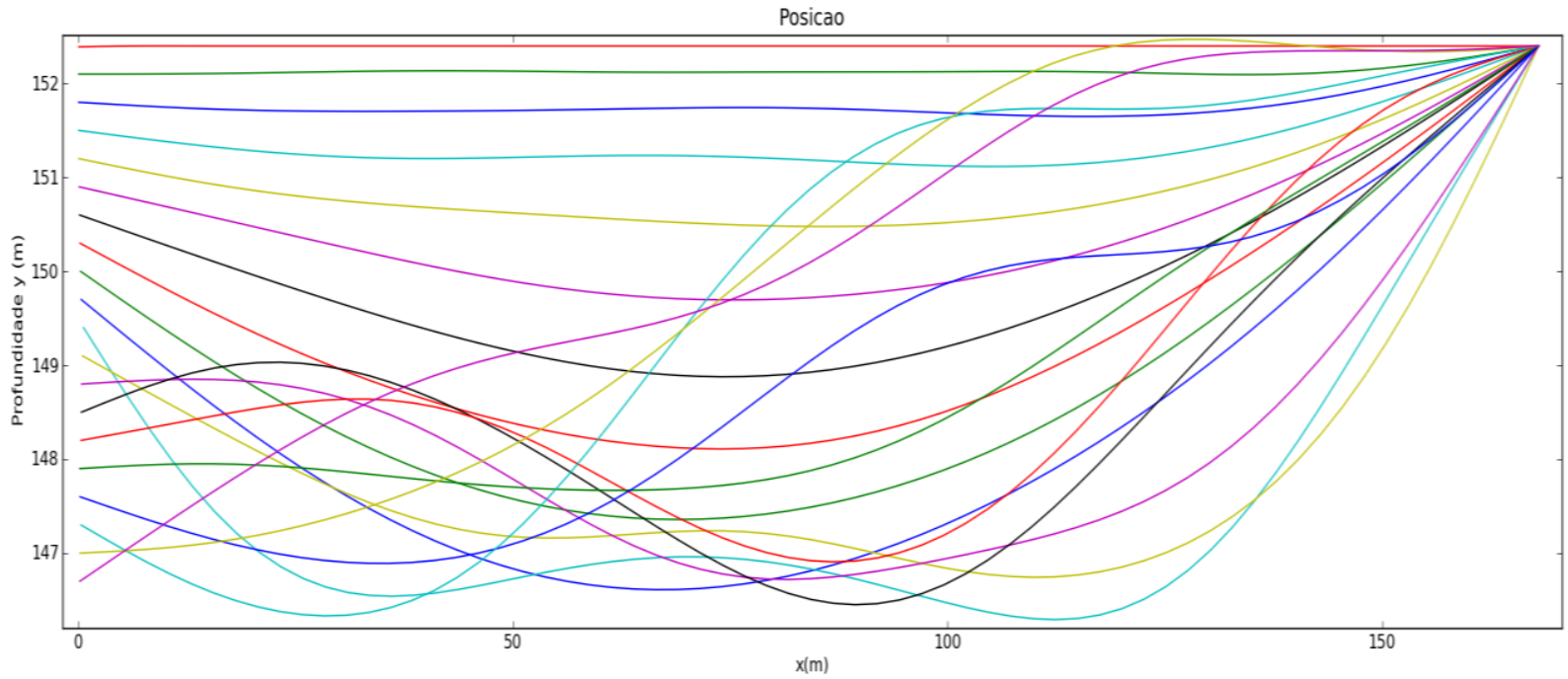

Figura 51. Deformadas durante a instalação de um riser.

Assim, na Figura 51 mostram-se as configurações deformadas ao longo do tempo, sendo que a extremidade esquerda é guiada para baixo. 
A Figura 52 contém os esforços desenvolvidos no risers durante o processo de instalação.
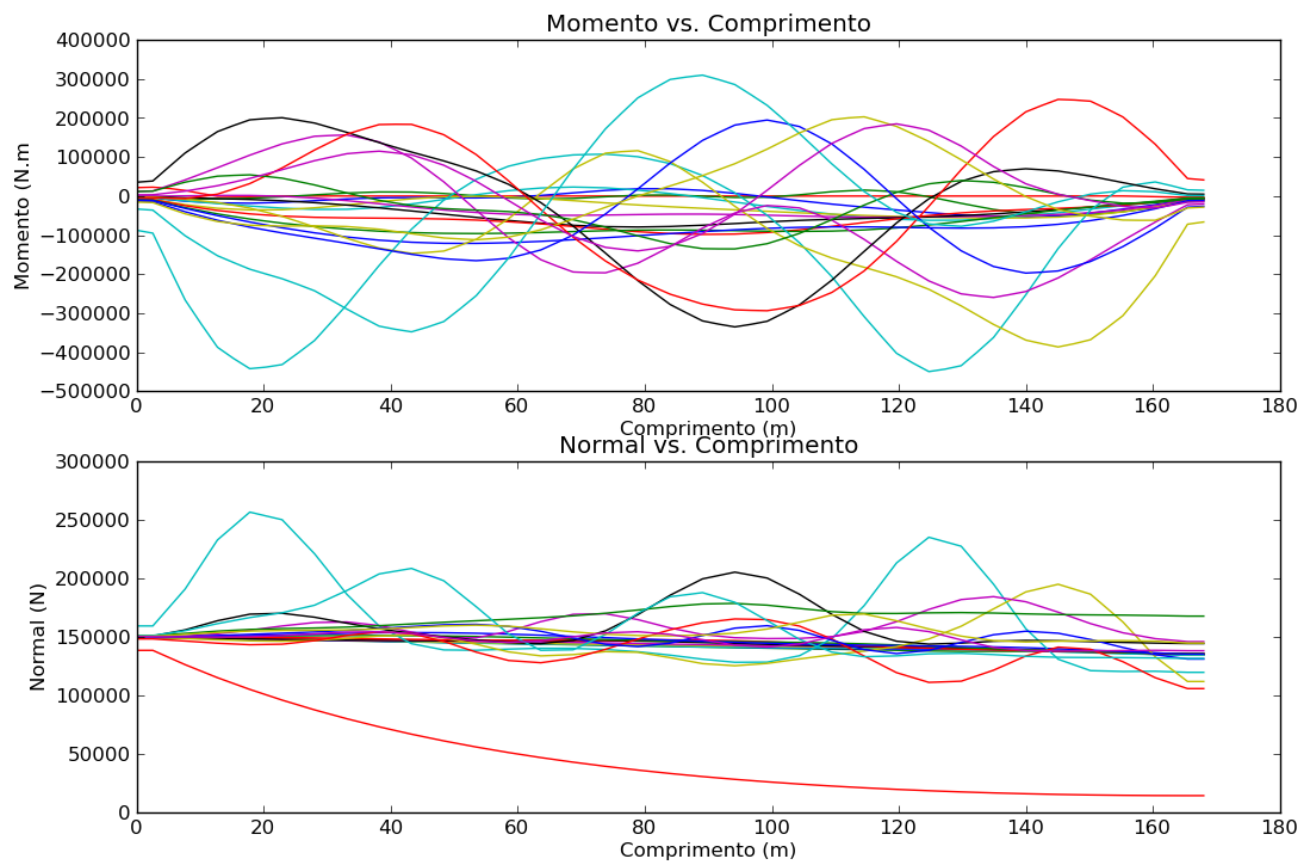

Figura 52. Esforços dentro do riser durante a instalação.

O comportamento mostrado nas figuras anteriores mostra que, quando considerado o solo os esforços sofrem grandes variações. Aprecia-se em especial o incremento no momento fletor. O código computacional mostra-se totalmente estável ao fornecer o comportamento da estrutura sob as condições deste exemplo.

\subsection{Riser com configuração Lazy-Wave}

Analisa-se um riser em configuração Lazy-Wave, no qual, parte da estrutura encontra-se apoiada sobre o solo e em um intervalo intermediário possui flutuadores. Esta configuração mostra-se na Figura 53, a qual se extrai do trabalho de Mourelle (1993). Busca-se com este exemplo simular risers com configurações diferentes à catenária. 


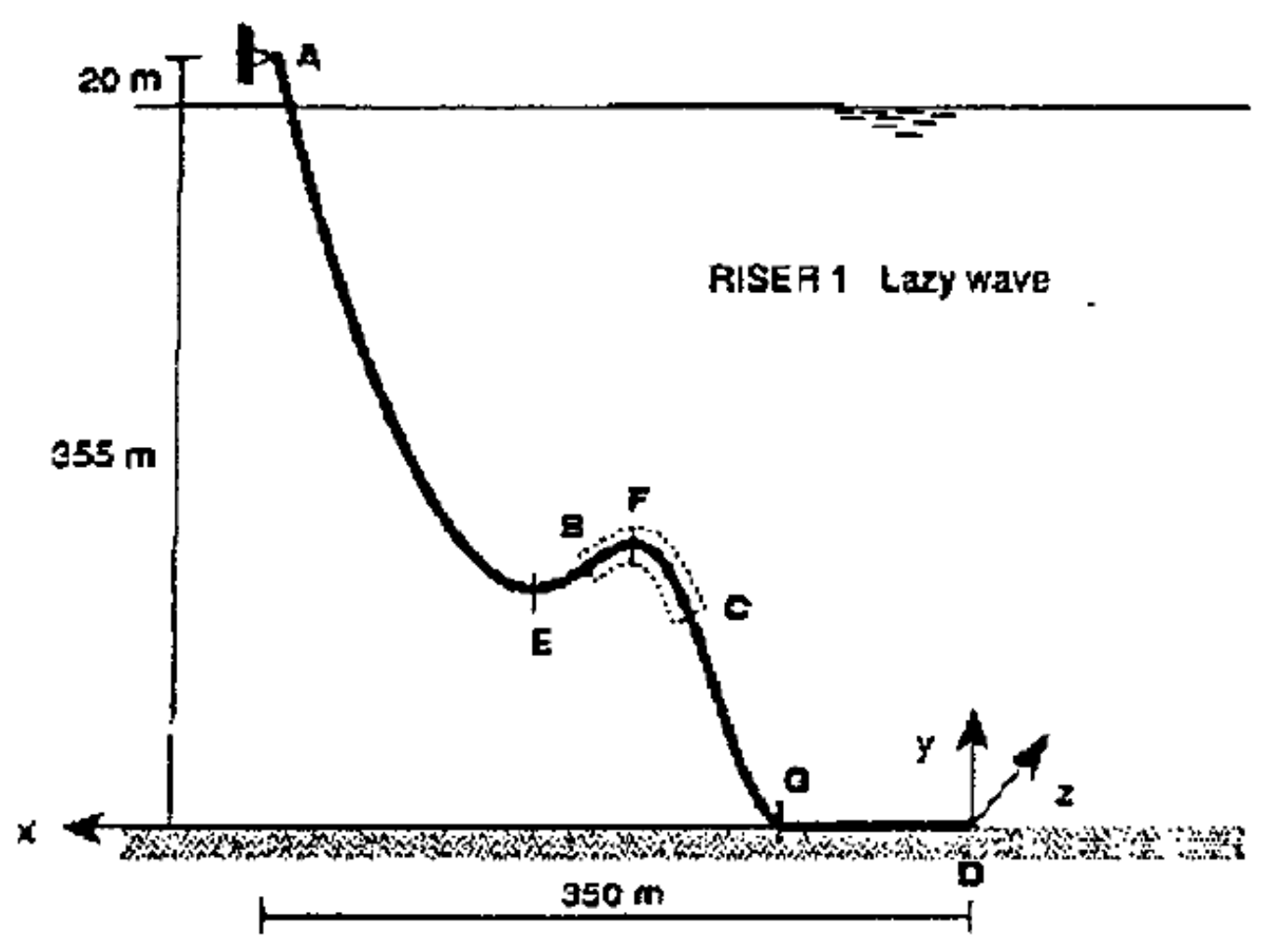

Figura 53. Configuração Lazy Wave. Figura extraída de Mourelle (1993).

Este exemplo é adaptado do trabalho de Mourelle (1993), porém existem diferenças nas propriedades das seções transversais utilizadas. Na sua tese Mourelle (1993) reporta os valores do módulo de rigidez axial, o módulo de rigidez flexional, o módulo de rigidez torcional, assim como também o valor do diâmetro externo. Verificou-se que não existe uma seção tubular homogênea equivalente que consiga satisfazer os valores utilizados por Mourelle (1993), pelo qual se adotou a seção descrita na Tabela 22.

Nesta configuração, o riser tem flutuadores instalados em um comprimento intermediário, o qual na Figura 53 limita-se pelos pontos B e C. Estes flutuadores, além de aliviarem o peso da linha que deve ser suportado pelo flutuante, conferem certa restauração diante das solicitações laterais (MOURELLE, 1993). As 
propriedades da seção dos flutuadores são mostradas na Tabela 23. O trecho com flutuadores esquematiza-se na Figura 54.

Tabela 22. Dados do riser em configuração lazy-wave.

\begin{tabular}{|l|c|}
\hline Comprimento $L$ & $589.5 \mathrm{~m}$. \\
\hline Rigidez à flexão $E I$ & $1.63 \times 10^{7} \mathrm{N.m}$ \\
\hline Rigidez axial $E A$ & $1.75 \times 10^{-2} \mathrm{~N}$ \\
\hline Carregamento distribuído $q$ & $-873.09 \mathrm{~N} / \mathrm{m}$ \\
\hline Profundidade da água & $355 \mathrm{~m}$. \\
\hline Diâmetro externo & $0.2154 \mathrm{~m}$. \\
\hline Diâmetro interno & $0.1554 \mathrm{~m}$. \\
\hline Cota do solo & $-0.01 \mathrm{~m}$. \\
\hline Rigidez do solo $k$ & $1.00 \times 10^{4} \mathrm{~N} / \mathrm{m} / \mathrm{m}$ \\
\hline Densidade do riser & $7850 \mathrm{Kg} / \mathrm{m}^{3}$ \\
\hline Coeficiente de arrasto transversal & 1.0 \\
\hline Coeficiente de inercia & 2.0 \\
\hline Coeficiente de arrasto tangencial & 0.01 \\
\hline Passo de tempo $\Delta t$ & 0.005 \\
\hline Número de passos de tempo & 4000 \\
\hline Período $T$ & $12 \mathrm{seg}$ \\
\hline Amplitude na direção heave $A$ & $4 \mathrm{~m}$. \\
\hline
\end{tabular}

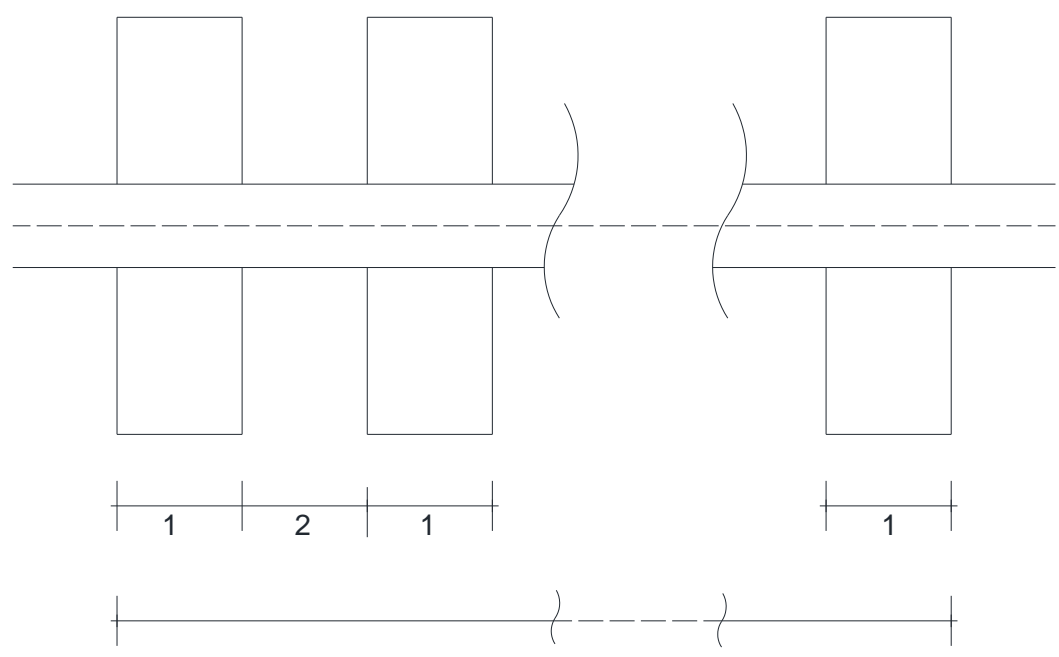

90

Figura 54. Trecho com flutuadores.

O solo é simulado como tendo um comportamento elástico linear, o qual segue o modelo de Winkler descrito na seção 5.2. A rigidez utilizada para as molas, assim como a cota adotada para o solo são mostradas na Tabela 22. Os parâmetros do 
método das penalidades utilizados para auxiliar na aplicação da restrição do solo são mostrados na Tabela 24.

Tabela 23. Propriedades do trecho com flutuadores.

\begin{tabular}{|l|c|}
\hline Rigidez à flexão $E I$ & $5.53 \times 10^{9} \mathrm{~N} . \mathrm{m}^{2}$ \\
\hline Rigidez axial $E A$ & $1.17 \times 10^{11} \mathrm{~N}$ \\
\hline Carregamento distribuído $q$ & $-3453.0 \mathrm{~N} / \mathrm{m}$ \\
\hline Diâmetro externo & $0.855 \mathrm{~m}$. \\
\hline Diâmetro interno & $0.1554 \mathrm{~m}$. \\
\hline
\end{tabular}

Para identificar a importância da posição inicial neste tipo de estruturas, o riser é simulado utilizando duas metodologias diferentes. Na primeira delas realiza-se uma simulação previa para encontrar a configuração estática, a qual se utiliza como a posição inicial para a análise dinâmica. Na segunda, a análise dinâmica inicializase a partir de uma configuração qualquer, no caso é extraida do trabalho de Mourelle (1993), a qual não é a configuração de equilíbrio estático.

Tabela 24. Dados dos parâmetros utilizados penalidade.

\begin{tabular}{|l|l|}
\hline Penalidade inicial & 20 \\
\hline Passo de redução da penalidade & 0.5 \\
\hline Tolerância no método de Newton-Raphson & $1.0 \times 10-6$ \\
\hline Penalidade mínima (tolerância do método) & 0.01 \\
\hline
\end{tabular}

A primeira modelagem divide-se em dois passos. Incialmente realiza-se uma análise estática da estrutura. A configuração inicial mostra-se na Figura 55 representada pela curva em azul. A curva do equilíbrio estático é representada na mesma figura pela curva vermelha. Na segunda parte desta modelagem, realiza-se uma análise dinâmica, sendo que a posição inicial é a configuração de equilíbrio encontrada no último passo da análise anterior.

Na Figura 56 mostram-se os esforços na estrutura quando atingida a posição de equilíbrio estático. Observa-se que o esforço normal apresenta um comportamento oscilatório na região dos flutuadores, isto se deve à variação da 124 
seção transversal nestes elementos. Nesta configuração os esforços, tanto normal como de momento fletor, concentram-se antes da região dos flutuadores. Nota-se na Figura 59 que os esforços dinâmicos oscilam ao redor daqueles obtidos na posição de equilíbrio estático.

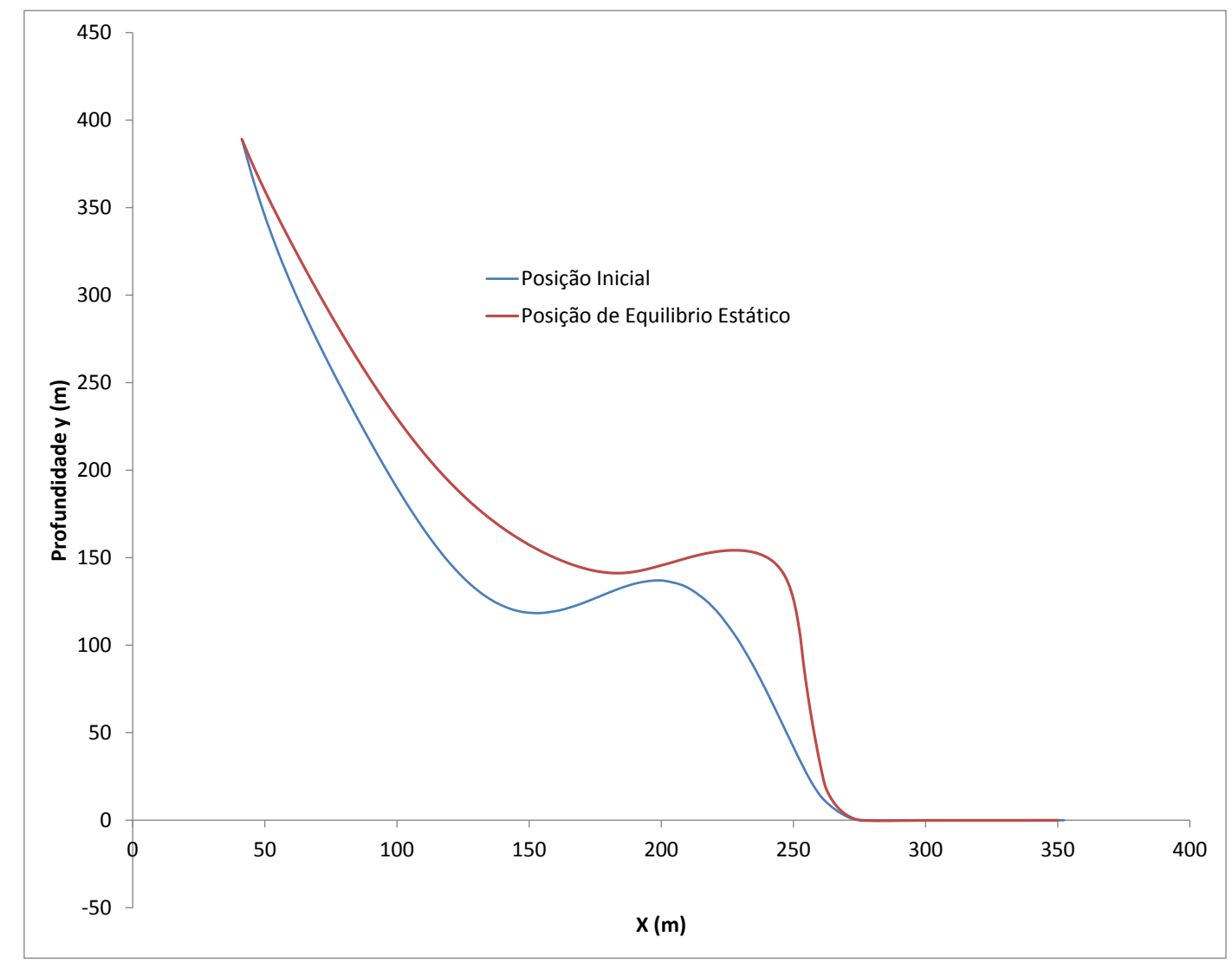

Figura 55. Configuração inicial e configuração de equilíbrio estático do riser em Lasy-wave.

Tal como para os esforços, as configurações de equilíbrio dinâmico também oscilam ao redor da posição estática, ver Figura 57. Na Figura 58 mostra-se o detalhe da região em contato com o solo (zoom). 

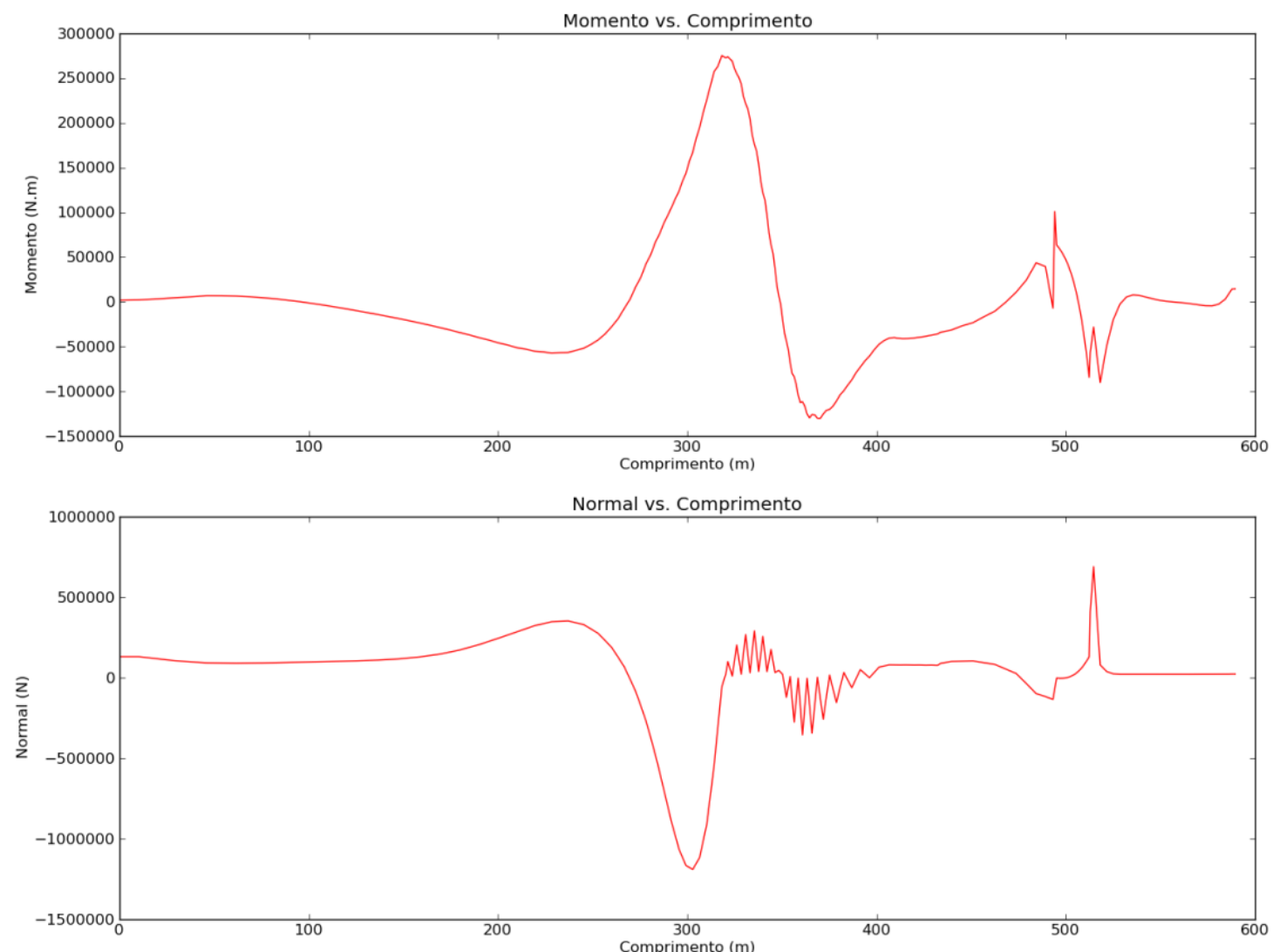

Figura 56. Esforços na posição de equilíbrio estático.

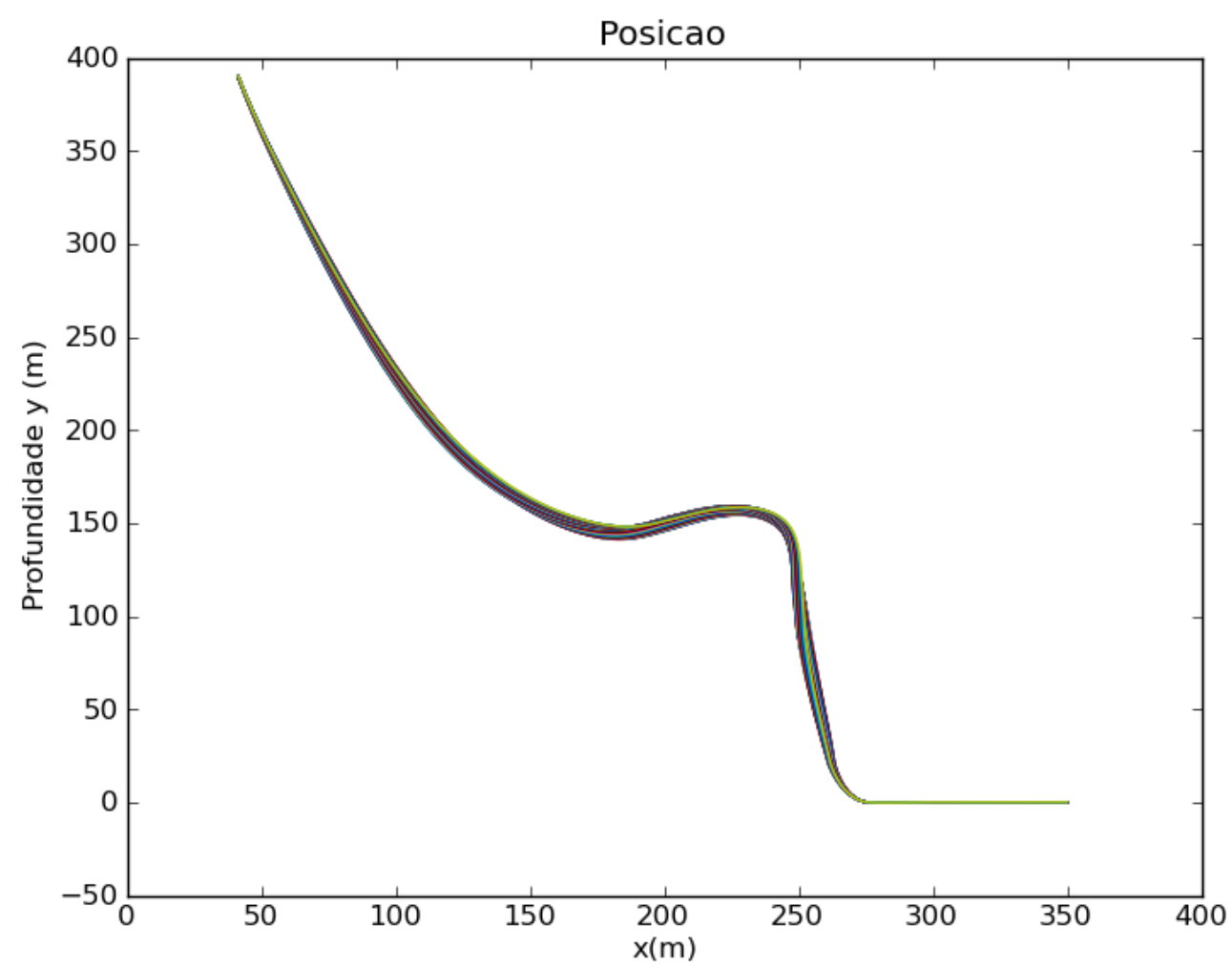

Figura 57. Deformadas no passo do tempo, com a posição estática como indeformada. 


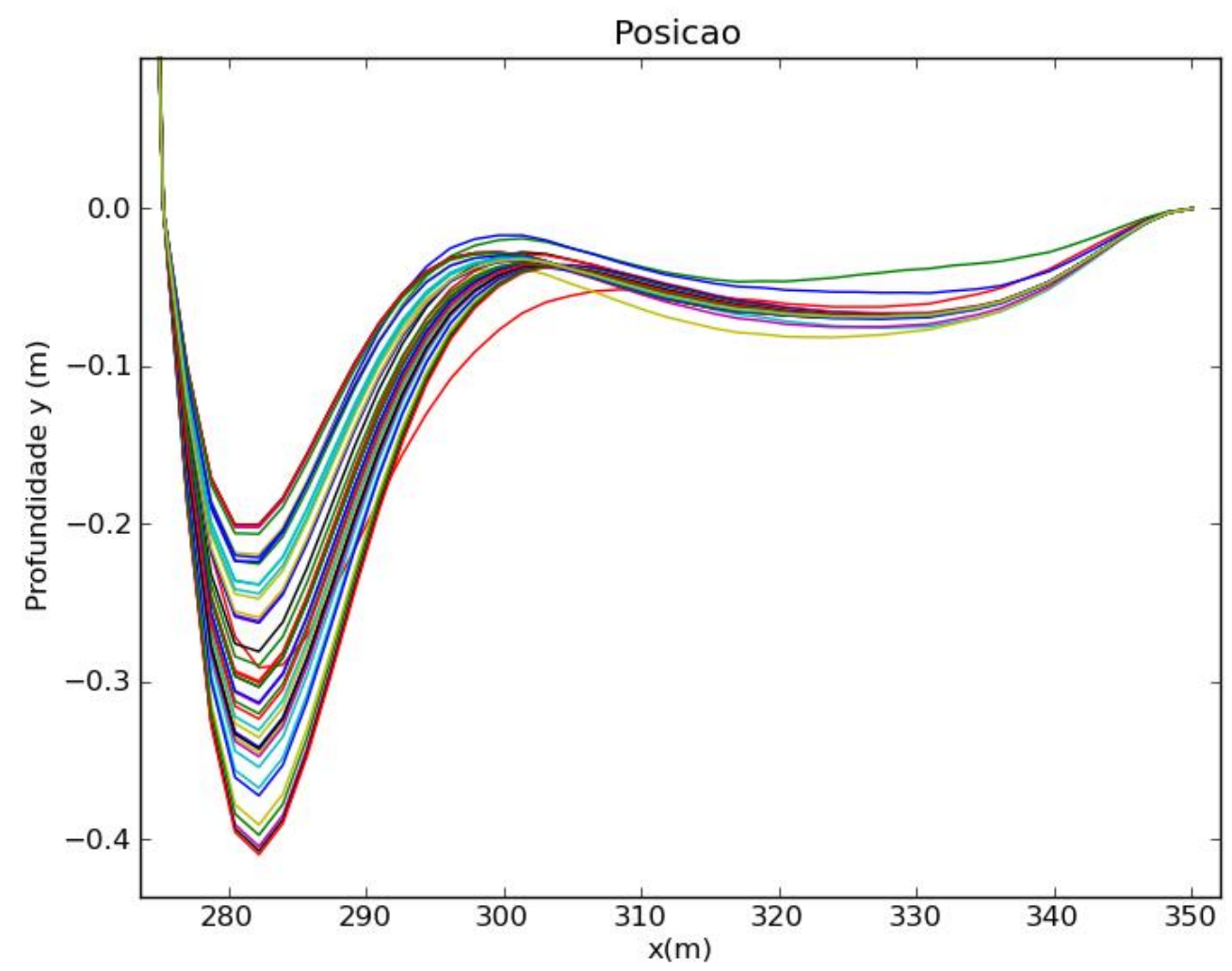

Figura 58. Zoom na região TDZ das deformadas no passo do tempo, com a posição estática como indeformada.

Uma segunda forma é utilizada para realizar a análise dinâmica. Esta consiste em utilizar diretamente a curva azul da Figura 55 como posição inicial, ou seja, sem calcular a configuração estática de equilíbrio. Comparando a Figura 60 e Figura 62 com a Figura 57 e Figura 59, nota-se que existe um comportamento diferente entre as duas metodologias, tanto para as posições como para os esforços. Os esforços e os deslocamentos são menores quando a posição inicial é a configuração de equilíbrio estático. Observa-se na Figura 61 que o comportamento na TDZ é totalmente diferente se não se utiliza a posição de equilíbrio estático. 

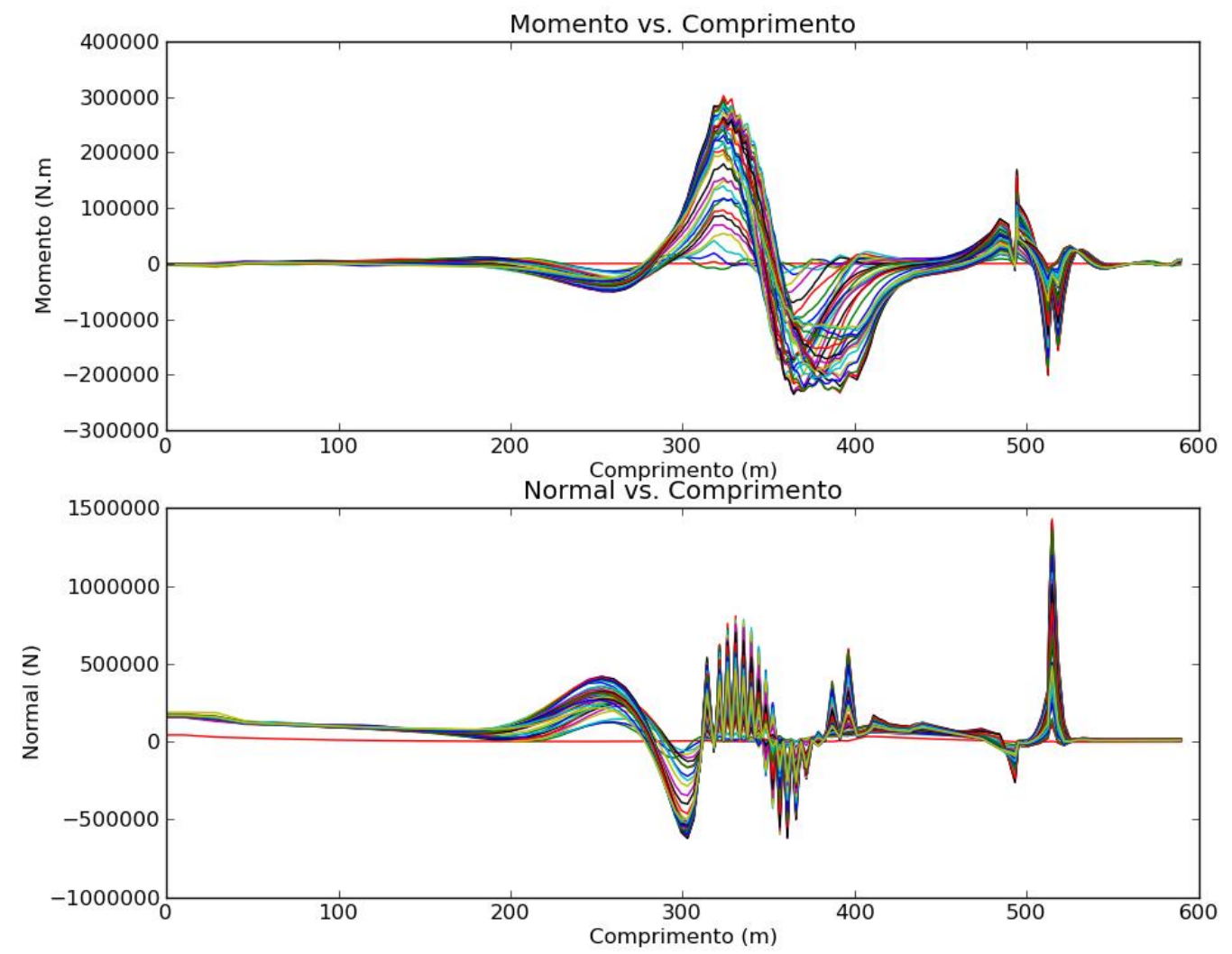

Figura 59. Esforços à medida que o tempo avança, com a posição estática como indeformada.

$\mathrm{Na}$ literatura recomenda-se que a configuração inicial da análise dinâmica seja a posição de equilíbrio estático (YAZDCHI; CRISFIELD, 2002). Embora o comportamento do código computacional seja mais estável e robusto quando se faz este passo, é importante notar que o comportamento real da estrutura nem sempre segue esta sequência de passos de carga. Com isto, em algumas análises dinâmicas de risers, talvez seja melhor inicializar o problema desde uma configuração real, em vez de uma posição estática. Quando nenhuma das configurações reais da estrutura seja conhecida ou fácil de obter, então a posição de equilíbrio estático torna-se a melhor opção para dar inicio à análise dinâmica. 


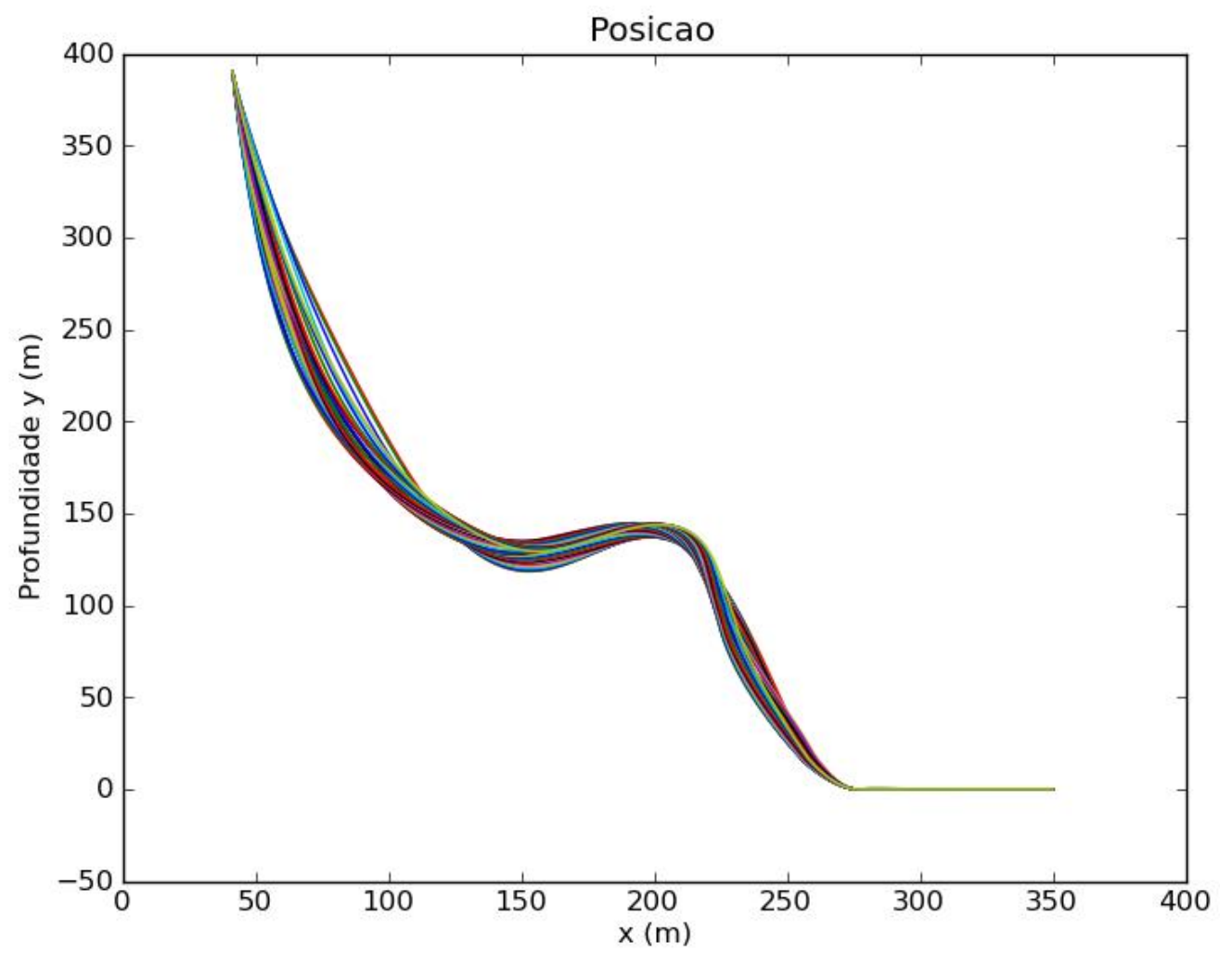

Figura 60. Deformadas à medida que o tempo avança, sem calcular a posição estática.

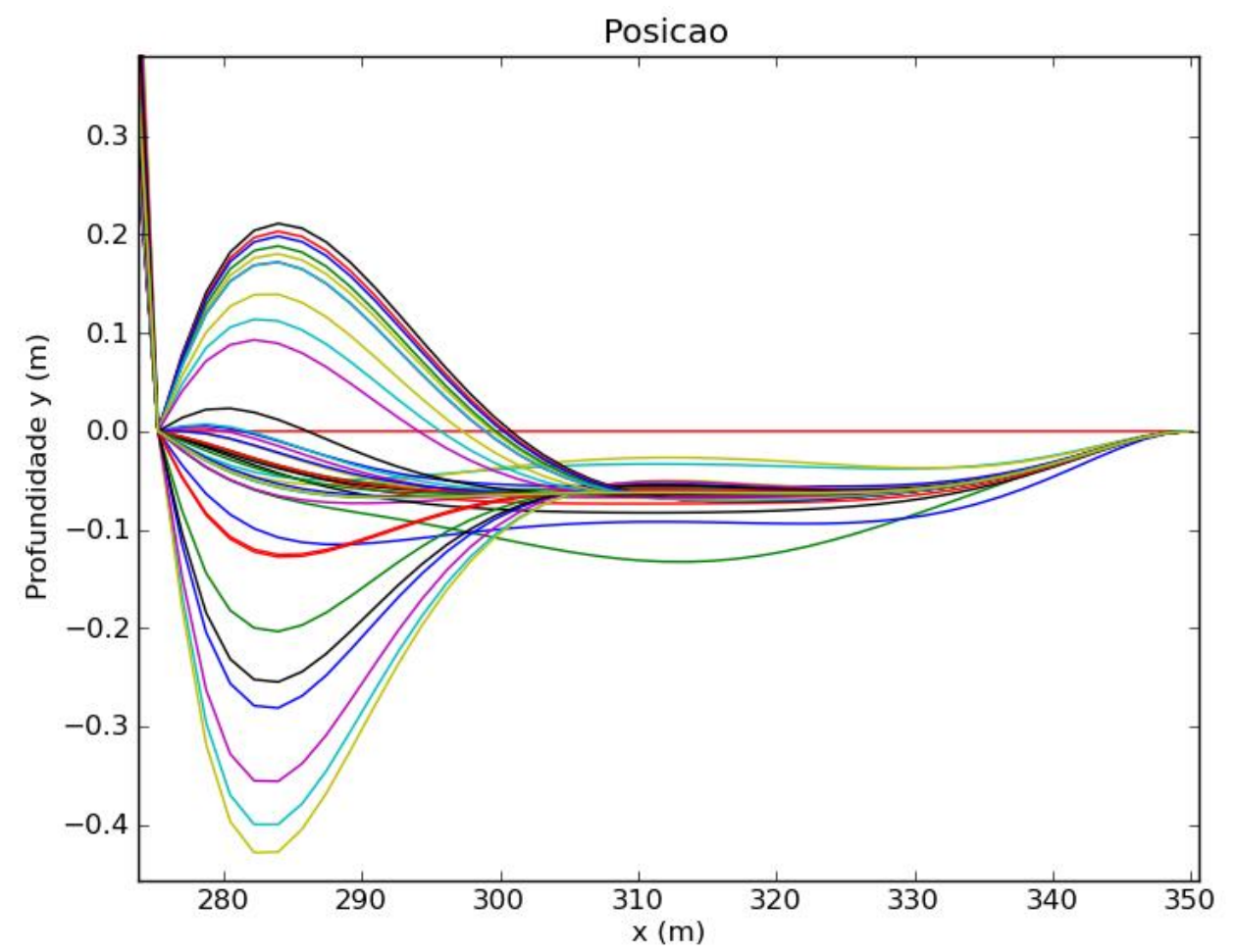

Figura 61. Zoom das deformadas na TDZ à medida que o tempo avança, sem calcular a posição estática. 

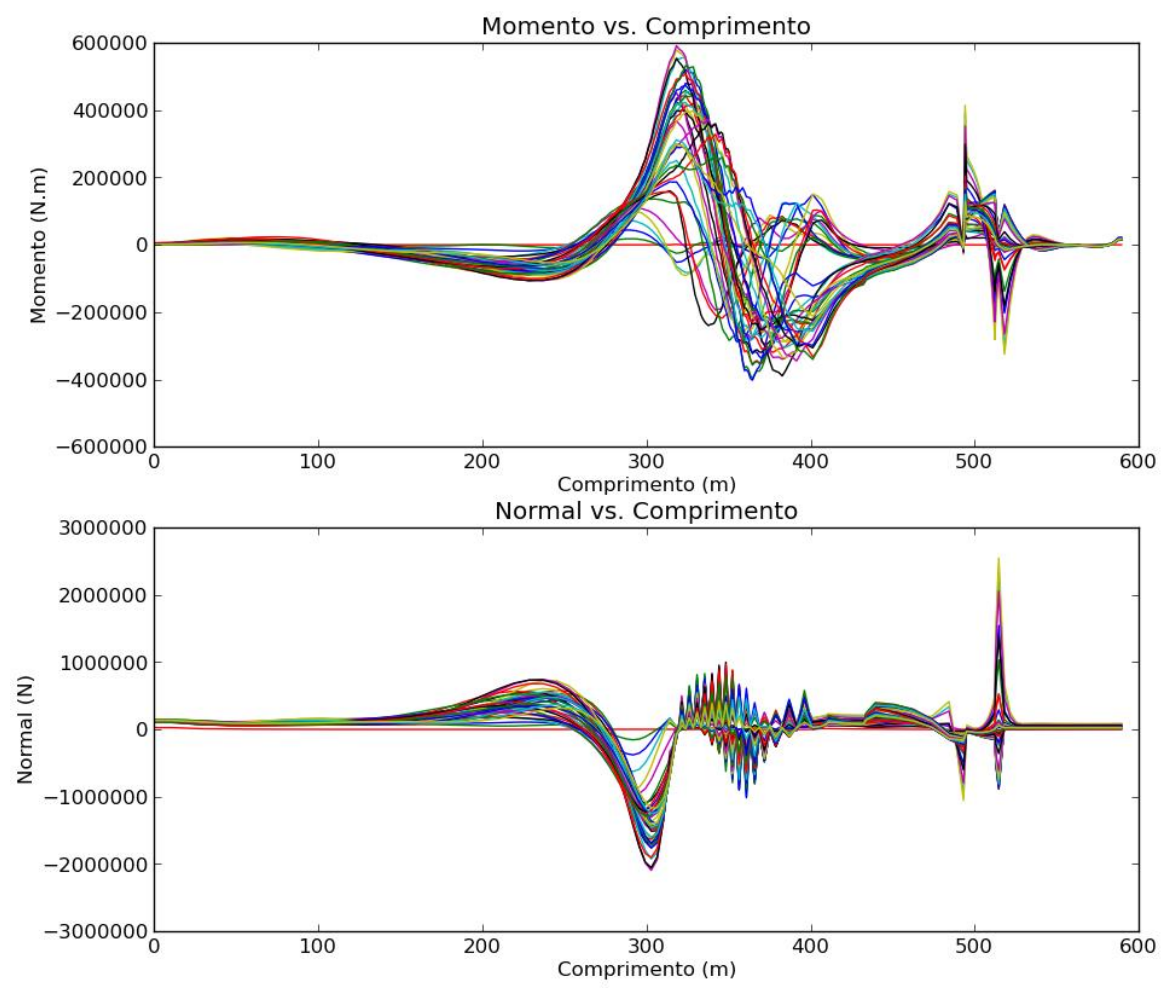

Figura 62. Esforços à medida que o tempo avança, sem calcular a posição estática.

\subsection{Riser rígido de perfuração desconectado.}

Esta aplicação simula a instalação de um riser de perfuração. Na extremidade inferior encontram-se sujeitos à estrutura dois equipamentos. O primeiro deles é o "Low Marine Riser Package (LMRP)" e o outro é o "Blow-Out Preventor (BOP)".

O LMRP forma-se por um conjunto de transdutores de impulsos elétricos que servem para comandar o BOP. O BOP é um equipamento instalado na cabeça do poço com o objetivo de evitar escapamentos e explosões (MOURELLE, 1993). $\mathrm{Na}$ Figura 63 é ilustrada a figura modelada no exemplo.

Este exemplo foi adaptado do trabalho de Mourelle (1993), porém existem diferenças nas propriedades das seções transversais utilizadas. 
Tabela 25. Propriedade do riser desconectado.

\begin{tabular}{|l|c|}
\hline Comprimento $L$ & $1030.0 \mathrm{~m}$. \\
\hline Comprimento do LMRP & $3.36 \mathrm{~m}$. \\
\hline Comprimento do BOP & $12.418 \mathrm{~m}$. \\
\hline Rigidez à flexão $E I$ & $1.57 \times 10^{7} \mathrm{N.m}$ \\
\hline Rigidez axial $E A$ & $2.4 \times 10^{9} \mathrm{~N}$ \\
\hline Carregamento distribuído $q$ & $-1136.0 \mathrm{~N} / \mathrm{m}$ \\
\hline Profundidade da água & $1030.0 \mathrm{~m}$. \\
\hline Diâmetro externo & $0.2445 \mathrm{~m}$. \\
\hline Diâmetro interno & $0.2129 \mathrm{~m}$. \\
\hline Diâmetro hidráulico & $0.3530 \mathrm{~m}$. \\
\hline Densidade do riser & $7850 \mathrm{Kg} / \mathrm{m}^{3}$ \\
\hline Coeficiente de arrasto transversal & 0.9 \\
\hline Coeficiente de inercia & 2.0 \\
\hline Coeficiente de arrasto tangencial & 0.01 \\
\hline Passo de tempo $\Delta t$ & 0.03 \\
\hline Número de passos de tempo & 40000 \\
\hline Período $T$ & $12 \mathrm{seg}$ \\
\hline Amplitude na direção heave $A$ & $3.12 \mathrm{~m}$. \\
\hline Amplitude na direção surge $A$ & $3.12 \mathrm{~m}$. \\
\hline
\end{tabular}

O riser é engastado na extremidade superior e livre na outra. Os dados geométricos utilizados são mostrados na Tabela 25. As cargas utilizadas no exemplo são: peso próprio (representado pela força distribuída q), empuxo, cargas da interação fluido-estrutura (calculadas com a formula de Morison) e deslocamentos aplicados na extremidade superior (correspondentes aos movimentos da plataforma). Os deslocamentos são aplicados nas direções heave e surge, sendo que cada um deles segue a formula (123), na Figura 66 observa-se a sequência dos deslocamentos aplicados.

Tabela 26. Perfil de velocidades da corrente sobre o riser desconectado.

\begin{tabular}{|r|r|}
\hline cota $(\mathrm{m})$ & vel $(\mathrm{m} / \mathrm{s})$ \\
\hline 0 & 0.69 \\
\hline 400 & 0.69 \\
\hline 500 & 0.77 \\
\hline 700 & 0.43 \\
\hline 995 & 1.91 \\
\hline
\end{tabular}




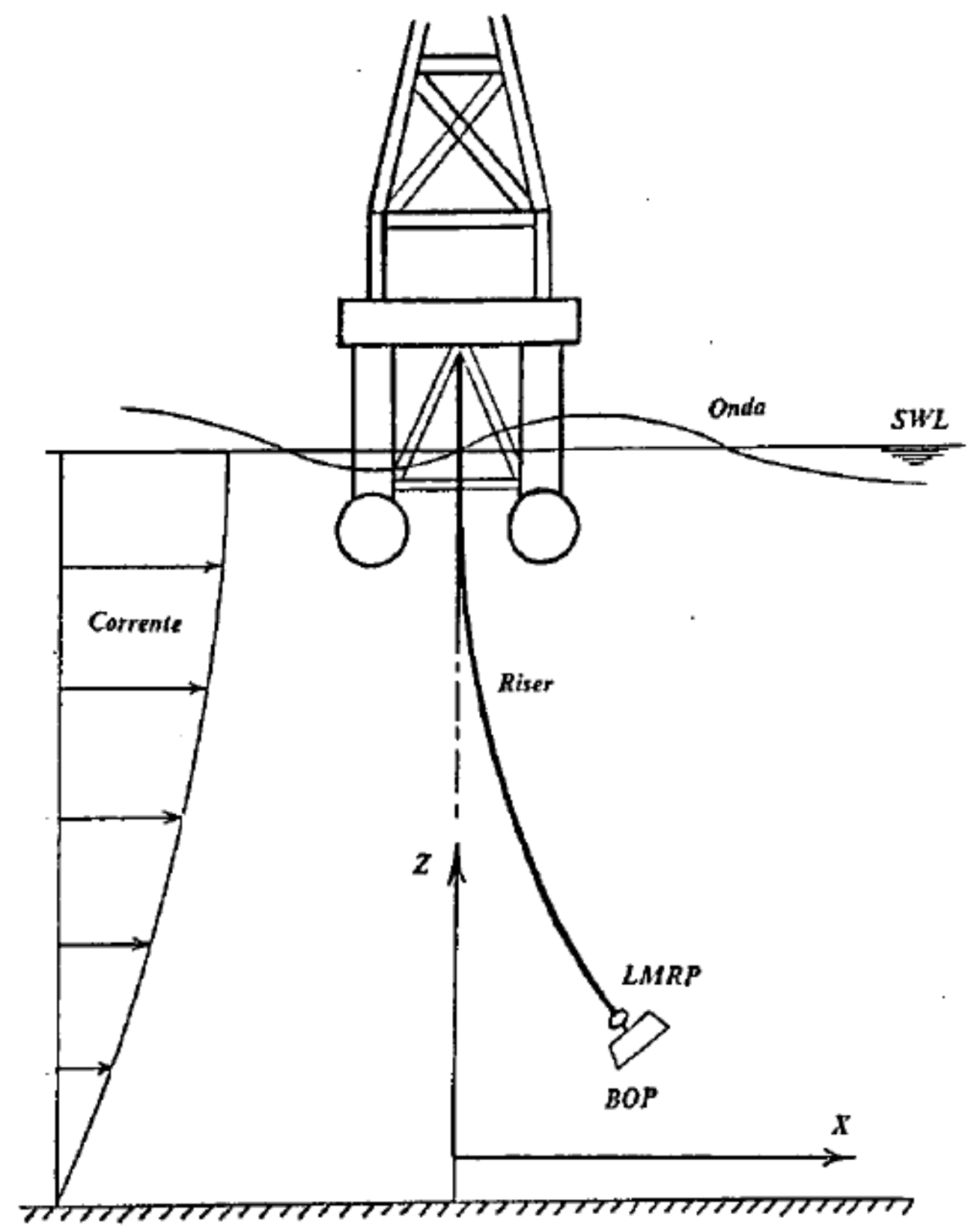

Figura 63. Riser rígido de perfuração desconectado, extraída de Mourelle (1993).

A Tabela 26 contém o perfil de velocidades da corrente que atuam sobre o riser.

Utiliza-se uma malha de elementos finitos quadráticos (três nós por elemento) para toda a estrutura. $\mathrm{Na}$ parte do riser o comprimento discretiza-se com 50 
elementos, sendo que os nós encontram-se espaçados por $10.14 \mathrm{~m}$. O LMRP tem um elemento e seus nós têm um espaçamento de $1.68 \mathrm{~m}$. No BOP também se utiliza um elemento quadrático com seus nós separados por $6.21 \mathrm{~m}$.

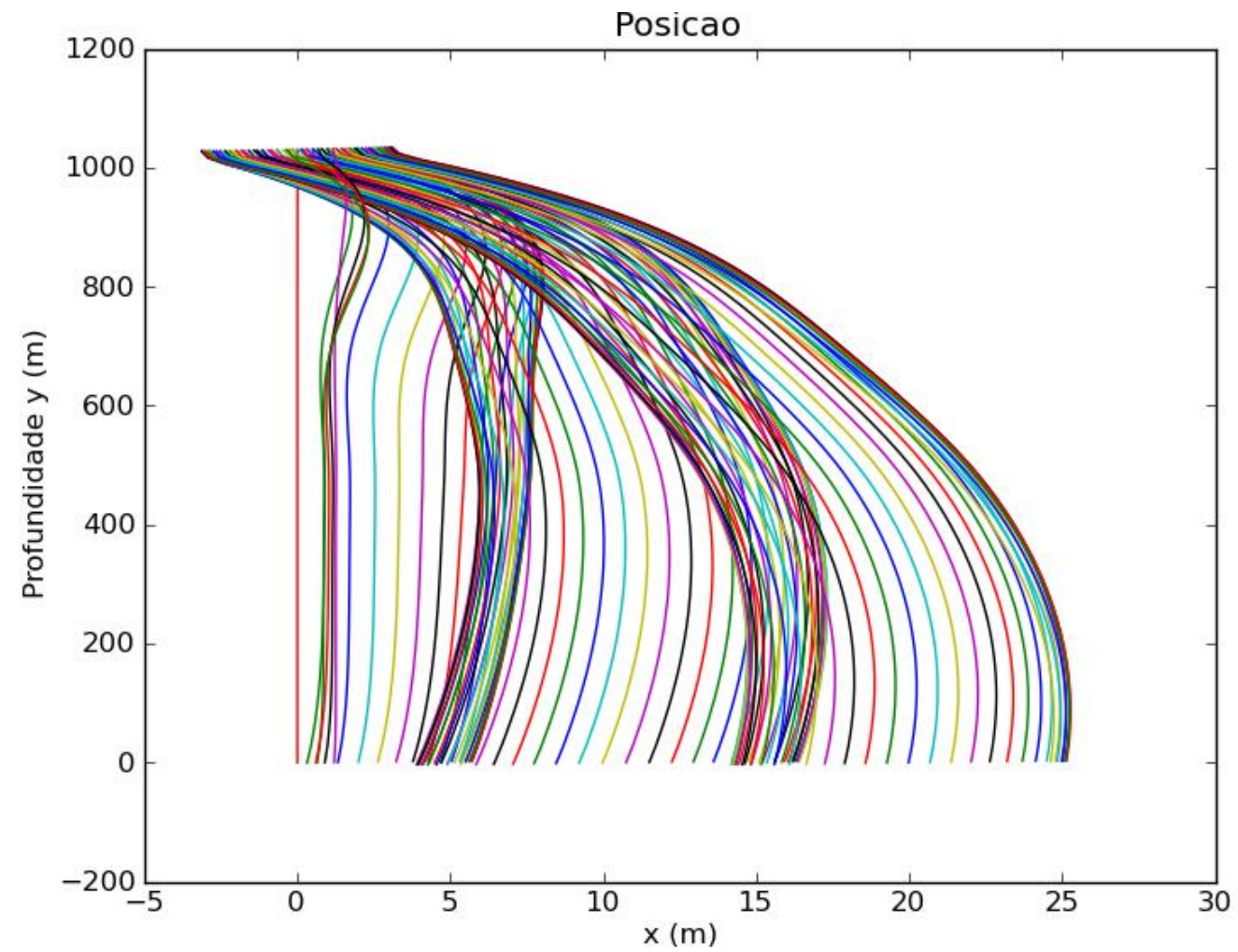

Figura 64. Configurações deformadas do riser rígido de perfuração durante o processo de instalação.

Neste riser utilizam-se três ciclos de deslocamentos impostos no seu topo. $\mathrm{Na}$ Figura 64, a qual contem as configurações deformadas de equilíbrio dinâmico à medida que o tempo avança, observa-se que cada um destes ciclos oscila ao redor de uma posição diferente. Após o primeiro ciclo, os deslocamentos são bastante amortecidos, isto se deve às forças de arrasto consideradas. Os esforços produzidos durante este procedimento encontram-se na Figura 65. 

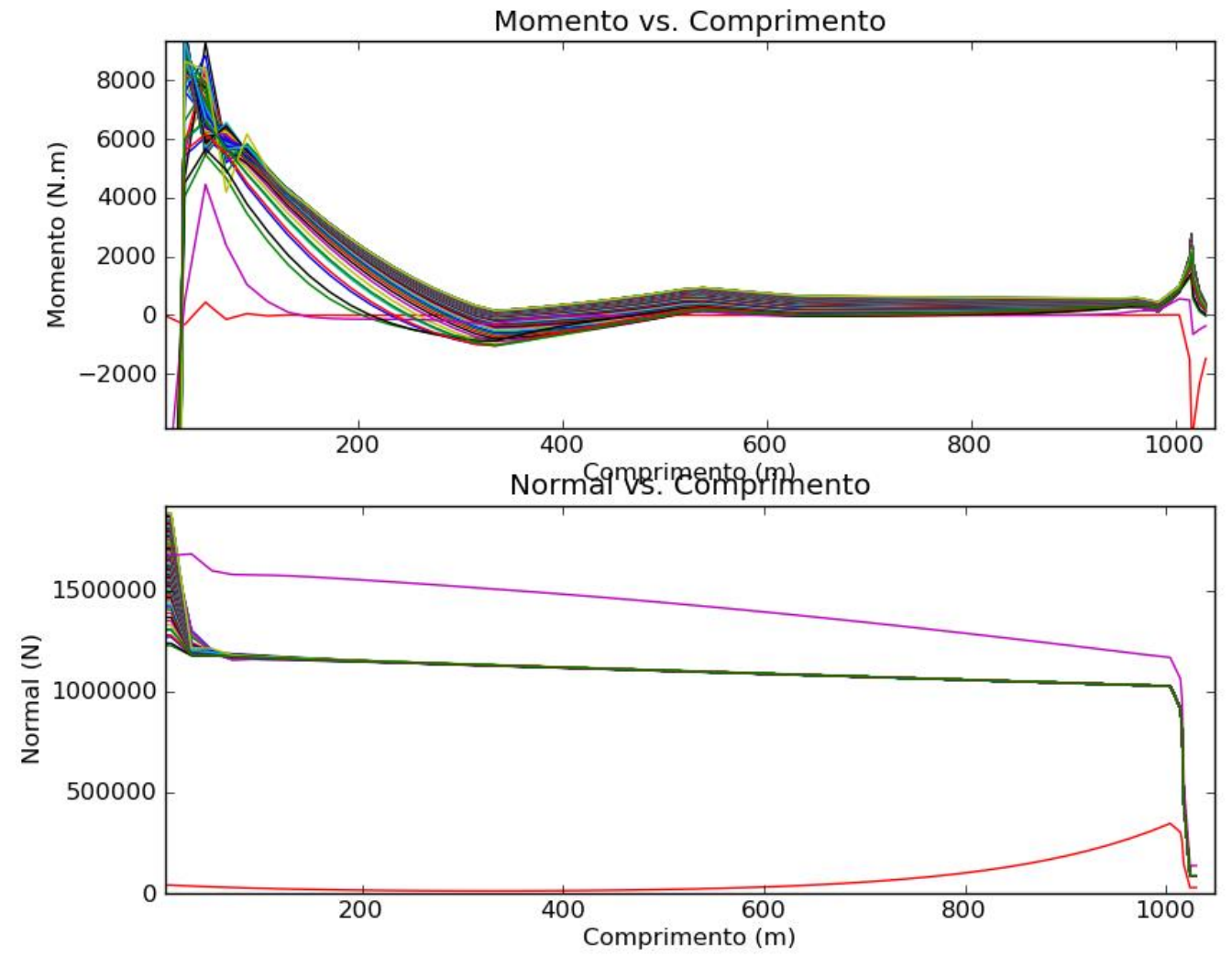

Figura 65. Esforços no riser de perfuração.

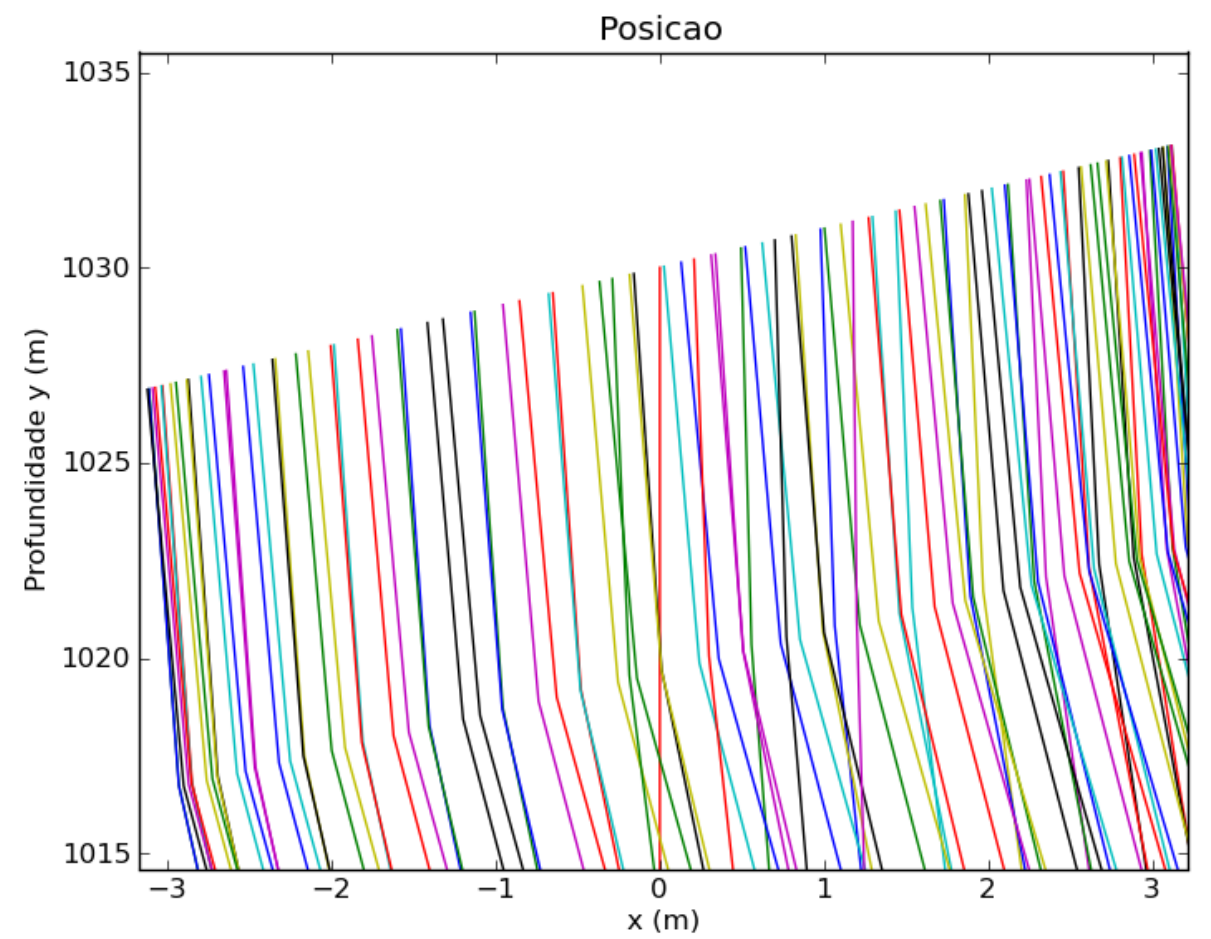

Figura 66. Deslocamento imposto na extremidade do riser de perfuração. 


\subsection{Mangote flexível entre duas plataformas.}

Esta estrutura é um tubo flexível suspenso entre uma plataforma fixa e uma semi-submersível. A situação corresponde a uma condição em que a plataforma semi-submersível aproxima-se à plataforma fixa pela ruptura de um dos seus cabos de ancoragem. Isto se aprecia na Figura 67. A finalidade deste exemplo é simular um riser em uma situação limite. Este exemplo de aplicação é adaptado do trabalho de Mourelle (1993).

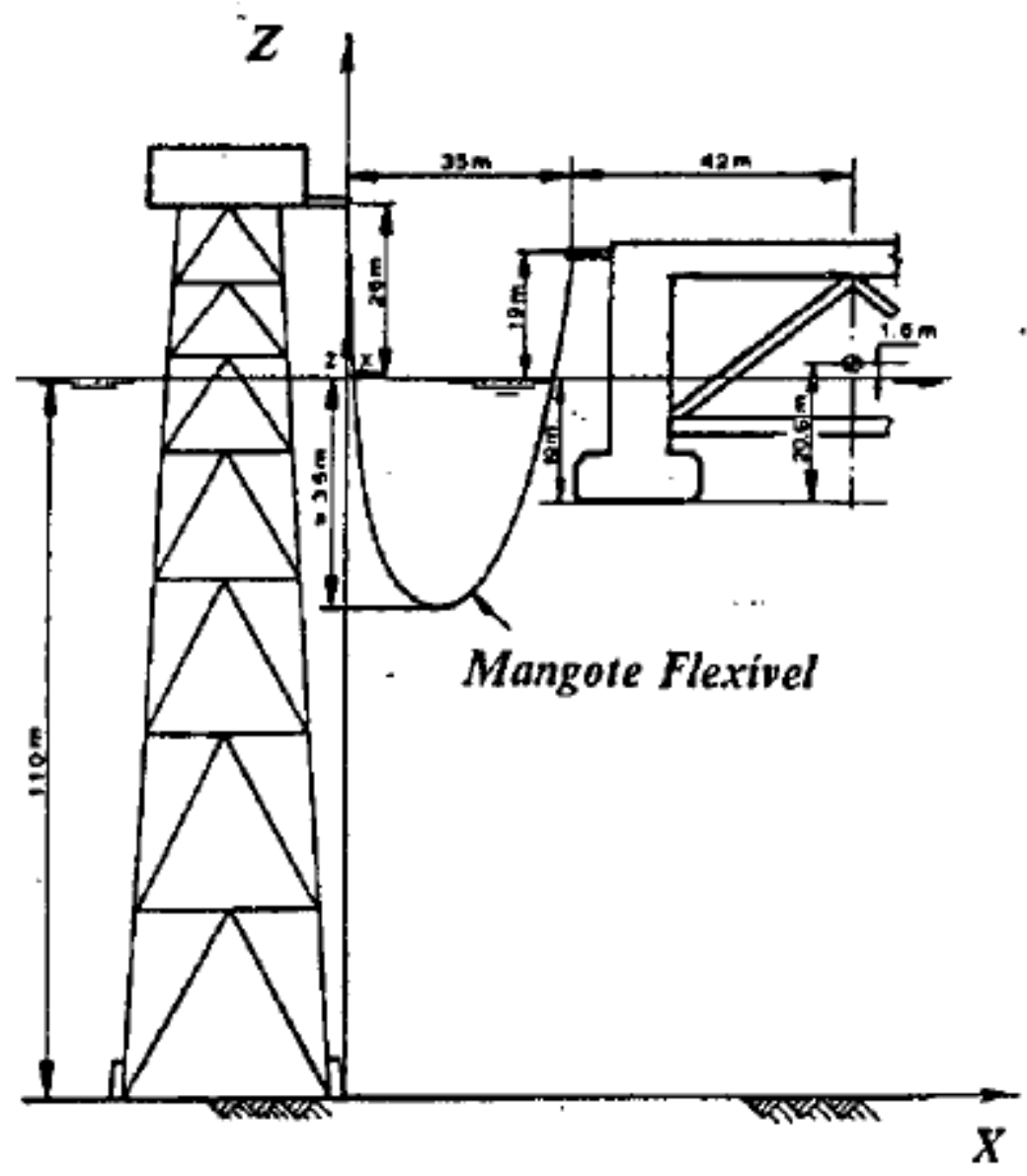

Figura 67. Mangote flexível entre duas plataformas, extraída de Mourelle (1993). 
Na Tabela 27 encontram-se as propriedades do riser flexível modelado neste exemplo, assim como também os dados dos carregamentos e dos parâmetros utilizados.

Tabela 27. Propriedade do riser flexível.

\begin{tabular}{|l|c|}
\hline Comprimento $L$ & $130.0 \mathrm{~m}$. \\
\hline Rigidez à flexão $E I$ & $4.09 \times 10^{9} \mathrm{N.m}$ \\
\hline Rigidez axial $E A$ & $7.81 \times 10^{7} \mathrm{~N}$ \\
\hline Carregamento distribuído $q$ & $-2200.0 \mathrm{~N} / \mathrm{m}$ \\
\hline Profundidade da água & $110.0 \mathrm{~m}$. \\
\hline Diâmetro externo & $0.2445 \mathrm{~m}$. \\
\hline Diâmetro interno & $0.120 \mathrm{~m}$. \\
\hline Diâmetro hidráulico & $0.3530 \mathrm{~m}$. \\
\hline Densidade do riser & $7850 \mathrm{Kg} / \mathrm{m}^{3}$ \\
\hline Coeficiente de arrasto transversal & 1.0 \\
\hline Coeficiente de inercia & 2.0 \\
\hline Coeficiente de arrasto tangencial & 0.01 \\
\hline Passo de tempo $\Delta t$ & 0.005 \\
\hline Número de passos de tempo & 22400 \\
\hline Período $T$ & $15 \mathrm{seg}$ \\
\hline Amplitude na direção heave $A$ & $5.27 \mathrm{~m}$. \\
\hline Amplitude na direção surge $A$ & $8.60 \mathrm{~m}$. \\
\hline
\end{tabular}

Na Tabela 28 apresenta-se o perfil de velocidades da corrente que atua sobre 0 riser.

Tabela 28. Perfil de velocidades da corrente sobre o riser flexível.

\begin{tabular}{|r|r|}
\hline cota $(\mathrm{m})$ & vel $(\mathrm{m} / \mathrm{s})$ \\
\hline 0 & 0.00 \\
\hline 3.0 & 0.50 \\
\hline 60.0 & 0.70 \\
\hline 108.0 & 0.75 \\
\hline 110.0 & 0.75 \\
\hline
\end{tabular}

O riser é articulado das duas extremidades. As cargas aplicadas no exemplo são: peso próprio (representado pela força distribuída q), empuxo, cargas da iteração fluido estrutura (calculadas com a formula de Morison) e deslocamentos aplicados na extremidade à direita (correspondentes aos movimentos da plataforma devidos à corrente, ver Figura 72). Os deslocamentos são aplicados nas direções 136 
heave e surge, sendo que, em cada uma das direções são descritos pela equação (123), os deslocamentos aplicados mostram-se na Figura 72.

Utiliza-se uma malha de 33 elementos finitos quadráticos (três nós por elemento) para toda a estrutura. Assim, a projeção sobre o eixo horizontal da distância que separa os nós é de $0.79 \mathrm{~m}$.

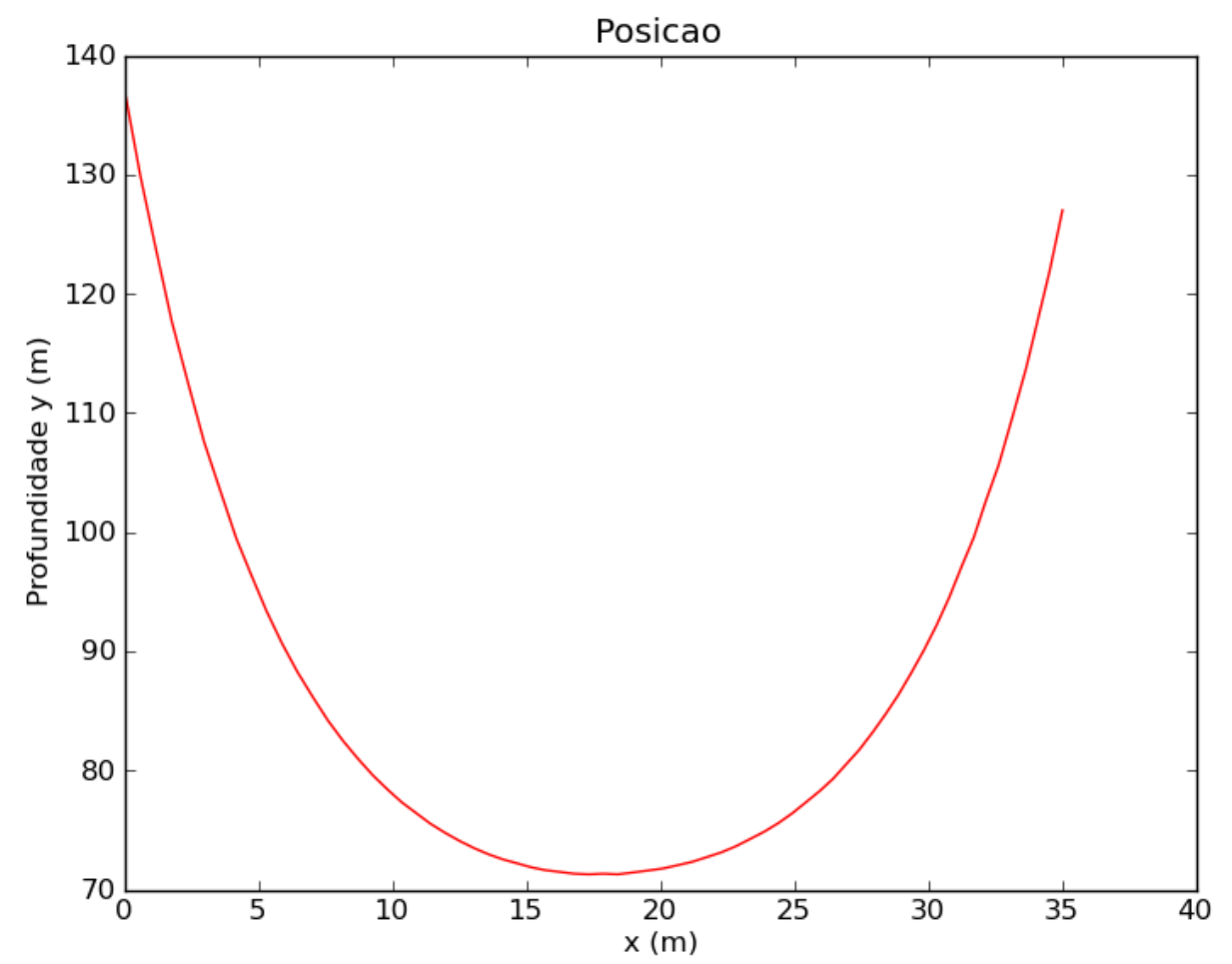

Figura 68. Posição inicial utilizada para o inicio da análise estática.

Na Figura 68 mostra-se a posição inicial utilizada no inicio da análise estática para se encontrar a configuração de equilíbrio estático, a qual se mostra na Figura 69. Os esforços da análise estática encontram-se na Figura 70.

Utilizando a configuração estática como posição inicial realiza-se a análise dinâmica. Os resultados desta análise são mostrados na Figura 71 e na Figura 73. 


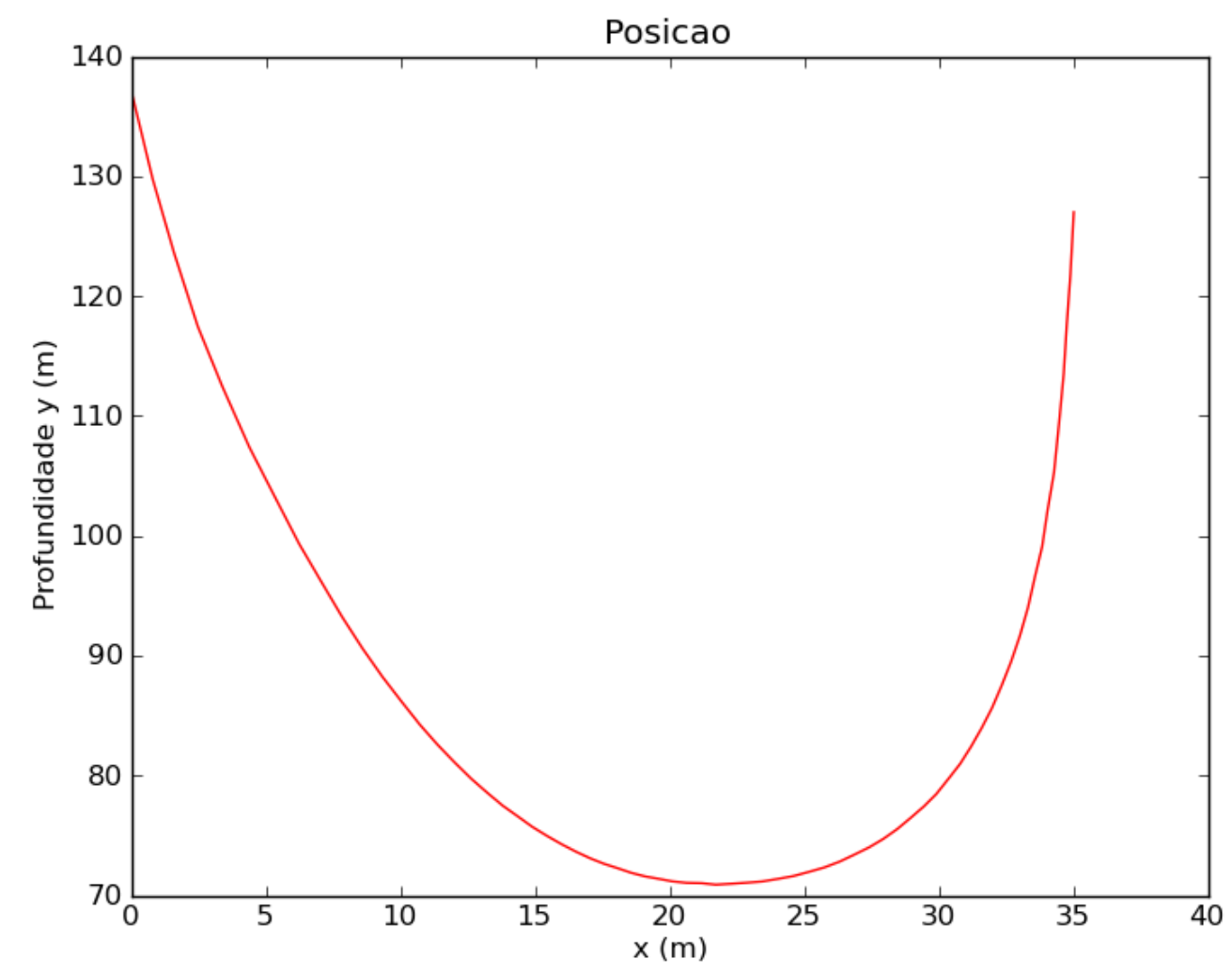

Figura 69. Configuração de equilíbrio estático.
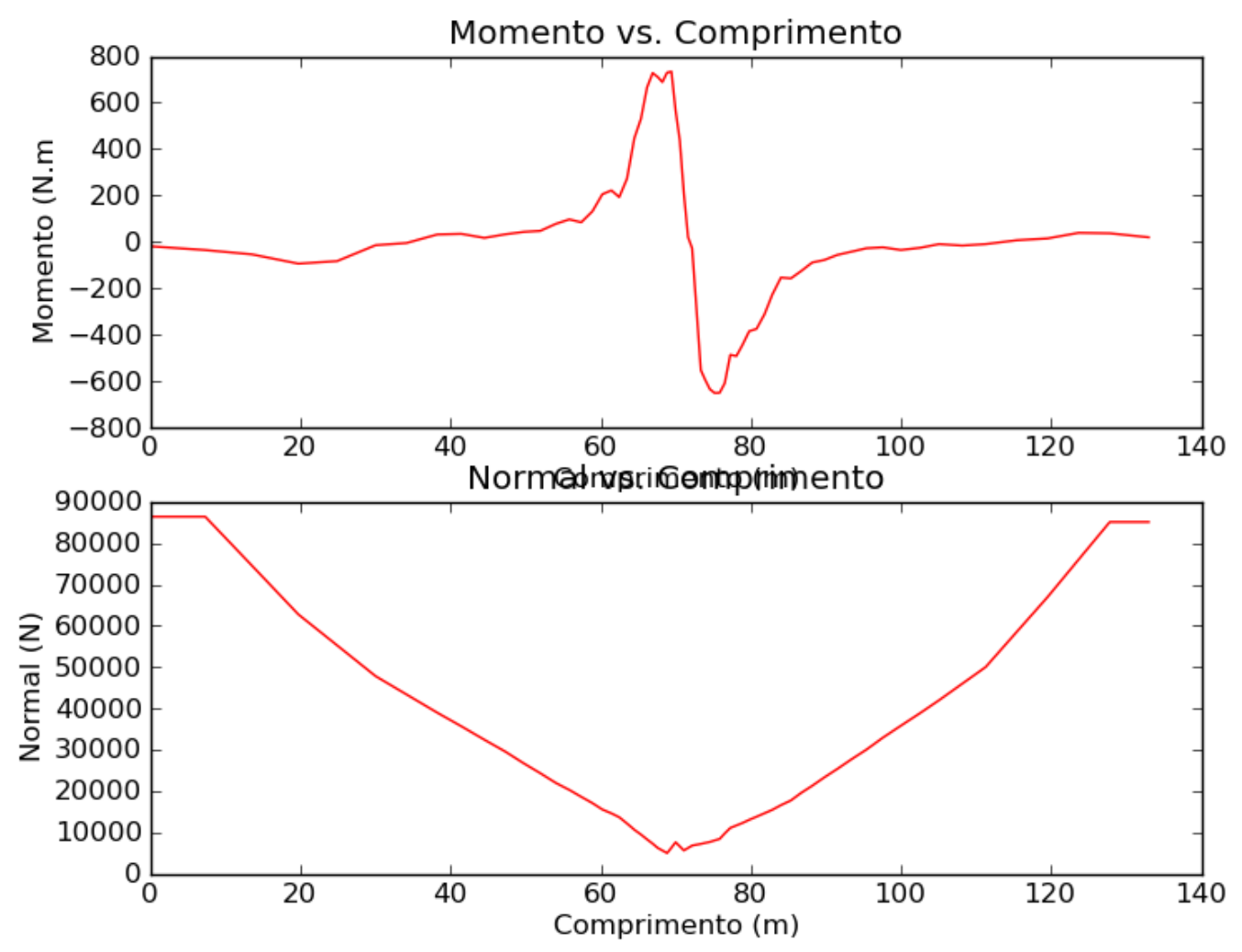

Figura 70. Esforços na posição de equilíbrio estático. 


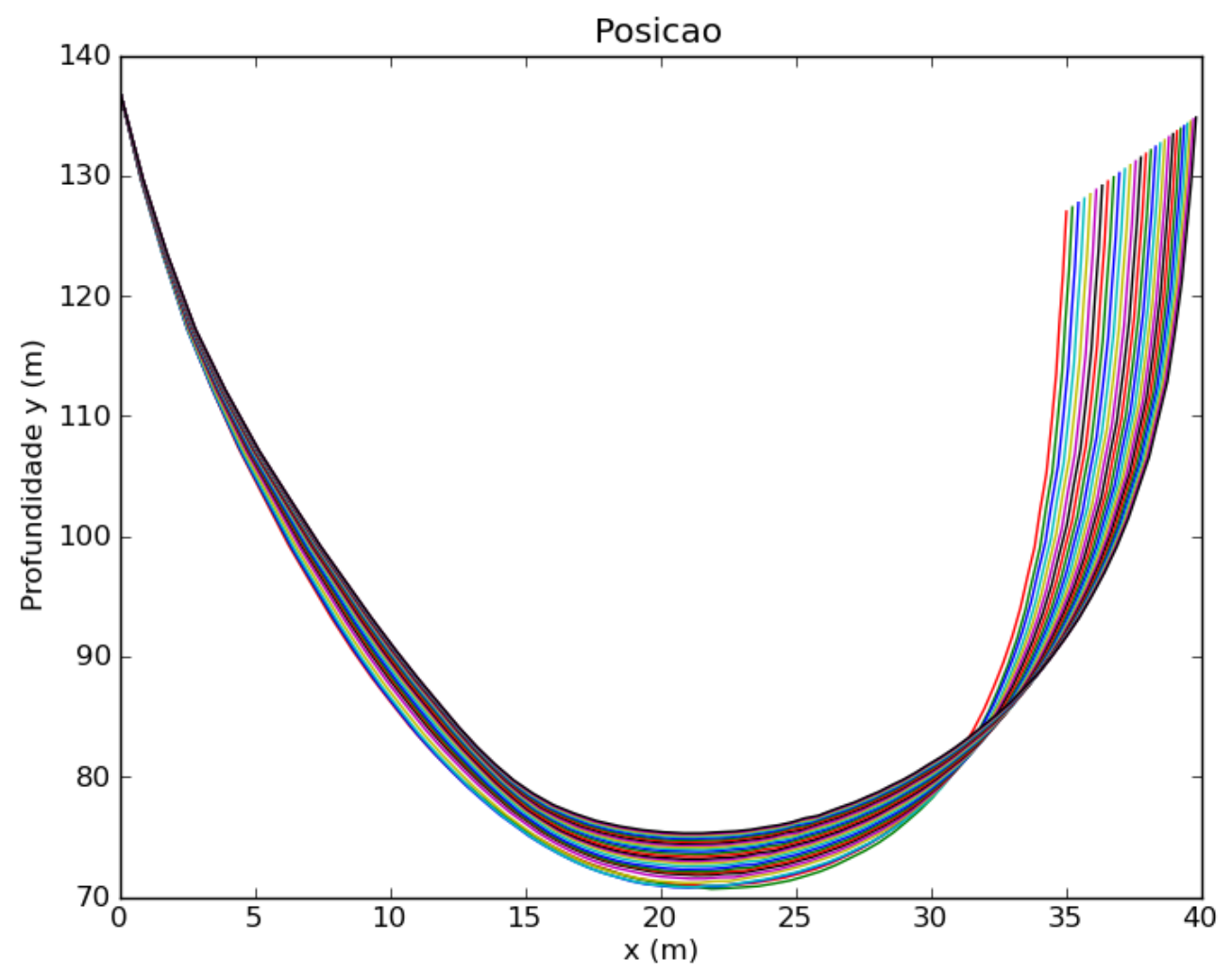

Figura 71. Configurações dinâmicas.

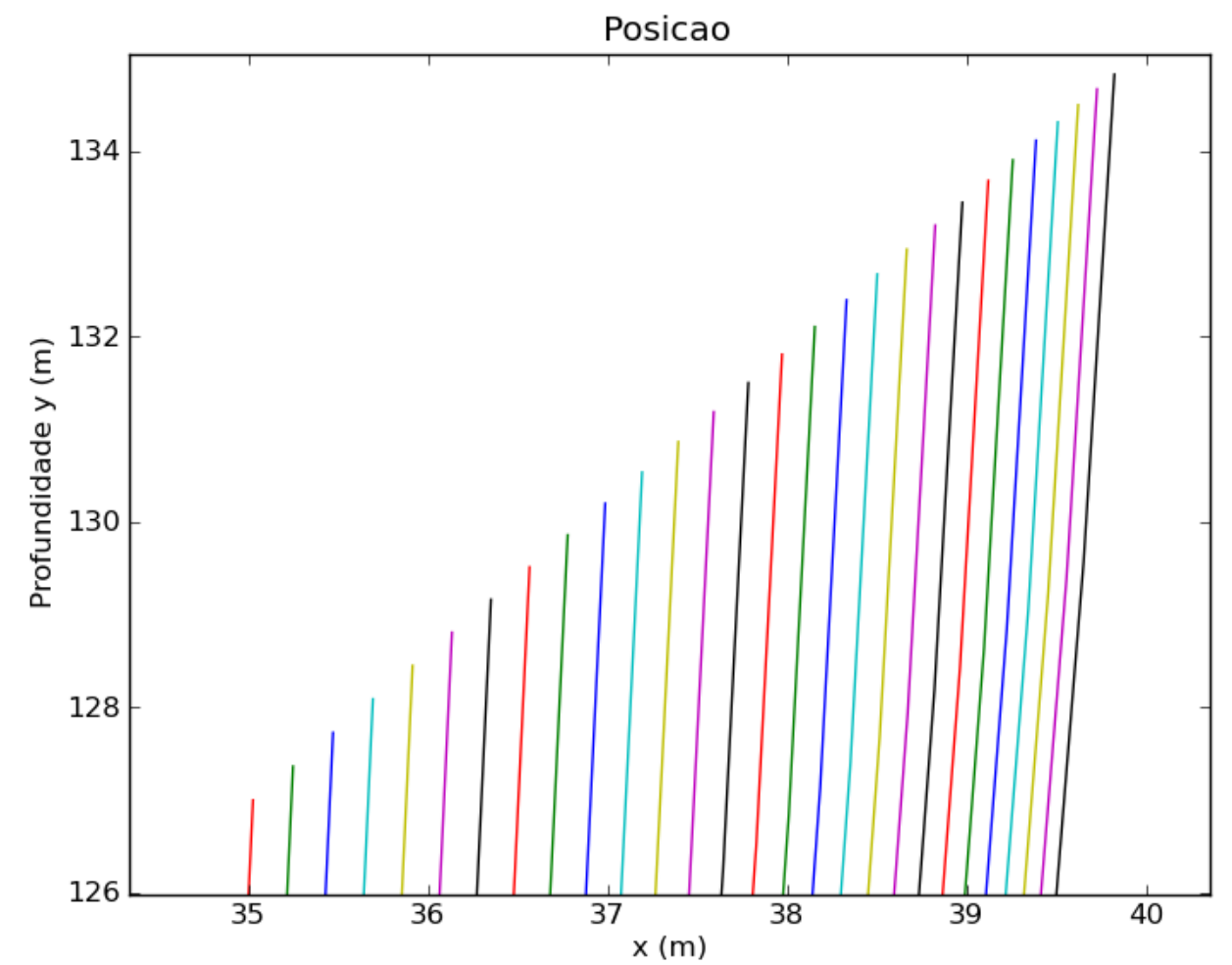

Figura 72. Deslocamentos impostos na extremidade direita do mangote. 

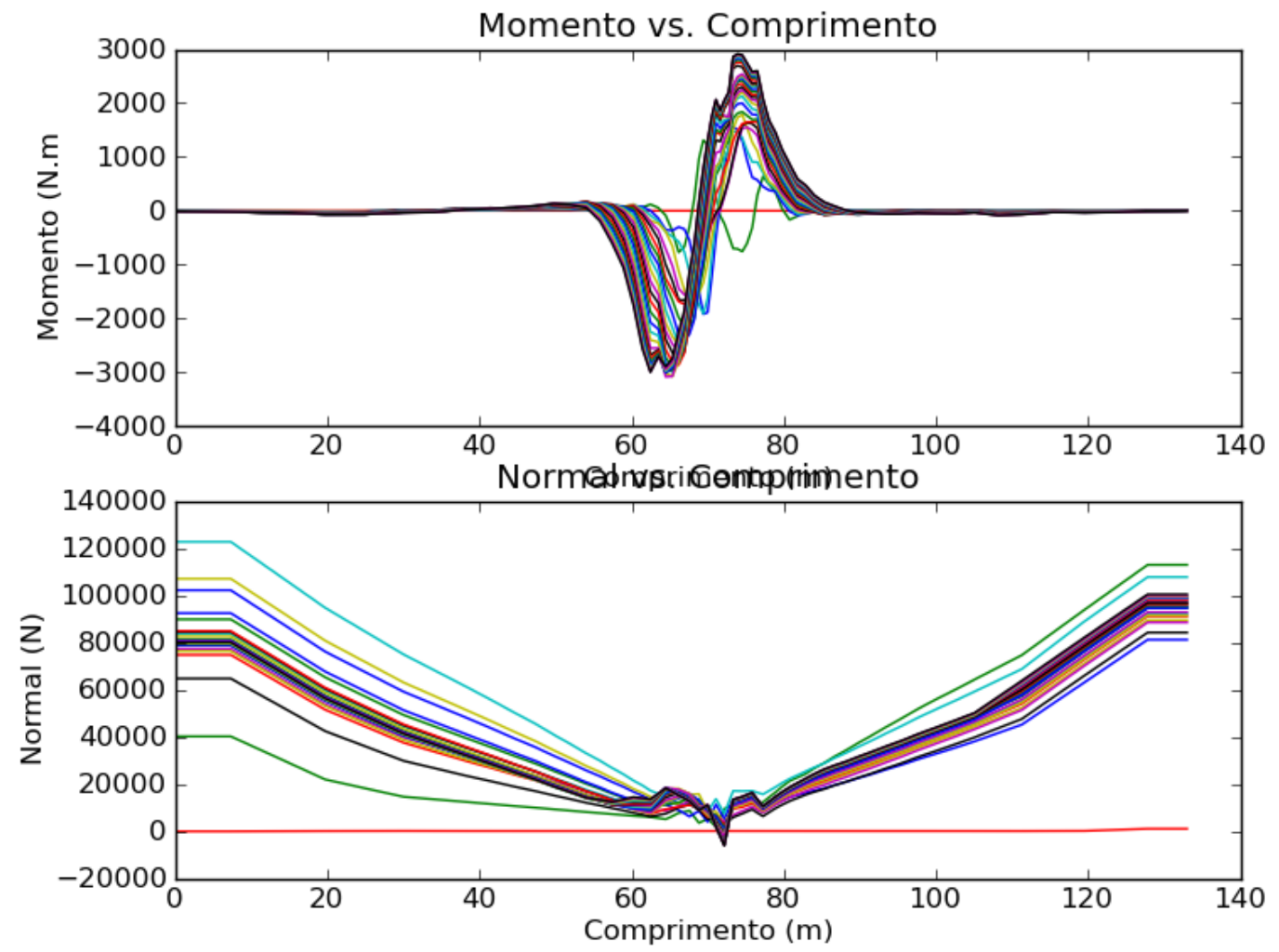

Figura 73. Esforços desenvolvidos durante a análises dinâmica.

Na Figura 73 nota-se que o vértice do riser (ponto inferior) é submetido a um momento fletor crítico, enquanto que as extremidades possuem os maiores esforços normais. A tendência encontrada na Figura 73 (referente à forma geral e a escala dos valores) é coerente com os resultados mostrados por Mourelle (1993), porém os resultados não são iguais, já que existe uma variação nos dados geométricos da estrutura, pois os valores da rigidez à flexão $E I$ e da rigidez axial $E A$, reportados por Mourelle (1993), não possuem uma seção tubular homogênea equivalente. 


\section{Conclusões.}

Do ponto de vista computacional as propostas originais referentes à formulação posicional deste trabalho foram implementadas com sucesso, a saber: Métodos de penalização da matriz Hessiana para a determinação de configurações de equilíbrio estático de risers altamente flexíveis, aplicação suave de movimentos horizontais e verticais no topo do riser para a simulação da movimentação de embarcações e plataformas e finalmente a técnica de penalização para a consideração de contato linear e não linear entre o riser e o solo.

Do ponto de vista da validação de formulações para aplicações, conclui-se que, devido ao forte comportamento não linear geométrico deste tipo de estruturas, a dependência dos resultados com relação ao método numérico empregado é bastante grande e indica-se a necessidade da existência de "benchmarks" experimentais, altamente controlados, de forma a confirmar a precisão das metodologias propostas e assim possibilitar sua calibração.

Para aplicações reais, observou-se nos exemplos abordados, a existência de um conjunto muito amplo de informações importantes para os modelos e uma sensibilidade elevada da resposta a esses parâmetros físicos. Além disso, e talvez o ponto de maior importância, é a forte dependência das análises em relação às condições iniciais, que em problemas reais são, na verdade, desconhecidas.

Estes problemas indicam que os caminhos futuros das pesquisas associadas à modelagem de risers submersos devem incluir diversas análises estatísticas, como por exemplo: Análise da sensibilidade dos métodos empregados aos parâmetros físicos adotados, análise de confiabilidade e sensibilidade das respostas às 
condições iniciais dos risers e influência das técnicas de instalação nas condições iniciais de análise. 


\section{Referências bibliográficas}

ANTONIO, L. M. Análise da iteração solo-estrutura aplicada a riser rígido em catenária através da formulação co-rotacional. Campinas: UNICAMP, 2011.

API, A. P. I. Comparison of marine drilling riser analysis API Bulletin.1977.

ARMERO, F.; ROMERO, I. In the formulation if high-frequency dissipative timestepping algorithms for nonlinear dynamics. Part I: low-order methods for two model problems and nonlinear elastodynamics. Computer Methods in Applied Mechanics and Engineering, v. 190, p. 2603-2649, 2001a.

ARMERO, F.; ROMERO, I. In the formulation if high-frequency dissipative timestepping algorithms for nonlinear dynamics. Part II: Second-order methods. Computer Methods in Applied Mechanics and Engineering, p. 6783-6824, 2001b.

ATADAN, A. S. et al. Analytical and numerical analysis of the dynamics of a marine riser connected to a floating platform. Ocean Engineering, v. 24, p. 111-131, 1997.

AUBENY, C. P.; BISCONTIN, G. Seafloor Interaction with Steel Catenary Risers. 2006.

AUBENY, C. P.; BISCONTIN, G. Seafloor-riser interaction model. International Journal of Geomechanics, v. 9, n. 3, p. 133-141, 2009.

AUBENY, C. P.; SHI, H.; MURFF, J. D. Collapse loads for a cylinder embedded in trench in cohesive soil. International Journal of Geomechanics, v. 5, p. 320-325, 2005. 
BERGAN, P. G.; MATHISEN, K. M. Hydrostatic loading and stability analysis of structures with large displacements. International Journal for Numerical Methods in Engineering, v. 22, p. 575-595, 1986.

BERNITSAS, M. N.; KOKARAKIS, J. E.; IMRON, A. Large deformation threedimensional static analysis of deep water marine risers. Applied Ocean Research, v. 7 , p. $178-187,1985$.

BRISEGHELLA, L.; MAJORANA, C. E.; PELLEGRINO, C. Conservation of angular momentum and energy in the integration of non-linear dynamic equations. Computer Methods in Applied Mechanics and Engineering, v. 179, p. 247-263, 1999.

BUI, Q. V. Modified Newmark family for non-linear dynamic analysis. International Journal for Numerical Methods in Engineering, v. 61, p. 1390-1420, 2004.

CENPES/D. ANFLEX “Análise Não-linear de Risers e Linhas de Ancoragem” (Cenpes/Diprex/Sedem, Ed.), 1993.

CHAI, Y. T.; VARYANI, K. S.; BARLTROP, N. D. P. Three-dimensional lump-mass formulation of a catenary riser with bending, torsion and irregular seabed interaction effect. Ocean Engineering, v. 29, p. 1503-1525, 2002.

CHATJIGEORGIOU, I. K. A finite differences formulation for the linear and nonlinear dynamics of 2D catenary risers. Ocean Engineering, v. 35, p. 616-636, 2008.

CODA, H. B. Two dimensional analysis of inflatable structures by the positional FEM. Latin American Journal of Solids and Structures, v. 6, p. 187-212, 2009. 
CODA, H. B.; GRECO, M. A simple FEM formulation for large deflection 2D frame analysis based on position description. Computer Methods in Applied Mechanics and Engineering, v. 193, n. 33-35, p. 3541-3557, 20 ago. 2004.

CODA, H. B.; PACCOLA, R. R. Unconstrained finite element for geometrical nonlinear dynamics of shells. Mathematical Problems in Engineering, v. 2009, p. 32, 2009.

CODA, H. B.; PACCOLA, R. R. A FEM procedure based on positions and unconstrained vectors applied to non-linear dynamic of 3D frames. Finite Elements in Analysis and Design, v. 47, p. 319-333, 2011.

COLAJANNI; FALSONE, P.; RECUPERO, A. Simplified formulation of solution for beams on winkler foundation allowing discontinuities due to loads contraints. International Journal of Engineering, v. 25, p. 75-83, 2009.

CRISFIELD, M. A.; GALVANETTO, U.; JELENIC, G. Dynamics of 3-D co-rotational beams. Computational Mechanics, v. 20, p. 507-519, 1997.

DUNLAP, W. A.; BHOHANALA, R. P.; MORRIS, D. V. Burial of vertically loaded offshore pipelinesProc., 22nd Annual Offshore Technology Conf. Anais...Houston: 1990

EDUARDO SANTOS MELLO. Modelos de sistema passivo de compensação de heave para operações de instalação de equipamentos submarinos em águas ultraprofundas. [s.I.] Universidade Federal de Rio de Janeiro, 2004.

FALTINSEN, O. M. Sea loads on ships and offshore structures. UK: 1990. p. 328. 1990. 
GARCÍA-PALACIOS, J.; SAMARTIN, A.; NEGRO, V. A nonlinear analysis of laying a floating pipeline on the seabed. Engineering Structures, v. 31, p. 1120-1131, 2009.

GRECO, M.; CODA, H. B. Positional FEM formulation for flexible multi-body dynamic analysis. Journal of Sound and Vibration, v. 290, p. 1141-1174, 2006.

HILBERT, H. M.; HUGHES, T. J. R.; TAYLOR, R. L. improved numerical dissipation for time integration algorithms. Earthquake Engineering Structural Dynamics, v. 5, p. 283-292, 1977.

HOFFMAN, D. et al. Design of flexible marine risers in deep and shallow water23rd Annual Offshore Technology Conference (OTC). Anais...Houston, Tx: 1991

HOSSEINI KORDKHEILI, S. A. A new continuum based non-linear finitel element formulation for modeling of dynamic response of deep water riser behavior. [s.l.] Brunel University, 2009.

HOSSEINI KORDKHEILI, S. A. A new continuum based non-linear finite element formulation for modeling of dynamic response of deep water riser behavior. Mechanical Engineering Department, School of Engineering and Design Brunel University, v. Doctor, p. 141, 2009.

HOSSEINI KORDKHEILI, S. A.; BAHAI, H. Non-linear finite element analysis of flexible risers in presence of buoyancy force and seabed interastion boundary condition. Archive of Applied Mechanics, v. 78, p. 765-774, 2008. 
HOSSEINI KORDKHEILI, S. A.; BAHAI, H.; MIRTAHERI, M. An updated analysis of three-dimensional flexible riser structures. Ocean Engineering, v. 38, p. 793-803, 2011.

HOWELL, C. T. Numerical analysis of 2D non-linear cable equations with application to low tension problems. International Journal of Offshore Polar Engineering, v. 2, p. $110-113,1992$.

HU, H. J. E. et al. Centrifuge modelling of SCR vertical motion at touchdown zone. Ocean Engineering, v. 38, p. 888-899, 2011.

HUGHES, T. The finite element method. New Jersey: Dover, 1987.

HUGHES, T. J. R. A note on the stability of Newmark's algorithm in nonlinear structural dynamics. Berkeley, California, USA: Division of Structural Engineering and Structural Mechanics, Deparment of Civil Engineering, University of California, 1975.

KRAINCANIC, I.; KEBADZE, E. Slip initiation and progression in helical armouring layers of unbonded flexible pipes and its effects on pipe bending behavior. Journal of Strain Analysis, v. 36, p. 265-275, 2001.

KUHL, D.; CRISFIELD, M. A. Energy-conserving and decaying algorithms in nonlinear structural dynamics. International Journal for Numerical Methods in Engineering, v. 45, p. 569-599, 1999.

KYRIAKIDES, S.; CORONA, E. N. V.-3. Mechanics of offshore pipelines Buckling and collapse. [s.l.] Elsevier, 2007. v. 1p. 400 
LACARBONARA, W.; PACITTI, A. Nonlinear Modeling of Cables with Flexural Stiffness. Mathematical Problems in Engineering, v. 2008, p. 21, 2008.

LAIER, J. E. Hermitian lumped mass matrix formulation for flexural wave propagation. Communications in Numerical Methods in Engineering, v. 14, p. 43-49, 1998.

LANCZOS, C. The variational principles of mechanics. 4 edition ed. New York: 1970

LANGER, C. G. Relationships for deep water suspended pipe spans International Conference on Ocean, Offshore and Artic Engineering (OMAE). Anais...Houston: 1985

LAVER, K.; CLUKEY, E.; EVANS, T. Steel catenary touchdown point vertical interaction modelsOffshore -Technology Conference OTC 16628, 2004.

LOW, Y. M.; LANGLEY, R. S. Time and frequency domain coupled analysis of deepwater floating production systems. Applied Ocean Research, v. 28, p. 371385, 2006.

MACIEL, D. N. Análise de problemas elásticos não lineares geométricos empregando o método dos elementos finitos posicional. [s.l.] Universidade de São Paulo, 2008.

MARTÍNEZ, C. E.; GONCALVES, R. Laying modeling of submarine pipelines using contact elments into a corotational formulation. Journal of Offshore Mechanics and Artic Engineering, v. 125, p. 145-152, 2003. 
MCNAMARA, J. F.; O'BRIEN, P. G.; GILROY, S. G. Non-linear analysis of flexible risers using hybrid finite elementsInternational Conference on Ocean, Offshore and Artic Engineering (OMAE). Anais...Tokyo, Japan: 1986

MORINI, O. G. Método dos elementos finitos posicional aplicado à análise estática de risers. Campinas: Universidade Estadual de Campinas, 2009.

MORISON, J. O. et al. The force exerted by surface waves on piles. petroleum Transactions, v. 189, p. 149-154, 1950.

MOURELLE, M. M. Análise dinâmica de sistemas estruturais constituídos por linhas marítimas. [s.I.] UFRJ, 1993.

NAKHAEE, A.; ZHANG, J. Trenching effects on dynamic behavior of a steel catenary riser. Ocean Engineering, v. 37, p. 277-288, 2010.

NEWMARK, M. N. A Method of computation for Structural Dynamics. Journal of the Engineering Mechanics Division, ASCE, p. 67-94, 1959.

NORDGREN, R. P. On computation of the motion of elastic rods. Journal of Applied Mechanics, p. 777-780, 1974.

PASCON, J. P. Sobre modelos constitutivos não lineares para materiais com gradação funcional exibindo grandes deformações: implementação numérica em formulação não linear geométrica. [s.I.] Universidade de São Paulo, 2012.

PATEL, M. H.; SEYED, F. B. Review of flexible riser modelling and analysis techniques. Engineering Structures, v. 17, p. 293-304, 1995. 
PATEL, M. N.; SAROHIA, S. Finite-element analysis of the marine riser. Engineering Structures, v. 6, p. 175-184, 1984.

PESCE, C. P. et al. Steel catenary risers for deep water applications5th International Symposium on Offshore and Polar Engineering. Anais...The Hague, Holand: 1995

PESCE, C. P.; ARANHA, J. A. P.; MARTINS, C. A. The soil rigity effect in touchdown boundary layer of a catenary riser: static problemOffshore and Polar Engineering Conference. Anais...Montreal: 1998

PESCE, C. P.; MARTINS, C. DE A.; SILVEIRA, L. M. Y. Riser-soil interaction: local dynamics at TDP and a discussion on the eigenvalue and the VIV problems. Journal of Offshore Mechanics and Artic Engineering, v. 128, p. 39-55, 2006.

PIMENTA, P. M.; CAMPELLO, E. M. B.; WRIGGERS, P. An exact conserving algorithm for nonlinear dynamics with rotational DOFs and general hyperelasticity. Part 1: Rods. Computer Mechanics, v. 42, p. 715-732, 2008.

QUARTERONI, A.; SACCO, R.; SALERI, F. N. V.-37. Numerical Mathematics. 2000. v. 37p. 654.2000.

SANCHES, C. T. T. Modos não-lineares de vibração e controle ativo de risers. São Paulo: Universidade de São Paulo, 2009.

SANCHES, R. A. K. Sobre o acoplamento fluido-casca utilizando o método dos elementos finitos. [s.I.] Universidade de São Paulo, 2011. 
SEYED, F. B.; PATEL, M. H. Mathematics of Flexible Risers Including Pressure and Internal Flow Effects. Marine Structures, v. 5, p. 121-150, 1992.

SIMO, J. C.; TARNOW, N.; WONG, K. K. Exact energy-momentum conserving algorithms and symplectic schemes for nonlinear dynamics. Computer Methods in Applied Mechanics and Engineering, v. 100, p. 63-116, 1992.

SOUSA, J. R. M. Análise local de linhas flexíveis pelo método dos elementos finitos. [s.I.] UFRJ, 2005.

TEIXEIRA, P. R. F. Simulação numérica da interação de escoamentos tridimensionais de fluidos compressíveis e incompressíveis e estruturas deformáveis usando o método de elementos finitos. Porto Alegre: Universidade Federal do Rio Grande do Sul, 2001.

TIKHONOV, V. S.; FISHER, A. S. An efficient procedure of static analysis of long ocean mining pipelnternational Conference on Ocean, Offshore and Artic Engineering (OMAE). Anais...Tokyo: 1986

WILLIS, N. R. R.; WEST, P. T. J. Interaction between deepwater catenary risers and soft seabed: Large scale sea trialsOTC 13113. Anais...2001

YAZDCHI, M.; CRISFIELD' ， M. A. Buoyancy forces and the 2D finite element analysis of flexible offshore pipes and risers. International Journal for Numerical Methods in Engineering, v. 54, p. 61-68, 2002a.

YAZDCHI, M.; CRISFIELD, M. A. Non-linear dynamic behaviour of fexible marine pipes and risers. v. 54, p. 1265-1308, 2002b. 


\section{Anexos}

9.1 Anexo 1: Termos adicionais na matriz Hessiana devidos ao solo não linear.

Mostra-se abaixo o programa realizado no Software Wolfran Mathematica 6.0. para o cálculo das derivadas de cada uma forças, no respectivo intervalo. Primero são mostradas as equações das forças em cada um dos intervalos e na sequência mostram-se as derivadas com relação à posição.

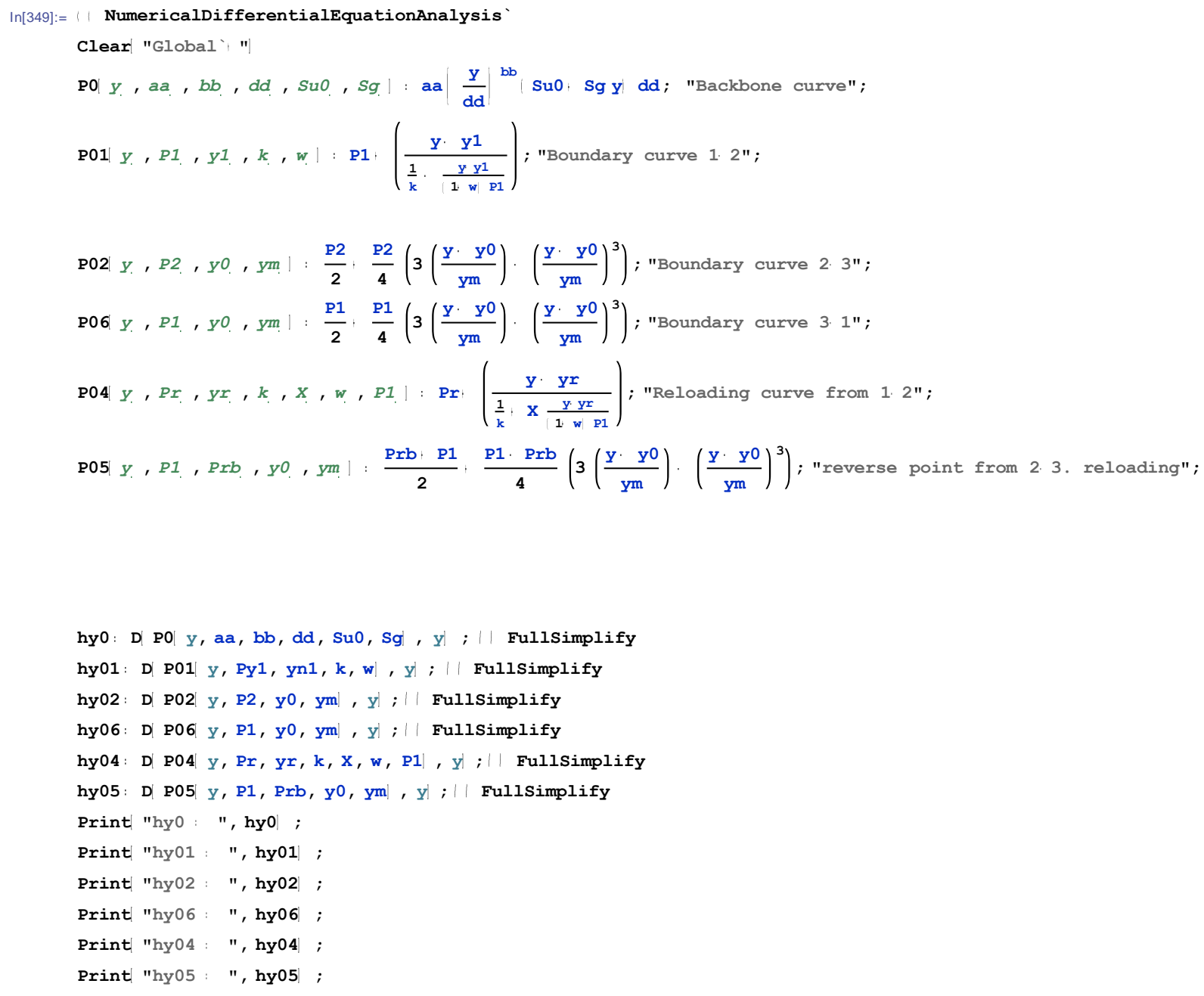




$$
\begin{aligned}
& \text { hy0: aa dd Sg }\left|\frac{y}{d d}\right|^{\text {bb }}+\text { aa bb }\left|\frac{y}{d d}\right|^{1, b b} \mid \text { Su0 }+ \text { Sg y } \\
& \text { hy01: } \frac{1}{\frac{1}{k} \cdot \frac{\mathrm{y} \cdot \mathrm{yn} 1}{\operatorname{Py} 1|1+\mathrm{w}|}}+\frac{\mathrm{y} \cdot \mathrm{yn} 1}{\operatorname{Py} 1|1+\mathrm{w}|\left|\frac{1}{\mathrm{k}} \cdot \frac{\mathrm{y} \cdot \mathrm{yn} 1}{\operatorname{Py} 1 \mid 1+\mathrm{w}}\right|^{2}} \\
& \text { hy02: } \frac{1}{4} \mathrm{P} 2\left(\frac{3|\mathrm{y} \cdot \mathrm{y} 0|^{2}}{\mathrm{ym}^{3}}+\frac{3}{\mathrm{ym}}\right) \\
& \text { hy06: } \frac{1}{4} \mathrm{P} 1\left(\frac{3|\mathrm{y} \cdot \mathrm{y} 0|^{2}}{\mathrm{ym}^{3}}+\frac{3}{\mathrm{ym}}\right) \\
& \text { hy04: } \frac{1}{\frac{1}{\mathrm{k}}+\frac{\mathrm{X}|\mathrm{y} \cdot \mathrm{yr}|}{\mathrm{P} 1|1+\mathrm{w}|}} \cdot \frac{\mathrm{x}|\mathrm{y} \cdot \mathrm{yr}|}{\mathrm{P} 1|1+\mathrm{w}|\left|\frac{1}{\mathrm{k}}+\frac{\mathrm{x}|\mathrm{y} \cdot \mathrm{yr}|}{\mathrm{P} 1|1+\mathrm{w}|}\right|^{2}} \\
& \text { hy0 : aa dd Sg }\left|\frac{y}{d d}\right|^{\text {bb }}+\text { aa bo }\left|\frac{y}{d d}\right|^{\cdot 1+b b} \mid \text { Su0 }+ \text { Sg y } \\
& \text { hy01 : } \frac{1}{\frac{1}{\mathrm{k}} \cdot \frac{\mathrm{y} \cdot \mathrm{yn} 1}{\operatorname{Py} 1|1+\mathrm{w}|}}+\frac{\mathrm{y} \cdot \mathrm{yn} 1}{\operatorname{Py} 1|1+\mathrm{w}|\left|\frac{1}{\mathrm{k}} \cdot \frac{\mathrm{y} \cdot \mathrm{yn} 1}{\operatorname{Py} 1 \mid 1+\mathrm{w}}\right|^{2}} \\
& \text { hy02: } \frac{1}{4} \mathrm{P} 2\left(\frac{3|\mathrm{y} \cdot \mathrm{y} 0|^{2}}{\mathrm{ym}^{3}}+\frac{3}{\mathrm{ym}}\right) \\
& \text { hy06: } \frac{1}{4} \mathrm{P} 1\left(\frac{3\left|\mathrm{y} \cdot \mathrm{y}^{0}\right|^{2}}{\mathrm{ym}^{3}}+\frac{3}{\mathrm{ym}}\right) \\
& \text { hy04: } \frac{1}{\frac{1}{\mathrm{k}}+\frac{\mathrm{X}|\mathrm{y} \cdot \mathrm{yr}|}{\mathrm{P} 1\left|1_{1} \mathrm{w}\right|}} \cdot \frac{\mathrm{x}|\mathrm{y} \cdot \mathrm{yr}|}{\mathrm{P} 1|1+\mathrm{w}|\left|\frac{1}{\mathrm{k}}+\frac{\mathrm{X}|\mathrm{y} \cdot \mathrm{yr}|}{\mathrm{P} 1|1+\mathrm{w}|}\right|^{2}} \\
& \text { hy05: } \frac{1}{4}|\operatorname{P1} \cdot \operatorname{Prb}|\left(\frac{3|y \cdot y 0|^{2}}{y^{3}}+\frac{3}{y m}\right)
\end{aligned}
$$

